


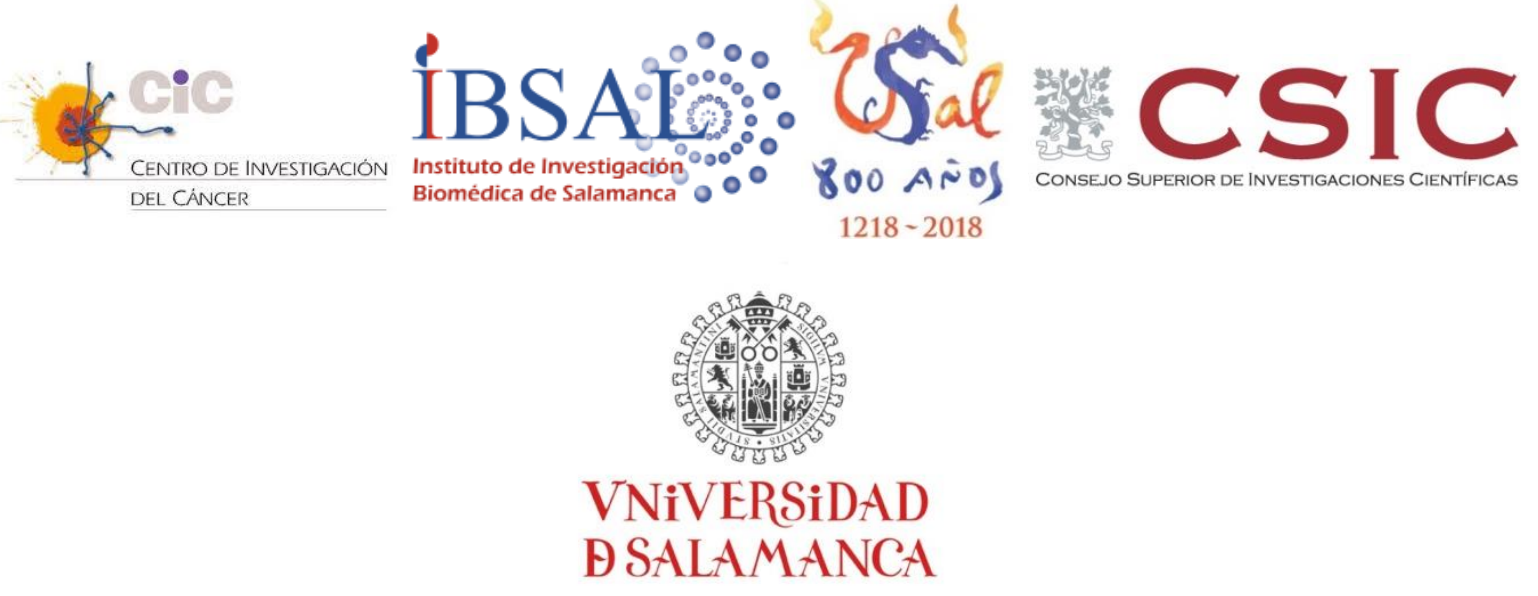

CENTRO DE INVESTIGACIÓN DEL CÁNCER

INSTITUTO DE BIOLOGÍA MOLECULAR Y CELULAR DEL CÁNCER (CSIC-USAL)

\title{
Papel de C3G plaquetario en angiogénesis y metástasis tumoral
}

\author{
MEMORIA PARA OPTAR AL GRADO DE DOCTOR \\ PRESENTADA POR \\ Víctor Miguel Martín Granado
}

Bajo la dirección de los Doctores

Carmen Guerrero Arroyo

José Ramón González Porras

Salamanca, 2017 

Dra. CARMEN GUERRERO ARROYO, Profesora Titular del Departamento de Medicina, Instituto de Biología Molecular y Celular del Cáncer (IBMCC, CSIC-Universidad de Salamanca); y Dr. JOSÉ RAMÓN GONZÁLEZ PORRAS, Jefe del grupo de Patología Trombótica del Instituto de Investigación Biomédica de Salamanca, Jefe de la Unidad de Trombosis y Hemostasia del Hospital Universitario de Salamanca, y Profesor Asociado del Departamento de Medicina de la Universidad de Salamanca.

\section{CERTIFICAN:}

Que D. Víctor Miguel Martín Granado, licenciado en Biología por la Universidad Central de Venezuela, ha realizado bajo su dirección el trabajo de Tesis Doctoral que lleva por título "Papel de C3G plaquetario en angiogénesis y metástasis tumoral", y considera que éste reúne originalidad y contenidos suficientes para que sea presentada ante el Tribunal correspondiente y optar al Grado de Doctor por la Universidad de Salamanca.

Y para que conste, y a los efectos oportunos, expide el presente certificado en Salamanca a 17 de septiembre de 2017.

Fdo, Dra. Carmen Guerrero Arroyo

Directora de la Tesis

Fdo, Dr. José Ramón González Porras

Co-director de la Tesis 

Este trabajo se ha enmarcado dentro de los proyectos del Plan nacional $\mathrm{I}+\mathrm{D}+\mathrm{i}$ "Análisis in vitro e in vivo de la función de C3G en diferentes tipos celulares y su impacto en patologías cardiovasculares y en metástasis" (SAF2013-48210-C2-1-R) y "Función de C3G en el desarrollo tumoral y en la patofisiología del hígado. Implicación del C3G plaquetario en la angiogénesis y en enfermedades hepáticas y cardiovasculares" (SAF2016-76588-C2-2-R) financiados por el Ministerio de Economía y Competitividad y el Fondo Europeo de Desarrollo Regional; y de los proyectos del Programa de apoyo a proyectos de investigación de la Consejería de Educación de la junta de Castilla y León titulados "Estudio del papel de C3G y p38 MAPK en la función plaquetaria y el desarrollo de neutrófilos: implicaciones en la regulación de la leucemia mieloide crónica" (SA157A12-1) y "Papel de C3G en la regulación de la función plaquetaria: Implicaciones en angiogénesis y aplicación al diagnóstico y tratamiento de la enfermedad trombótica" (SA017U16). 

A mi madre y mi abuela 

"We keep moving forward, opening new doors, and doing new things, because we're curious and curiosity keeps leading us down new paths"

Walt Disney 



\section{Agradecimientos}

A mi directora de tesis, la Dra. Carmen Guerrero por haberme dado la oportunidad de trabajar con ella durante mis estudios de Máster y Doctorado, por sus innumerables aportaciones y dedicación para que este trabajo pudiera ser realizado de la mejor manera posible, y por su interés en que sus estudiantes siempre tuviéramos las mejores condiciones posibles para elaborar nuestro proyecto.

Al Dr. José Ramón González Porras por su colaboración con la logística involucrada en diferentes experimentos, así como por sus apreciados comentarios.

Al Dr. José María de Pereda por sus valiosos comentarios y por su colaboración con los experimentos de clonación y transfección.

Al Dr. Ramón Muñoz Chápuli y la Dra. Rita Carmona por su colaboración con el modelo experimental de infiltración de células endoteliales en botones de Matrigel.

Al Dr. Miguel Pericacho Bustos por el suministro de las células tumorales 3LL y por su importante ayuda con la puesta a punto del ensayo de angiogénesis in vitro.

A la Dra. Almudena Porras por el suministro de las células tumorales B16F10 y por sus valiosos comentarios.

A Sara G., Sara O., Mario, Arturo y el resto de compañeros del Lab 17 por su amistad y por su colaboración con diferentes experimentos.

A Curro, Conrad, Óscar, Santiago y el resto de compañeros del Lab19 por su amistad y por las buenas conversaciones a la hora del café.

A Laura San Segundo por su fundamental colaboración con el modelo animal de metástasis.

A Isabel Ramos del animalario del CIC por su invaluable asistencia con el mantenimiento de los ratones y su genotipado.

A Ángel y el resto del equipo del Servicio de Microscopía del CIC por sus asistencia con los experimentos microscopía confocal de inmunofluorescencia.

A Susana, Telmo, Mamen y el resto del equipo del Servicio de Patología Molecular Comparada del CIC por su asistencia con los análisis histológicos.

Al Servicio de Proteómica del CIC por su asistencia con el análisis proteómico del secretoma plaquetario.

A mi madre, mi hermana, mi abuela, y a Marianny por ayudar en mi catarsis a lo largo de distintas etapas de este arduo trayecto.

A todos los ratones que sin ser conscientes, dieron todo de sí mismos para poder llevar a cabo este trabajo y contribuir al avance del conocimiento científico. 



\section{Tabla de contenido}

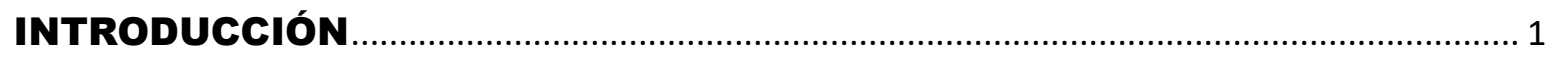

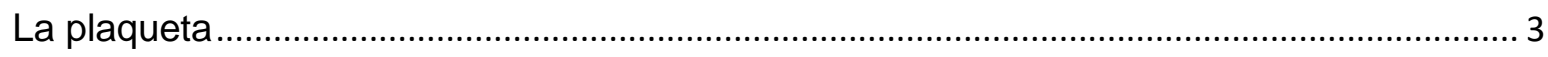

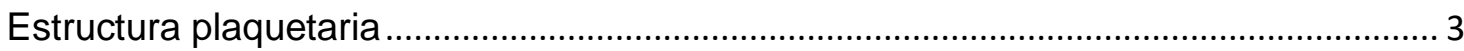

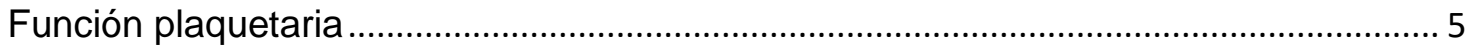

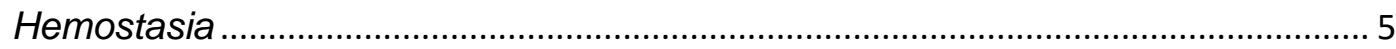

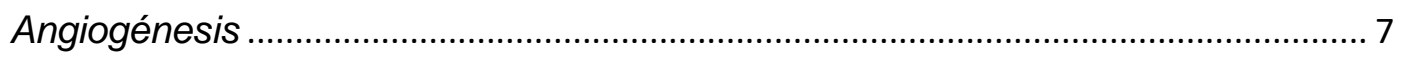

Desarrollo tumoral y metástasis .......................................................................... 11

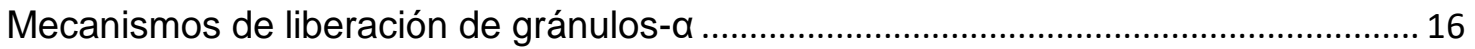

Papel de VAMP7 en la liberación de gránulos- $\alpha$.................................................... 18

C3G

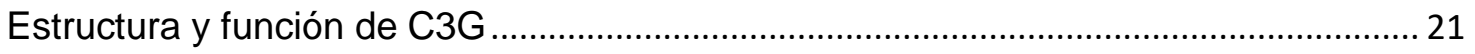

Ruta de C3G-Rap1 en plaquetas ............................................................................. 23

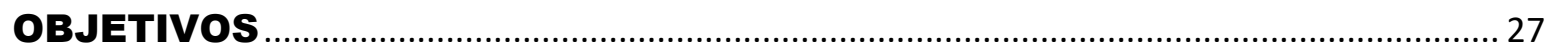

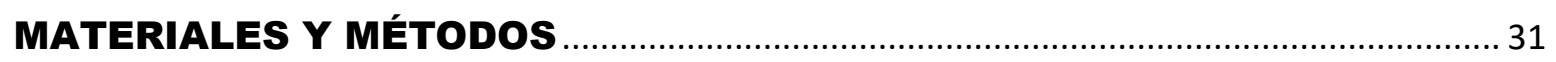

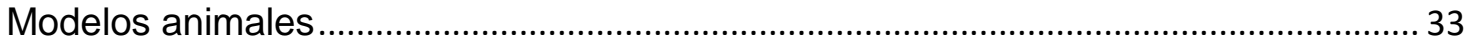

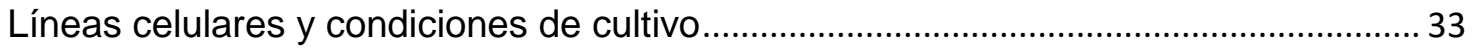

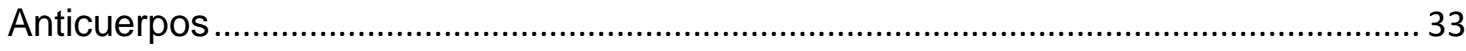

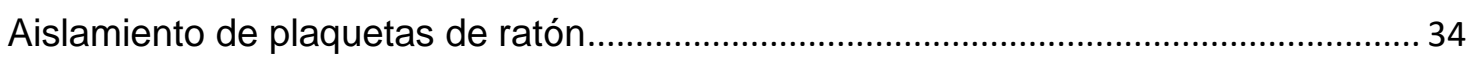

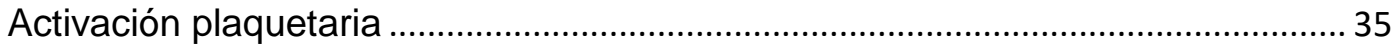

Aislamiento del secretoma, restos citosólicos y membranas plaquetarias............ 35

Análisis proteómico del secretoma plaquetario....................................................... 36

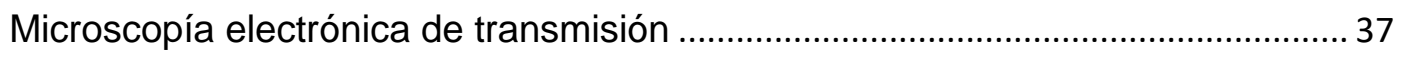

Microscopía confocal de inmunofluorescencia........................................................... 37

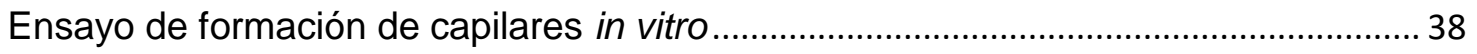

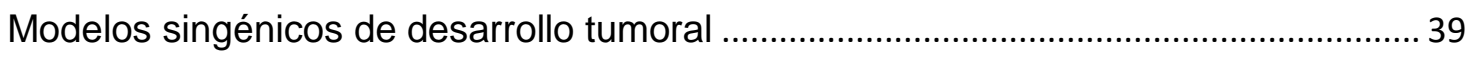

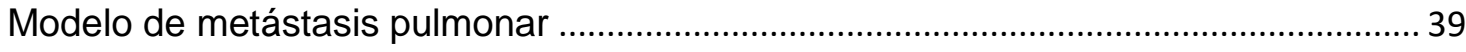

Modelo de angiogénesis in vivo por inducción con oxazolona....................................... 40

Ensayo de angiogénesis in vivo en botones de Matrigel ............................................ 40

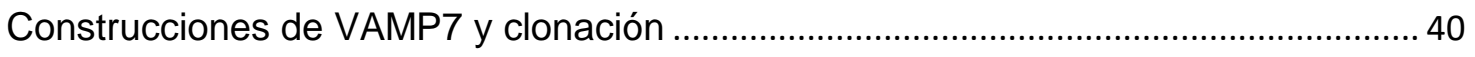




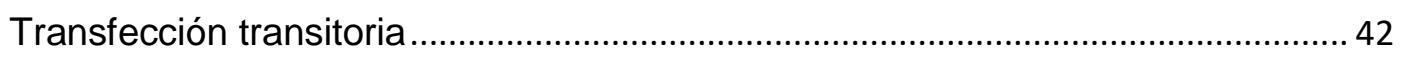

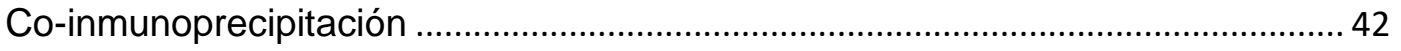

Cuantificación de proteínas, SDS-PAGE y Western blot ................................................ 43

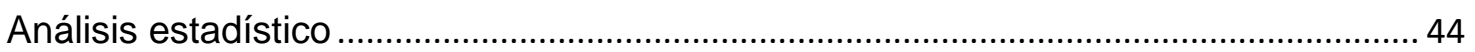

RESULTADOS

Función reguladora de C3G en la liberación de factores angiogénicos por plaquetas activadas

La liberación de factores anti-angiogénicos se encuentra disminuida en plaquetas $T g C 3 G$ y $T g C 3 G \Delta$ Cat activadas con trombina o ADP.

Los factores pro- y anti-angiogénicos se encuentran almacenados de manera diferencial en plaquetas de ratón

C3G regula la liberación de VEGF, bFGF, endostatina y TSP-1 de plaquetas de ratón activadas con $A D P$ o trombina

El secretoma de plaquetas $T g C 3 G$ y $T g C 3 G \triangle C$ at activadas con trombina o ADP promueve la angiogénesis in vitro.

Función del C3G plaquetario en la regulación de la angiogénesis in vivo y la metástasis tumoral

Las plaquetas TgC3G y TgC3G $\Delta$ Cat promueven la angiogénesis in vivo: vascularización y crecimiento de tumores heterotópicos de ratón. 66

El C3G plaquetario facilita la metástasis de células de melanoma 71

Las plaquetas TgC3G y TgC3G $\Delta$ Cat promueven la angiogénesis in vivo: vascularización en orejas de ratón inflamadas por tratamiento con oxazolona.... 71 El C3G plaquetario regula la angiogénesis in vivo: infiltración de células endoteliales en botones de Matrigel implantados subcutáneamente en ratones. 73

Mecanismos moleculares involucrados en la regulación mediada por C3G de la secreción plaquetaria de factores angiogénicos ..... 75

C3G interacciona con VAMP7 en plaquetas TgC3G y TgC3G $\triangle$ Cat ...................... 75

C3G y C3G $\Delta$ Cat promueven la extensión plaquetaria sobre sustrato 79

\section{DISCUSIÓN}

Función reguladora de C3G en la liberación de factores angiogénicos por plaquetas activadas

Función del C3G plaquetario en la regulación de la angiogénesis in vivo y la metástasis tumoral

Mecanismos moleculares involucrados en la regulación mediada por C3G de la secreción plaquetaria de factores angiogénicos 
CONCLUSIONES

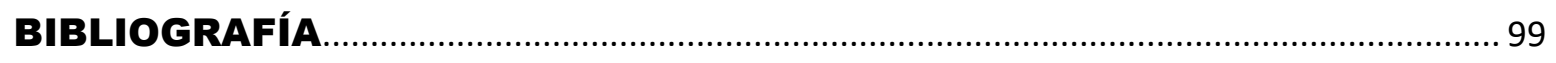

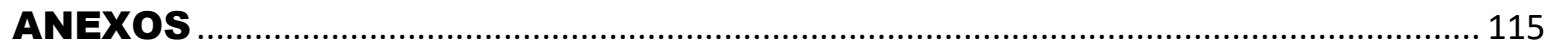



INTRODUCCIÓN 



\section{La plaqueta}

Las plaquetas, o trombocitos, son fragmentos citoplasmáticos de alrededor de 2-5 $\mu \mathrm{m}$ de diámetro, con forma discoidal y carentes de núcleo (Gerrard \& White, 1980; White, 2007). Se originan en la médula ósea a través de la fragmentación de finas extensiones citoplasmáticas similares a pseudópodos (proplaquetas) que despliegan los megacariocitos, en un proceso conocido como trombopoyesis (Becker \& De Bruyn, 1976). Una vez formadas, las plaquetas tienen un tiempo de vida medio de 7-10 días en el torrente sanguíneo hasta que son eliminadas por el sistema retículoendotelial, también conocido como sistema fagocítico mononuclear, principalmente en hígado y bazo (Harker, 1977; Nayak et al., 2013). Como regla general, el promedio de plaquetas circulantes en humanos es de 150-400 x 10\%/L (Schmitt et al., 2001).

En el ratón, las plaquetas tienen un tamaño menor $(0,5 \mu \mathrm{m}$ de diámetro), al igual que un tiempo menor de vida media en el torrente sanguíneo (3-4 días). En contraste, tienen un mayor número de plaquetas circulantes, encontrándose un valor promedio de $1000-1500 \times 10^{9} / \mathrm{L}$ (Schmitt et al., 2001).

\section{Estructura plaquetaria}

Las plaquetas presentan en su citoplasma diferentes orgánulos secretorios que contienen sustancias con actividad biológica (Figura 11). Entre ellos se encuentran los gránulos- $\alpha$, los gránulos densos y los lisosomas. Otros orgánulos que también pueden ser encontrados en las plaquetas son las mitocondrias y los glicosomas, los cuales están principalmente involucrados en funciones del metabolismo energético (White, 2007).

Los gránulos-a son los más abundantes, ya que se encuentran entre 50 y 80 de ellos por plaqueta (Frojmovic \& Milton, 1982). Estos gránulos contienen una amplia variedad de péptidos y proteínas entre las que se incluyen alrededor de 300 moléculas diferentes. Entre estas proteínas, se encuentran factores procoagulantes, reguladores de la fibrinólisis, factores de crecimiento, quimiocinas, moduladores inmunitarios y moléculas de adhesión (Maynard et al., 2007; Zufferey et al., 2014).

Los gránulos densos son casi 10 veces menos abundantes que los gránulos- $\alpha$, además de ser más pequeños. Se encuentran en promedio de 1 a 1,4 gránulos densos por sección de micrografía (White, 1969; Berger et al., 1996). Estos gránulos están caracterizados por contener fundamentalmente diferentes metabolitos como serotonina, histamina, ADP, ATP, pirofosfato, $\mathrm{Ca}^{2+} \mathrm{y} \mathrm{Mg}^{2+}$ (Fukami, 1992; McNicol \& Israels, 1999). 
Los lisosomas son los menos abundantes de los gránulos secretorios, encontrándose entre 0 y 1 por plaqueta. Su contenido consiste básicamente en hidrolasas ácidas, catepsinas y proteínas de membrana lisosomal (Dangelmaier \& Holmsen, 1980).

Otro aspecto importante de la estructura plaquetaria es el sistema canalicular abierto (OCS - open canalicular system), el cual consiste en una serie de invaginaciones sinuosas de la membrana externa que se internan en el citoplasma de manera serpenteante (White, 2007). El OCS incrementa significativamente el área total de membrana externa de la plaqueta, proporcionando un medio para la captación de sustancias a partir del plasma, así como para la secreción de los productos almacenados en los orgánulos secretorios durante la activación plaquetaria (White \& Escolar, 1991). El OCS también tiene una participación importante en la extensión plaquetaria durante la adhesión a una pared vascular dañada. En este proceso, las plaquetas pueden aumentar hasta un $420 \%$ el área de superficie expuesta, siendo el OCS, junto con los gránulos plaquetarios, las principales fuentes de suministro de membrana (Escolar et al., 1989; Peters et al., 2012; Koseoglu et al., 2015).

A

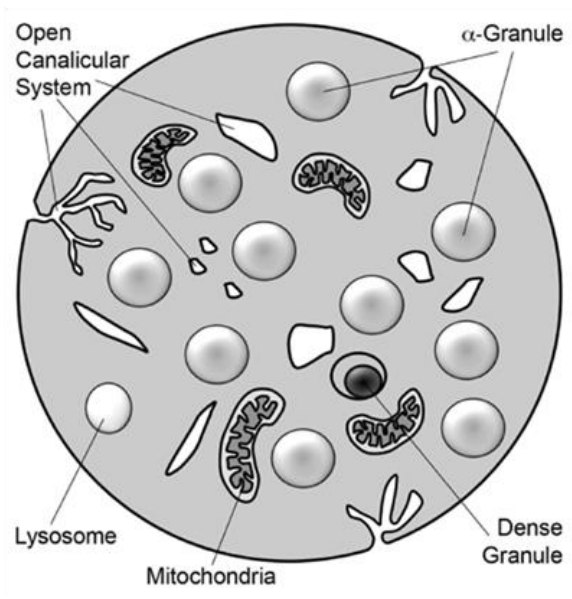

B

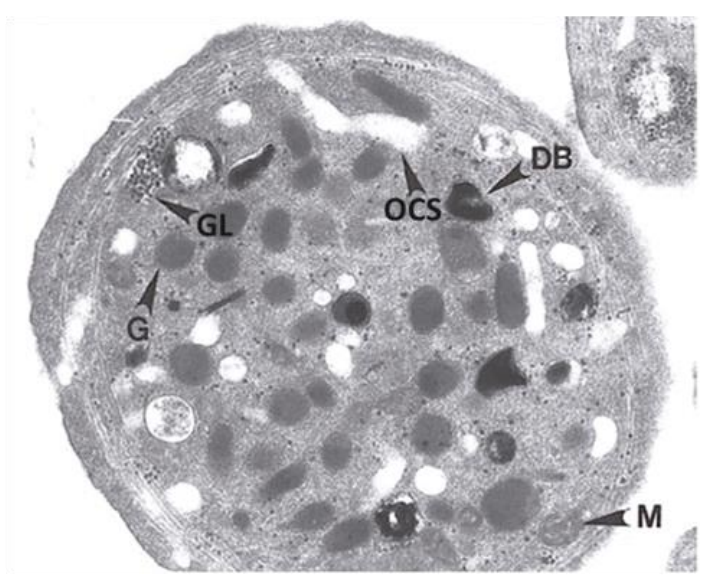

Figura 11. Ultraestructura plaquetaria. Dibujo esquemático (A) y micrografía con magnificación x25000 (B) de la ultraestructura plaquetaria. Se representan los diferentes orgánulos secretorios, mitocondrias, glicosomas y el sistema canalicular abierto. G: gránulo-a, DB: gránulo denso, M: mitocondria, GL: glicosoma, OCS: sistema canalicular abierto. Tomado de Fitch-Tewfik and Flaumenhaft (2013) (A) y modificado de White (2007) (B). 


\section{Función plaquetaria}

Las plaquetas tienen su función principal en la hemostasia donde son activadas ante un daño del endotelio vascular, generándose un tapón plaquetario que inicia la detención de la hemorragia. Las plaquetas también están involucradas en otros procesos como reacciones inmunitarias, inflamación, enfermedades neurológicas, enfermedades cardiovasculares, angiogénesis y cáncer (Broos et al., 2011; Leslie, 2010; Ware et al., 2013). En las secciones siguientes, se profundiza en el papel que tienen las plaquetas en la hemostasia, la angiogénesis, y en el desarrollo tumoral y la metástasis.

\section{Hemostasia}

En condiciones fisiológicas, la plaqueta circula en sangre sin interaccionar con el endotelio. Las células endoteliales producen moléculas como prostaciclina $\left(\mathrm{PGI}_{2}\right)$ y óxido nítrico que liberan localmente y previenen la activación plaquetaria. Cuando se produce un daño que altera la integridad de la pared endotelial, las plaquetas quedan expuestas a proteínas como el colágeno y el factor de Von Willebrand (VWF). Estas moléculas producen la captura de las plaquetas en la región del daño, promueven su activación inicial y estimulan la reorganización del citoesqueleto, lo que resulta en su extensión sobre la pared vascular expuesta, adhiriéndose más estrechamente a ésta (Figura I2A) (Brass et al., 2007). Del mismo modo, esta activación inicial promueve la liberación del contenido de los gránulos plaquetarios. Por otra parte, el daño en la pared endotelial ocasiona la exposición del factor tisular, produciéndose la activación de la trombina, que actúa también como un potente agonista plaquetario (Broos et al., 2011; Clemetson, 2012).

Entre las moléculas que son liberadas tras la activación plaquetaria inicial, se encuentran el ADP y el tromboxano $A_{2}\left(T X A_{2}\right)$. Estas moléculas actúan como agonistas plaquetarios y producen la transducción de señales a través de sus receptores respectivos, estimulándose la agregación de un mayor número de plaquetas, a través de un ciclo de retroalimentación positivo, lo cual amplifica la señal de activación (Figura I2B). La activación de los receptores de los principales agonistas plaquetarios solubles (ADP, $\mathrm{TXA}_{2}$ y trombina) converge en eventos de señalización comunes que concluyen en la activación de la integrina allbß3 (glicoproteína GPIIb/IIla). La activación de esta integrina genera un aumento de la afinidad por su ligando, el fibrinógeno, el cual puede unirse al mismo tiempo a dos receptores de este tipo, actuando como enlace entre diferentes plaquetas, lo que constituye la base fundamental de la agregación plaquetaria ( $\mathrm{Li}$ et al., 2011; Broos et al., 2011; Clemetson, 2012). 
A. Inicio de la activación plaquetaria.

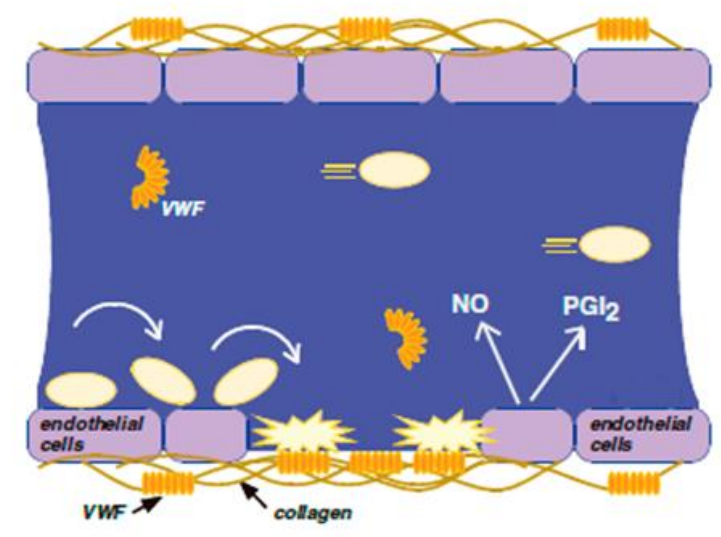

B. Amplificación de la activación.

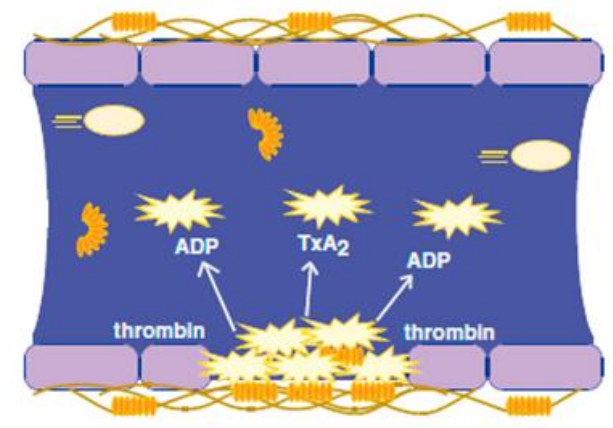

C. Establecimiento del tapón hemostático.

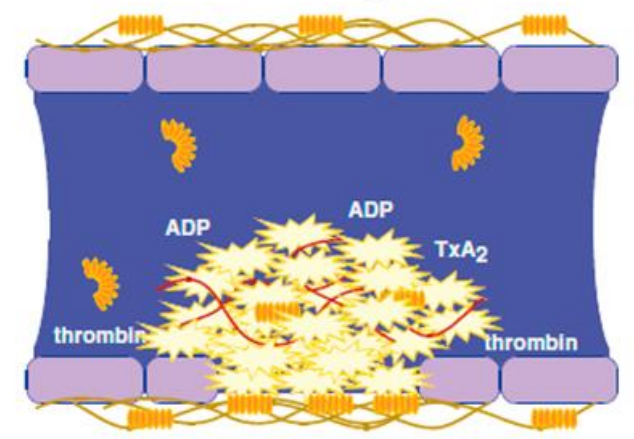

Figura 12. Función plaquetaria en la hemostasia. (A) En condiciones fisiológicas normales, el endotelio produce $\mathrm{PGl}_{2}$ y NO, que inhiben la activación plaquetaria. Ante un daño en el endotelio, se exponen proteínas como colágeno y VWF que interaccionan con las plaquetas y son los principales responsables del inicio de su activación. (B) Tras la activación inicial, las plaquetas liberan moléculas como ADP y $\mathrm{TXA}_{2}$ que actúan como amplificadores de la señal de activación a través de un ciclo de retroalimentación positivo. Estos agonistas solubles, junto con la trombina, producen la activación de la integrina allb $\beta 3$, incrementándose su afinidad por el fibrinógeno, el cual puede unirse al mismo tiempo a dos receptores de este tipo, actuando como enlace entre diferentes plaquetas. (C) La activación de la cascada de coagulación por la trombina, produce una malla de fibrina (líneas rojas) que interacciona con las plaquetas agregadas y contribuye a reforzar y establecer el tapón hemostático. VWF: factor de Von Willebrand. NO: óxido nítrico. $\mathrm{PGl}_{2}$ : prostaciclina. $\mathrm{TXA}_{2}$ : tromboxano $\mathrm{A}_{2}$. Modificado de Brass et al. (2007).

La activación de la trombina durante la hemostasia también produce la activación en paralelo de la cascada de coagulación, que finaliza con la transformación del fibrinógeno en fibrina. La fibrina se estructura en una malla que interacciona con las plaquetas agregadas, y contribuye a reforzar y establecer el tapón hemostático (Figura I2C) (Brass et al., 2007). 


\section{Angiogénesis}

La angiogénesis es la generación de nuevos capilares sanguíneos a partir de vasos preexistentes, y está involucrada en procesos como organogénesis, reparación tisular o progresión tumoral (Lyden et al., 2001; Grunewald et al., 2006). Durante el inicio del proceso de angiogénesis, un microambiente pro-angiogénico en la matriz extracelular (ECM) de un capilar sanguíneo, genera la selección de algunas células endoteliales (EC) que llevarán a cabo el sprouting o brote. Estas células se conocen como células tip, y dirigen el crecimiento del nuevo capilar (Figura I3A). Durante este paso, las células tip inhiben la adquisición de este fenotipo por parte de las EC adyacentes. La adquisición del fenotipo de célula tip involucra la pérdida de la polaridad apical-basal de la EC y la adquisición de una capacidad migratoria e invasiva. En este paso inicial de la angiogénesis también se eliminan los contactos de células murales, como pericitos, y se degrada la matriz extracelular (ECM) de la pared vascular en la región donde se ha seleccionado la célula tip. Posteriormente, gradientes de factores de crecimiento como VEGF y bFGF, así como otras moléculas quimiotácticas, promueven la migración e invasión de las células tip en la ECM a favor del gradiente de concentración de los diferentes factores pro-angiogénicos (Figura 13B). A medida que la célula tip migra a lo largo de la ECM, las EC adyacentes proliferan y se genera progresivamente el cuerpo del nuevo capilar, rodeándose de nueva ECM y promoviéndose el reclutamiento de pericitos a la pared vascular formada (Figuras I3B y I3C). Por último, durante la maduración del nuevo vaso sanguíneo, se forma el lumen del capilar, se completa la deposición de la ECM a su alrededor, se estabilizan los contactos EC-EC, y se estabiliza la adhesión de los pericitos a la pared vascular (Figuras I3C y I3D). La restauración del flujo sanguíneo restituye el suministro de nutrientes y oxígeno al tejido adyacente, por lo que disminuyen las señales pro-angiogénicas, mediadas principalmente por la hipoxia de las células del tejido en cuestión (Adams \& Alitalo, 2007; Clapp et al., 2009; Potente et al., 2011).

Otro proceso que media la generación de nuevos capilares sanguíneos es la vasculogénesis. En este caso, la formación del nuevo capilar involucra el reclutamiento de células progenitoras endoteliales (EPC) de la médula ósea, que son incorporadas a la pared vascular en crecimiento. Además, también pueden contribuir al crecimiento del nuevo vaso sanguíneo, a través de la promoción del brote y la proliferación de otras EC adyacentes (Figura 14) (Urbich \& Dimmeler, 2004; Adams \& Alitalo, 2007). 
A. Selección de la célula tip

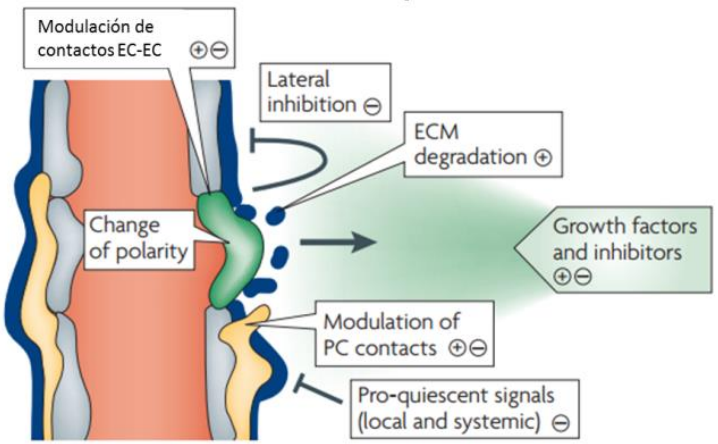

\section{Crecimiento del brote}

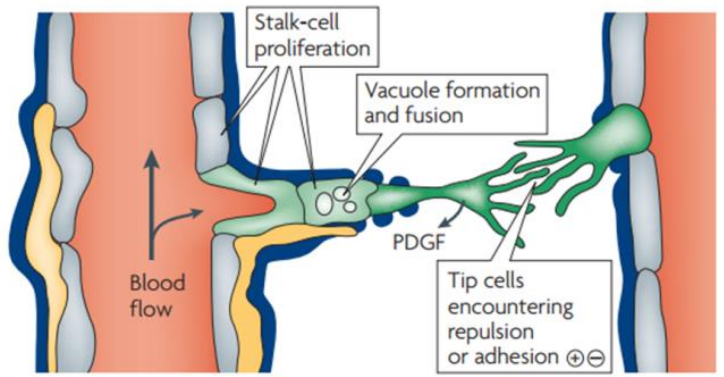

B. Invasión y migración de la célula tip

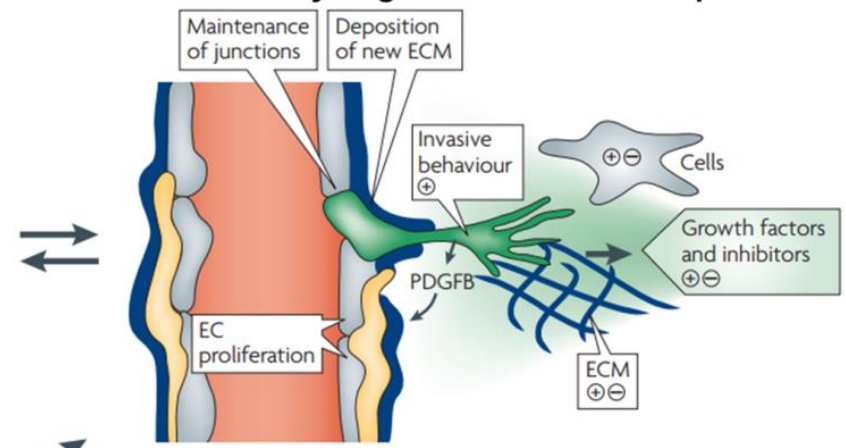

\section{Perfusión y maduración}
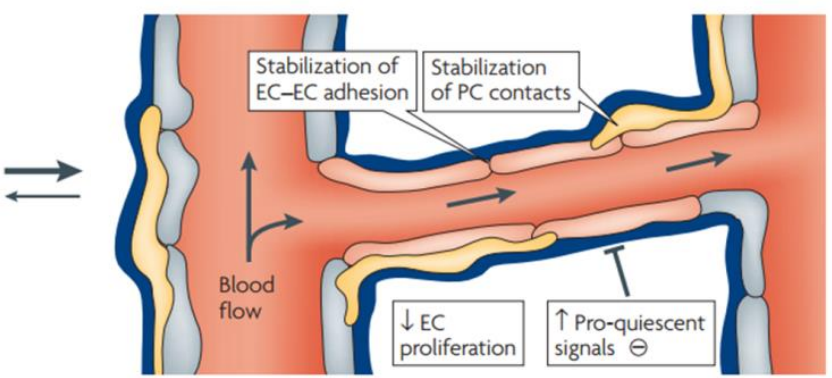

Figura 13. Crecimiento de vasos sanguíneos mediante angiogénesis. (A) Un microambiente proangiogénico en la matriz extracelular (ECM) de un vaso sanguíneo determina la adquisición del fenotipo de célula tip (verde) por parte de una célula endotelial (EC) (gris). En este paso inicial, también se eliminan los contactos entre pericitos (amarillo) y la pared vascular, y se degrada la ECM que la delimita. (B) La célula tip invade la ECM y migra a favor de un gradiente de concentración de factores pro-angiogénicos. (C) Las EC adyacentes a la célula tip proliferan y forman el cuerpo del nuevo capilar. (D) La formación del lumen y la perfusión del capilar formado, la deposición de la ECM a su alrededor, la estabilización de contactos EC-EC y la adhesión de pericitos a la pared vascular determinan la maduración del nuevo vaso sanguíneo. Modificado de Adams \& Alitalo (2007).

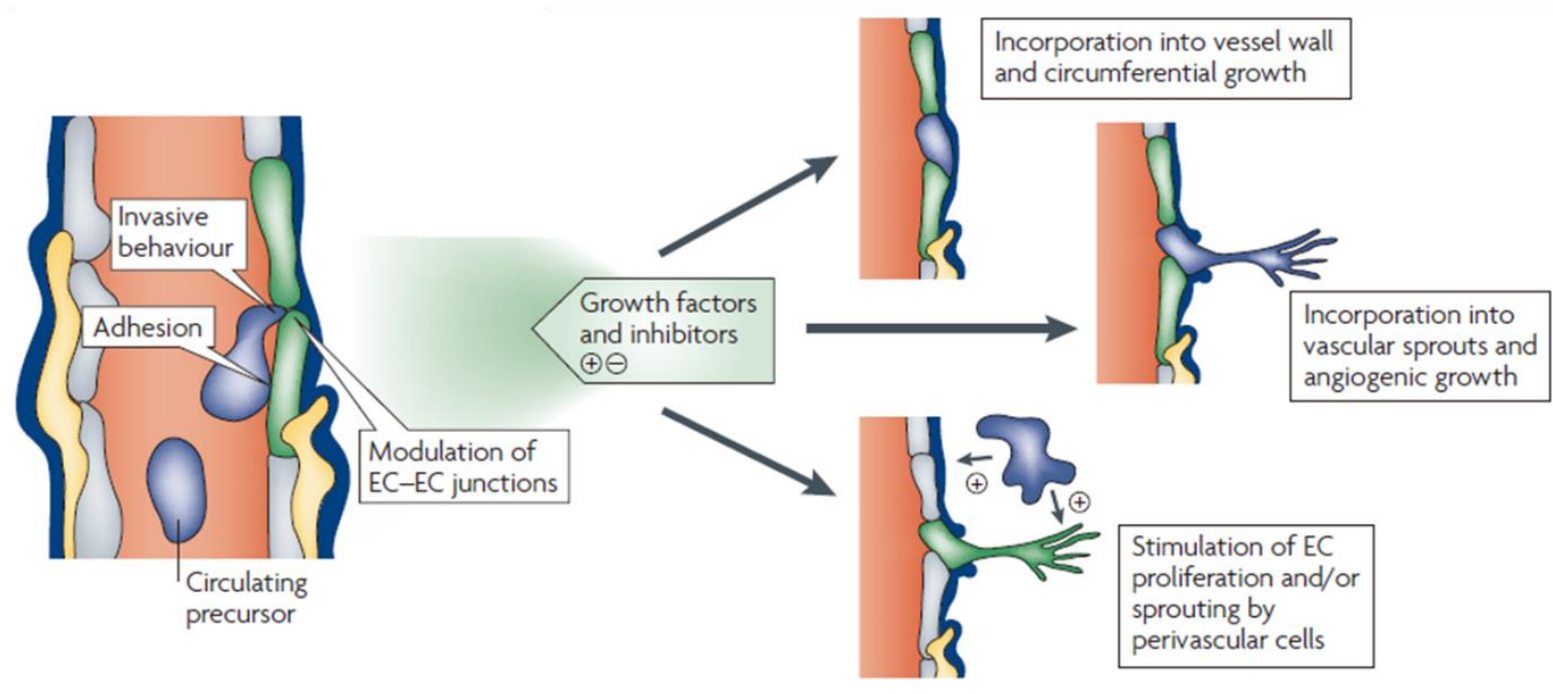

Figura 14. Crecimiento de vasos sanguíneos mediante vasculogénesis. Células progenitoras endoteliales (EPC) (azul) son reclutadas desde la médula ósea y se incorporan a la pared vascular del capilar en formación. Las EPC también contribuyen al crecimiento del vaso sanguíneo mediante la promoción del brote y la proliferación de otras células endoteliales. Modificado de Adams \& Alitalo (2007). 
La participación de las plaquetas en la angiogénesis ha sido descrita en diferentes modelos in vivo (Rhee et al., 2004; Kisucka et al., 2006; Feng et al., 2011). Las plaquetas son reclutadas a zonas donde ha ocurrido un daño vascular, y allí son activadas por diferentes agonistas solubles y componentes de la matriz extracelular. Esto produce la secreción de numerosas proteínas de sus gránulos-a entre las que se incluyen hasta 30 factores, tanto pro-angiogénicos como anti-angiogénicos. Otros productos de secreción incluyen factores de crecimiento y citoquinas que actúan sobre diferentes células, incluyendo células endoteliales, y regulan su actividad (Coppinger et al., 2004; 2007; Piersma et al., 2009; Battinelli et al., 2011; Etulain et al., 2013).

Entre los factores pro-angiogénicos contenidos en los gránulos- $\alpha$ se encuentran: VEGF (Vascular Endothelial Growth Factor), PDGF (Platelet Derived Growth Factor), bFGF (Basic Fibroblast Growth Factor), EGF (Epidermal Growth Factor), HGF (Hepatocyte Growth Factor), IGF (Insuline-like Growth Factor), angiopoyetina, y metaloproteinasas de matriz (MMP-1, -2 y -9), entre otros (Nurden et al., 2008; Blair \& Flaumenhaft, 2009; Patzelt \& Langer, 2012). Estos factores promueven la proliferación, migración e invasión de las células endoteliales durante la angiogénesis (Adams \& Alitalo, 2007; Clapp et al., 2009; Potente et al., 2011; Patzelt \& Langer, 2012). Las plaquetas también contienen CXCL12 (SDF-1-a) en sus gránulos- $\alpha$, el cual está involucrado en el reclutamiento de EPC desde la médula ósea y su adhesión al endotelio vascular, contribuyendo a la generación de nuevos vasos sanguíneos por vasculogénesis (Urbich \& Dimmeler, 2004; Massberg et al., 2006; Feng et al., 2011).

Los gránulos- $\alpha$ plaquetarios también incluyen numerosos factores antiangiogénicos. Entre ellos se encuentra la trombospondina-1 (TSP-1), que representa hasta el $20 \%$ del contenido de proteínas en los gránulos y es un potente inhibidor de la proliferación de las células endoteliales, además de promover su apoptosis (Jiménez et al., 2000; Lawler, 2002). Otros factores anti-angiogénicos encontrados en los gránulos- $\alpha$ incluyen al PF4 (Platelet factor 4), la angiostatina y la endostatina (Bikfalvi, 2004; Italiano et al., 2008; Patzelt \& Langer, 2012). También se encuentran diferentes inhibidores de metaloproteinasas de matriz como TIMP-1 y -4, que regulan negativamente la migración de las células endoteliales en la ECM y por tanto tienen un efecto anti-angiogénico (Blair \& Flaumenhaft, 2009).

Existen evidencias que indican que los factores pro- y anti-angiogénicos se encuentran segregados en subpoblaciones diferentes de gránulos- $\alpha$, y que su liberación puede ser específica dependiendo del agonista, regulándose la angiogénesis en el sitio de 
activación de las plaquetas (Italiano et al., 2008; Battinelli et al., 2011; Chatterjee et al., 2011). En estudios realizados por Italiano y col. (2008) en plaquetas humanas, se encontró que el VEGF y la endostatina se encuentran almacenados en gránulos- $\alpha$ diferentes, ya que evidenciaron la ausencia de co-localización de las señales de inmunofluorescencia correspondientes a cada factor (Figura I5A). Adicionalmente, hallaron que estas diferencias en el empaquetamiento de ambos factores angiogénicos se encuentran desde el origen de la plaqueta, ya que observaron su segregación diferencial en las extensiones citoplasmáticas de los megacariocitos que dan lugar a las plaquetas (proplaquetas) (Figura I5B). Del mismo modo, hallaron que el bFGF y la TSP-1 se encuentran almacenados de manera diferencial tanto en plaquetas como en proplaquetas.
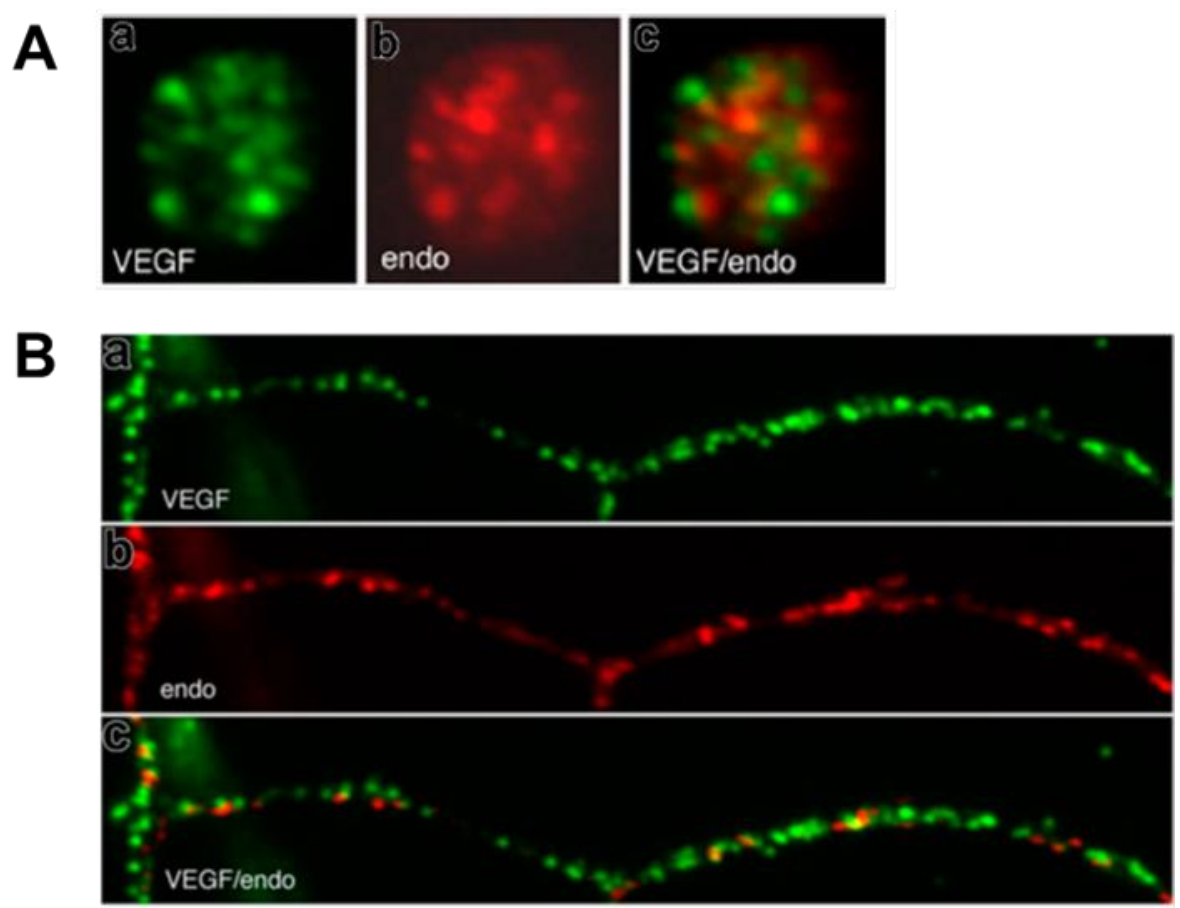

Figura I5. EI VEGF y la endostatina se encuentran empaquetados de manera diferencial en plaquetas y proplaquetas humanas. Imágenes de microscopía confocal de inmunofluorescencia de la distribución subcelular de VEGF (verde), endostatina (rojo) y su superposición en plaquetas (A) y proplaquetas (B) humanas. Tomado de Italiano et al. (2008).

Estudios previos también indican que los factores pro- y anti-angiogénicos podrían ser liberados de manera diferencial tras la activación plaquetaria. En este sentido, se ha encontrado que la activación por PAR1, ADP, e incluso células tumorales MCF-7, promueven la liberación de factores pro-angiogénicos como el VEGF. Además, el secretoma generado exhibe un carácter pro-angiogénico in vitro. En contraste, la 
activación por PAR4 y TXA $\mathrm{T}_{2}$ promueve la liberación de factores anti-angiogénicos como la endostatina, y los secretomas generados inhiben la angiogénesis in vitro (Figura 16) (Italiano et al., 2008; Battinelli et al., 2011; Chatterjee et al., 2011). Sin embargo, resultados de otros autores sugieren que, tanto el almacenamiento de las proteínas en los gránulos- $\alpha$, como su liberación son procesos estocásticos, encontrándose que las proteínas pro- y anti-angiogénicas muestran poca segregación funcional en diferentes subpoblaciones de gránulos (Kamykowski et al., 2011; Jonnalagadda et al., 2012).

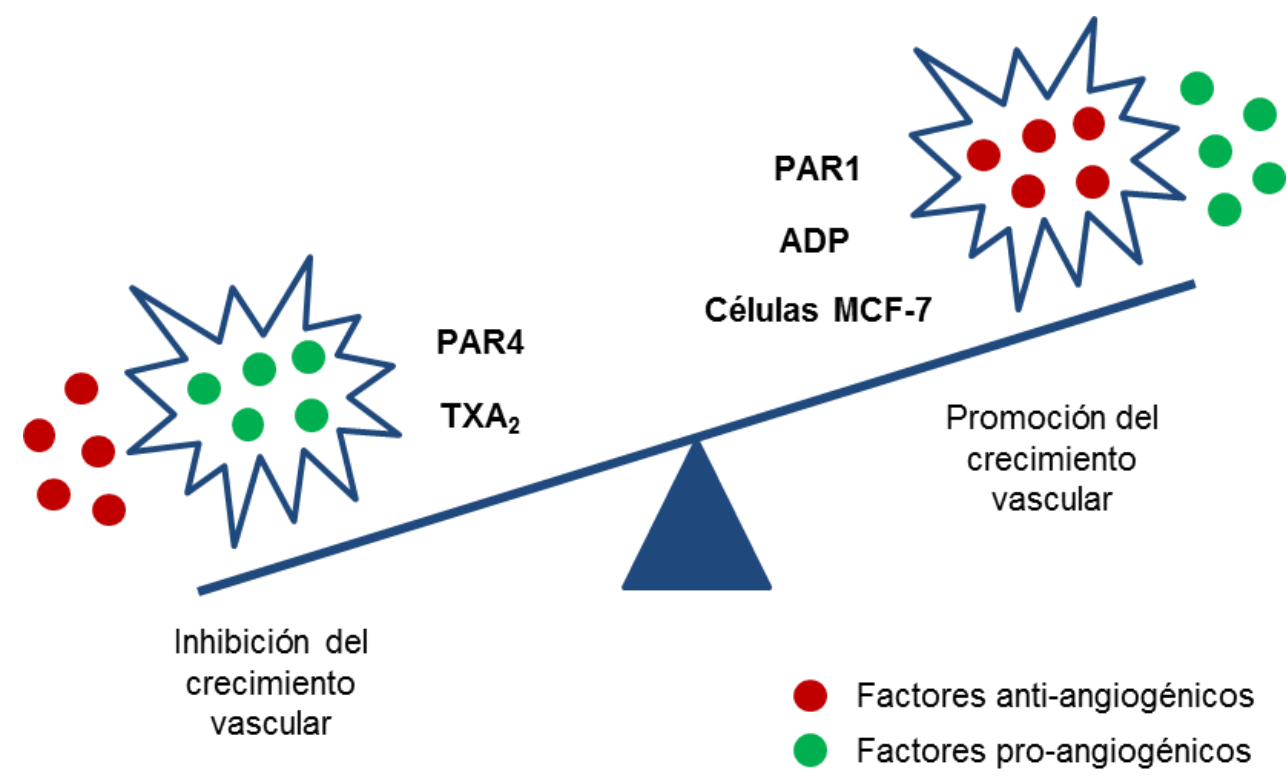

Figura 16. La activación plaquetaria inducida por agonistas específicos determina el balance de factores pro- y anti-angiogénicos en el secretoma a través de su liberación diferencial. La activación plaquetaria por PAR4 y $\mathrm{TXA}_{2}$ produce un secretoma con carácter general anti-angiogénico, mientras que la activación por PAR1, ADP y células tumorales MCF-7 induce la liberación de un secretoma que promueve la angiogénesis.

\section{Desarrollo tumoral y metástasis}

La relación entre plaquetas y cáncer fue documentada por primera vez a mediados del siglo XIX por Trousseau, quien observó un cuadro de coagulación sanguínea excesiva en pacientes, ocasionado por la presencia de un carcinoma (Khorana, 2003). Actualmente, se conoce que pacientes con cáncer presentan un estado de hipercoagulación sanguínea, anormalidades plaquetarias y un incremento del riesgo de enfermedad tromboembólica (Khorana \& Connolly, 2009). Existen numerosos estudios que demuestran que la activación plaquetaria se encuentra amplificada en diversos tipos de cáncer y que las plaquetas pueden detectarse en la vasculatura tumoral (Verheul et al., 
2000; Sierko \& Wojtukiewicz, 2004). De hecho, en la mayoría de malignidades, el grado de trombocitosis en el paciente se encuentra inversamente correlacionado con su supervivencia, lo que le convierte en un marcador de mal pronóstico (Monreal et al., 1998; Symbas et al., 2000; Ikeda et al., 2002). Además, se conoce que los tumores pueden secretar citoquinas como IL-1, IL-6, GM-CSF y GCS-F, que estimulan la trombopoyesis y contribuyen al desarrollo de la trombocitosis (Suzuki et al., 1992; Estrov et al., 1995; Kaser et al., 2001).

La activación plaquetaria por células tumorales puede ocurrir tanto a nivel local en la vasculatura tumoral, como a nivel sistémico (Sierko \& Wojtukiewicz, 2007). Entre los mecanismos mediante los cuales las células tumorales pueden activar a las plaquetas se encuentran la secreción de agonistas plaquetarios y la interacción directa a través de contactos célula-célula (Bambace \& Holmes, 2011; Gay \& Felding-Habermann, 2011). En este sentido, diferentes estudios demuestran la presencia de trombina in situ en distintos tipos de tumores, incluyendo melanoma, cáncer de ovario y carcinoma de células renales (Wojtukiewicz et al., 1990a; 1990b; Zacharski et al., 1993). Por otra parte, se ha detectado que pacientes con cáncer presentan un incremento en la activación de diferentes componentes de la cascada de coagulación como el factor VII y el factor tisular (Kakkar et al., 1995). El factor tisular expresado por numerosos tipos de células tumorales interacciona con el factor VII, y juntos activan al factor X, que a su vez produce la activación de la trombina, lo que contribuye a la progresión tumoral (Nierodzik \& Karpatkin, 2006; Jain et al., 2010).

En otros estudios, se ha encontrado que el ADP también produce la activación plaquetaria por diferentes líneas de células tumorales como neuroblastoma, melanoma y carcinoma de mama (Bastida et al., 1986; Boukerche et al., 1994; Alonso-Escolano et al., 2004). Además, el $\mathrm{TXA}_{2}$ liberado por la plaqueta al ser activada por diferentes líneas de células tumorales, tiene igualmente un papel fundamental en la amplificación de la activación y la agregación plaquetaria en el contexto del desarrollo tumoral (Pacchiarini et al., 1991).

Por último, algunos receptores plaquetarios involucrados en adhesión celular como la integrina allb $\beta 3$ y la P-selectina, pueden interaccionar con células tumorales en la circulación sanguínea y contribuir a su metástasis (Borsig et al., 2002; Trikha et al., 2002). De hecho, el bloqueo de la integrina allbß3 con anticuerpos neutralizantes o la deleción de P-selectina en plaquetas, disminuye el número de metástasis detectadas en pulmón, en modelos experimentales de ratón (Erpenbeck \& Schön, 2010). 
La activación de las plaquetas por parte de las células tumorales puede contribuir a la promoción del desarrollo del tumor y a las metástasis hematógenas, a través de diferentes mecanismos. En cuanto a las metástasis, las plaquetas pueden favorecer la migración e invasión de la célula tumoral durante su intravasación, la protección durante su tránsito en la circulación sanguínea, y su adhesión a la vasculatura de los tejidos diana en los cuales se extravasa y establece (Figuras I7A e I7B) (Nierodzik \& Karpatkin, 2006; Bambace \& Holmes, 2011; Gay \& Felding-Habermann, 2011; Li, 2016). La participación de las plaquetas en este proceso se ha demostrado en diferentes modelos de ratón, en los cuales la depleción de las plaquetas produce una inhibición de las metástasis, mientras que su reconstitución recupera la actividad metastásica (Gasic et al., 1968; Karpatkin et al., 1988; Camerer et al., 2004; Erpenbeck \& Schön, 2010).

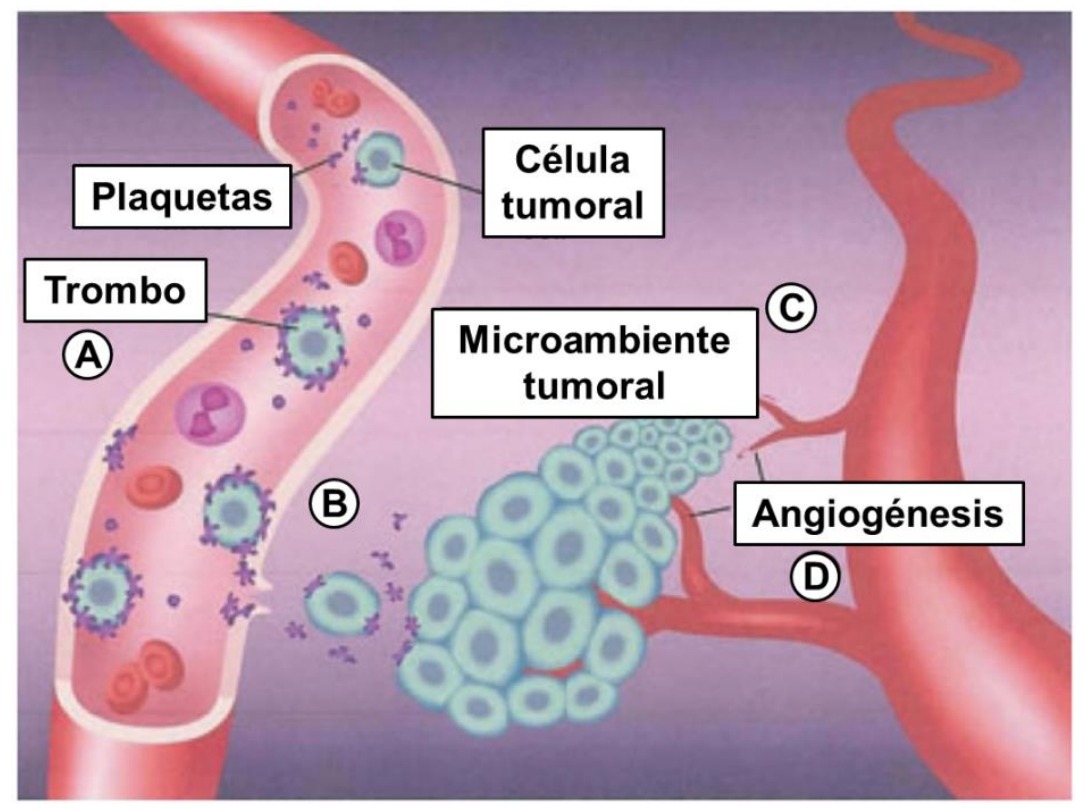

Figura 17. Participación de las plaquetas en el desarrollo tumoral y la metástasis. Las plaquetas pueden ser activadas por células tumorales en el torrente sanguíneo y formar una cobertura que las protege del sistema inmunitario y del estrés físico de la circulación sanguínea (A). También contribuyen a la adhesión de las células tumorales al endotelio vascular, y a su extravasación y establecimiento de las metástasis en tejidos distantes (B). En el sitio en que se encuentra establecido el tumor, las plaquetas pueden ser activadas y liberar numerosos factores de crecimiento, moléculas pro-angiogénicas y moléculas pro-inflamatorias que contribuyen a la generación de un microambiente pro-tumorigénico y al desarrollo de la angiogénesis tumoral (C y D). Modificado de Bambace \& Holmes (2011).

En relación a los eventos de intravasación y extravasación de la célula tumoral, las plaquetas activadas promueven su capacidad de migración e invasión a través de la secreción de numerosas metaloproteinasas de matriz que colaboran en la degradación de la matriz extracelular (Rolli et al., 2003; Deryugina \& Quigley, 2006). Además, se conoce 
que las plaquetas promueven la transición epitelial-mesenquimal (EMT) de las células tumorales, a través de la liberación de TGF- $\beta$ (Transforming Growth Factor- $\beta$ ), lo cual incrementa su capacidad migratoria e invasiva (Labelle et al., 2011).

Por otra parte, la agregación de las plaquetas alrededor de la célula tumoral durante su tránsito en sangre, la protege del estrés físico y del ataque de elementos del sistema inmunitario como células NK (Natural killer T cell) (Kopp et al., 2009; Gay \& Felding-Habermann, 2011). Durante este evento, la integrina plaquetaria allbß3 y la P-selectina tienen un papel fundamental en la interacción entre plaquetas y células tumorales (Karpatkin et al., 1988; Erpenbeck \& Schön, 2010). Además, se conoce que la capacidad de inducir la agregación plaquetaria está correlacionada con el potencial metastásico de las células tumorales en diferentes modelos in vitro e in vivo (Karpatkin et al., 1988; Nierodzik \& Karpatkin, 2006; Gay \& Felding-Habermann, 2011).

Por último, también se conoce que las plaquetas facilitan la adhesión de las células tumorales al endotelio de tejidos diana. Por una parte, estudios en modelos de ratón indican que los agregados de plaquetas y células tumorales tienen la habilidad de diseminarse y embolizar en la microvasculatura pulmonar (Malik, 1983). Por otra parte, diferentes estudios demuestran la participación de las selectinas plaquetarias en la interacción inicial de los agregados de plaquetas y células tumorales con el endotelio de los tejidos diana. Este evento precede la adhesión firme de la célula tumoral, tras lo cual ocurre su extravasación de la circulación sanguínea (Kim et al., 1998; 1999; McCarty et al., 2000; Läubli \& Borsig, 2010).

La activación plaquetaria en el sitio del tumor, produce la liberación de numerosos factores de crecimiento, moléculas pro-angiogénicas y moléculas pro-inflamatorias que contribuyen a la generación de un microambiente pro-tumorigénico y al desarrollo de la angiogénesis tumoral (Figuras I7C e I7D) (Hanahan \& Weinberg, 2011; Weis \& Cheresh, 2011; Li, 2016). En el caso de la inflamación, las plaquetas activadas pueden liberar moléculas como IL-8, IL-1 $\beta$, CCL5, CD40L e histamina que estimulan la expresión de receptores de adhesión en la superficie de las células endoteliales, la liberación de quimiocinas, y el reclutamiento e infiltración de leucocitos en el tejido durante la respuesta inflamatoria (Davì \& Patrono, 2007; von Hundelshausen \& Weber, 2007). En la última década se ha demostrado que la reacción inflamatoria asociada a un tumor tiene como resultado el incremento de la tumorigénesis y la promoción del desarrollo del cáncer, principalmente por efectos mediados por células del sistema inmunitario innato. Estas células liberan diferentes moléculas en el microambiente tumoral incluyendo factores de 
crecimiento, de supervivencia y pro-angiogénicos; además de MMPs, y moléculas que promueven la EMT de las células tumorales, lo cual contribuye a su proliferación, desarrollo y capacidad migratoria e invasiva (DeNardo et al., 2010; Grivennikov et al., 2010; Hanahan \& Weinberg, 2011). Adicionalmente, las células del sistema inmunitario innato pueden liberar sustancias como especies reactivas de oxígeno que son altamente mutagénicas y aceleran la evolución del tumor hacia estados de mayor malignidad (Grivennikov et al., 2010).

En relación al papel de las plaquetas en la angiogénesis tumoral, se conoce que tienen un efecto promotor de la generación de nuevos vasos sanguíneos, lo que contribuye al desarrollo de los tumores sólidos (Weis \& Cheresh, 2011; Li, 2016). La formación de nuevos vasos sanguíneos es un evento fundamental en el crecimiento de los tumores y en la formación de las metástasis, ya que se conoce que un tumor no puede crecer más de 0,5-1 mm de diámetro sin generar una nueva red vascular (Folkman, 2002). Los diferentes mecanismos mediante los cuales las células tumorales pueden activar a las plaquetas, promueven su adhesión y acumulación en la vasculatura tumoral, produciéndose agregados plaquetarios y micro-trombos en los capilares del tumor (Verheul et al., 2000; Sabrkhany et al., 2011). Además, tal como se ha explicado previamente, las plaquetas contienen diversos factores pro- y anti-angiogénicos que liberan de manera diferencial al ser activadas por las células tumorales, y que pueden promover la angiogénesis en este contexto mediante los mismos mecanismos que actúan en un entorno fisiológico (Battinelli et al., 2011; Kuznetsov et al., 2012; Li, 2016). En este sentido, tanto la promoción de la liberación de factores pro-angiogénicos (VEGF, bFGF, PDGF y MMPs), como la regulación negativa de la liberación de factores antiangiogénicos (TSP-1, PF4, endostatina, angiostatina) pueden contribuir a la estimulación de la angiogénesis tumoral (Sabrkhany et al., 2011; Weis \& Cheresh, 2011; Li, 2016). Por ejemplo, se conoce que la carencia de TSP-1 en plaquetas acelera el crecimiento y la vascularización de tumores heterotópicos implantados en ratones (Feng et al., 2011). Por último, las plaquetas también pueden contribuir a la formación de nuevos vasos sanguíneos en el tumor mediante vasculogénesis, al estimular el reclutamiento de EPCs de la médula ósea, en una función que depende de la liberación del contenido de sus gránulos-a (Feng et al., 2011; Kuznetsov et al., 2012). 


\section{Mecanismos de liberación de gránulos- $\alpha$}

Durante la activación plaquetaria, las diferentes moléculas contenidas en los gránulos- $\alpha$ son liberadas al medio extracelular, donde desencadenan diferentes funciones de acuerdo al contexto fisiológico en el cual se produzca la activación. Los gránulos- $\alpha$ liberan su contenido mediante la fusión a membranas conectadas con la superficie de la plaqueta, como el OCS o la membrana extracelular (Flaumenhaft, 2003). La maquinaria molecular principal responsable de esta fusión está constituida por las proteínas SNARE (soluble NSF attachment protein receptors). Las SNAREs son proteínas asociadas a membranas, y se encuentran orientadas hacia el citosol. Las SNAREs asociadas a los gránulos se denominan v-SNAREs (vesicular SNAREs), mientras que aquellas asociadas a las membranas diana (OCS y la membrana extracelular) se conocen como t-SNAREs (target SNAREs). La asociación de las v-SNAREs con las t-SNAREs produce la energía requerida para la fusión de las membranas y la liberación del contenido de los gránulos al medio extracelular (Figura I8) (Südhof \& Rothman, 2009).

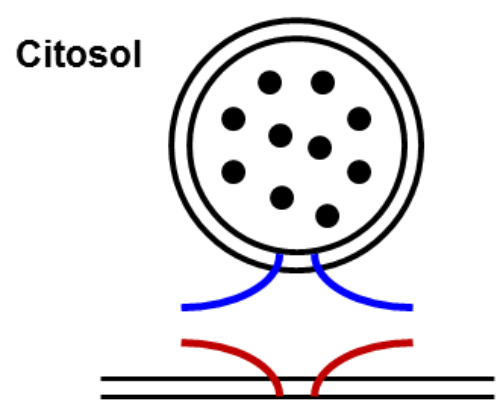

\section{Extracelular}

Figura 18. Mecanismo de fusión de los gránulos-a plaquetarios a la membrana del OCS y a la membrana extracelular. Los gránulos-a plaquetarios contienen en su superficie proteínas v-SNARE (azul) que se asocian a proteínas t-SNARE encontradas en las membranas diana (rojo), tras la activación plaquetaria. La asociación entre proteínas SNARE produce la fusión de las membranas y la posterior liberación del contenido de los gránulos al medio extracelular. Modificado de Blair \& Flaumenhaft (2009).

Entre las v-SNARE conocidas en plaquetas se encuentran VAMP2, 3, 7 y 8; mientras que entre las t-SNARE se incluyen sintaxina-2, -4, -7 y -11, y SNAP-23, -25 y -29 (Blair \& Flaumenhaft, 2009). Estudios en ratones indican que VAMP8 es la vSNARE dominante involucrada en la exocitosis de los gránulos- $\alpha$, mientras que VAMP3 y VAMP2 tienen un papel compensatorio (Schraw et al., 2003; Ren et al., 2007). En cuanto a las sintaxinas, se ha demostrado que ratones carentes de sintaxina-2, -4 , o ambas, tienen 
una secreción plaquetaria esencialmente normal (Ye et al., 2012). Por otra parte, en plaquetas humanas se ha encontrado que la falta de sintaxina-11 produce un defecto importante en la exocitosis de los gránulos plaquetarios (Ye et al., 2012). En relación a las proteínas SNAP, no existen evidencias de que SNAP-25 o SNAP-29 participen en la liberación de los gránulos- $\alpha$ plaquetarios, mientras que el papel de SNAP-23 en esta función ha sido plenamente establecido (Flaumenhaft et al., 1999; Lemons et al., 2000; Lai \& Flaumenhaft, 2003).

En la regulación de la actividad de las SNAREs participan proteínas de la familia Sec1/Munc. Estas proteínas actúan como cepos moleculares, uniéndose a las SNAREs e inhibiendo su función (Koseoglu \& Flaumenhaft, 2013; Fitch-Tewfik \& Flaumenhaft, 2013) . En plaquetas se ha detectado Munc18a, b y c, y Munc13-4 (Blair \& Flaumenhaft, 2009). En el caso de Munc18c, se encontró que está directamente involucrada en la regulación de la liberación de los gránulos- $\alpha$, ya que el uso de un anticuerpo que bloquea su unión con la sintaxina-4 aumenta la exocitosis de este tipo de gránulos plaquetarios (Houng et al., 2003). Por otra parte, pacientes con deficiencia de Munc18b, la cual se une a la sintaxina-11, presentan niveles disminuidos de esta sintaxina en las plaquetas y un defecto significativo en la exocitosis de los gránulos plaquetarios (Al Hawas et al., 2012). En el caso de Munc13-4, se ha encontrado que está involucrada en la regulación de la liberación de los gránulos densos (Shirakawa et al., 2004). Además de las proteínas Sec1/Munc mencionadas, se ha detectado CDCrel-1, la cual es una proteína que también se une a sintaxinas, y su deficiencia produce la amplificación de la secreción en plaquetas de ratón tras la activación con colágeno (Dent et al., 2002).

Las proteínas de la familia Rab, pertenecientes a la superfamilia de GTPasas pequeñas Ras, también participan en la regulación de la actividad de las proteínas SNARE (Fitch-Tewfik \& Flaumenhaft, 2013; Koseoglu \& Flaumenhaft, 2013; Bhuin \& Roy, 2014). La expresión de las proteínas Rab es ubicua, y se conoce que mediante la activación de sus efectores, participan en los procesos de formación de vesículas, transporte de las vesículas a través de elementos del citoesqueleto, y su reclutamiento y fusión a las membranas diana (Bhuin \& Roy, 2014). En células nucleadas se ha demostrado que las proteínas Rab pueden interaccionar, a través de sus efectores, con moléculas como Munc18c (Zerial \& McBride, 2001). En plaquetas, se conoce que la activación por trombina genera la fosforilación de las proteínas Rab3b, 6 y 8; siendo la fosforilación de Rab6 un mecanismo dependiente de PKC (Karniguian et al., 1993; Fitzgerald \& Reed, 1999). Por otra parte, se ha encontrado que Rab4 está involucrada en 
la liberación de gránulos- $\alpha$ dependiente de $\mathrm{Ca}^{2+}$ (Shirakawa et al., 2000). También hay evidencias que apuntan a que RabGDI, un inhibidor general de GTPasas Rab, inhibe la liberación de gránulos-a, pero no de gránulos densos (Shirakawa et al., 2000). Adicionalmente, diferentes estudios demuestran que la actividad de $\mathrm{Rab} 27 \mathrm{a} / \mathrm{b}$ es importante en la formación de los gránulos plaquetarios, la producción de proplaquetas por los megacariocitos, y la interacción entre proteínas SNARE durante la fusión de los gránulos a la membrana extracelular (Blair \& Flaumenhaft, 2009; Fitch-Tewfik \& Flaumenhaft, 2013).

\section{Papel de VAMP7 en la liberación de gránulos-a}

Las proteínas VAMP pueden ser clasificadas según su longitud en VAMPs cortas o "brevinas" y VAMPs largas o "longinas", dependiendo del dominio encontrado en su región $\mathrm{N}$-terminal. En este sentido, las brevinas (VAMP2, 3 y 8, en plaquetas) poseen una región corta y variable de 10-20 aminoácidos mientras que las longinas (VAMP7 en plaquetas) contienen un dominio conservado de 120-140 aminoácidos (dominio longina) (Figura 19) (Rossi et al., 2004).

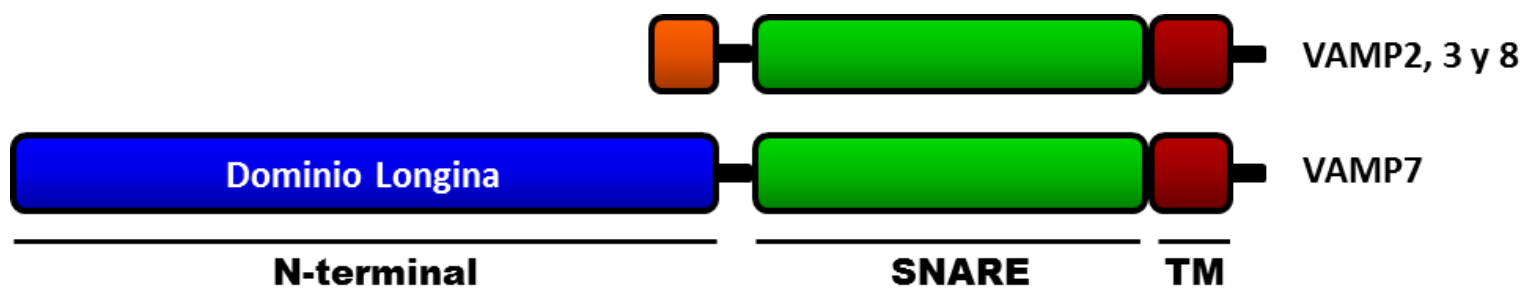

Figura 19. Esquema de la estructura de las proteínas VAMP plaquetarias. En el extremo N-terminal VAMP2, 3 y 8 contienen una región corta variable (naranja), mientras que VAMP7 contiene un dominio longina conservado de 120-140 aminoácidos. En el extremo C-terminal, todas las proteínas VAMP poseen un dominio SNARE conservado (verde) mediante el cual interaccionan con las t-SNARE, y un dominio transmembrana (TM - rojo) que funciona como anclaje a la membrana de los gránulos o vesículas.

VAMP7, también conocida como TI-VAMP (tetanus neurotoxin-insensitive vessicle associated protein), es una proteína de $25 \mathrm{kD}$ que es relativamente abundante en plaquetas humanas y de ratón, y es la única VAMP plaquetaria que posee un dominio longina similar a profilina (profilin-like) en su extremo N-terminal (Rossi et al., 2004; Graham et al., 2009). VAMP7 se encuentra involucrada en los eventos de fusión requeridos durante el remodelado de las membranas en diferentes tipos celulares. Numerosos estudios demuestran su participación en funciones como el crecimiento de neuritas (Martinez-Arca et al., 2000; 2001; Alberts et al., 2006), el remodelado de 
membranas asociado a la actividad fagocítica de los macrófagos (Braun et al., 2004), la secreción de lisosomas durante la migración celular (Bretscher, 1996), el transporte de vesículas hacia la membrana apical en células epiteliales (Pocard et al., 2007), y la liberación de vesículas autofágicas al espacio extracelular (Fader et al., 2012).

Las funciones de las proteínas VAMP en plaquetas han sido recientemente estudiadas por diferentes grupos y se conoce que tienen un papel fundamental en la secreción de los gránulos plaquetarios tras la activación (Schraw et al., 2003; Ren et al., 2007; Koseoglu et al., 2015). En secciones anteriores, se ha expuesto la existencia de distintas subpoblaciones de gránulos- $\alpha$ que almacenan de forma diferencial factores pro- y anti-angiogénicos, que son liberados de manera específica dependiendo del agonista plaquetario (Italiano et al., 2008; Battinelli et al., 2011; Chatterjee et al., 2011). Estudios recientes sugieren que las proteínas VAMP plaquetarias participan en los diferentes mecanismos moleculares involucrados en este fenómeno. En este sentido, se ha encontrado en plaquetas humanas que los gránulos- $\alpha$ que almacenan factores proangiogénicos expresan en su superficie moléculas de VAMP7 como v-SNARE principal, mientras que los gránulos- $\alpha$ que contienen factores anti-angiogénicos poseen VAMP8 en su superficie (Peters et al., 2012). Además, los gránulos- $\alpha$ VAMP7+ se mueven a la periferia de las plaquetas durante la extensión sobre sustrato, sugiriendo un posible rol en esta función plaquetaria (Peters et al., 2012). Del mismo modo, se ha demostrado que la deleción de VAMP7 afecta negativamente diferentes funciones plaquetarias como la agregación, la secreción de gránulos- $\alpha$ y gránulos densos, o la extensión sobre sustrato (Koseoglu et al., 2015). En cuanto a VAMP8, se conoce que es fundamental en la liberación de los gránulos- $\alpha$, gránulos densos y lisosomas, tras la activación plaquetaria, ya que su deleción ocasiona un defecto significativo en estas funciones (Ren et al., 2007). En el caso de VAMP2 y VAMP3, estas parecen tener un papel redundante y secundario a la función de VAMP8, y no son esenciales en la función secretoria de los gránulos plaquetarios (Schraw et al., 2003; Ren et al., 2007).

La regulación específica de la actividad de VAMP7 puede ocurrir mediante una interacción autoinhibitoria que involucra al dominio longina. Por ejemplo, se conoce que la sobreexpresión de este dominio produce la inhibición del crecimiento de neuritas, axones y dendritas en células neuroendocrinas PC12 y en neuronas del hipocampo. En contraste, la sobreexpresión de un mutante de VAMP7 con una deleción del dominio longina, produce una estimulación significativa en el desarrollo de las neuritas y en la formación de 
los complejos SNARE (Martinez-Arca et al., 2000; 2001). Por otra parte, se conoce que VAMP7 interacciona con una pequeña región de 67 aminoácidos, denominada dominio ID (interacting domain) de la proteína VARP (Vps9 domain and ankyrin-repeat-containing protein), la cual es un activador GEF (Guanine nucleotide exchange factor) de Rab21 (Burgo et al., 2009; Schäfer et al., 2012; Koseoglu et al., 2015). Existen evidencias que sugieren que VARP actúa como regulador positivo de VAMP7 mediante mecanismos que dependen tanto de su actividad GEF de Rab21 como de su interacción directa, ya que el silenciamiento de VARP produce un defecto en el crecimiento de neuritas en neuronas del hipocampo (Burgo et al., 2009). En otro estudio, se evaluó estructuralmente la interacción entre VAMP7 y VARP, hallándose que tanto VARP como el dominio longina de VAMP7 atrapan a su dominio SNARE en una conformación inactiva, por lo que la interacción directa de VARP constituiría una regulación negativa (Schäfer et al., 2012). En plaquetas, también se ha demostrado una interacción entre VAMP7, VARP y Arp2/3, dependiente de la activación plaquetaria. En este sentido, la activación promovería la liberación de VAMP7 y Arp2/3 de VARP. Posteriormente, VAMP7 interaccionaría con las t-SNARE en la membrana extracelular y Arp2/3 actuaría en la reorganización del citoesqueleto de actina durante la secreción de los gránulos y la extensión de la plaqueta sobre sustrato (Koseoglu et al., 2015).

\section{C3G}

C3G (마k-SḨ-domain-binding quanine nucleotide-releasing factor) es un activador GEF de las proteínas Rap1/2, R-Ras y TC21 de la familia Ras, y de la proteína TC10 de la familia Rho (Gotoh et al., 1995; 1997; Ohba et al., 2000; Chiang et al., 2001). Las proteínas Ras y Rho pertenecen a la superfamilia de GTPasas pequeñas Ras, las cuales son moléculas que operan como interruptores en rutas de señalización, al alternar entre un estado inactivo (unidas a GDP) y un estado activo (unidas a GTP) (Figura I10). El intercambio de GDP por GTP está determinado por la acción de GEFs, mientras que la hidrólisis del GTP a GDP, por parte de las GTPasas, requiere de la acción de proteínas activadoras de la actividad GTPasa (GAP - GTPase-activating proteins) (Bos et al., 2007). Mediante la activación de GEFs determinados, por diferentes estímulos extracelulares, las GTPasas acoplan la señal de activación de receptores de membrana con diversas respuestas celulares, a través de la estimulación de rutas de señalización específicas (Takai et al., 2001; Raaijmakers \& Bos, 2009). De este modo, las GTPasas pequeñas están involucradas en el control de procesos celulares como expresión génica, 
reorganización del citoesqueleto y tráfico vesicular; regulando respuestas biológicas como proliferación, supervivencia, diferenciación, motilidad, apoptosis, entre otros (Takai et al., 2001).

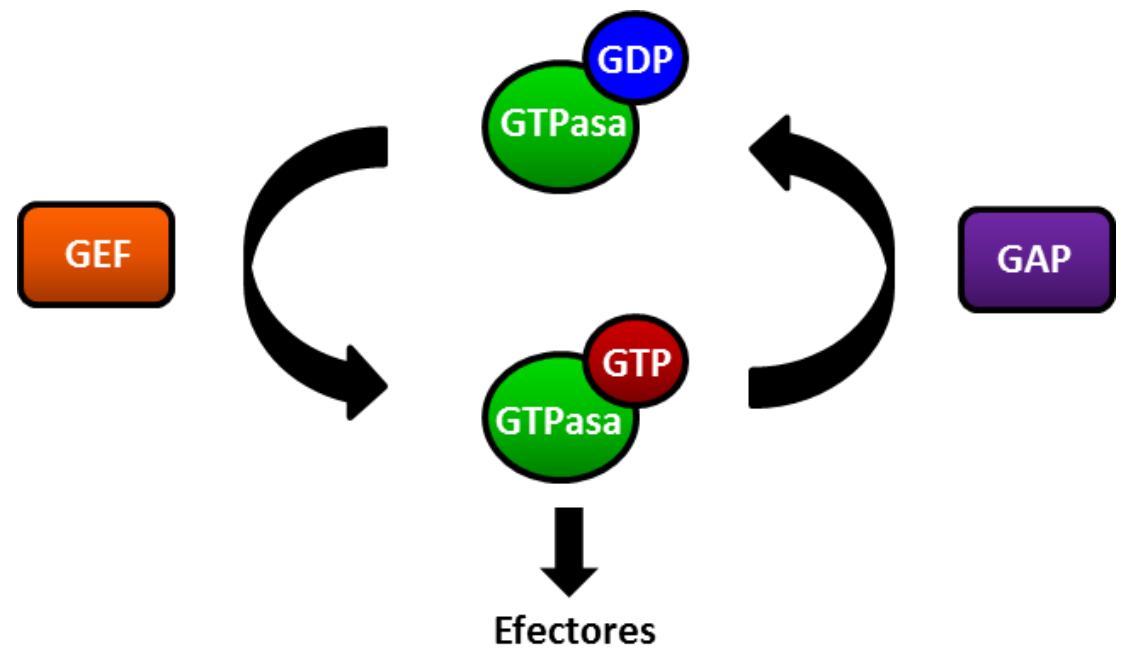

Figura 110. Ciclo de activación de las proteínas GTPasas pequeñas. Las GTPasas operan como interruptores moleculares en rutas de señalización, alternando entre un estado activo unidas a GTP y un estado inactivo unidas a GDP. El intercambio de GDP por GTP en la GTPasa (activación) está catalizado por GEFs. El incremento de la actividad GTPasa de estas proteínas, que genera la hidrólisis de GTP y produce GDP (inactivación), está catalizado por GAPs. GEF: factor intercambiador de nucleótidos de guanina. GAP: proteína activadora de la actividad GTPasa.

\section{Estructura y función de C3G}

La proteína C3G, también conocida como RapGEF1, tiene un tamaño de $\sim 140$ kDa y muestra una expresión ubicua (Tanaka et al., 1994). Su estructura presenta varios dominios modulares bien diferenciados entre sí, tanto estructural como funcionalmente (Figura 111). En la región $\mathrm{N}$-terminal, se encuentra un segmento que interacciona con E-cadherina (residuos 144-230) durante la formación de las uniones adherentes (Hogan et al., 2004). En la región central, se encuentra un dominio SH3-b (SH3-binding) que contiene cinco motivos ricos en prolinas (Pro-x-x-Pro) característicos de sitios de unión a dominios SH3. Los cuatro motivos ricos en prolina más próximos a la región C-terminal interaccionan con el dominio $\mathrm{SH} 3$ de Crk, mientras que el motivo más próximo a la región $\mathrm{N}$-terminal interacciona con el dominio $\mathrm{SH} 3$ de p130Cas (Knudsen et al., 1994; Kirsch et al., 1998). Además, se conoce que la región central de C3G interacciona con otras proteínas efectoras que presentan dominios $\mathrm{SH} 3$ en su estructura como Grb2, Hck, c-Abl y Bcr-Abl (Tanaka et al., 1994; Shivakrupa et al., 2003; Gutiérrez- 
Berzal et al., 2006; Radha et al., 2007; Maia et al., 2013). Por último, la región C-terminal de C3G contiene al dominio REM (Ras Exchange Motif) y al dominio catalítico CDC25-H (de homología con CDC25) que son los responsables de la actividad GEF de la molécula (Boriack-Sjodin et al., 1998; Quilliam et al., 2002).

\section{N-terminal}

SH3-b

REM

CDC25-H

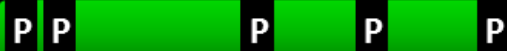

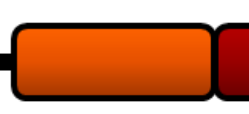

Interacción
con E-cadherina

\author{
Interacción \\ con dominios $\mathrm{SH} 3$
}

Dominio con actividad

RapGEF

Figura I11. Esquema de la estructura de C3G. La proteína C3G contiene diferentes dominios estructurales con funciones específicas. El extremo $\mathrm{N}$-terminal contiene un dominio de interacción con E-cadherina. El dominio central se denomina SH3-b (SH3-binding) y contiene regiones ricas en poli-prolinas (P). Este dominio puede interaccionar con dominios SH3 contenidos en proteínas adaptadoras como Crk o p130Cas, entre otras. El extremo C-terminal contiene al dominio REM y al dominio catalítico CDC25-H, responsables de la actividad GEF de C3G.

La inactivación en ratón del gen RAPGEF1 que codifica C3G es letal embrionaria, debido a la ausencia de actividad de Rap1. Esto sugiere que su función no puede ser compensada por otros RapGEFs en estadios tempranos del desarrollo (Ohba et al., 2001). C3G participa a través de la activación de Rap1 en procesos de adhesión y migración mediados por integrinas (de Jong et al., 1998; Arai et al., 1999; Oh et al., 2004). En este sentido, se conoce que su sobreexpresión estimula la extensión de células HeLa y de neuritas en células PC12 (Tsukamoto et al., 1999; Schönherr et al., 2010). Adicionalmente, numerosos estudios indican la participación de C3G en otras funciones celulares como proliferación, diferenciación, apoptosis y mantenimiento de los contactos célula-célula, además de tener importantes papeles en procesos fisiológicos como el metabolismo de la glucosa en adipocitos y músculo esquelético, la regulación del tamaño de la corteza cerebral, la regulación de las funciones de los linfocitos B y $\mathrm{T}$, y la maduración de vasos sanguíneos (revisado en Radha et al., 2011; Dayma \& Radha, 2016).

La señalización mediada por C3G en diferentes tipos celulares puede ser activada por diversos estímulos extracelulares que incluyen la activación de receptores de células T (TCR) (Reedquist et al., 1996), HGF (Sakkab et al., 2000), GH (Growth Hormone) (Ling et al., 2003), PDGF (Yokote et al., 1998), EGF (Okada \& Pessin, 1997), NGF (Nerve Growth Factor) (York et al., 1998), interferón-y (IFN-y) (Alsayed et al., 2000), 
eritropoyetina e IL-3 (Arai et al., 2001; Ling et al., 2003), y señales de adhesión a través de integrinas (Buensuceso \& O'Toole, 2000).

La activación de C3G puede ser regulada mediante su fosforilación en el residuo Tyr504 por quinasas de la familia Src (c-Src y Hck), por c-Abl (Radha et al., 2004; Shivakrupa et al., 2003; Mitra \& Radha, 2010) y por la oncoproteína Bcr-Abl (GutiérrezBerzal et al., 2006). Esta fosforilación es necesaria para la activación dependiente de Crk (Ichiba et al., 1999). Adicionalmente, C3G puede ser fosforilada en otros residuos de tirosina, pero su contribución a la regulación no ha sido estudiada (Mitra \& Radha, 2010). Recientemente, se ha descrito que C3G también puede ser fosforilada en residuos de serina por Cdk5/p35 y que esta modificación está relacionada con la activación de Rap1 (Utreras et al., 2013).

La actividad de C3G también puede estar regulada por la autoinhibición de la molécula. En este sentido, se conoce que la deleción de los aminoácidos 1-579, que incluye la región N-terminal y parte de la región SH3-b, resulta en una actividad catalítica constitutiva, lo que sugiere que esta región constituye un elemento regulador negativo en cis (Ichiba et al., 1999). Además, el efecto inhibitorio de la región N-terminal de C3G sobre su actividad catalítica podría estar ligado a interacciones intramoleculares entre esta región y el dominio REM, que darían lugar a la conformación autoinhibida de la molécula (Gómez, 2014).

\section{Ruta de C3G-Rap1 en plaquetas}

Rap1 es una GTPasa pequeña de la familia Ras que se expresa ubicuamente (Bos, 1998). La subfamilia Rap está compuesta por las proteínas Rap1a, Rap1b, Rap2a, Rap2b y Rap2c (Bokoch, 1993; Takai et al., 2001; Paganini et al., 2006). Rap1b se expresa abundantemente en megacariocitos maduros y plaquetas, constituyendo aproximadamente el $0.1 \%$ del total de las proteínas plaquetarias, lo que permite inferir su relevancia en este tipo celular (Torti \& Lapetina, 1994). Las plaquetas contienen Rap2b en una abundancia cerca de diez veces menor que Rap1b, mientras que Rap1a y Rap2a también han sido detectadas, pero en niveles muy bajos (Torti \& Lapetina, 1994; Klinz et al., 1992). Rap2c no se encuentra presente en las plaquetas (Paganini et al., 2006).

En plaquetas, el intercambio de GDP por GTP en Rap1b está catalizado por varias proteínas GEF, de las cuales la más relevante a nivel funcional es CalDAG-GEFI (Eto et al., 2002; Crittenden et al., 2004; Cifuni et al., 2008; Stefanini et al., 2009). Adicionalmente, diferentes estudios han demostrado la participación de otros GEFs en la 
activación de Rap1, incluyendo CalDAG-GEFIII y PDZ-GEF1 en humanos, y C3G en ratón (Schultess et al., 2005; Gutiérrez-Herrero et al., 2012; Benz et al., 2016).

Rap1b participa en la respuesta desencadenada por la mayoría de los agonistas solubles plaquetarios como ADP, epinefrina y trombina, tras la activación de sus correspondientes receptores acoplados a proteínas G (GPCR) (Figura I12) (Chrzanowska-Wodnicka et al., 2005; Li et al., 2010).

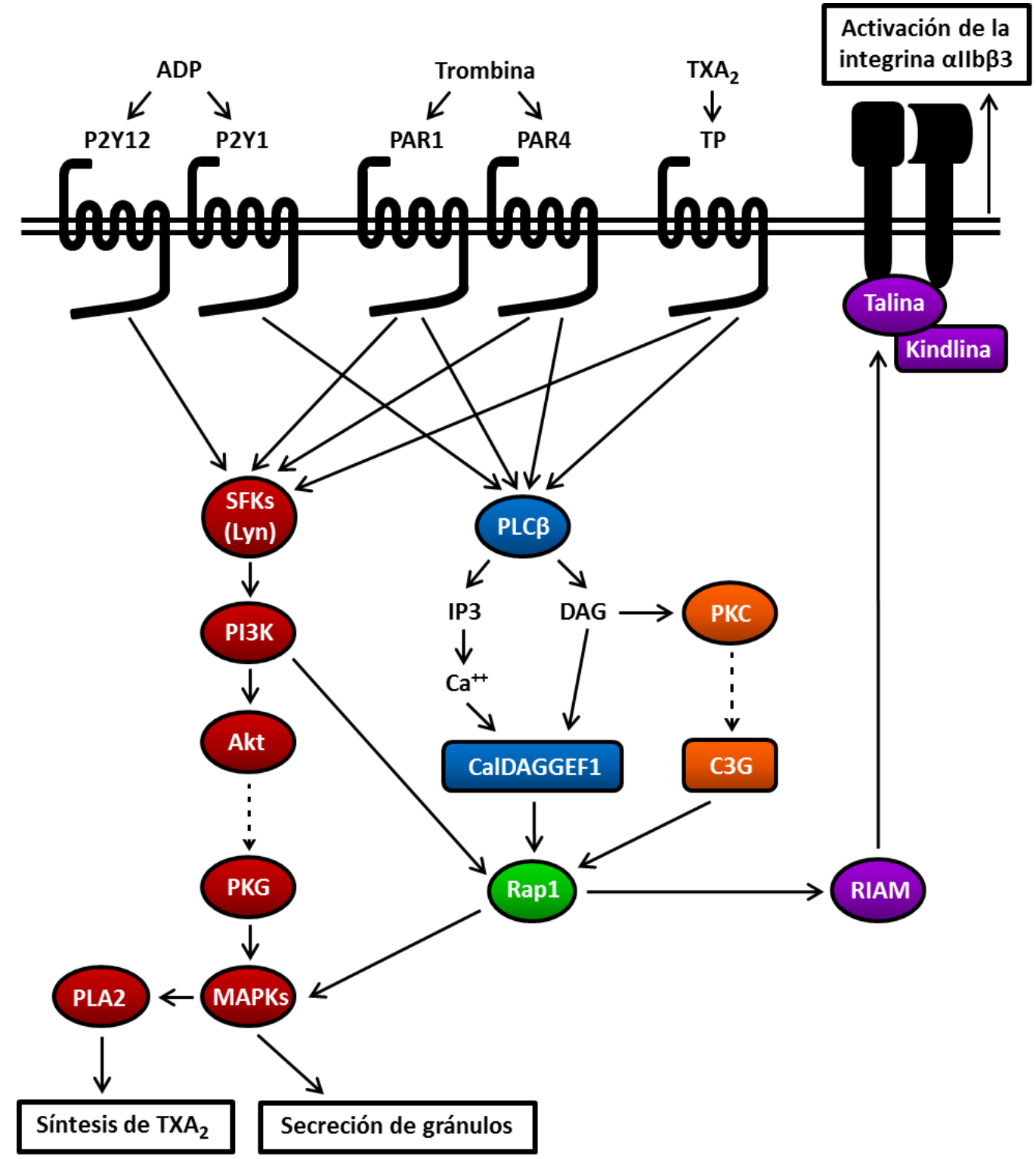

Figura 112. Rutas de activación de Rap1 en plaquetas. El tratamiento de las plaquetas con diferentes agonistas como $\mathrm{ADP}$, trombina $\circ \mathrm{TXA}_{2}$, puede producir la activación de Rap1 (verde) mediante rutas dependientes de $\mathrm{Ca}^{2+}$ y de la activación de CalDAG-GEFI (azul). Paralelamente, Rap1 también puede ser activado a través de rutas independiente de $\mathrm{Ca}^{2+}$, mediadas por PKC y C3G (naranja), o por PI3K (rojo). La activación de Rap1 desencadena diferentes funciones plaquetarias como la síntesis de $\mathrm{TXA}_{2}$ y la secreción de los gránulos (rojo), o la activación de la integrina allbß3 (morado). 
La mayoría de los agonistas plaquetarios producen la activación de Rap1b a través de rutas que involucran a CaIDAG-GEFI, que es dependiente tanto del incremento en el $\mathrm{Ca}^{2+}$ intracelular, como de la producción de diacilglicerol (DAG), generados por la activación de la fosfolipasa C (PLC) (Shattil \& Newman, 2004; Li et al., 2010). No obstante, Rap1b también puede ser activada por trombina a través de mecanismos independientes de $\mathrm{Ca}^{2+}$ que implican la activación de las rutas de PKC-C3G y PI3K (Crittenden et al., 2004; Cifuni et al., 2008; Stefanini et al., 2009; Gutiérrez-Herrero et al., 2012; Benz et al., 2016).

La activación de Rap1b desencadena diferentes funciones en la plaqueta. Por una parte, estimula la síntesis y liberación de $\operatorname{TXA}_{2}$ (Stefanini et al., 2009), lo cual promueve la amplificación de la señal de activación plaquetaria. Por otra parte, promueve la secreción de los gránulos plaquetarios (Stefanini et al., 2009; 2012), lo cual amplifica la activación de las plaquetas en un proceso mediado por ADP, además de producir la liberación concomitante de cientos de moléculas con funciones muy diferentes. Adicionalmente, Rap1b tiene un papel importante en las funciones de adhesión, agregación y extensión plaquetaria, a través de la activación de la integrina allbß3 (Crittenden et al., 2004; Chrzanowska-Wodnicka et al., 2005; Cifuni et al., 2008; Stefanini et al., 2009; GutiérrezHerrero et al., 2012), en un proceso mediado por su interacción con RIAM (Rap-1 interacting adaptor molecule), talina y kindlina (Lafuente et al., 2004; Watanabe et al., 2008; Harburger et al., 2009).

La expresión de C3G ha sido detectada a nivel de RNA y proteína tanto en plaquetas humanas (Rowley et al., 2011; Burkhart et al., 2012) como de ratón (Rowley et al., 2011; Zeiler et al., 2014). Además, nuestro grupo ha descrito, por primera vez, la participación de esta molécula en las rutas de activación plaquetaria independientes de $\mathrm{Ca}^{2+}$ (Gutiérrez-Herrero et al., 2012). Para ello hemos utilizado ratones transgénicos en los cuales el gen C3G humano, así como el mutante C3G $\Delta$ Cat (con una deleción del dominio catalítico GEF), se expresan bajo el control del promotor del gen PF4, específico de megacariocitos y plaquetas. Nuestros resultados muestran un papel relevante de C3G en la hemostasia. Así, los ratones transgénicos para C3G (TgC3G) muestran tiempos de sangrado significativamente menores que los de sus hermanos silvestres (WtC3G). Por el contrario, los ratones transgénicos para C3G $\Delta$ Cat (TgC3G $\Delta$ Cat), mostraron tiempos de sangrado significativamente mayores que los de sus controles (WtC3G $\Delta$ Cat). Estos resultados están apoyados por estudios, tanto de activación plaquetaria como de agregación, que muestran una mayor activación de las plaquetas TgC3G, en comparación 
con plaquetas silvestres, en respuesta a trombina, PMA, ADP y colágeno. Por el contrario, las plaquetas procedentes de animales $\mathrm{TgC} 3 \mathrm{G} \Delta$ Cat mostraron una menor activación que las de hermanos silvestres, lo que implica que el efecto de C3G está mediado por Rap1. Esta misma tendencia se encontró al evaluar el porcentaje de plaquetas con exposición de P-selectina en su superficie (marcador de secreción granular), tras la activación, sugiriendo un papel de C3G en la regulación de la liberación de los gránulos plaquetarios. Finalmente, también determinamos que C3G es el GEF de Rap1 responsable de su activación a través de PKC, una de las rutas plaquetarias inducidas por trombina (Gutiérrez-Herrero et al., 2012).

Basándonos en las evidencias descritas anteriormente, como la mayor activación de las plaquetas TgC3G y la mayor expresión de P-selectina en su superficie, C3G podría tener un papel modulador de la secreción plaquetaria. 
OBJETIVOS 



\section{Objetivo general}

Estudiar el papel de C3G en la regulación de la liberación de factores plaquetarios, con énfasis en los factores que regulan la angiogénesis, y su implicación en el crecimiento y la metástasis tumoral.

\section{Objetivos específicos}

Evaluar in vitro el papel regulador de C3G en la liberación de factores angiogénicos por plaquetas activadas.

Analizar in vivo el papel regulador del C3G plaquetario en la angiogénesis y la metástasis tumoral.

Profundizar en los mecanismos moleculares involucrados en la regulación mediada por C3G de la secreción plaquetaria de factores angiogénicos. 



\section{MATERIALES Y MÉETODOS}





\section{Modelos animales}

Las líneas de ratones transgénicos utilizadas fueron generadas como se describe en Gutiérrez-Herrero et al., (2012). Se utilizaron dos líneas de ratones transgénicos para el gen humano C3G (2C1 y 6A6) y una línea de transgénicos para C3G $\triangle$ Cat (8A3). La expresión de ambos transgenes es exclusiva de megacariocitos y plaquetas, ya que su transcripción está regulada por el promotor del gen PF4. En todos los experimentos se utilizaron ratones machos de 12-16 semanas de edad.

\section{Líneas celulares y condiciones de cultivo}

En la Tabla M1 se especifican las líneas celulares utilizadas en este trabajo, así como las condiciones de cultivo usadas para cada una de ellas.

\begin{tabular}{cccc}
\hline \multicolumn{4}{l}{ Tabla M1. Líneas celulares y condiciones de cultivo } \\
\hline Línea celular & Organismo & Tejido & Medio de cultivo \\
\hline HUVEC & Homo sapiens & Vena umbilical (endotelio vascular) & EGM $^{\text {TM }}$-2 BulletKit \\
3LL & (Lonza) \\
B16F10 & Mus musculus & Pulmón (carcinoma de Lewis) & DMEM \\
K562 & Homo sapiens & Médula ósea (leucemia mieloide & RPMl \\
HEK293T & Homo sapiens & Riñón (embrionario) & DMEM \\
\hline
\end{tabular}

El medio DMEM (Dulbecco's modified Eagle's medium) fue suplementado con FBS (suero fetal bovino) al 10\%, penicilina/estreptomicina $100 \mathrm{U} / \mathrm{mL}$ y L-glutamina $2 \mathrm{mM}$. Las células fueron cultivadas en un incubador a $37^{\circ} \mathrm{C}$ en atmósfera húmeda de $95 \%$ aire y $5 \% \mathrm{CO}_{2}$. Las células adherentes (HUVEC, 3LL y B16F10) fueron despegadas mediante el uso de Tripsina-EDTA. El número de células a utilizar en cada experimento fue determinado mediante tinción con azul de tripán en una cámara de Neubauer. El congelamiento y almacenamiento de las células en nitrógeno líquido, se realizó en medio completo suplementado con DMSO al 5\%.

\section{Anticuerpos}

En la Tabla M2 se detallan los anticuerpos primarios empleados en los diferentes métodos de este trabajo, así como sus características principales y las diluciones de trabajo utilizadas en cada caso. 
Tabla M2. Anticuerpos primarios utilizados en inmunofluorescencia (IF), Western blot (WB), inmunoprecipitación (IP) e inmunohistoquímica (IHC)

\begin{tabular}{|c|c|c|c|}
\hline Anticuerpo & Isotipo & Casa Comercial & Dilución \\
\hline$\beta$-actin (AC-15) & Ratón & Sigma-Aldrich (A5441) & $1: 1500$ (WB) \\
\hline bFGF & Conejo & Abcam (ab8880) & $1: 100$ (IF) \\
\hline$\beta$-tubulin (2-28-33) & Ratón & Sigma-Aldrich (T5293) & $1: 1000$ (WB) \\
\hline C3G (1008-4) & Conejo & Guerrero et al. (1998) & $1: 50$ (IF) \\
\hline C3G (C-19) & Conejo & Santa Cruz Biotechnology (sc-869) & 1:1000 (WB), 1:50 (IP) \\
\hline C3G $(H-300)$ & Conejo & Santa Cruz Biotechnology (sc-15359) & 1:1000 (WB), 1:50 (IP) \\
\hline CD31 & Conejo & Abcam (ab28364) & $1: 25(\mathrm{IHC})$ \\
\hline CD31 & Rata & BD Pharmingen (550274) & $1: 20$ (IF) \\
\hline Endostatin & Conejo & Thermo Scientific (PA1-601) & $1: 100$ (IF) \\
\hline GFP (B-2) & Ratón & Santa Cruz Biotechnology (sc-9996) & $1: 1000$ (WB) \\
\hline HA.11 (16B12) & Ratón & Covance (MMS-101R) & $1: 150($ IP) \\
\hline Integrin allb & Ratón & Santa Cruz Biotechnology (sc-166599) & $1: 1000$ (WB) \\
\hline Oregon Green® 514 Phalloidin & - & Thermo Scientific (O7465) & $1: 150$ (IF) \\
\hline P-selectin (C-20) & Cabra & Santa Cruz Biotechnology (sc-6941) & $1: 100(\mathrm{IHC})$ \\
\hline SYBL1 (158.2) (VAMP7) & Ratón & Abcam (ab36195) & $1: 25$ (IF) \\
\hline Thrombospondin (A6.1) & Ratón & Thermo Scientific (MA5-13398) & $1: 200$ (IF), 1:1000 (WB) \\
\hline TI-VAMP $(\mathrm{H}-55)$ & Conejo & Santa Cruz Biotechnology (sc-67060) & 1:500 (WB), 1:50 (IP) \\
\hline VEGF (VG-1) & Ratón & Abcam (ab1316) & $1: 200$ (IF), 1:500 (WB) \\
\hline
\end{tabular}

La Tabla M3 muestra los diferentes anticuerpos secundarios empleados, así como sus características principales y las diluciones de trabajo utilizadas en cada caso.

\begin{tabular}{|c|c|c|c|}
\hline Anticuerpo & Isotipo & Casa Comercial & Dilución \\
\hline Goat anti-mouse IgG, DyLight 680 & Cabra & Thermo Scientific (35518) & $1: 5000(\mathrm{WB})$ \\
\hline Goat anti-rabbit IgG, DyLight 680 & Cabra & Thermo Scientific (35568) & $1: 5000(\mathrm{WB})$ \\
\hline Anti-rabbit Cy3 lgG $(\mathrm{H}+\mathrm{L})$ & Cabra & Abcam (ab6939) & $1: 50$ (IF) \\
\hline Anti-mouse Cy5 IgG $(\mathrm{H}+\mathrm{L})$ & Burro & Jackson Immunoresearch (715-175-150) & $1: 50$ (IF) \\
\hline Anti-rat Cy5 lgG $(\mathrm{H}+\mathrm{L})$ & Burro & Jackson Immunoresearch (712-175-150) & $1: 100(\mathrm{IF})$ \\
\hline
\end{tabular}

\section{Aislamiento de plaquetas de ratón}

Los ratones fueron anestesiados utilizando Isoflurano al $2 \%$ y se extrajeron 600 $1000 \mu \mathrm{L}$ de sangre de cada uno, a través de punción cardiaca. La sangre fue recolectada 
en tubos conteniendo una solución de citrato trisódico como anticoagulante (Sarstedt®) y centrifugada a $150 \mathrm{~g}$ durante $8 \mathrm{~min}$. Los sobrenadantes se trasvasaron a nuevos tubos Eppendorf y se centrifugaron a $150 \mathrm{~g}$ durante $8 \mathrm{~min}$. Los sobrenadantes conteniendo las plaquetas fueron trasvasados a un tubo nuevo y centrifugados a $1400 \mathrm{~g}$ durante $10 \mathrm{~min}$. Tras esta centrifugación, los sobrenadantes fueron aspirados y descartados, mientras que los botones plaquetarios fueron resuspendidos en $400 \mu \mathrm{L}$ de tampón Tyrode's $(\mathrm{NaCl} 130$ $\mathrm{mM}$, citrato trisódico $10 \mathrm{mM}, \mathrm{NaHCO}_{3} 9 \mathrm{mM}$, dextrosa $6 \mathrm{mM}, \mathrm{MgCl}_{2} 0,9 \mathrm{mM}, \mathrm{KH}_{2} \mathrm{PO}_{4}$ $0,81 \mathrm{mM}$, Tris $10 \mathrm{mM}, \mathrm{pH}$ 7,4) antes de centrifugar una última vez a $1400 \mathrm{~g}$ durante 10 min. Finalmente, los sobrenadantes fueron descartados y los botones plaquetarios resuspendidos en tampón Tyrode's.

\section{Activación plaquetaria}

Las plaquetas aisladas de ratones del mismo genotipo (6 ratones para análisis del secretoma y del contenido plaquetario; 4 ratones para inmunofluorescencia y coinmunoprecipitación) fueron recolectadas en una única suspensión ajustada a $400 \mu \mathrm{L}$ con tampón Tyrode's. La suspensión fue suplementada con cloruro de calcio $2 \mathrm{mM}$ y separada en dos tubos conteniendo $200 \mu \mathrm{L}$ cada uno. Las plaquetas fueron activadas en condiciones de agitación (1100 rpm) con trombina 0,2 U/mL o ADP $25 \mu \mathrm{M}$, durante 5 min a 37ํㅡ, en un Eppendorf ThermoMixer®. La reacción fue detenida colocando los tubos en hielo, o por la adición de un volumen de formaldehído $4 \%$ en el caso de los análisis de microscopía confocal.

\section{Aislamiento del secretoma, restos citosólicos y membranas plaquetarias}

Las plaquetas activadas fueron centrifugadas a $2500 \mathrm{~g}$ durante $10 \mathrm{~min}$ a $4^{\circ} \mathrm{C}$ para aislar el secretoma plaquetario, el cual fue almacenado a $-80^{\circ} \mathrm{C}$ hasta su uso posterior. Por otra parte, el pellet de plaquetas fue destinado al análisis por Western blot del contenido citosólico y de la fracción de membranas. Para ello, se realizó una lisis con tampón RIPA modificado (2X: Tris $100 \mathrm{mM} \mathrm{pH=7.5,} \mathrm{NaCl} 400 \mathrm{mM}, \mathrm{MgCl}_{2} 5 \mathrm{mM}$, Igepal $2 \%$, Glicerol 20\%, PMSF 1mM y cOmplete® (Roche) diluido 1/25 a partir del stock). Posteriormente, se centrifugaron los lisados a $16000 \mathrm{~g}$ durante $10 \mathrm{~min}$ a $4^{\circ} \mathrm{C}$. Los sobrenadantes fueron separados y considerados como el contenido citosólico remanente tras la activación. Los pellets fueron considerados como la fracción de membrana de las plaquetas activadas y se prepararon agregando directamente tampón Laemmli (2X: Tris$\mathrm{HCl} 125 \mathrm{mM}$, pH 6,8, SDS 4\%, glicerol 55\%, $\beta$-mercaptoetanol $2 \%$, azul de bromofenol 
0,02\%; 4X: Tris-HCl 250mM, pH 6,8, SDS 8\%, glicerol 40\%, $\beta$-mercaptoetanol 4\%, azul de bromofenol $0,04 \%$ ) para su análisis posterior por Western blot.

\section{Análisis proteómico del secretoma plaquetario}

Para la evaluación del perfil proteico general del secretoma plaquetario por SDSPAGE, los secretomas aislados fueron ultracentrifugados a 50000 r.p.m. durante 1 hora a $4^{\circ} \mathrm{C}$ utilizando un rotor 100.3 TLA (Beckman Optima®), con la finalidad de remover las microvesículas. La pureza del secretoma fue confirmada por la ausencia de la integrina allb, específica de membranas plaquetarias. Las proteínas en el secretoma purificado fueron concentradas mediante la utilización de filtros Amicon-Ultracel®-3K, los cuales permiten concentrar todas aquellas proteínas con un tamaño mayor a 3 kDa. Para ello, las muestras fueron colocadas en los filtros y se centrifugaron a $3200 \mathrm{~g}$ por 50 min a $4^{\circ} \mathrm{C}$. En todos los casos, el volumen final de muestra concentrada fue de $100 \mu \mathrm{L}$ aproximadamente. Posteriormente, se separaron electroforéticamente $20 \mu \mathrm{g}$ de proteína de cada secretoma concentrado en un gel de poliacrilamida preparativo $(16 \times 14 \mathrm{~cm})$ en gradiente de 6 a 15\%. Las bandas resultantes fueron visualizadas mediante tinción de plata compatible con análisis de espectrometría de masas (Chevallet et al., 2006).

Paralelamente, se realizó un análisis proteómico de muestra completa en el cual los secretomas plaquetarios aislados fueron analizados de manera íntegra, sin haberlos concentrado previamente. Las proteínas en la muestra completa fueron digeridas con tripsina de acuerdo a procedimientos estándar y analizadas por cromatografía líquida acoplada a espectrometría de masas en tándem (LC-MS/MS), utilizando un sistema nanoUPLC (nanoAcquity, Waters Corp., Milford/MA, USA) acoplado a un espectrómetro de masas LTQ-Velos-Orbitrap (Thermo Fisher Scientific, San Jose/CA, USA). El algoritmo de búsqueda MASCOT fue utilizado para el análisis de los espectros adquiridos, mediante el uso del software Proteome Discoverer (Thermo Scientific - v.1.4.1.14) contra una base de datos proteómicos de ratón (AUP000000589) descargada de UniProt en Diciembre del 2015. La validación de los péptidos se realizó a través del uso del algoritmo Percolator (Käll et al., 2007). Se consideraron sólo las proteínas con más de dos péptidos diferentes detectados. La suma del número de péptidos detectado para cada proteína (PSM Peptide Spectrum Matches) fue utilizada como medida cuantitativa de la abundancia de cada una de ellas (Liu et al., 2012). 
La tinción con plata y el análisis de las proteínas por LC-MS/MS fueron realizados en el Servicio de Proteómica del Centro de Investigación del Cáncer, Salamanca.

\section{Microscopía electrónica de transmisión}

Las plaquetas fueron aisladas y fijadas con una mezcla de glutaraldehído $2 \%$ y paraformaldehído $1,6 \%$, en tampón fosfato $0,1 \mathrm{M} \mathrm{pH} 7,4$, durante 30 minutos. Posteriormente, se lavaron y fueron incluidas en agarosa $2 \%$ preparada en $\mathrm{H}_{2} \mathrm{Od}$. Los bloques fueron seccionados en cuatro pedazos, incubados en la solución de fijación durante 30 minutos y lavados, antes de ser procesados para su análisis por microscopía electrónica. Este análisis se llevó a cabo en el Servicio de Microscopía de la Universidad de Salamanca, mediante el uso de un microscopio electrónico de transmisión Tecnai Spirit Twin 120 kv, de acuerdo a procedimientos estándar.

\section{Microscopía confocal de inmunofluorescencia}

\section{Análisis de la secreción plaquetaria:}

Las plaquetas fueron aisladas y activadas con trombina o ADP, como se describe anteriormente. Tras detener la reacción de activación mediante la adición de un volumen de paraformaldehído 4\%, las plaquetas se fijaron incubando 15 minutos en esta solución a temperatura ambiente. Las suspensiones de plaquetas fijadas se aplicaron a cubreobjetos redondos de $12 \mathrm{~mm}$ de diámetro recubiertos con poli-L-lisina, y se dejaron asentar durante 50 minutos. Posteriormente, se retiraron las plaquetas no adheridas mediante aspiración y se lavaron los cubreobjetos con PBS.

Análisis de la extensión plaquetaria sobre sustrato:

Las plaquetas fueron aisladas como se describe anteriormente, y se resuspendieron en $500 \mu \mathrm{L}$ de tampón Tyrode's. Posteriormente, se activaron $150 \mu \mathrm{L}$ de esta suspensión con trombina $0,2 \mathrm{U} / \mathrm{mL}$ y se aplicaron inmediatamente a cubreobjetos redondos de $12 \mathrm{~mm}$ de diámetro recubiertos con poli-L-lisina. Las plaquetas fueron incubadas a $37^{\circ} \mathrm{C}$ durante 30 minutos para permitir su adhesión y extensión sobre el sustrato. Las plaquetas no adheridas fueron retiradas mediante aspiración, y las plaquetas extendidas se fijaron con paraformaldehído 4\% durante 15 minutos. Tras la fijación, los cubreobjetos fueron lavados con PBS. 
En ambos casos, las plaquetas adheridas a los cubreobjetos fueron permeabilizadas, mediante la incubación con Tritón-X-100 0,2\% durante 5 minutos. Las plaquetas permeabilizadas se lavaron con PBS y se bloquearon con albúmina sérica bovina (BSA) al 1\% en PBS durante toda la noche. Posteriormente, se incubaron con los anticuerpos primarios o con Phalloidin-Oregon Green® 514 (Tabla M2) durante dos horas en la misma solución. Las plaquetas incubadas con anticuerpos primarios fueron lavadas con PBS e incubadas con los anticuerpos secundarios (Tabla M3) durante una hora. Finalmente, todos los cubreobjetos fueron lavados con PBS y agua destilada antes de ser montados con una solución de Mowiol (Sigma) para su visualización. Esta fue realizada mediante un sistema de microscopía confocal Zeiss LSM515 utilizando el objetivo de inmersión 100x/1,4 Oil Plan-ApoChromat Ph1 y un zoom óptico adicional de 2,5x. La cuantificación de las señales de fluorescencia y la determinación del área de las plaquetas extendidas se realizó utilizando el software para análisis de imágenes ImageJ 1.48v (National Institutes of Health, USA). Del mismo modo, este software fue utilizado para el cálculo del coeficiente de correlación de Manders entre las señales de fluorescencia, mediante el plugin JACoP (Bolte and Cordelières, 2006; Dunn et al., 2011; Peters et al., 2012).

\section{Ensayo de formación de capilares in vitro}

La capacidad angiogénica de los secretomas se estudió mediante el análisis de la inducción de la formación de capilares sobre una matriz de Matrigel® in vitro. Para ello, se combinaron 33.000 células endoteliales humanas (HUVEC) resuspendidas en medio suplementado diluido (1:5 con PBS en un volumen total de $37,5 \mu \mathrm{L}$ ), con $15 \mu \mathrm{L}$ de cada secretoma diluido con PBS en un volumen final de 37,5 $\mu \mathrm{L}$. Los $75 \mu \mathrm{L}$ totales de la mezcla fueron sembrados sobre la matriz gelificada en placas de 96 pocillos. Las células fueron incubadas a $37^{\circ} \mathrm{C}$ y $\mathrm{CO}_{2} 5 \%$ para permitir la formación de capilares. La determinación de los parámetros indicadores de angiogénesis se realizó cada media hora entre las 2 y 5 horas mediante el uso de un microscopio invertido de contraste de fases Zeiss Axiovert. Los parámetros determinados fueron: el número de ramificaciones (punto de intersección de tres o más capilares), largo medio de cada segmento maestro (segmentos delimitados por dos ramificaciones) y el área media de cada malla interna (espacios cerrados delimitados por segmentos maestros). El análisis de los parámetros mencionados se realizó a través del software para análisis de imágenes ImageJ 1.48v (National Institutes 
of Health, USA). Los datos se representan como el promedio de cada parámetro a lo largo de la duración del experimento.

\section{Modelos singénicos de desarrollo tumoral}

La inducción del crecimiento de tumores heterotópicos de carcinoma de pulmón de Lewis fue realizada mediante la inyección de $10^{6}$ células $3 \mathrm{LL}$ en el lomo de los ratones, dejándose crecer por 11 días. En el caso de los tumores heterotópicos de melanoma, se inyectaron $3,3 \times 10^{5}$ células $\mathrm{B} 16 \mathrm{~F} 10$ y se dejaron crecer por 15 días. El tamaño de los tumores (largo y ancho) fue medido de manera interdiaria mediante el uso de un calibre. Al final del experimento, se sacrificaron los ratones y se pesaron los tumores luego de su extracción. Los tumores fueron fijados mediante la incubación en paraformaldehído 4\% durante toda la noche a temperatura ambiente, antes de ser procesados para su inclusión en bloques de parafina. Los estudios histológicos fueron realizados a partir de cortes teñidos con hematoxilina/eosina o de cortes analizados mediante inmunohistoquímica. En este último caso, se evaluaron los marcadores CD31 (células endoteliales) y P-selectina (plaquetas), incubando con los anticuerpos primarios según se describe en la Tabla M2. Las tinciones de la inmunohistoquímica fueron realizadas con el sistema automatizado Discovery (Roche). Los revelados se realizaron mediante el uso del Chromo Map Kit (Roche) o del Chromo Map Kit + Purple (Roche).

La inclusión en bloques de parafina de los tejidos fijados, así como los cortes y tinciones histoquímicas se realizaron en el Servicio de Patología Molecular Comparada del Centro de Investigación del Cáncer, Salamanca.

\section{Modelo de metástasis pulmonar}

El establecimiento de metástasis pulmonares de células B16F10 fue inducido mediante la inyección de $2,5 \times 10^{5}$ células en $100 \mu \mathrm{L}$ de PBS, a través de la vena lateral de la cola de los ratones (Erpenbeck et al., 2010). A los 15 días, se extrajeron los pulmones y se cuantificaron las metástasis superficiales. Posteriormente, los pulmones fueron fijados en paraformaldehído $4 \%$ para su posterior análisis histoquímico mediante tinciones de hematoxilina/eosina de cortes del tejido incluido en parafina. 


\section{Modelo de angiogénesis in vivo por inducción con oxazolona}

Los ratones fueron afeitados en su región abdominal y se pre-sensibilizaron mediante la aplicación tópica de oxazolona (Sigma) al $2 \%$ en una mezcla de acetona y aceite de máiz (4:1). Tras seis días, se indujo la hipersensibilidad por contacto mediante la aplicación tópica de oxazolona $1 \%$ en la mezcla descrita, en una oreja de cada animal. El grosor de la oreja tratada fue cuantificado utilizando un calibre milimetrado a las 0, 24 y 48 horas posteriores al tratamiento. Los animales se procesaron a las 48 horas y las orejas tratadas fueron disecadas y fijadas en paraformaldehído $4 \%$ para su posterior análisis histoquímico mediante tinciones de hematoxilina/eosina de cortes del tejido incluido en parafina.

\section{Ensayo de angiogénesis in vivo en botones de Matrigel}

El Matrigel utilizado fue suplementado con bFGF (Peprotech \#450-33) $1 \mathrm{mg} / \mathrm{mL}$ y se inyectaron $300 \mu \mathrm{L}$ en la región abdominal de los ratones. Tras 7 días, los ratones se sacrificaron y se extrajeron los botones de Matrigel. Estos fueron fijados en pararformaldehído 4\% durante 4 horas, para luego ser lavados en PBS, crioprotegidos en soluciones de sacarosa $15 \%$ y $30 \%$, embebidos en OCT (medio para cortes congelados) y congelados en isopentano enfriado con nitrógeno líquido. Se realizaron criosecciones del tejido de $10 \mu \mathrm{m}$ de grosor y se almacenaron a $-20^{\circ} \mathrm{C}$ hasta su uso. Las criosecciones fueron rehidratadas con Tris-PBS (TPBS) y bloquedas con una solución de suero de oveja 16\%, BSA 1\% y Tritón-X-100 0,1\% en TPBS (SBT). El análisis por inmunofluorescencia se realizó incubando las secciones con el anticuerpo primario contra CD31 (Tabla M2) en SBT toda la noche a $4^{\circ} \mathrm{C}$, lavando con PBS, e incubando con el anticuerpo secundario (Tabla M3) durante 1 hora a temperatura ambiente. Los núcleos fueron teñidos con DAPI (Sigma). Las imágenes se capturaron en un microscopio confocal Leica SP5.

\section{Construcciones de VAMP7 y clonación}

El cDNA de la region citosólica completa del VAMP7 humano (aa 1-188) y de sus dominios longina (aa 1-120) y SNARE (aa 121-188) fueron obtenidos a partir del clon pEGF-VAMP7 (1-220) (Addgene \#42316). Cada región fue definida según lo reportado previamente por Martínez-Arca y col. (2000). Los primers utilizados para la amplificación de cada fragmento se especifican en la Tabla M4 y están basados en (Schäfer et al., 2012). 


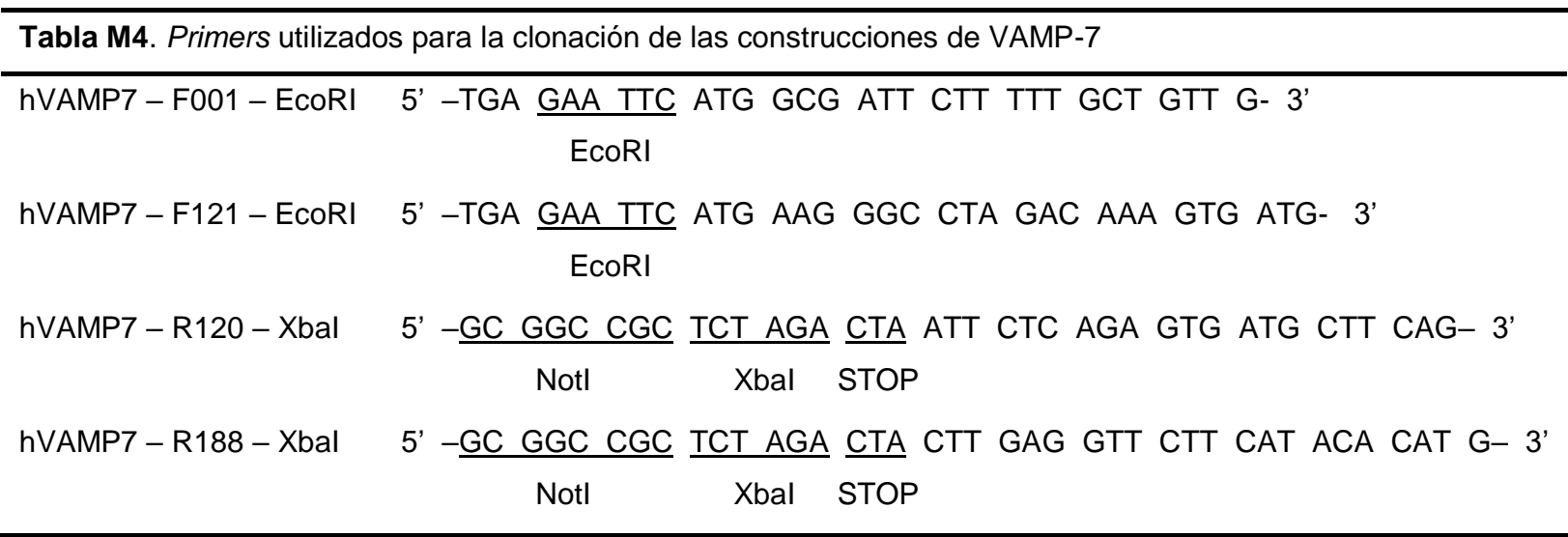

Las construcciones fueron clonadas en un plásmido derivado del vector de expresión mamífero pcDNA3, proporcionado por el Dr. J.M. Pereda (IBMCC, Salamanca), y denominado pcDNA3-CFP-C4 (Figura M1). Este vector incluye la secuencia para la proteína fluorescente cian (CFP - cyan fluorescent protein) y permite crear proteínas de fusión etiquetadas en su extremo $\mathrm{N}$-terminal. Además, incluye un linker flexible compuesto por cinco repeticiones de glicina-serina entre la CFP y la proteína fusionada, lo que permite la disminución de interferencias estéricas no deseadas. La clonación dentro de este plásmido se realizó mediante el uso de los sitios EcoRI y Xbal, que fueron insertados en las secuencias de nuestras construcciones a través de los primers indicados anteriormente.

La construcción de C3G etiquetada con HA en su extremo N-terminal, contenida en el vector de expresión derivado de pCEFL-HA (Chiariello et al., 2000), fue proporcionada por el Dr. J.M. Pereda (IBMCC, Salamanca). El diseño y construcción de esta proteína de fusión ha sido descrito previamente (Gómez, 2014). Por otra parte, el diseño y construcción de C3G $\Delta$ Cat clonada en el vector de expresión pLTR2, se ha descrito previamente (Guerrero et al., 1998).

EI DNA recombinante fue mantenido en la cepa $\mathrm{DH} 5 a$ de $E$. coli. Las bacterias se cultivaron en placas de agar LB (Luria Bertani) o en medio líquido LB $\circ 2 x Y T$. En todos los casos, la selección por antibióticos fue mantenida añadiendo ampicilina (100 mg/L) al medio. EI DNA recombinante fue purificado de los cultivos bacterianos mediante el uso de los kits GeneJET ${ }^{\oplus}$ Plasmid Miniprep o Maxiprep, de acuerdo a las especificaciones del fabricante. 


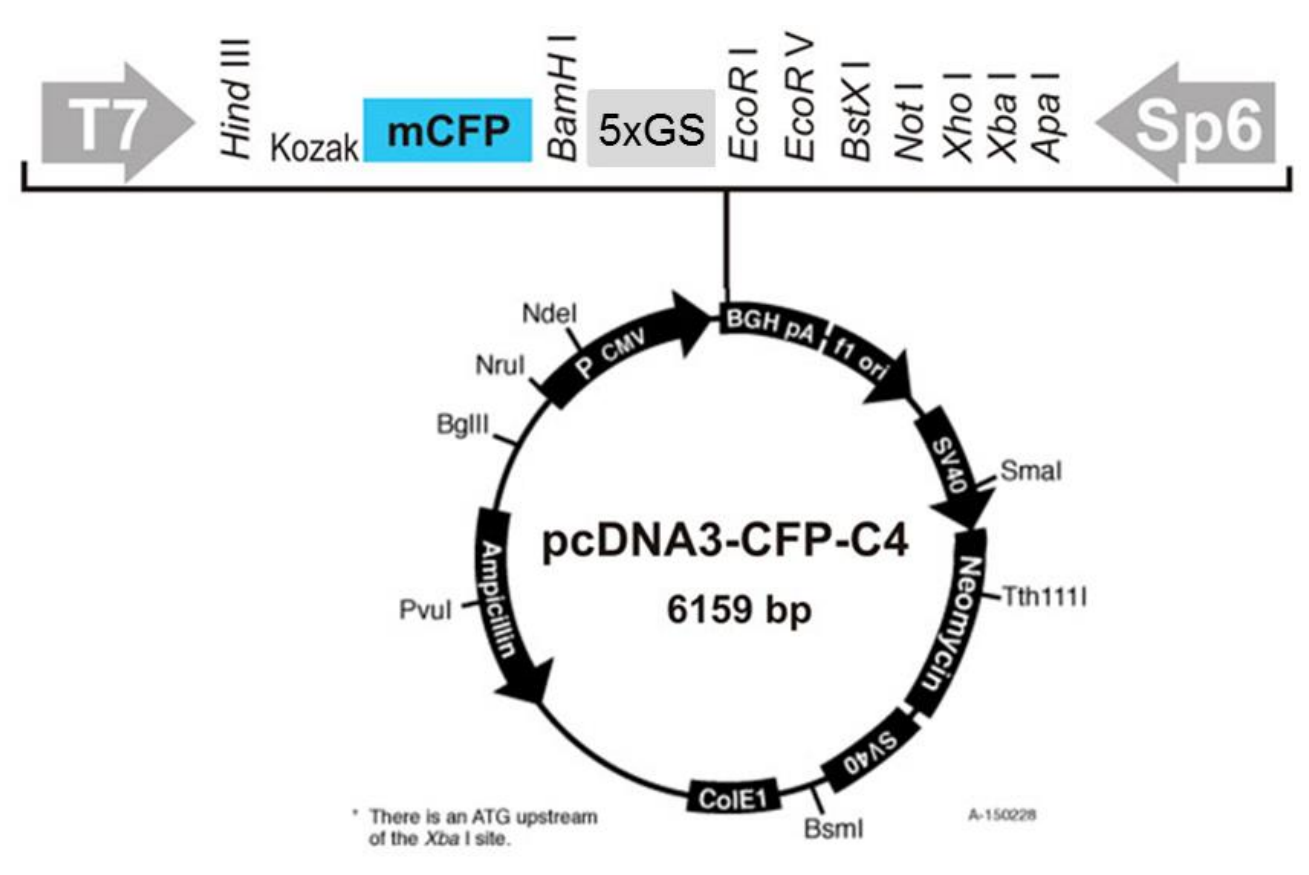

Figura M1. Vector de expresión mamífero pcDNA3-CFP-C4. Esquema representativo de la disposición de las secuencias de la proteína CFP, del linker flexible y del sitio de clonación múltiple en el vector.

\section{Transfección transitoria}

Las transfecciones se realizaron en células HEK293T al 50\% de confluencia, en placas de $10 \mathrm{~cm}$ de diámetro. Estas co-transfecciones consistieron en la introducción de la construcción de C3G o C3G $\triangle$ Cat, en conjunto con cada una de las construcciones de VAMP7 indicadas anteriormente. Para ello, se incorporaron al medio de cultivo $500 \mu \mathrm{L}$ de $\mathrm{NaCl} 150 \mathrm{mM}$ conteniendo $10 \mu \mathrm{L}$ de polietilenimina (PEI) y 2,5 $\mu \mathrm{g}$ de cDNA de cada una de las dos construcciones co-transfectadas. Las células se dejaron incubar por 48 horas, y posteriormente fueron lisadas para llevar a cabo la co-inmunoprecipitación, tal como se describe en la siguiente sección.

\section{Co-inmunoprecipitación}

Plaquetas activadas:

Las plaquetas fueron aisladas y activadas como se describió anteriormente. Posteriormente, las plaquetas fueron centrifugadas a $1400 \mathrm{~g}$ durante $10 \mathrm{~min}$ a $4^{\circ} \mathrm{C}$. Los pellets de plaquetas fueron lisados en $500 \mu \mathrm{L}$ de tampón RIPA (1X: Tris $20 \mathrm{mM} \mathrm{pH}=7.5$, $\mathrm{NaCl} 150 \mathrm{mM}$, Triton-X-100 1\%, deoxicolato de sodio 0,1\%, SDS 0,1\%, PMSF 1mM, NaF $5 \mathrm{mM}, \mathrm{Na}_{3} \mathrm{VO}_{4} 1 \mathrm{mM}$ y $\mathrm{cOmplete} \circledast$ (Roche) $1 \mathrm{X}$ ). Los lisados fueron aclarados 
centrifugando a $16000 \mathrm{~g}$ durante $10 \mathrm{~min}$ a $4^{\circ} \mathrm{C}$, y posteriormente se incubaron con el anticuerpo primario (Tabla M2) durante 2 horas a $4^{\circ} \mathrm{C}$ en rotación.

Líneas celulares:

Las células K562 fueron activadas con PMA (Phorbol-12-myristate-13-acetate) $20 \mathrm{nM}$ durante $10 \mathrm{~min}$. Posteriormente, fueron lavadas con PBS y lisadas en $500 \mu \mathrm{L}$ de tampón RIPA. Las células HEK293T fueron transfectadas como se describe anteriormente, y a las 48 horas fueron lavadas con PBS y lisadas en $500 \mu \mathrm{L}$ de tampón RIPA. La proteína fue cuantificada (ver a continuación) y se incubaron 300-500 $\mu \mathrm{g}$ (K562) o $1000 \mu \mathrm{g}$ (HEK293T) de proteína de cada lisado con el anticuerpo primario (Tabla M2) durante 2 horas a $4^{\circ} \mathrm{C}$ en rotación.

En todos los casos, una vez finalizada la incubación con el anticuerpo primario, se añadieron $100 \mu \mathrm{L}$ de resina proteína G-agarosa 4 RapidRun® (ABT) (40 $\mu \mathrm{L}$ originales lavados con tampón RIPA 3 veces y resuspendidos en $100 \mu \mathrm{L}$ finales) y se dejó incubar 1 hora adicional bajo las mismas condiciones. Posteriormente, se purificaron los complejos mediante una centrifugación a $250 \mathrm{~g}$ durante 1,5 minutos a $4^{\circ} \mathrm{C}$, y realizando 3 lavados con tampón RIPA mediante centrifugaciones adicionales bajo las mismas condiciones. Finalmente, las proteínas inmunoprecipitadas se prepararon para su análisis posterior por Western blot, agregando directamente $20 \mu \mathrm{L}$ de tampón Laemmli $2 \mathrm{X}$ a la resina lavada.

\section{Cuantificación de proteínas, SDS-PAGE y Western blot}

La concentración de proteína en los secretomas fue cuantificada mediante el uso del protocolo de cuantificación de proteínas (absorbancia a $280 \mathrm{~nm}$ ) del sistema NanoDrop2000 (Thermo Scientific). La concentración de proteínas en los lisados celulares y en los secretomas concentrados fue cuantificada utilizando el método de Bradford (1976). Cantidades específicas de proteínas fueron mezcladas con tampón Laemmli y hervidas a $95^{\circ} \mathrm{C}$ durante 5 minutos. La separación de las proteínas fue realizada mediante electroforesis en geles de poliacrilamida (SDS-PAGE), para luego ser transferidas a membranas Immobilon-P (Millipore) y analizadas por Western blot, de acuerdo a procedimientos estándar. Los anticuerpos primarios utilizados se muestran en la Tabla M2, mientras que los anticuerpos secundarios se pueden observar en la Tabla M3. La inmunoreactividad fue detectada mediante el sistema de imagen Oddysey (Li-COR, Inc.). 


\section{Análisis estadístico}

Los análisis fueron realizados en el programa IBM SPSS Statistics 23.0.0.0v (IBM Corporation, USA). La normalidad de los conjuntos de datos fue verificada mediante la prueba Kolmogorov-Smirnov. La homogeneidad de las varianzas fue verificada mediante la prueba de Levene. Las diferencias entre las medias de diferentes grupos se determinaron mediante la prueba t de student. Los resultados están representados como la media \pm s.e.m. (error estándar de la media). En todos los casos, se consideraron que las diferencias fueron estadísticamente significativas cuando la $p<0,05$. 
RESULTADOS 



\section{Función reguladora de $C 3 G$ en la liberación de factores angiogénicos por plaquetas activadas}

En la sección inicial de este trabajo, evaluamos la función de C3G en la regulación de la secreción de factores por plaquetas activadas, con especial énfasis en las proteínas moduladoras de la angiogénesis. Con esta finalidad, realizamos un análisis proteómico y evaluamos los cambios a nivel general en la secreción de diferentes factores. Posteriormente, estudiamos de manera específica, a través de microscopía confocal de inmunofluorescencia, la liberación de factores pro- y anti-angiogénicos específicos. Finalmente, analizamos la capacidad angiogénica general de los secretomas plaquetarios aislados mediante un ensayo de angiogénesis in vitro.

\section{La liberación de factores anti-angiogénicos se encuentra disminuida en plaquetas TgC3G y TgC3GACat activadas con trombina o ADP}

Previamente, se ha demostrado que C3G tiene un papel importante en la función plaquetaria, a través de su función en la ruta PKC-C3G-Rap1b. Entre los efectos del C3G plaquetario se encuentra que promueve la liberación de los gránulos- $\alpha$, según se ha evidenciado por el incremento de P-selectina en la superficie plaquetaria tras su activación (Gutiérrez-Herrero et al., 2012). Para profundizar en el estudio sobre el efecto que el C3G plaquetario tiene en la secreción de los gránulos-a y la liberación de su contenido, realizamos un análisis proteómico de secretomas aislados de plaquetas de nuestros ratones transgénicos (TgC3G y TgC3G $\Delta$ Cat) y sus respectivos controles silvestres (WtC3G y WtC3G $\Delta$ Cat), activadas con trombina o ADP.

En primer lugar, se estandarizó el método para el aislamiento del secretoma de las plaquetas de ratón, basándonos en el trabajo realizado por Coppinger et al. (2004). En la Figura R1 se puede apreciar que los secretomas purificados se encuentran aislados de restos plaquetarios y otros fragmentos de membrana, según se evidencia por la ausencia de la subunidad allb de la integrina plaquetaria, que es utilizada como marcador de membranas de plaquetas.

Las concentraciones de proteína determinadas en los secretomas se muestran en la Tabla R1. En todos los casos, la concentración se encontró en el mismo orden de magnitud, y no se observaron grandes diferencias entre genotipos. Sin embargo, se encontraron diferencias en la cantidad de proteína secretada en respuesta a los distintos 
agonistas, donde la trombina promovió la liberación de una mayor cantidad de proteína en todos los genotipos, con respecto al ADP.

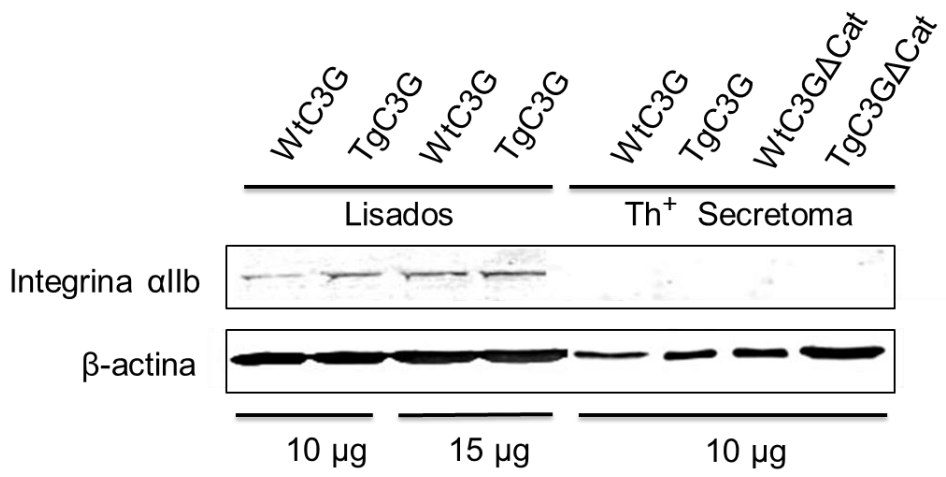

Figura R1. Análisis de la pureza de los secretomas plaquetarios aislados. Determinación por Western blot de la expresión de la subunidad allb de la integrina plaquetaria en lisados y en los secretomas aislados de plaquetas activadas con trombina $0,2 \mathrm{U} / \mathrm{mL}(\mathrm{Th}+)$. La expresión de $\beta$-actina fue utilizada como control de carga.

El análisis por microscopía electrónica de transmisión de plaquetas de cada genotipo en reposo demostró la existencia de variaciones en la cantidad de los gránulos contenidos en ellas. En este sentido, se encontró que la abundancia de plaquetas con un contenido de gránulos mayor que tres por sección fue menor en el genotipo TgC3G, con respecto al control WtC3G. En contraste, el genotipo TgC3G $\Delta$ Cat presentó un número mayor de plaquetas con más de tres gránulos por sección, con respecto a su control silvestre (Tabla R1 y Figura R2).

Tabla R1. Concentración de proteína secretada por plaquetas activadas y abundancia de gránulos en plaquetas de ratón en reposo.

\begin{tabular}{|c|c|c|c|c|}
\hline \multirow{2}{*}{ Genotipo } & \multicolumn{2}{|c|}{ Proteína secretada $(\mu \mathrm{g} / \mu \mathrm{L})$} & \multicolumn{2}{|c|}{$\begin{array}{c}\text { Abundancia de gránulos por } \\
\text { plaqueta }(\%)\end{array}$} \\
\hline & Activación con trombina & Activación con ADP & 0 - 3 gránulos & > 3 gránulos \\
\hline WtC3G & 0,50 & 0,24 & 47,32 & 52,68 \\
\hline TgC3G & 0,43 & 0,19 & 63,82 & 36,18 \\
\hline WtC3G $\Delta$ Cat & 0,47 & 0,25 & 64,29 & 35,71 \\
\hline $\operatorname{TgC} 3 G \Delta$ Cat & 0,45 & 0,28 & 53,22 & 46,78 \\
\hline
\end{tabular}



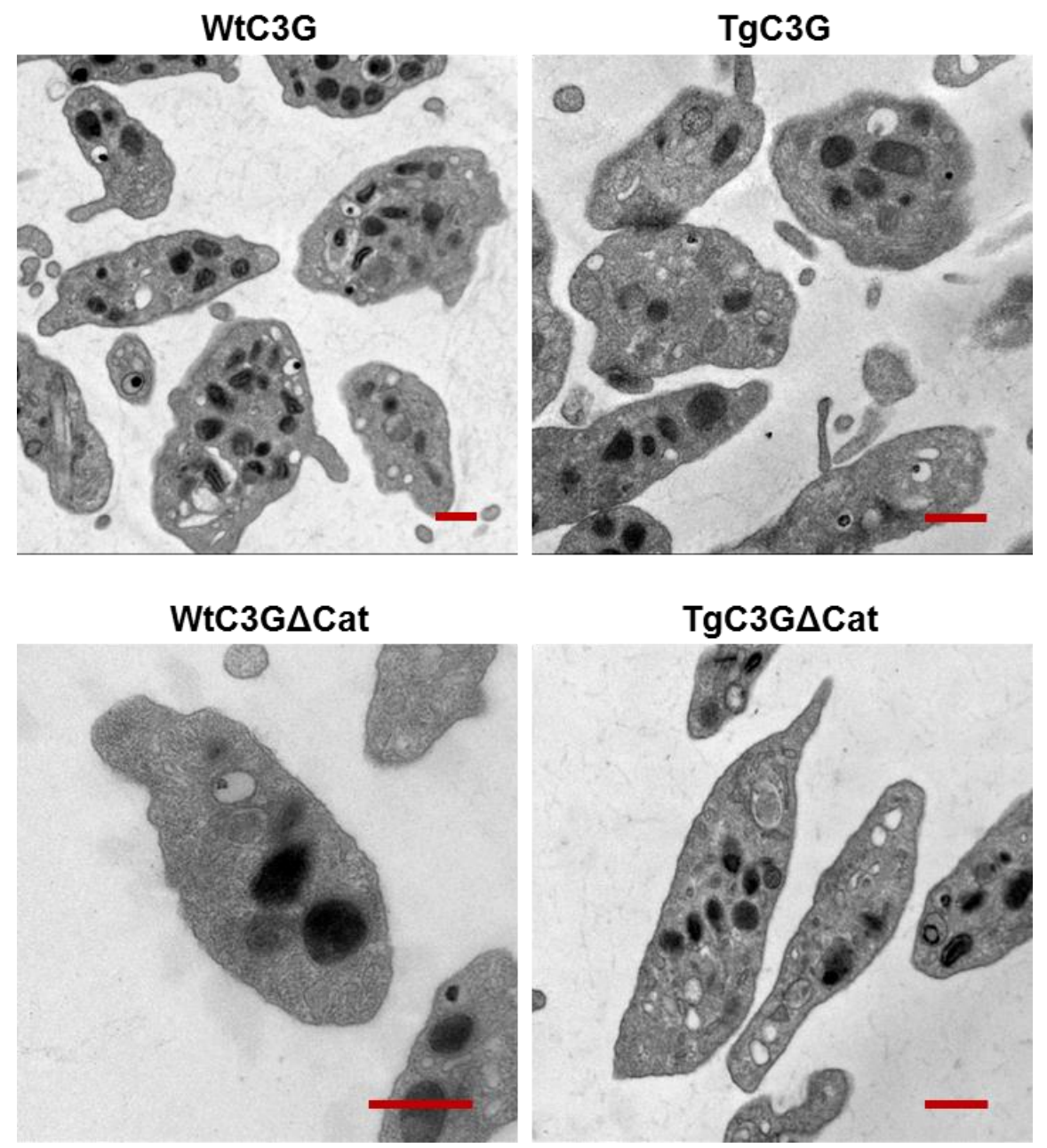

Figura R2. Abundancia de gránulos en plaquetas de ratón en reposo. Imágenes representativas de microscopía electrónica de transmisión mostrando la abundancia de gránulos en plaquetas en reposo, correspondientes a cada genotipo de ratón $(n=3)$. Barra: $500 \mathrm{~nm}$.

Para la evaluación del perfil proteico general, se realizó una separación en SDSPAGE de las proteínas contenidas en los secretomas de plaquetas de cada genotipo activadas con trombina. Los secretomas se concentraron previamente, por lo que las proteínas con masa molecular menor a $3 \mathrm{kDa}$ no fueron detectadas. En la Figura R3, se muestran los diferentes perfiles proteicos, observándose que existen diferencias cualitativas (diferente número de bandas) y cuantitativas (diferente intensidad de las bandas) entre los diferentes genotipos. Las diferencias más evidentes las presenta el secretoma de las plaquetas TgC3G, en el cual se aprecia un mayor número de bandas, así como bandas más intensas, en comparación con el resto de los grupos. En el secretoma de plaquetas TgC3G $\Delta$ Cat también se aprecian diferencias, aunque más 
discretas, en número de bandas e intensidad de éstas, con respecto al control WtC3G $\Delta$ Cat. Estos resultados nos condujeron a realizar un estudio más detallado, para lo cual llevamos a cabo un análisis proteómico de muestra completa por cromatografía liquida de alto rendimiento acoplada a espectrometría de masas en tándem (LC-MS/MS). Este método no requería una concentración previa de los secretomas, por lo que ofrecía la oportunidad de evaluar el rango completo de proteínas, y además, obtener datos cuantitativos de la abundancia relativa de cada proteína en la muestra (\#PSM - peptide spectrum matches - Liu et al., 2012).

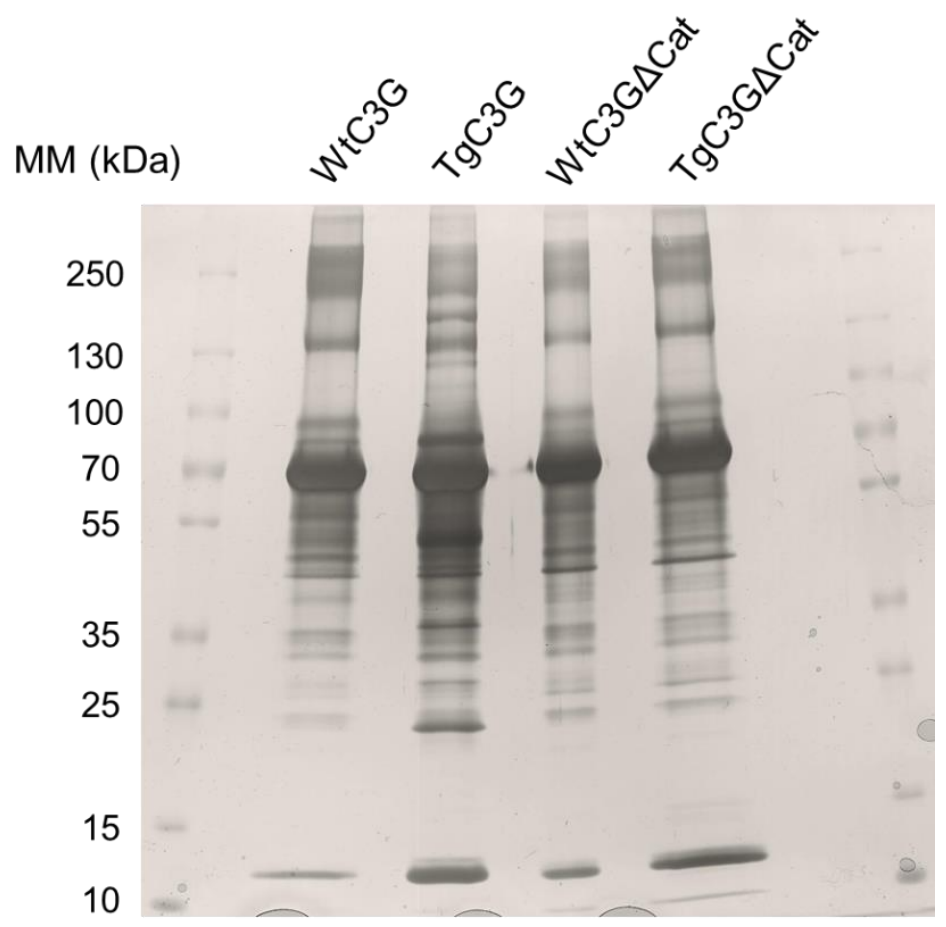

Figura R3. Perfil proteico general del secretoma de plaquetas activadas con trombina. SDS-PAGE en gradiente $(6-15 \%)$ de $20 \mu \mathrm{g}$ del secretoma plaquetario de los diferentes genotipos de ratón, producido por la activación con trombina $0,2 \mathrm{U} / \mathrm{mL}$. Las proteínas fueron visualizadas por tinción de plata. MM: masa molecular.

Las Tablas R2 y R3 detallan las 20 proteínas más abundantes encontradas en el secretoma de las plaquetas activadas con trombina o ADP, respectivamente. En ambos casos, se encontraron proteínas secretadas involucradas en diferentes procesos fisiológicos a nivel cardiovascular. Entre ellas destacan proteínas como el fibrinógeno, involucrado en la coagulación sanguínea, el plasminógeno en la fibrinolisis, la apolipoproteína A-1 implicada en el transporte de lípidos en sangre, el factor de von 
Willebrand (vWF) y la trombospondina-1 (TSP-1) en agregación plaquetaria y angiogénesis, y proteínas inhibidoras de proteasas como la a-2-macroglobulina o la a-1antitripsina 1-3. Por otra parte, la mayoría de las proteínas detectadas en el secretoma tras la activación con ambos agonistas, han sido detectadas previamente en estudios realizados sobre el secretoma de plaquetas humanas activadas con trombina (Coppinger et al., 2004) o TRAP (thrombin receptor activating peptide) (Piersma et al., 2009).

Tabla R2. Proteínas más abundantes presentes en el secretoma de plaquetas activadas con trombina.

\begin{tabular}{|c|c|c|c|c|c|c|c|}
\hline \multirow{2}{*}{ № Uniprot } & \multirow{2}{*}{ Proteína } & \multirow{2}{*}{$\begin{array}{c}\text { MM } \\
{[k D a]}\end{array}$} & \multicolumn{4}{|c|}{ \#PSM } & \multirow{2}{*}{$\begin{array}{c}\text { Detección en } \\
\text { secretoma } \\
\text { humano }\end{array}$} \\
\hline & & & WgC3G & $\operatorname{TgC3G}$ & WtC3G $\Delta$ Cat & $\mathrm{TgC} 3 \mathrm{G} \Delta \mathrm{Cat}$ & \\
\hline P07724 & Albúmina sérica & 68.6 & 603 & 635 & 650 & 790 & * $\dagger$ \\
\hline Q80YQ1 & Trombospondina-1 & 129.6 & 194 & 151 & 163 & 99 & * $\quad+$ \\
\hline Q921I1 & Serotransferrina & 76.6 & 129 & 111 & 127 & 158 & * $†$ \\
\hline Q9Z126 & Factor plaquetario 4 & 11.2 & 99 & 85 & 71 & 65 & * $†$ \\
\hline Q61838 & a-2-macroglobulina & 165.7 & 68 & 41 & 67 & 89 & * $†$ \\
\hline Q00623 & Apolipoproteina A-I & 30.5 & 47 & 34 & 42 & 71 & * $†$ \\
\hline A8DUK4 & $\beta$-globina & 15.7 & 37 & - & 54 & 66 & * $†$ \\
\hline P60710 & Actina, citoplasmática 1 & 41.7 & 48 & 37 & 59 & 29 & * $\dagger$ \\
\hline P63260 & Actina, citoplasmática 2 & 41.7 & 47 & 36 & 57 & 29 & * $\quad \dagger$ \\
\hline P26039 & Talina-1 & 269.6 & 47 & 21 & 55 & 31 & * $†$ \\
\hline A0A0R4J0I1 & MCG1051009 & 46.6 & 24 & 20 & 54 & 56 & - \\
\hline P01942 & Hemoglobina $\alpha$ & 15.0 & 42 & 26 & - & 60 & * $†$ \\
\hline E9PV24 & Fibrinógeno cadena $\alpha$ & 87.3 & 39 & 18 & 31 & - & * $\quad \dagger$ \\
\hline Q91X72 & Hemopexina & 51.2 & 28 & 17 & 25 & 23 & * $†$ \\
\hline P21614 & $\begin{array}{c}\text { Proteína de unión a } \\
\text { vitamina } D\end{array}$ & 53.5 & 21 & 14 & 26 & 26 & * $\quad \dagger$ \\
\hline P01027 & Complemento C3 & 186.3 & 25 & 6 & 28 & 22 & * \\
\hline E9QPU1 & Factor de von Willebrand & 308.9 & 25 & 12 & 29 & 19 & * $†$ \\
\hline P20918 & Plasminógeno & 90.7 & 22 & 2 & 30 & 22 & * $†$ \\
\hline P28665 & Murinoglobulina-1 & 165.1 & 14 & 7 & 26 & 12 & - \\
\hline Q00896 & a-1-antitripsina 1-3 & 45.7 & 13 & 14 & 14 & 22 & * $\dagger$ \\
\hline
\end{tabular}

El \#PSM (peptide spectrum matches) fue utilizado como medida cuantitativa de la abundancia relativa de cada proteína en el secretoma (Liu et al., 2012). (*) Ortólogos detectados en secretoma de plaquetas humanas activadas con trombina (Coppinger et al., 2004) o $(\dagger)$ activadas con TRAP (thrombin receptor activating peptide) (Piersma et al., 2009). (-) Indica que el ortólogo humano no ha sido detectado en secretomas plaquetarios hasta la fecha. El análisis fue realizado con $15 \mu \mathrm{L}$ a partir de $200 \mu \mathrm{L}$ de secretoma aislados de plaquetas de 3 ratones de cada genotipo. MM: masa molecular. 
Tabla R3. Proteínas más abundantes presentes en el secretoma de plaquetas activadas con ADP.

\begin{tabular}{|c|c|c|c|c|c|c|c|}
\hline \multirow{2}{*}{ № Uniprot } & \multirow{2}{*}{ Proteína } & \multirow{2}{*}{$\begin{array}{c}\text { MM } \\
{[\mathrm{kDa}]}\end{array}$} & \multicolumn{4}{|c|}{ \#PSM } & \multirow{2}{*}{$\begin{array}{l}\text { Detección en } \\
\text { secretoma } \\
\text { humano }\end{array}$} \\
\hline & & & WgC3G & TgC3G & WtC3G $\Delta$ Cat & TgC3G $\Delta$ Cat & \\
\hline P07724 & Albúmina sérica & 68,6 & 501 & 684 & 616 & 685 & * $\dagger$ \\
\hline Q92111 & Serotransferrina & 76,7 & 110 & 117 & 115 & 120 & * $\dagger$ \\
\hline Q61838 & a-2-macroglobulina & 165,7 & 81 & 51 & 73 & 58 & * $\dagger$ \\
\hline Q80YQ1 & Trombospondina-1 & 129,6 & 72 & 62 & 84 & 44 & * $\dagger$ \\
\hline Q00623 & Apolipoproteina A-I & 30,6 & 29 & 30 & 47 & 66 & * $\dagger$ \\
\hline P60710 & Actina, citoplasmática 1 & 41,7 & 48 & 24 & 45 & 29 & * $\dagger$ \\
\hline A0A0R4J0I1 & MCG1051009 & 46,6 & 43 & 20 & 43 & 39 & - \\
\hline P63260 & Actina, citoplasmática 2 & 41,8 & 46 & 22 & 43 & 26 & * $†$ \\
\hline P26039 & Talina-1 & 269,7 & 50 & 19 & 37 & 16 & * $\dagger$ \\
\hline P01027 & Complemento C3 & 186,4 & 42 & 25 & 23 & 19 & * \\
\hline Q91X72 & Hemopexina & 51,3 & 41 & 24 & 23 & 15 & * $\dagger$ \\
\hline P21614 & $\begin{array}{c}\text { Proteína de unión a } \\
\text { vitamina } D\end{array}$ & 53,6 & 33 & 26 & 22 & 19 & * $†$ \\
\hline Q8VDD5 & Miosina-9 & 226,2 & 38 & 17 & 25 & 7 & $\dagger$ \\
\hline B7FAU9 & Filamina, a & 280,3 & 21 & 18 & 18 & 13 & * $†$ \\
\hline Q8K0E8 & Fibrinógeno cadena $\beta$ & 54,7 & 40 & 7 & 14 & 7 & * $†$ \\
\hline P20918 & Plasminógeno & 90,7 & 30 & 10 & 16 & 11 & * $\dagger$ \\
\hline Q00896 & a-1-antitripsina 1-3 & 45,8 & 14 & 14 & 19 & 16 & * $\quad \dagger$ \\
\hline P28665 & Murinoglobulina-1 & 165,2 & 24 & 7 & 17 & 13 & - \\
\hline P17742 & $\begin{array}{l}\text { Peptidil-prolil cis-trans } \\
\text { isomerasa A }\end{array}$ & 18,0 & 19 & 16 & 17 & 8 & - \\
\hline Q9Z126 & Factor plaquetario 4 & 11,2 & 12 & 10 & 21 & 17 & * $\dagger$ \\
\hline
\end{tabular}

EI \#PSM (peptide spectrum matches) fue utilizado como medida cuantitativa de la abundancia relativa de cada proteína en el secretoma (Liu et al., 2012). ( ${ }^{*}$ ) Ortólogos detectados en secretoma de plaquetas humanas activadas con trombina (Coppinger et al., 2004) o (†) activadas con TRAP (thrombin receptor activating peptide) (Piersma et al., 2009). (-) Indica que el ortólogo humano no ha sido detectado en secretomas plaquetarios hasta la fecha. El análisis fue realizado con $15 \mu \mathrm{L}$ a partir de $200 \mu \mathrm{L}$ de secretoma aislados de plaquetas de 3 ratones de cada genotipo. MM: masa molecular.

En cuanto a las diferencias halladas en la abundancia de las proteínas secretadas, resultó interesante encontrar una disminución en la liberación de los factores antiangiogénicos TSP-1, vWF y el factor plaquetario 4 (PF4) en los secretomas de las plaquetas de ratones TgC3G y TgC3G $\Delta$ Cat, respecto a sus controles, tras la activación con trombina (Tabla R2). Resultados similares fueron encontrados en los secretomas de plaquetas activadas con ADP, aunque en este caso sólo TSP-1 y PF4 se encontraron entre las 20 proteínas más abundantes (Tabla R3). En las tablas suplementarias que se encuentran como anexo de este trabajo se pueden observar las 100 proteínas más abundantes contenidas en los secretomas de las plaquetas de ratones de cada genotipo, 
al ser activadas con trombina (Tablas A1 y A2) o ADP (Tablas A3 y A4). En la Tabla A4 se observa que la liberación del vWF también se encuentra disminuida en las plaquetas TgC3G y TgC3G $\triangle$ Cat tras la activación con ADP. Otros factores anti-angiogénicos como la a-1-antitripsina 1-5 y el inhibidor de metaloproteinasa 3, se encontraron también disminuidos en el secretoma de plaquetas TgC3G y TgC3G $\Delta$ Cat activadas con trombina, en comparación con sus respectivos controles silvestres. Además, también se observaron menores niveles de la a-2-macroglobulina en secretomas del genotipo TgC3G. En cuanto a los secretomas de plaquetas activadas con ADP, se encontró una menor secreción de a-2-macroglobulina, $\alpha$-1-antitripsina 1-2, $\alpha$-1-antitripsina 1-4 y $\alpha$-1-antitripsina 1-5 en ambos genotipos transgénicos.

En conjunto, los resultados indican que ambos transgenes de C3G parecen estar involucrados en la regulación de la secreción diferencial de proteínas de plaquetas de ratón activadas con trombina o $\mathrm{ADP}$, incluyendo la disminución de la liberación de diferentes factores anti-angiogénicos.

\section{Los factores pro- $y$ anti-angiogénicos se encuentran almacenados de manera diferencial en plaquetas de ratón}

En los últimos años, se ha reportado la existencia de mecanismos de secreción diferencial de los factores angiogénicos de plaquetas humanas al ser activadas con agonistas específicos (Italiano et al., 2008; Battinelli et al., 2011; Chatterjee et al., 2011). Parte de estos mecanismos de secreción diferencial parecen estar fundamentados en la segregación de factores pro- y anti-angiogénicos en diferentes subpoblaciones de gránulos- $\alpha$ (Italiano et al., 2008). Sin embargo, resultados de otros autores sugieren que, tanto el almacenamiento de las proteínas en los gránulos- $\alpha$, como su secreción son procesos estocásticos, encontrándose que las proteínas pro- y anti-angiogénicas muestran poca segregación funcional en diferentes subpoblaciones de gránulos (Kamykowski et al., 2011; Jonnalagadda et al., 2012).

Estos antecedentes, nos llevaron a evaluar si las plaquetas de ratón presentan una segregación diferencial de factores angiogénicos en distintos gránulos- $\alpha$. Para ello, analizamos mediante microscopía confocal de inmunofluorescencia la localización subcelular de dos factores pro-angiogénicos: VEGF y bFGF, y de dos factores antiangiogénicos: endostatina y TSP-1, en plaquetas en reposo de cada uno de los genotipos de nuestros modelos de ratón. La Figura R4 muestra la ausencia de co-localización entre las señales de VEGF (verde) y endostatina (rojo) en todos los genotipos, lo cual indica 
que estos dos factores estarían siendo almacenados de manera diferencial, de forma similar a lo reportado por Italiano et al. (2008) en plaquetas humanas. Por otra parte, se encontró una segregación diferencial similar al evaluar la distribución de bFGF y TSP-1 (Figura R5), reforzando los datos anteriores y proporcionando una base sobre la cual hipotetizar la posible secreción diferencial de ambos tipos de factores angiogénicos en plaquetas de ratón.

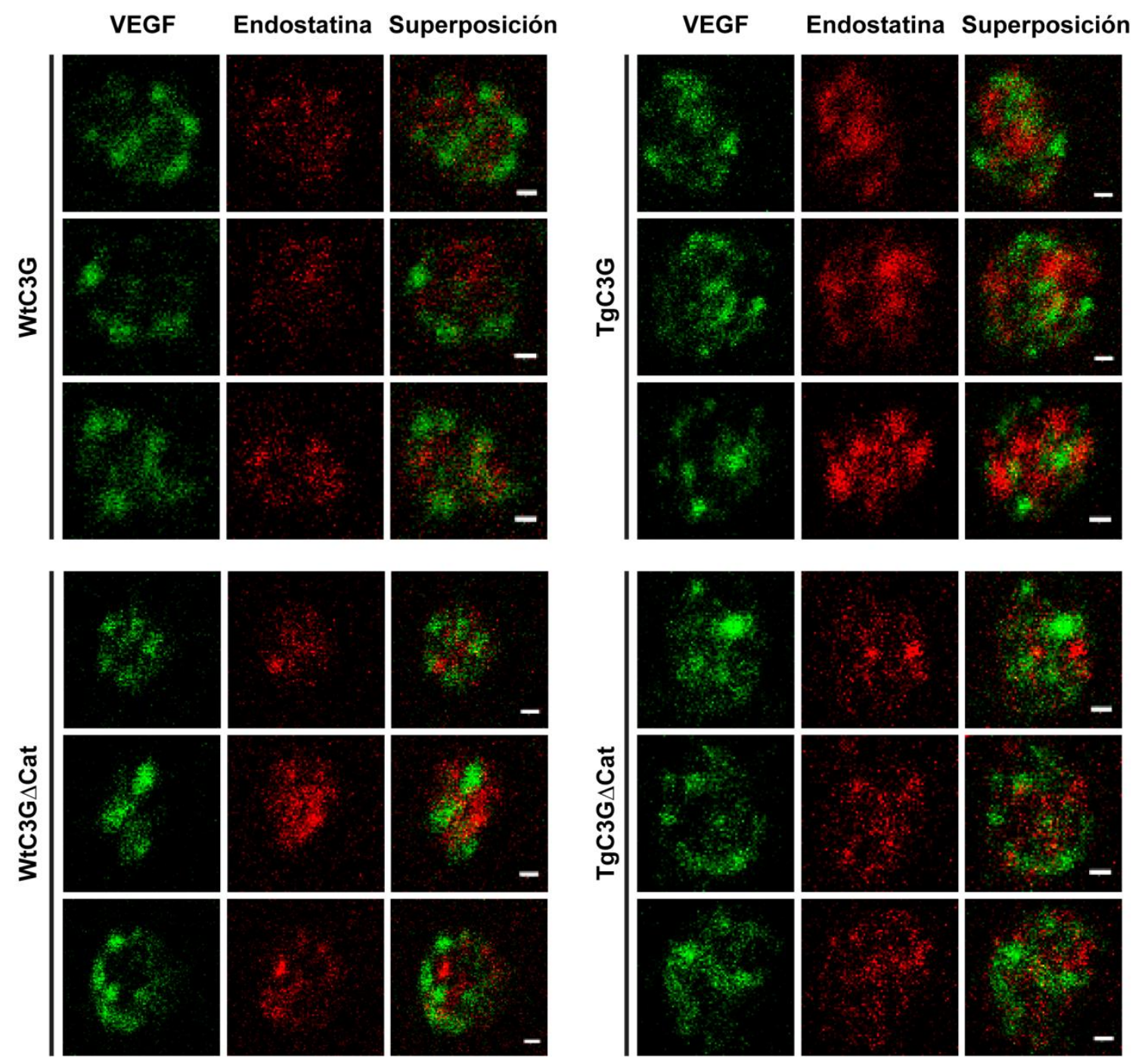

Figura R4. Los factores angiogénicos VEGF y endostatina se distribuyen de manera diferencial en los gránulos- $\alpha$ de plaquetas de ratón en reposo. Análisis por microscopía confocal de inmunofluorescencia de la distribución subcelular de VEGF (verde), endostatina (rojo) y su superposición en plaquetas de ratón en reposo. Se muestran 3 plaquetas representativas de cada genotipo. Barra: 0,4 $\mu \mathrm{m}$. 


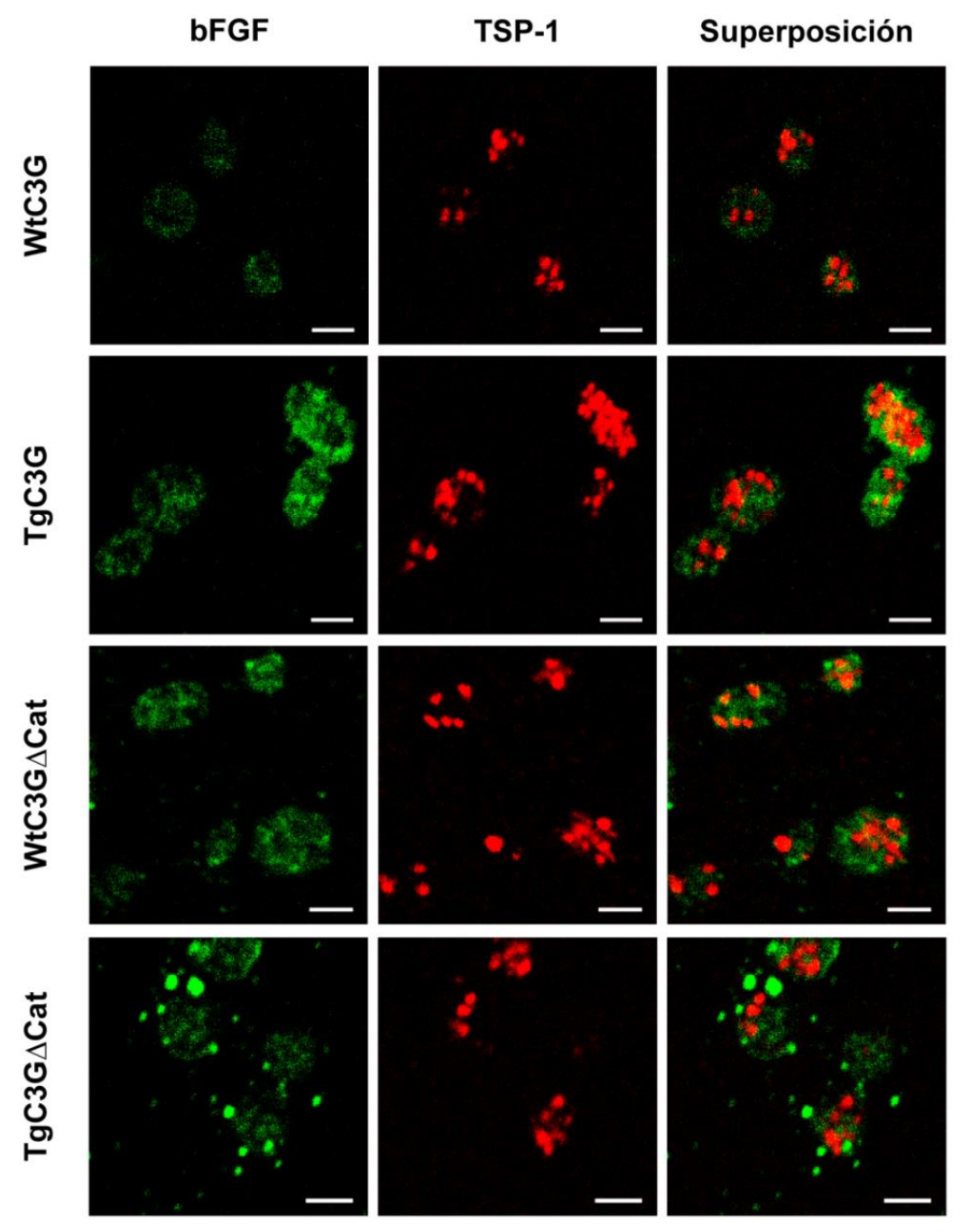

Figura R5. Los factores angiogénicos bFGF y TSP-1 se distribuyen de manera diferencial en gránulosa de plaquetas de ratón en reposo. Análisis por microscopía confocal de inmunofluorescencia de la distribución subcelular de bFGF (verde), trombospondina-1 (TSP-1) (rojo) y su superposición en plaquetas en reposo de cada genotipo de ratón. Barra: $2 \mu \mathrm{m}$.

C3G regula la liberación de VEGF, bFGF, endostatina y TSP-1 de plaquetas de ratón activadas con ADP o trombina

En estudios previos realizados en plaquetas humanas, se ha encontrado que factores pro-angiogénicos como el VEGF son liberados de manera diferencial al activar el receptor de trombina PAR1 o al estimular con ADP. Por otra parte, factores antiangiogénicos como la endostatina son liberados tras la activación del receptor de trombina PAR4 o al estimular con agonistas como el tromboxano $\mathrm{A}_{2}$ (Italiano et al., 2008; Battinelli et al., 2011; Chatterjee et al., 2011). A partir de los resultados del análisis proteómico inicial, y sobre la base de que factores pro- y anti-angiogénicos específicos 
parecen almacenarse de manera discreta en las plaquetas de nuestros ratones, decidimos evaluar si C3G tiene un papel en la secreción diferencial de estos factores en plaquetas activadas. Para ello, analizamos la liberación de VEGF o bFGF (proangiogénicos) y endostatina o TSP-1 (anti-angiogénicos) mediante microscopía confocal de inmunofluorescencia en plaquetas de nuestros modelos de ratones transgénicos activadas con ADP o trombina (Figuras R6-R9).

La Figura R6A muestra la secreción de VEGF y endostatina en plaquetas activadas con ADP. En ella se observa que el ADP promueve la liberación diferencial de VEGF en las plaquetas de ratón de ambos genotipos silvestres, mientras que la endostatina se mantiene en el interior de las plaquetas, en concordancia con referencias previas en plaquetas humanas (Battinelli et al., 2011). En las plaquetas transgénicas tampoco se detectó una liberación evidente de endostatina. No obstante, en contraste con los controles silvestres, el VEGF fue retenido de manera significativa en las plaquetas TgC3G, lo cual sugiere un papel inhibidor de C3G en la liberación de este factor. Por otra parte, las plaquetas $\mathrm{TgC} 3 \mathrm{G} \Delta$ Cat también mostraron un grado de retención de VEGF significativamente mayor, en comparación con los controles silvestres, según se evidenció al cuantificar la señal de fluorescencia correspondiente a este factor en plaquetas de todos los genotipos tras la activación (Figura R6B). Este resultado sugiere un papel de C3G, independiente de su actividad GEF, en la regulación de la liberación del VEGF en plaquetas activadas con ADP.

La Figura R7A muestra la secreción de VEGF y endostatina en plaquetas activadas con trombina. En ella se observa que este agonista promueve la liberación diferencial de endostatina en las plaquetas de ratón de ambos genotipos silvestres, mientras que el VEGF se mantiene principalmente retenido, en concordancia con estudios previos en plaquetas humanas (Italiano et al., 2008; Battinelli et al., 2011). En las plaquetas transgénicas tampoco se observó que el VEGF fuera liberado de manera evidente tras la activación. Curiosamente, las plaquetas TgC3G presentaron niveles de secreción de endostatina significativamente mayores que su control silvestre. En cambio, las plaquetas $\operatorname{TgC} 3 G \Delta$ Cat presentaron niveles de secreción de endostatina significativamente menores que los de su control, según se evidenció al cuantificar la señal de fluorescencia correspondiente a este factor en plaquetas de todos los genotipos tras la activación (Figura R7B). Este resultado sugiere un papel de la actividad GEF de C3G en la regulación de la liberación de endostatina en plaquetas activadas con trombina. 


\section{A}
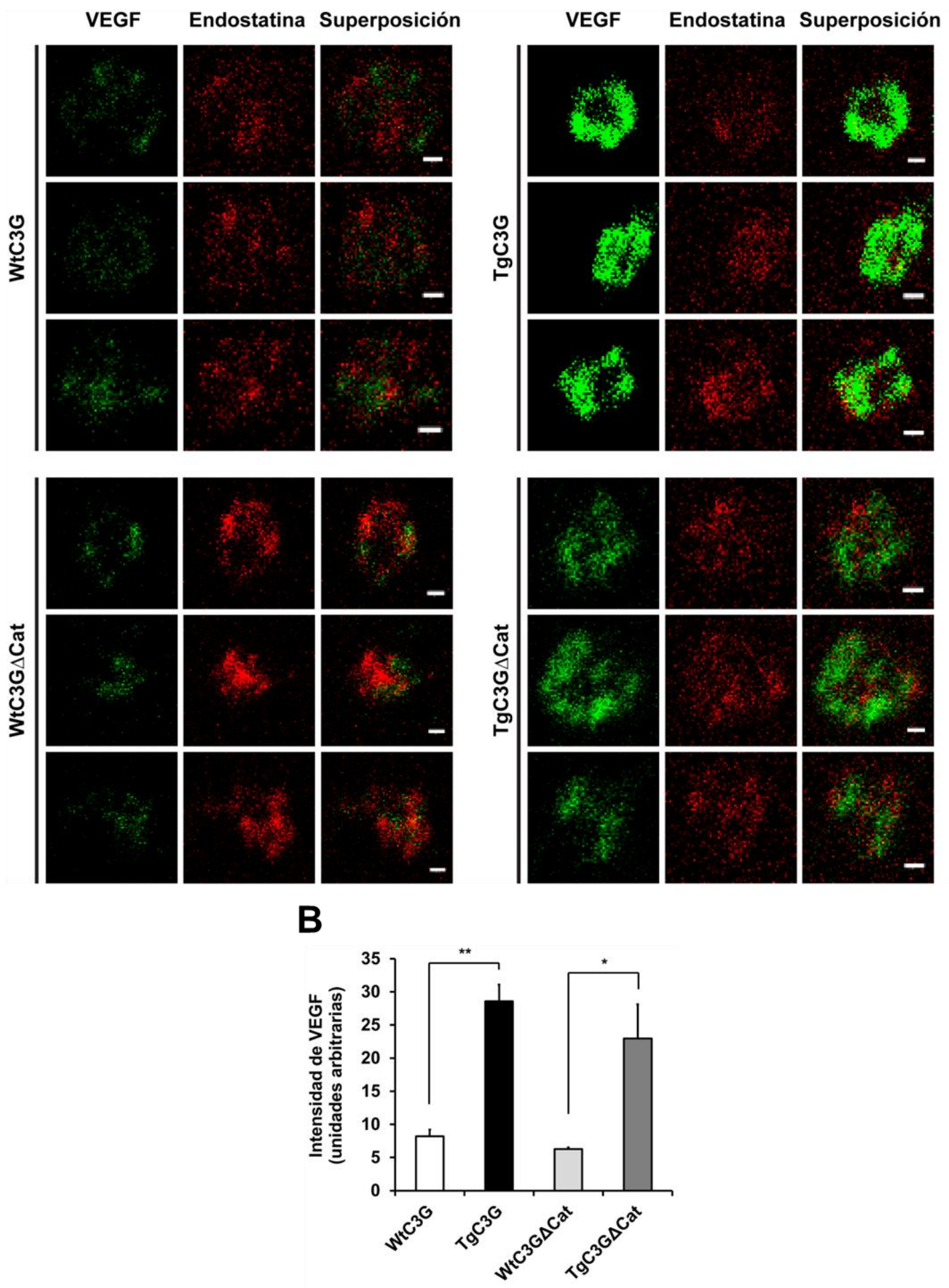

Figura R6. C3G y C3G $\Delta$ Cat inhiben la liberación de VEGF en plaquetas activadas con ADP. (A) Análisis por microscopía confocal de inmunofluorescencia de la distribución subcelular de VEGF (verde), endostatina (rojo) y su superposición en plaquetas de ratón activadas con ADP $25 \mu \mathrm{M}$ durante 5 min. Se muestran 3 plaquetas representativas de cada genotipo. Barra: 0,4 $\mu \mathrm{m}$. (B) Intensidad de la señal de fluorescencia para VEGF en plaquetas de cada genotipo $(n=3)$. ${ }^{*} p<0,05 ;{ }^{* *} p<0,01$. 


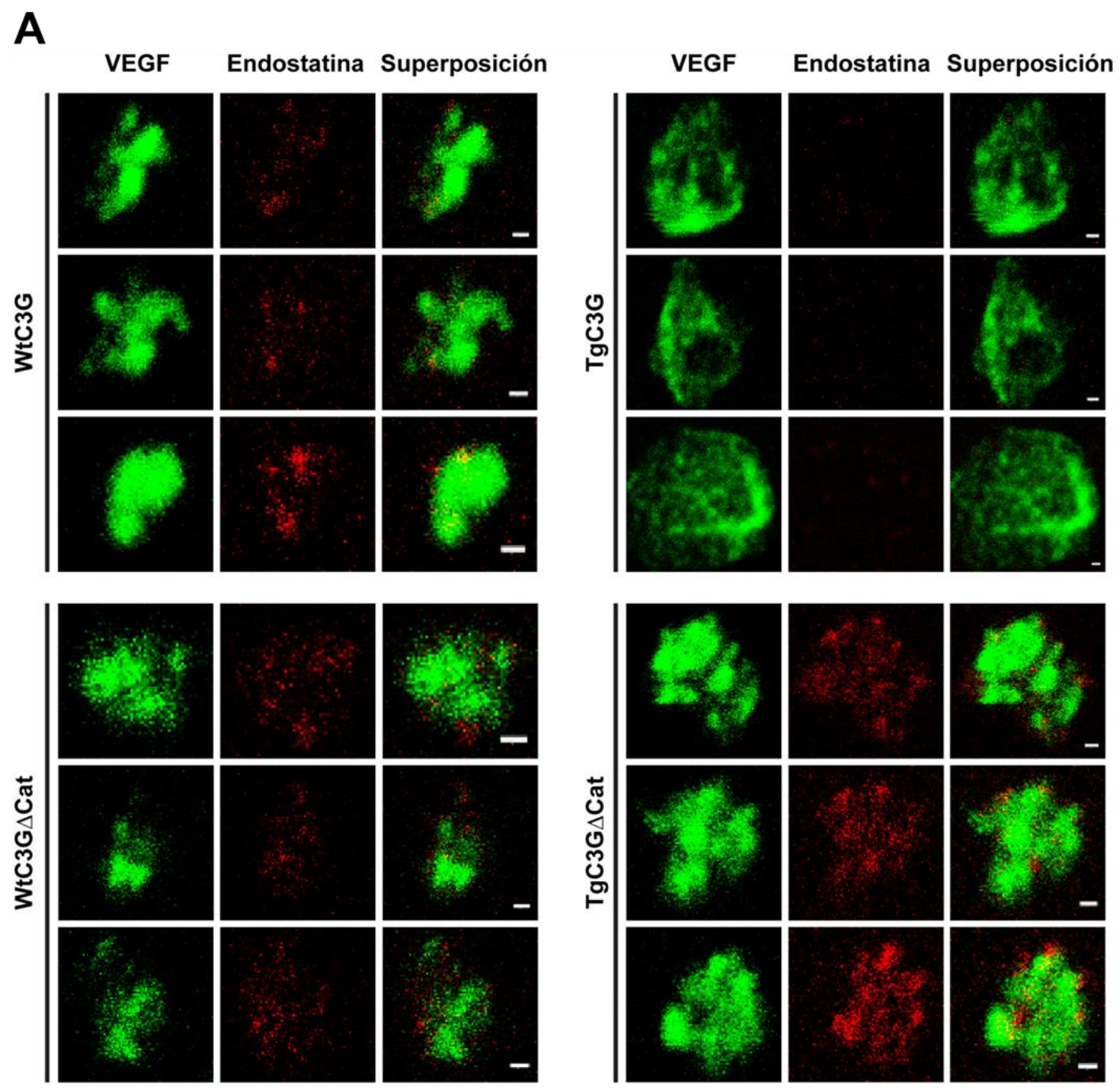

B

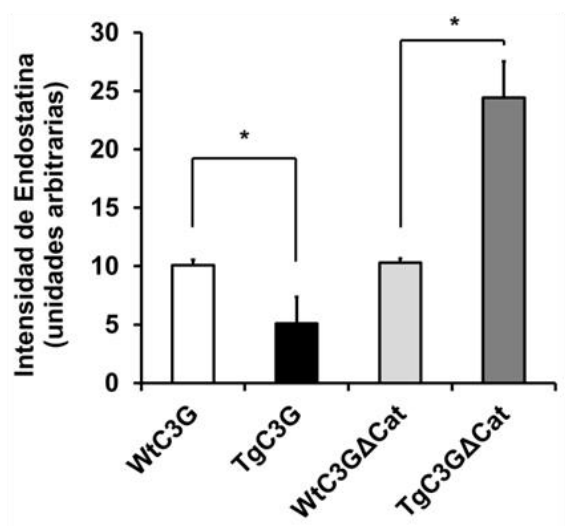

Figura R7. C3G promueve la liberación de endostatina en plaquetas activadas con trombina. (A) Análisis por microscopía confocal de inmunofluorescencia de la distribución subcelular de VEGF (verde), endostatina (rojo) y su superposición en plaquetas de ratón activadas con trombina $0,2 \mathrm{U} / \mathrm{mL}$ durante $5 \mathrm{~min}$. Se muestran 3 plaquetas representativas de cada genotipo. Barra: 0,4 $\mu \mathrm{m}$. (B) Intensidad de la señal de fluorescencia para endostatina en plaquetas de cada genotipo $(n=3)$. * $p<0,05$. 
La Figura R8A muestra la secreción de bFGF y TSP-1 en plaquetas de ratón de los diferentes genotipos activadas con trombina, encontrándose que este agonista produjo la liberación diferencial de TSP-1 en las plaquetas de todos los genotipos, mientras que el bFGF fue principalmente retenido. Es interesante resaltar que la cuantificación de las señales correspondientes a cada factor (Figuras R8B y R8C) demostró que la liberación de TSP-1 fue significativamente menor por parte de las plaquetas TgC3G en comparación con su control silvestre, mientras que esta misma tendencia se observó en las plaquetas $\operatorname{TgC3G} \Delta$ Cat, con respecto a las plaquetas WtC3G $\Delta$ Cat, sin llegar a ser significativa. Por otra parte, la inhibición de la liberación del bFGF fue de mayor magnitud en las plaquetas de ratones de ambos genotipos transgénicos, en comparación con sus respectivos controles silvestres. Los resultados relativos a la liberación de la TSP-1 concuerdan con los encontrados en el análisis proteómico (Tabla R2), mientras que la inhibición de liberación de bFGF en las plaquetas activadas de ambos genotipos transgénicos mostró las mismas diferencias observadas para el factor pro-angiogénico VEGF al activar las plaquetas con ADP (Figura R6).

Para corroborar la inhibición de la liberación de los factores pro-angiogénicos por parte de C3G, se realizó un análisis por inmunofluorescencia detectando de manera conjunta VEGF y bFGF en plaquetas activadas con trombina o ADP. En la Figura R9A se observa que, en efecto, VEGF y bFGF parecen ser retenidos en plaquetas TgC3G y $\operatorname{TgC3G} \Delta$ Cat, con respecto a sus controles silvestres, tanto al activar con trombina como con ADP. La cuantificación de las señales de fluorescencia correspondientes a cada factor (Figuras R9B y R9C) demostró que la retención de VEGF en las plaquetas activadas de ambos genotipos transgénicos fue significativa, en comparación con sus respectivos controles. En el caso del bFGF, se encontró que su retención en plaquetas TgC3G activadas fue significativa con respecto a las plaquetas WtC3G, mientras que en plaquetas $\mathrm{TgC} 3 \mathrm{G} \Delta$ Cat se observó la misma tendencia sin llegar a ser estadísticamente significativa. Estos resultados apoyan los datos anteriores en relación a la función de C3G, independiente de su actividad GEF, en la retención de ambos factores proangiogénicos, VEGF (Figura R6) y bFGF (Figura R8), en plaquetas de ratón activadas con trombina o ADP. 


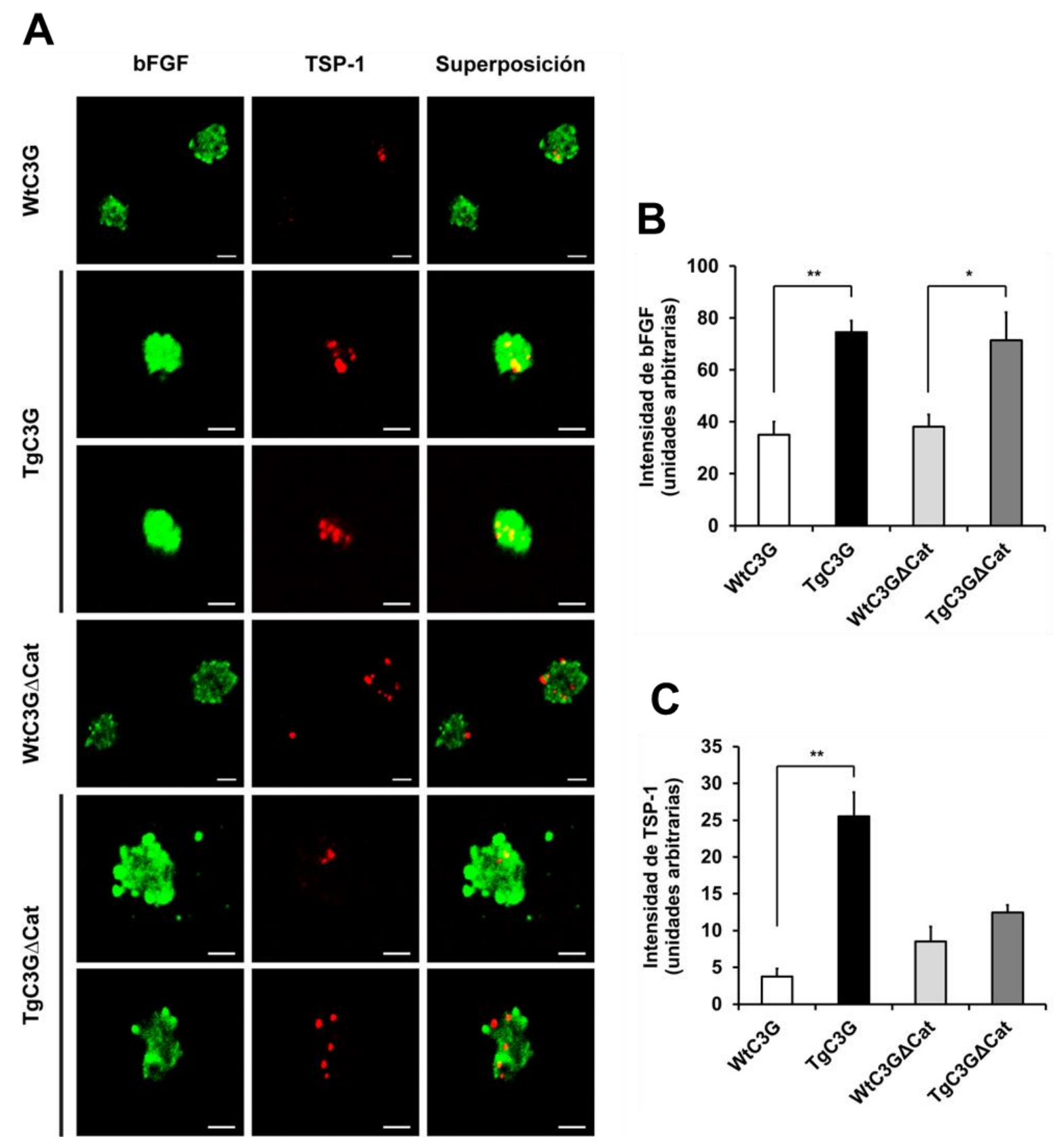

Figura R8. C3G y C3G $\triangle$ Cat inhiben la liberación de bFGF y TSP-1 en plaquetas activadas con trombina. (A) Análisis por microscopía confocal de inmunofluorescencia de la distribución subcelular de bFGF (verde), trombospondina-1 (TSP-1) (rojo) y su superposición en plaquetas de ratón activadas con trombina $0,2 \mathrm{U} / \mathrm{mL}$ durante 5 min. Barra: $2 \mu \mathrm{m}$. Los gráficos muestran la intensidad de fluorescencia para bFGF (B) ० TSP-1 (C) en plaquetas de cada genotipo $(n=3)$. ${ }^{*} p<0,05 ;{ }^{* *} p<0,01$. 
A
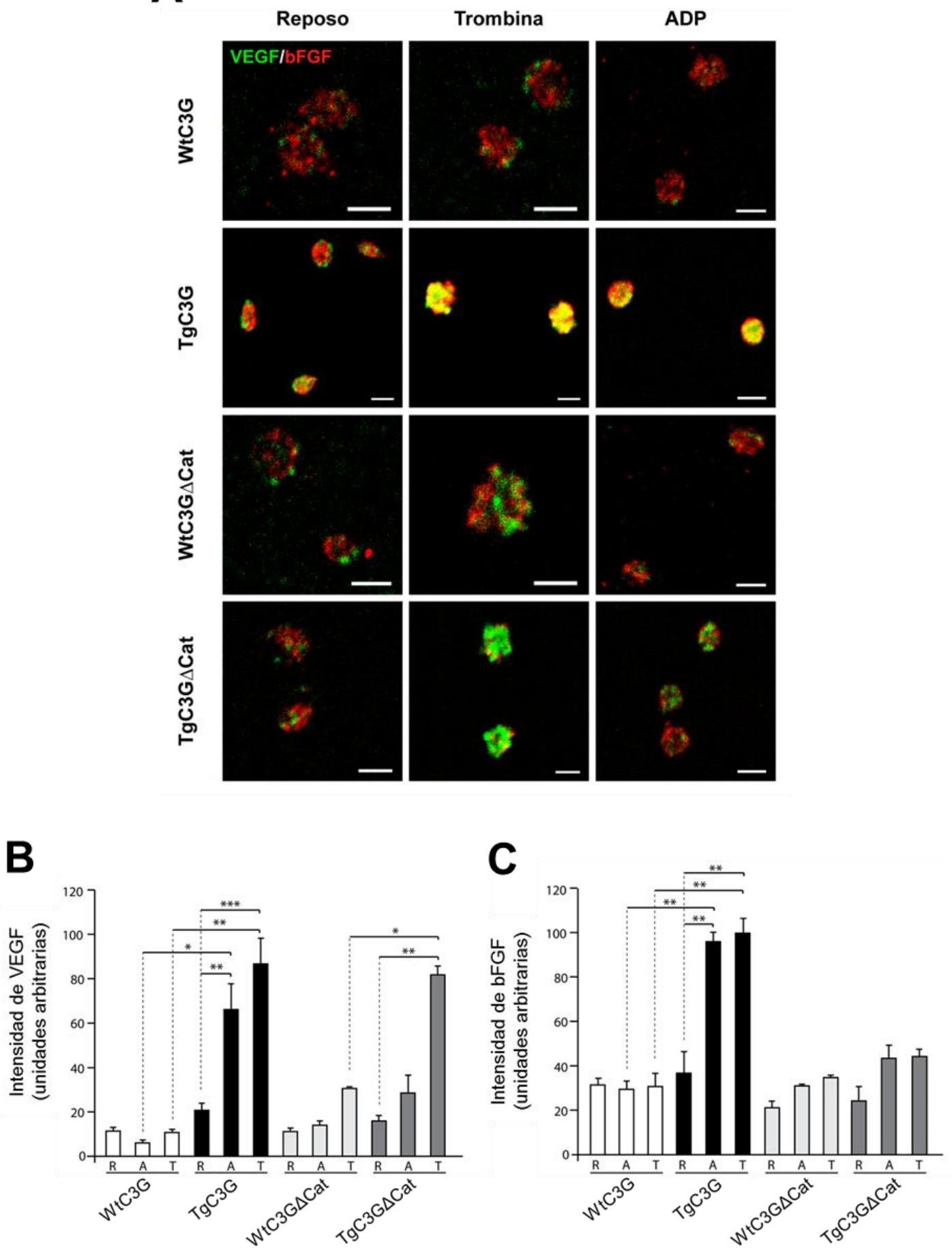

Figura R9. Los factores pro-angiogénicos VEGF y bFGF son retenidos en plaquetas TgC3G y TgC3G $\Delta$ Cat, tras la activación con trombina o ADP. (A) Análisis por microscopía confocal de inmunofluorescencia de la distribución subcelular de VEGF (verde), bFGF (rojo) y su superposición en plaquetas de cada genotipo de ratón en estado de reposo, o tras ser activadas con trombina $0,2 \mathrm{U} / \mathrm{mL}$ o ADP $25 \mu \mathrm{M}$ durante $5 \mathrm{~min}$. Barra: $2 \mu \mathrm{m}$. Los gráficos muestran la intensidad de fluorescencia para VEGF (B) 0 bFGF (C) en plaquetas de cada genotipo y condición experimental: reposo (R), activadas con ADP (A) o trombina $(T) .{ }^{*} p<0,05 ;{ }^{* *} p<0,01 ;{ }^{* * *} p<0,001$. 
La retención de VEGF y TSP-1 en plaquetas de ratón activadas por trombina o ADP fue también evaluada por Western blot (Figura R10). El análisis se realizó mediante la detección de los niveles remanentes de estos factores en el interior de las plaquetas tras su activación. En este caso, se encontró que el VEGF parecía ser secretado en mayor proporción por las plaquetas de ambos genotipos transgénicos al ser activadas con trombina, ya que el contenido citosólico de VEGF fue menor en comparación con los controles (Figura R10A). Este resultado estaría en contradicción, en principio, con los resultados del análisis por inmunofluorescencia (Figura R6 y Figura R9). Sin embargo, se detectó que la mayor parte del VEGF se encontraba en la fracción de membrana (Figura R10B), por lo que no estaría siendo liberado en el secretoma tras la activación, y se corroboraría su retención en las plaquetas transgénicas activadas. En cuanto a la liberación de TSP-1 en plaquetas activadas con trombina, también se observó un menor contenido de este factor en los lisados de las plaquetas transgénicas, indicando que estaría siendo secretado en mayor proporción por parte de ambas plaquetas transgénicas tras la activación (Figura R10A). No obstante, en este caso se encontró igualmente una retención de TSP-1 en la fracción de membrana (Figura R10B), que reduciría la cantidad de este factor efectivamente liberada. Por esta razón, estos datos estarían en concordancia con los resultados del análisis cuantitativo del secretoma plaquetario en el cual se encontró menor liberación de este factor por parte de plaquetas transgénicas tras la activación (Tablas R2 y R3). De igual forma, la retención de VEGF en membranas estaría también de acuerdo con la retención de VEGF observada por inmunofluorescencia (Figuras R7 y R9). La retención de VEGF y TSP-1 en la fracción de membrana de plaquetas $\mathrm{TgC} 3 \mathrm{G}$ y $\mathrm{TgC} 3 \mathrm{G} \triangle \mathrm{Cat}$, podría sugerir una posible función regulatoria de $\mathrm{C} 3 \mathrm{G}$, independiente de su actividad GEF, en la liberación de los gránulos- $\alpha$ que contienen a estos factores angiogénicos, lo cual podría ocurrir, por ejemplo, a través de interacciones específicas con proteínas de tráfico vesicular.

En el caso de la activación con ADP, no se encontraron diferencias evidentes en la liberación de VEGF o TSP-1 entre los diferentes genotipos (Figura R10A), probablemente debido a la menor potencia de este agonista y a la menor sensibilidad de este método con respecto al análisis proteómico de muestra completa. 


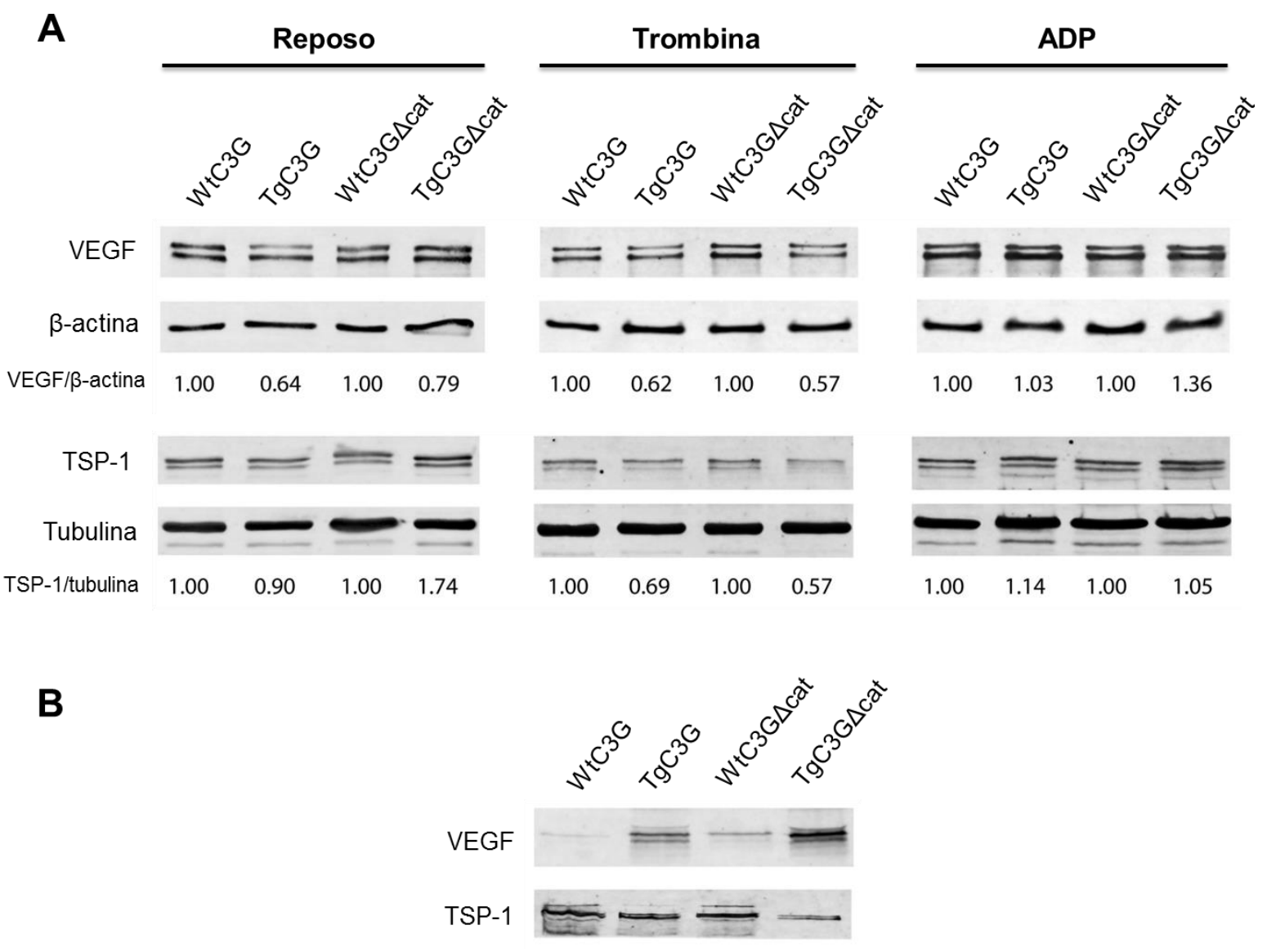

Figura R10. VEGF y TSP-1 se encuentran retenidos en la fracción de membrana de plaquetas TgC3G y TgC3G $\triangle$ Cat activadas con trombina o ADP. (A) Análisis por Western blot del contenido citosólico de plaquetas en reposo y del contenido citosólico remanente en plaquetas activadas con trombina o ADP. Se determinaron los niveles de $\beta$-actina y tubulina para su utilización como controles de carga. Se muestran las relaciones VEGF/ $\beta$-actina y TSP-1/tubulina normalizadas al control silvestre correspondiente a cada genotipo y condición. (B) Análisis por Western blot de los niveles de VEGF y trombospondina-1 (TSP-1) retenidos en fracciones de membrana, aisladas en conjunto con la fracción citosólica analizada en $\mathrm{A}$, a partir de los restos de plaquetas activadas con trombina.

En conjunto, todos los resultados mostrados sugieren la existencia de diferentes mecanismos, tanto GEF-dependientes como GEF-independientes, a través de los cuales C3G podría estar controlando la liberación diferencial de los factores pro-/antiangiogénicos de las plaquetas de ratón tras la activación con diferentes agonistas como trombina o ADP. 


\section{El secretoma de plaquetas TgC3G y TgC3GACat activadas con trombina o ADP promueve la angiogénesis in vitro}

Para profundizar en la relevancia fisiológica que pueden tener los hallazgos anteriores, analizamos el efecto de los secretomas de los ratones de los diferentes genotipos en un modelo de angiogénesis in vitro. Esto se realizó, evaluando la formación de redes de pseudocapilares en células HUVEC (ㅂuman Ümbilical Vein Endothelial Cells) expuestas al secretoma plaquetario aislado de cada genotipo tras la activación con trombina o ADP. Se cuantificaron 3 parámetros: número de uniones, largo promedio del segmento maestro y tamaño promedio de la malla, como indicadores de angiogénesis según se ha descrito previamente (DeCicco-Skinner et al., 2014).

Los secretomas de plaquetas transgénicas activadas con trombina promovieron la formación de redes de pseudocapilares con un mayor número de uniones, largo promedio del segmento maestro y tamaño medio de la malla, en comparación con las plaquetas de ratones silvestres (siendo estadísticamente significativos al menos dos de los parámetros) (Figura R11A). De igual manera, los secretomas de plaquetas TgC3G y TgC3G $\Delta$ Cat activadas con ADP promovieron la formación de redes de pseudocapilares más desarrolladas que los secretomas de plaquetas silvestres (Figura R11B). En este caso, sólo el número de uniones en la condición con secretoma TgC3G $\Delta$ Cat, y el tamaño medio de la malla en TgC3G presentaron significancia estadística, probablemente debido a que el ADP es un agonista plaquetario más débil que la trombina $y$, por tanto, promueve la secreción de una menor cantidad de proteína (Tabla R1) (Coppinger et al., 2007).

En general, estos resultados apoyan la existencia de una función pro-angiogénica para el C3G plaquetario en respuesta a la activación por trombina o ADP, y está en concordancia con la disminución en la secreción de TSP-1, uno de los principales factores anti-angiogénicos, por parte de ambos genotipos de plaquetas transgénicas, según lo observado en el análisis proteómico (Tablas R2 y R3) y en el análisis por microscopía confocal de inmunofluorescencia de plaquetas activadas con trombina (Figura R8). 
A

WtC3G

TgC3G

WtC3G $\Delta$ Cat

$\operatorname{TgC} 3 \mathrm{G} \Delta \mathrm{Cat}$
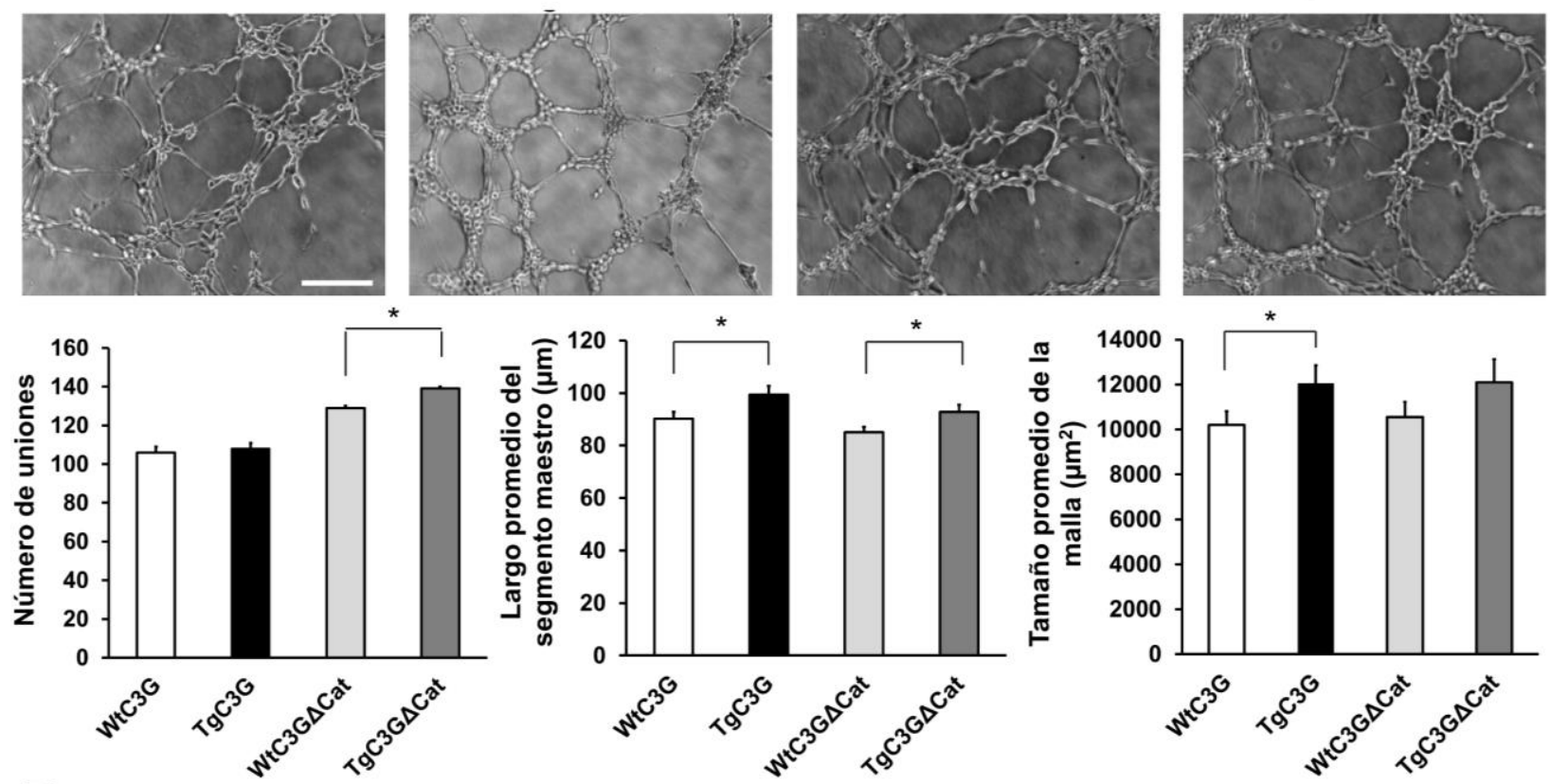

B

WtC3G

TgC3G

WtC3G $\Delta$ Cat

$\operatorname{TgC} 3 \mathrm{G} \Delta \mathrm{Cat}$
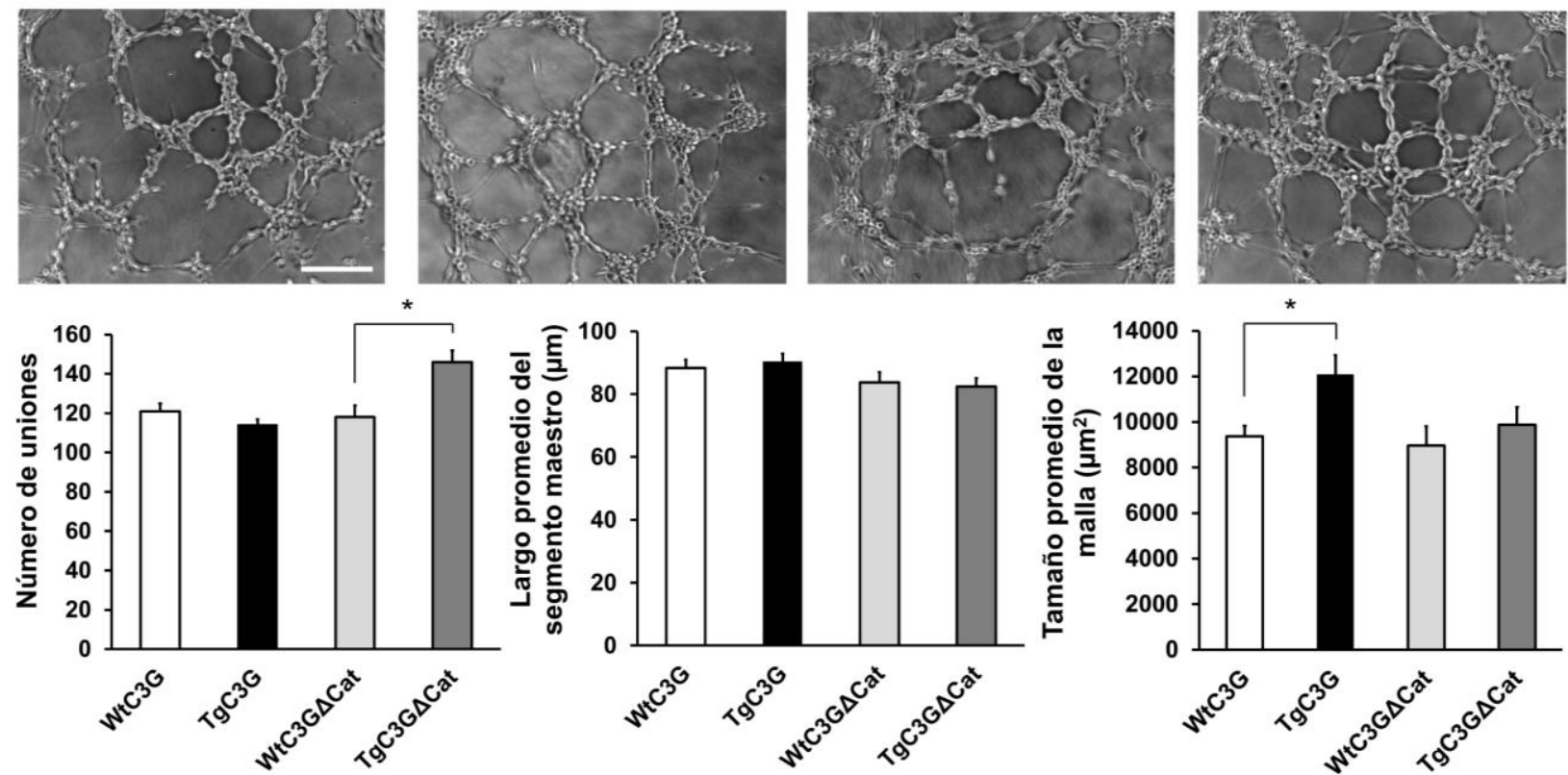

Figura R11. El secretoma de plaquetas TgC3G y TgC3G $\Delta$ Cat activadas con trombina o ADP promueve in vitro la formación de redes de pseudocapilares más desarrolladas. Se muestran imágenes representativas de pseudocapilares formados por células HUVEC, 2:30 horas después de ser sembradas sobre Matrigel y suplementadas con los secretomas de plaquetas de ratón estimuladas con trombina $(A) 0$ ADP (B). Barra: $100 \mu \mathrm{m}$. Los gráficos muestran los valores medios de diferentes características de la red evaluadas entre las 2 y 5 horas (ver Materiales y Métodos). Los segmentos maestros consisten en piezas de la red delimitadas por dos uniones no limítrofes. Los datos corresponden a tres experimentos independientes con cada condición por cuadruplicado. ${ }^{*} \mathrm{p}<0,05$. 


\section{Función del C3G plaquetario en la regulación de la angiogénesis in vivo y la metástasis tumoral}

Con la finalidad de conocer si la función pro-angiogénica del C3G plaquetario observada en los modelos experimentales in vitro, también se manifiesta en un contexto fisiológico in vivo, estudiamos tres modelos experimentales utilizando nuestros ratones transgénicos para C3G y C3G $\triangle$ Cat: (i) la angiogénesis producida en tumores singénicos de carcinoma de pulmón y de melanoma de ratón, (ii) la angiogénesis inducida en orejas de ratones tras el tratamiento con oxazolona, y (iii) la infiltración de células endoteliales en botones de Matrigel implantados en los ratones de cada genotipo. Adicionalmente, evaluamos la participación del C3G plaquetario en la facilitación de la metástasis tumoral de células de melanoma de ratón.

\section{Las plaquetas TgC3G y TgC3GACat promueven la angiogénesis in vivo: vascularización y crecimiento de tumores heterotópicos de ratón}

El crecimiento y progresión tumoral es dependiente del desarrollo de una nueva red vascular mediante angiogénesis (Folkman, 2002). En este sentido, se conoce que tanto las células tumorales como las células del microambiente tumoral pueden inducir la activación y agregación plaquetaria en el espacio peritumoral y la consecuente secreción de factores de crecimiento y factores proangiogénicos que pueden promover la progresión del tumor (Battinelli et al., 2011; Bambace \& Holmes, 2011; Kuznetsov et al., 2012). Sobre esta base, decidimos evaluar si C3G regula la capacidad angiogénica del secretoma plaquetario en un contexto in vivo, mediante la utilización de dos modelos heterotópicos de crecimiento tumoral en ratón. Para ello, utilizamos células de carcinoma de pulmón de Lewis (3LL) y células de melanoma B16F10, cuyos orígenes son de ratón, inyectadas subcutáneamente en el lomo de ratones de cada genotipo.

Los tumores $3 L L$ que se desarrollaron no presentaron diferencias significativas en su tamaño en el punto final del experimento (Figura R12A), aunque los de ratones TgC3G presentaron cierta tendencia a tener una masa mayor que aquellos desarrollados en ratones WtC3G. El análisis histoquímico reveló que los tumores de ratones TgC3G presentaban una mayor extensión de muerte celular en su interior (Figura R12B), que al ser cuantificada resultó estadísticamente significativa, en comparación con sus controles silvestres (Figura R12C). La extensión de muerte celular también presentó la misma tendencia en los tumores desarrollados en ratones $\mathrm{TgC} 3 G \Delta \mathrm{Cat}$, con respecto a sus controles silvestres. Sin embargo, esta diferencia no llegó a tener significancia estadística. 
La mayor extensión de muerte tumoral presente en los tumores de ratones TgC3G podría deberse a una mayor tasa de crecimiento y tumorigenicidad que podría estar correlacionada con diferencias en el potencial angiogénico del microambiente tumoral de estos ratones. Para profundizar en esta posibilidad, evaluamos directamente la vascularización de estos tumores, a través de una inmunohistoquímica contra el marcador de células endoteliales CD31. La Figuras R13A y R13B muestran que los tumores desarrollados en ratones $\mathrm{TgC} 3 \mathrm{G}$ presentaron un número de vasos significativamente mayor que los tumores de ratones WtC3G. El número de vasos presente en los tumores de ratones $\operatorname{TgC} 3 \mathrm{G} \Delta$ Cat no mostró diferencias significativas con respecto a los tumores de sus controles silvestres. Sin embargo, se encontró que los vasos de los tumores desarrollados en ratones $\mathrm{TgC} 3 \mathrm{G} \Delta$ Cat tenían un grosor significativamente mayor que los de sus controles silvestres, según se evidenció al cuantificar el área de éstos en relación al área total (Figuras R13A y R13C). El área relativa de los vasos presentes en los tumores de ratones TgC3G también fue significativamente mayor que la de los tumores desarrollados en ratones WtC3G, principalmente debido a la presencia de un mayor número de vasos por campo.

Para corroborar estos resultados, se utilizó un segundo modelo tumoral singénico, la línea de melanoma B16F10. Los tumores heterotópicos inducidos por las células B16F10 en ratones TgC3G exhibieron una masa significativamente mayor al final del experimento, con respecto a los tumores de ratones WtC3G (Figura R14A). Del mismo modo, se evaluó la vascularización en tinciones de hematoxilina/eosina y en inmunohistoquímica contra CD31 de secciones de los tumores. Al igual que en el caso de los tumores producidos por las células 3LL, los ratones TgC3G desarrollaron tumores B16F10 con un mayor número de vasos que los ratones WtC3G (Figura R14B y R14C). Por otra parte, se realizó un análisis inmunohistoquímico contra P-selectina (Figura R14C) en el que se encontró una mayor tinción de este marcador en los tumores de ratones TgC3G, con respecto a los de ratones WtC3G, indicando un mayor reclutamiento y activación de plaquetas en la vasculatura tumoral. Las células B16F10 inyectadas en ratones de la línea $8 \mathrm{~A} 3$ (WtC3G $\Delta$ Cat y TgC3G $\Delta$ Cat) no se desarrollaron en tumores visibles, probablemente debido a diferencias del fondo genético. En este sentido, las células B16F10 están originadas en ratones black, al igual que la línea de ratones 2C1 (WtC3G y TgC3G), mientras que los ratones de la línea 8A3 tienen un fondo genético agouti. 
En conjunto, los resultados sugieren que C3G proporciona a las plaquetas una capacidad pro-angiogénica in vivo que promueve el crecimiento y la vascularización tumoral, así como también un mayor reclutamiento y activación de las plaquetas en el sitio del tumor.

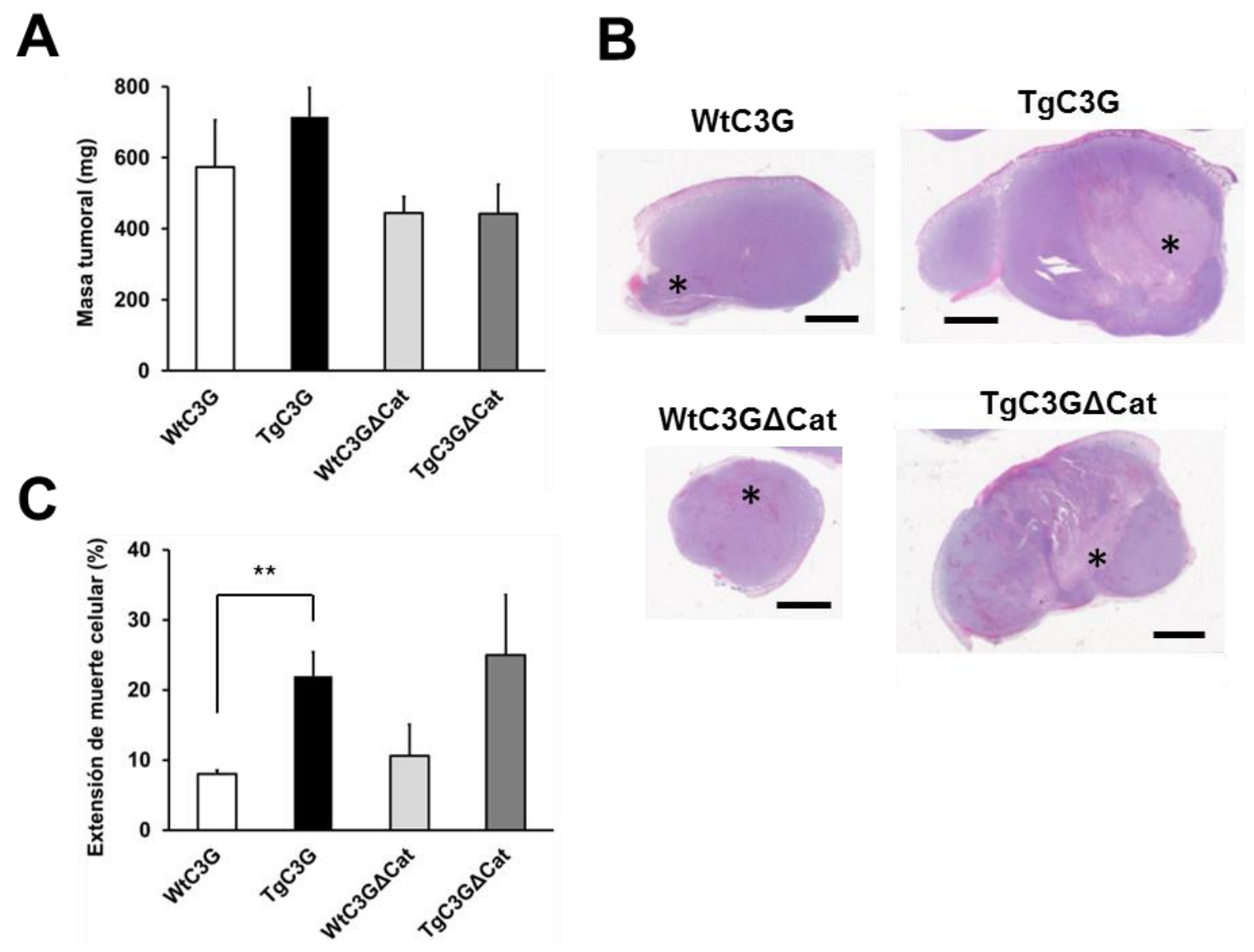

Figura R12. Las plaquetas TgC3G y TgC3G $\Delta$ Cat promueven el desarrollo de tumores heterotópicos de células $3 L L$ con una mayor extensión de muerte celular. (A) Cuantificación de la masa final de tumores $3 L L$ desarrollados en ratones de los diferentes genotipos $(n=5$ para WtC3G, $n=13$ para $\operatorname{TgC} 3 G, n=8$ para WtC3G $\Delta$ Cat y $n=12$ para $T g C 3 G \Delta C$ at). (B) Imágenes representativas de microscopía de luz de secciones de cada tumor. La tinción corresponde a hematoxilina/eosina y se indica la extensión de muerte celular $\left({ }^{*}\right)$. Barra: $2,5 \mathrm{~mm}$. (C) Cuantificación de la extensión de muerte celular representada como el porcentaje de área ocupada por células muertas con respecto al área total del tumor $(n=4$ para WtC3G y $\operatorname{TgC} 3 \mathrm{G}, \mathrm{n}=3$ para WtC3G $\Delta$ Cat y $\operatorname{TgC} 3 G \Delta$ Cat). ${ }^{*} p<0,01$. 
A

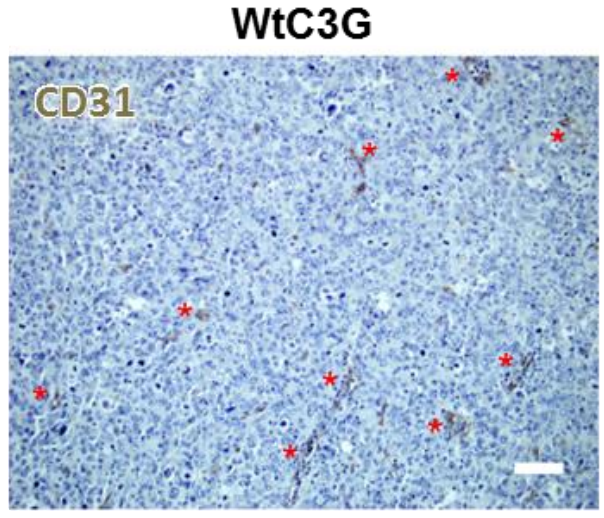

WtC3G $\Delta$ Cat

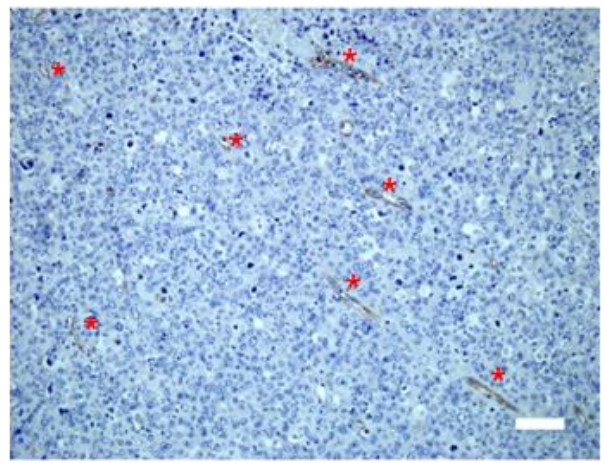

B

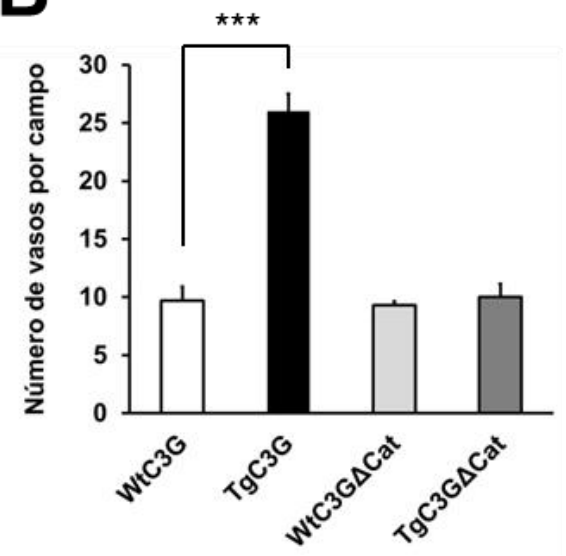

$\operatorname{TgC3G}$

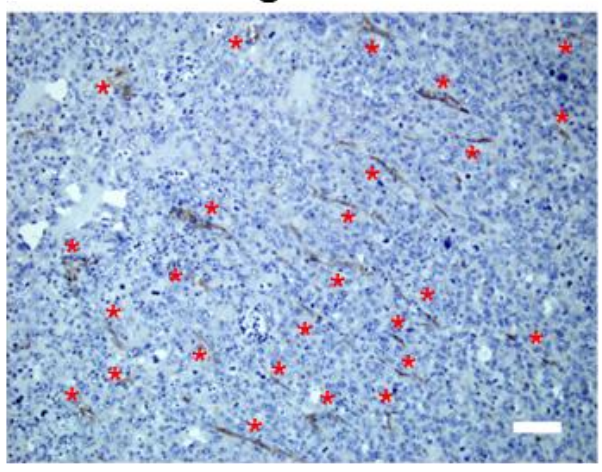

$\operatorname{TgC} 3 \mathrm{G} \Delta \mathrm{Cat}$

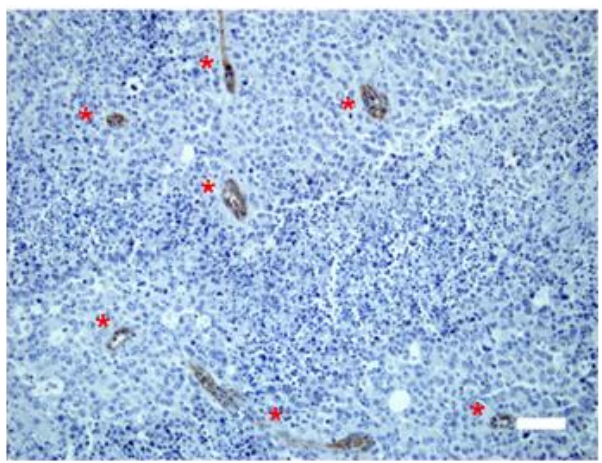

C

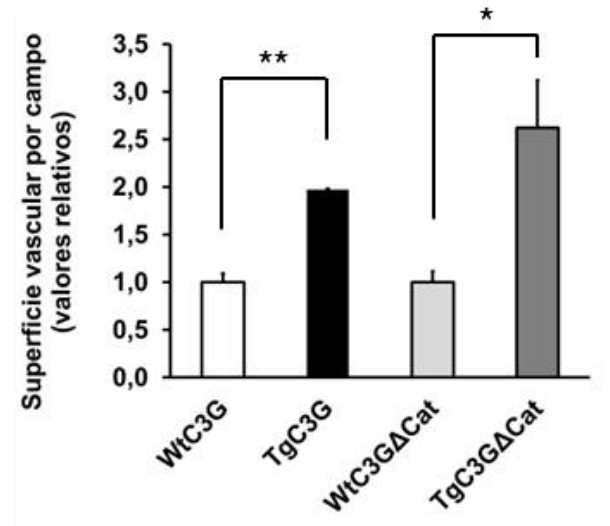

Figura R13. Las plaquetas $\mathrm{TgC} 3 \mathrm{G}$ y $\mathrm{TgC} 3 \mathrm{G} \Delta \mathrm{Cat}$ promueven una mayor magnitud de angiogénesis en tumores heterotópicos de células 3LL. (A) Imágenes representativas de microscopía de luz de secciones de tumores $3 \mathrm{LL}$ desarrollados en ratones de los diferentes genotipos. La tinción corresponde a la inmunohistoquímica contra CD31. Los capilares sanguíneos aparecen indicados (*). Barra: $20 \mu \mathrm{m}$. Los gráficos muestran la cuantificación del número de vasos sanguíneos (B) o de la superficie ocupada por los vasos en relación al área total $(C)$, en tres campos representativos de cada sección de tumor. ${ }^{*} \mathrm{p}<0,05$; ${ }^{* *} p<0,01 ; p<0,001$. 
A

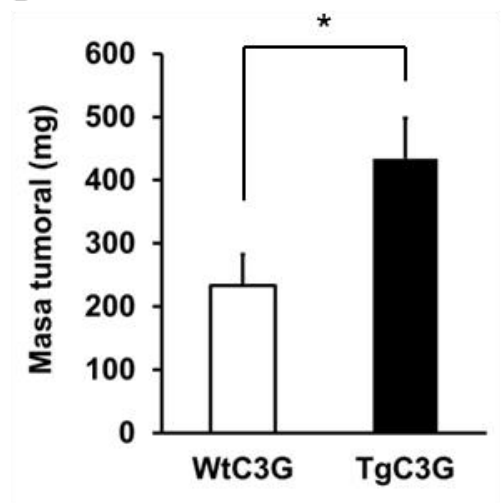

C
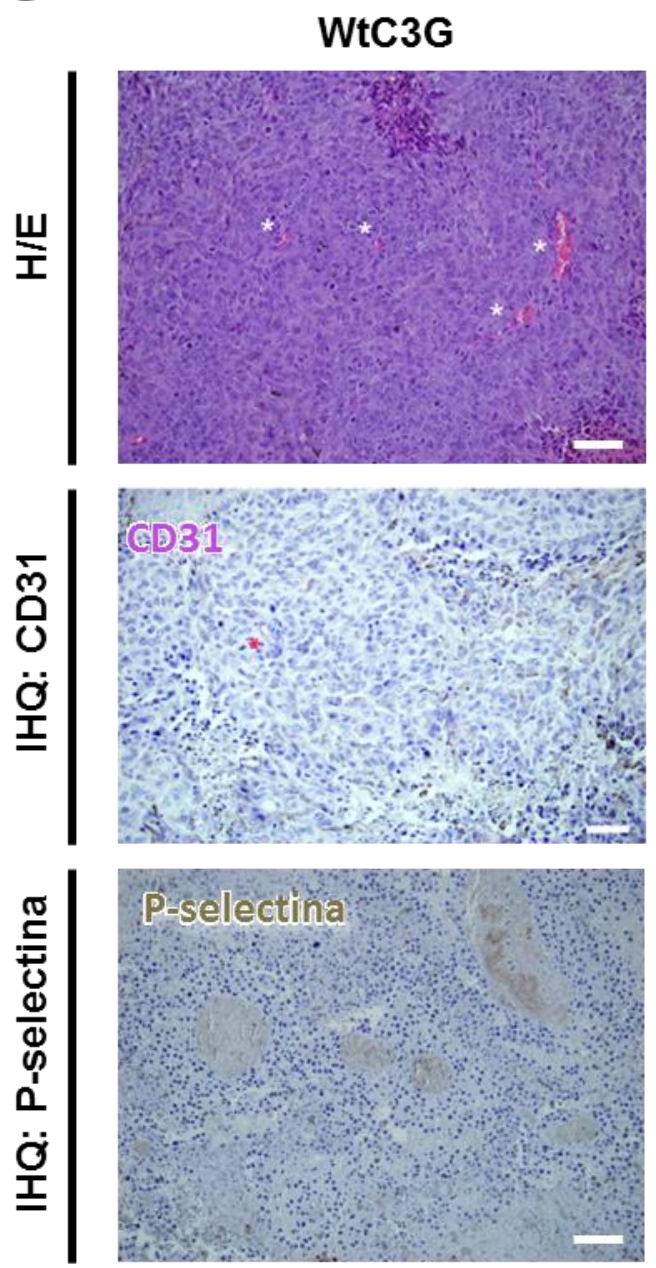

B

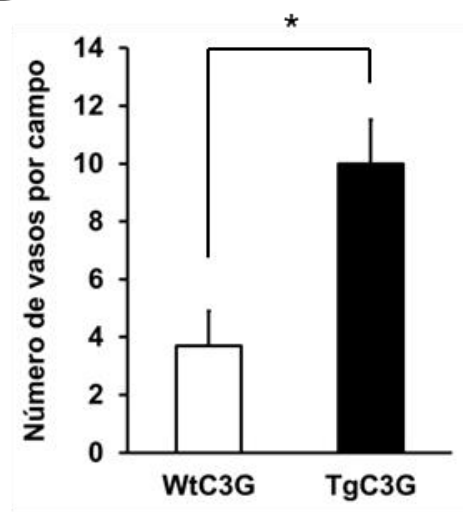

TgC3G
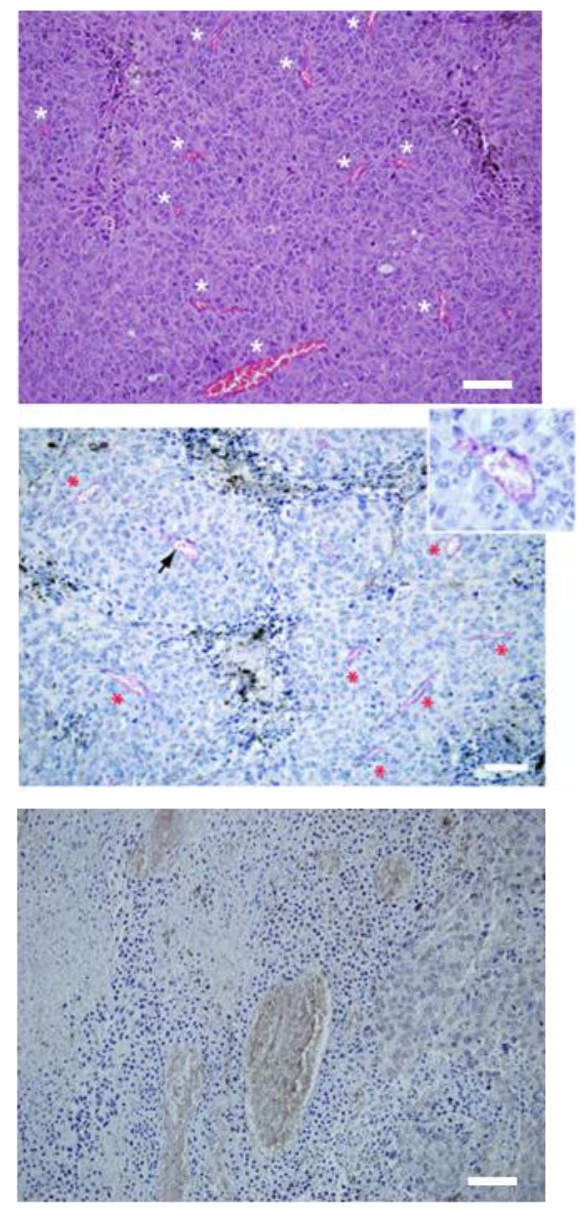

Figura R14. Las plaquetas TgC3G y TgC3G $\Delta$ Cat promueven el crecimiento y la angiogénesis de tumores heterotópicos de células de melanoma B16F10. (A) Cuantificación de la masa final de tumores B16F10 desarrollados en ratones WtC3G y TgC3G ( $n=8$ para WtC3G, $n=7$ para TgC3G). (B) Cuantificación del número de vasos sanguíneos en tres campos representativos por cada tumor. (C) Imágenes representativas de microscopía de luz de secciones de cada tumor. Las tinciones corresponden a hematoxilina/eosina $(\mathrm{H} / \mathrm{E})$ y a inmunohistoquímica contra CD31 o P-selectina (IHQ:CD31 o IHQ: P-selectina). Los capilares sanguíneos aparecen indicados $\left({ }^{*}\right)$. Barra: $20 \mu \mathrm{m}$. ${ }^{*} \mathrm{p}<0,05$. Recuadro ampliado: detalle de un vaso sanguíneo (señalado por una flecha) teñido mediante IHQ contra CD31. IHQ: inmunohistoquímica. 


\section{EI C3G plaquetario facilita la metástasis de células de melanoma}

Con la finalidad de conocer si el C3G plaquetario también se encuentra involucrado en la facilitación de las metástasis tumorales, utilizamos un modelo de metástasis pulmonar de células de melanoma B16F10. El promedio de metástasis superficiales encontradas en los pulmones de ratones TgC3G fue significativamente mayor que las encontradas en los pulmones de ratones silvestres. En concordancia con este dato, el análisis histológico de secciones de los pulmones de cada genotipo de ratón demostró la presencia de un número significativamente mayor de focos metastásicos en los ratones $\mathrm{TgC}$ GG, con respecto a los ratones WtC3G (Figura R15).

\section{Las plaquetas TgC3G y TgC3GACat promueven la angiogénesis in vivo: vascularización en orejas de ratón inflamadas por tratamiento con oxazolona}

Con la finalidad de confirmar la capacidad pro-angiogénica del C3G plaquetario in vivo, se evaluó un modelo de angiogénesis en orejas de ratón, en un contexto de inflamación inducida por oxazolona. La aplicación tópica de la oxazolona indujo un incremento significativo del grosor de las orejas de los ratones en todos los genotipos. Esta inflamación fue evidenciada a las 24 horas tras el tratamiento, manteniéndose inalterada a las 48 horas (Figura R16). Además, se encontró que ambas líneas de ratones transgénicos presentaron un grado de inflamación estadísticamente similar al hallado en los ratones silvestres respectivos. Por lo tanto, el C3G plaquetario no parece influir en el proceso de inflamación inducida por la oxazolona.

Sin embargo, el análisis histoquímico de las orejas inflamadas mostró que los ratones $\mathrm{TgC} 3 \mathrm{G}$ presentaban un número de vasos significativamente mayor con respecto a las orejas inflamadas de los ratones WtC3G (Figuras R17A y R17B). El número de vasos presente en orejas de ratones $\operatorname{TgC} 3 G \Delta$ Cat no mostró diferencias significativas con respecto a las orejas de sus controles silvestres. Sin embargo, se encontró que los vasos tenían un grosor significativamente mayor (Figuras R17A y R17C). El área relativa de los vasos presentes en las orejas de ratones $\mathrm{TgC} 3 \mathrm{G}$ también fue significativamente mayor que la de las orejas de ratones WtC3G, principalmente debido a la presencia de un mayor número de vasos por campo. En conjunto, estos resultados muestran la misma tendencia, en cuanto a la capacidad pro-angiogénica de las plaquetas de ambos genotipos transgénicos, observada en los modelos de tumor heterotópico, lo cual apoyaría el papel del C3G plaquetario en angiogénesis. 


\section{A}

\section{WtC3G}

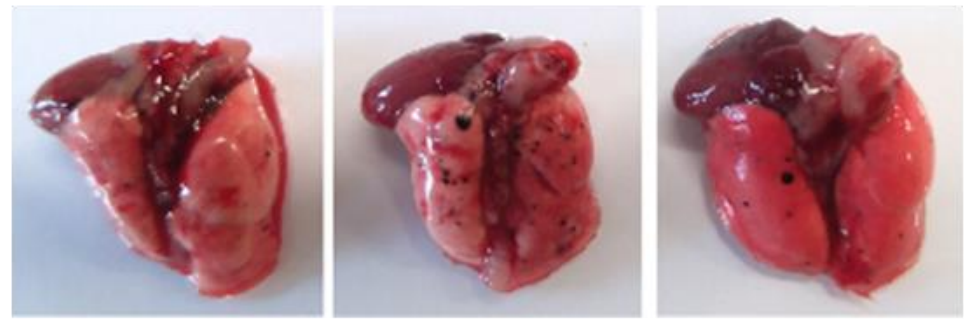

\section{$\operatorname{TgC3G}$}

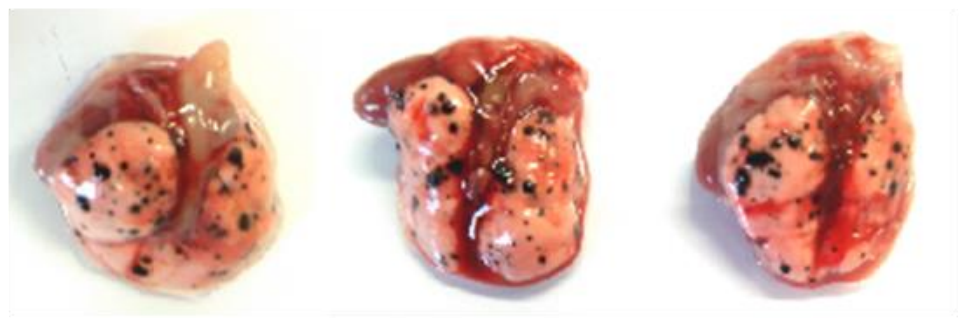

B

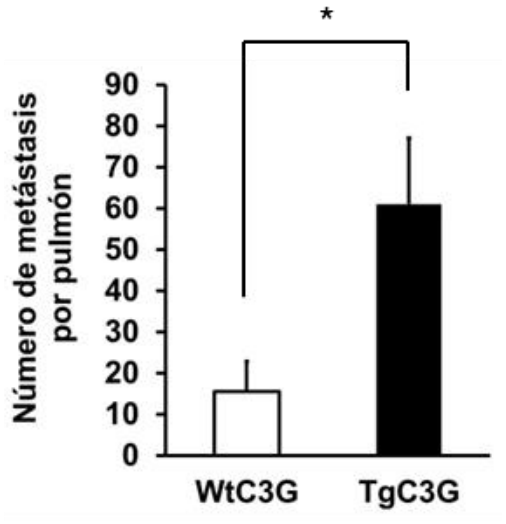

C
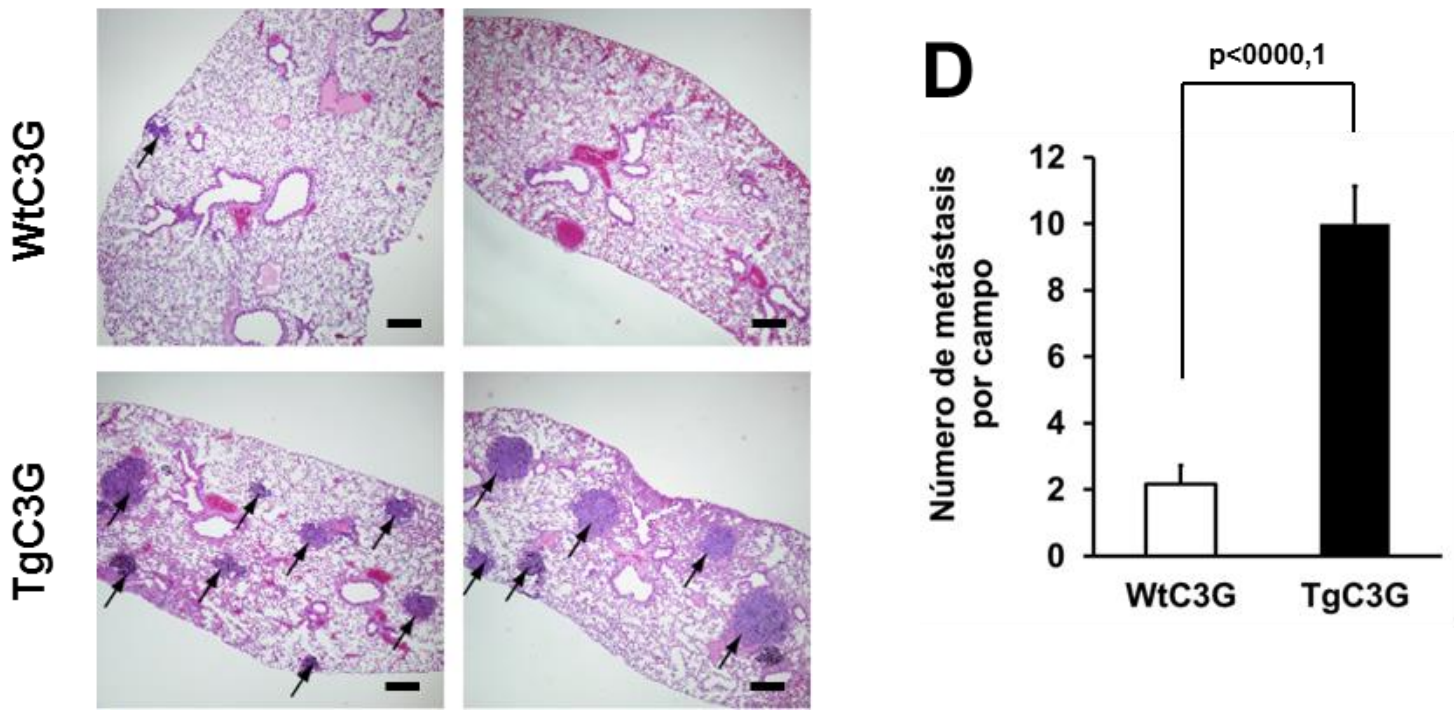

Figura R15. EI C3G plaquetario favorece la metástasis de células de melanoma B16F10. (A) Imágenes representativas de las metástasis superficiales en pulmones de ratones WtC3G y TgC3G. (B) Cuantificación del promedio de metástasis superficiales en pulmones de ratones de cada genotipo $(n=4)$. $(C)$ Imágenes representativas de microscopía de luz de secciones de pulmones de ratones WtC3G y TgC3G. La tinción corresponde a hematoxilina/eosina. Las metástasis pulmonares aparecen indicadas (flechas). Barra: $10 \mu \mathrm{m}$. (D) Cuantificación del número de metástasis por campo $(n=12)$ en secciones de pulmones de ratones WtC3G y TgC3G * $p<0,05$. 


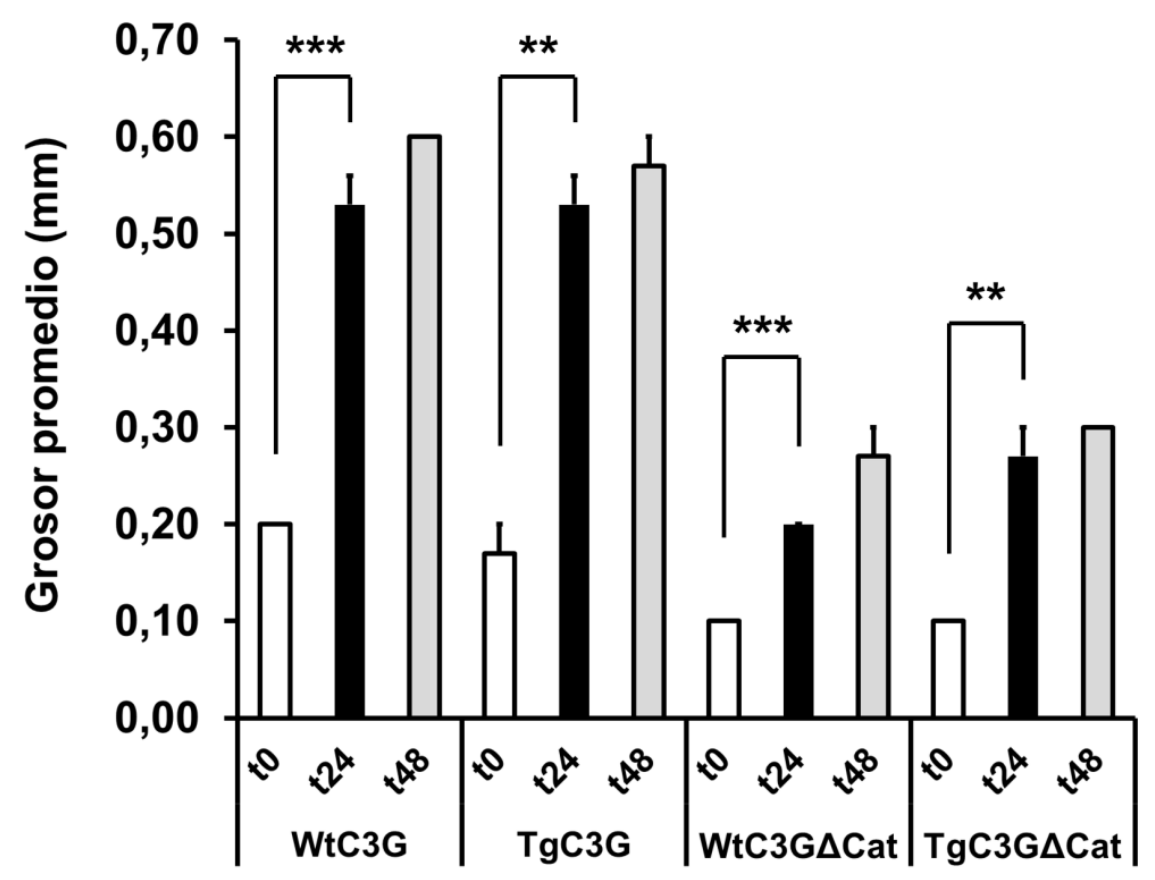

Figura R16. El C3G plaquetario no influye en la inflamación de las orejas de los ratones tras el tratamiento con oxazolona. Cuantificación del grosor promedio de orejas de tres ratones de cada genotipo tratadas con oxazolona. La medición se realizó al inicio del experimento (t0) y a las 24 y 48 horas posteriores al tratamiento (t24 y t48). ${ }^{* *} p<0,01 ; p<0,001$.

EI C3G plaquetario regula la angiogénesis in vivo: infiltración de células endoteliales en botones de Matrigel implantados subcutáneamente en ratones

Para ampliar la caracterización de la función del C3G plaquetario en la angiogénesis in vivo, se implantaron botones de Matrigel enriquecidos con bFGF en ratones de los diferentes genotipos, y se evaluó la infiltración de células endoteliales CD31 positivas. En este modelo, se encontró que los ratones TgC3G $\Delta$ Cat presentaron una mayor vascularización en los botones de Matrigel, con respecto a sus controles silvestres, aunque esta diferencia no resultó ser estadísticamente significativa $(p=0,06)$ (Figuras R18A y R18B). En el caso de los ratones TgC3G, no se encontraron diferencias aparentes en relación a los ratones WtC3G.

Estos resultados no están necesariamente en contradicción con los encontrados en el modelo de angiogénesis tumoral y en el modelo de angiogénesis inducida por inflamación, ya que los mecanismos involucrados en cada contexto fisiológico son diferentes, al igual que el grado de participación de las plaquetas en cada uno de ellos. 
A

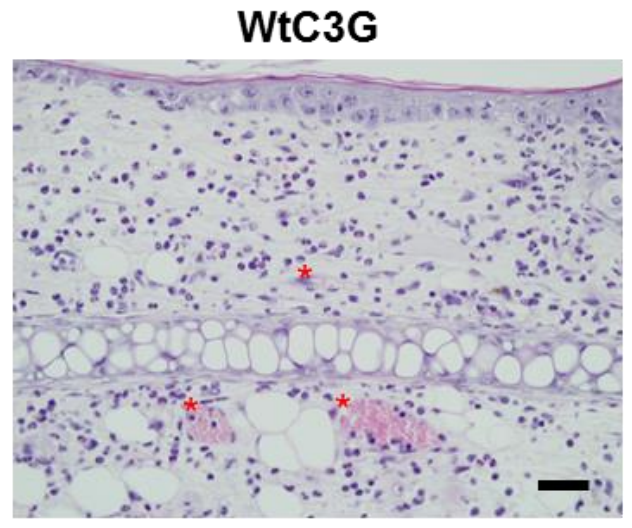

WtC3G $\Delta$ Cat

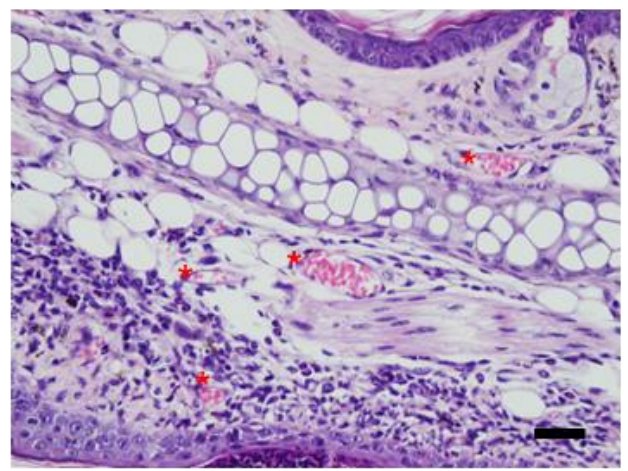

B

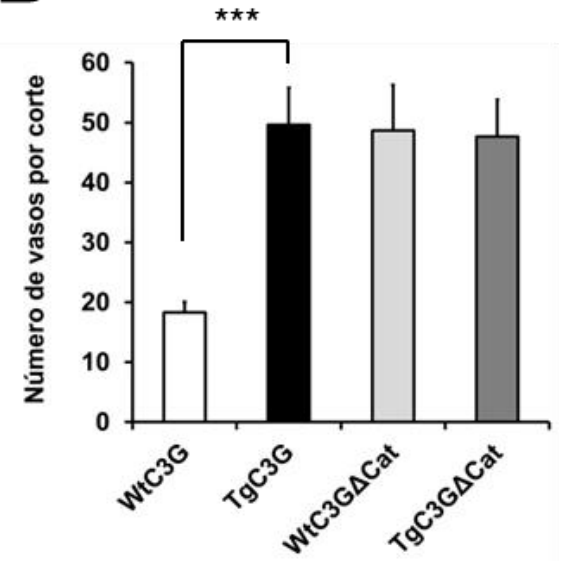

$\operatorname{TgC3G}$

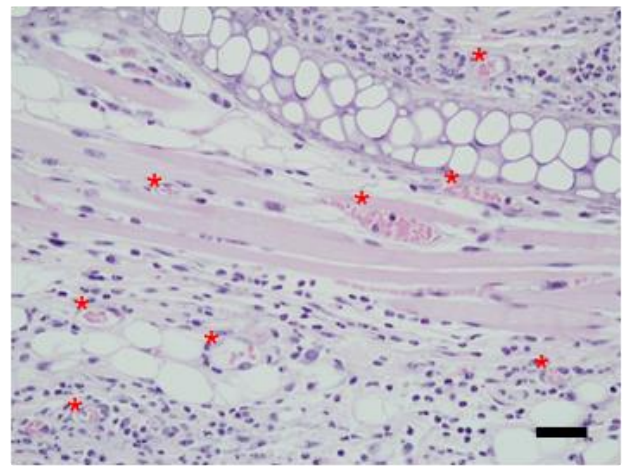

$\operatorname{TgC3G} \Delta$ Cat

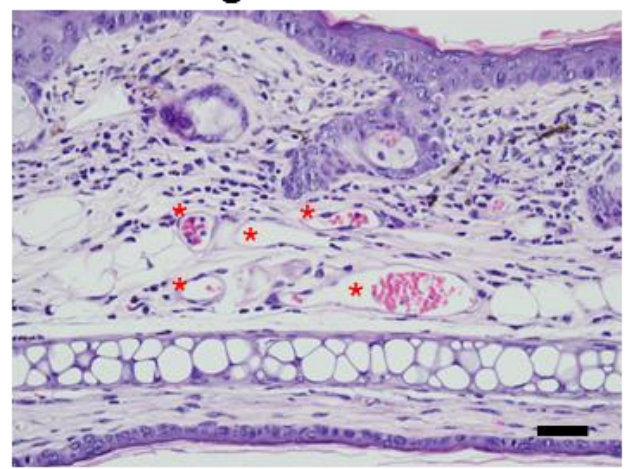

C

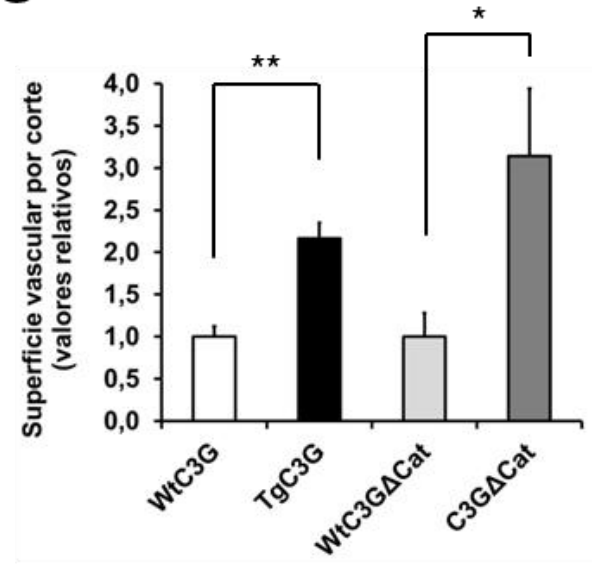

Figura R17. Las plaquetas TgC3G y TgC3G $\Delta$ Cat promueven una mayor magnitud de angiogénesis en orejas de ratón inflamadas por aplicación de oxazolona. (A) Imágenes representativas de microscopía de luz de secciones de orejas de ratones de los diferentes genotipos, tras 48 horas de la aplicación tópica de oxazolona. La tinción corresponde a hematoxilina/eosina. Los capilares sanguíneos aparecen indicados $\left(^{*}\right)$. Barra: $20 \mu \mathrm{m}$. Los gráficos muestran la cuantificación del número de vasos sanguíneos (B) o de la superficie ocupada por los vasos en relación al área total $(\mathrm{C})$, en secciones de orejas de tres ratones de cada genotipo. ${ }^{*} p<0,05 ;{ }^{* *} p<0,01 ;{ }^{* * *} p<0,001$. 


\section{A}

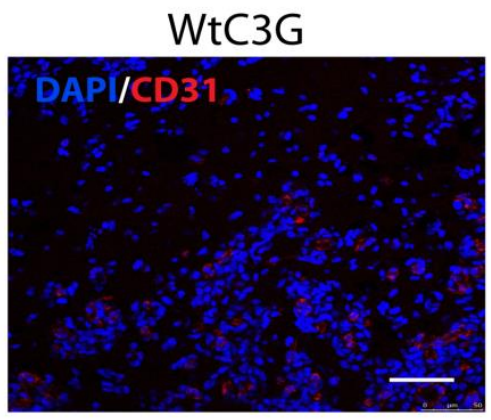

WtC3G $\Delta$ Cat

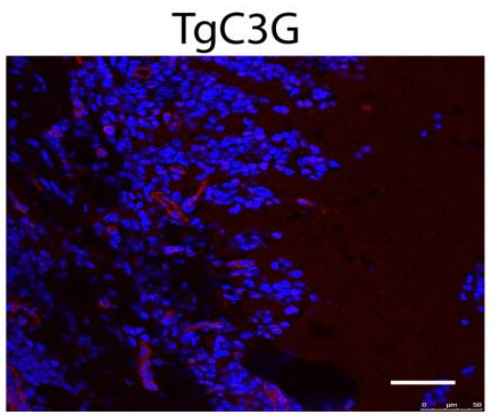

$\operatorname{TgC} 3 \mathrm{G} \Delta \mathrm{Cat}$
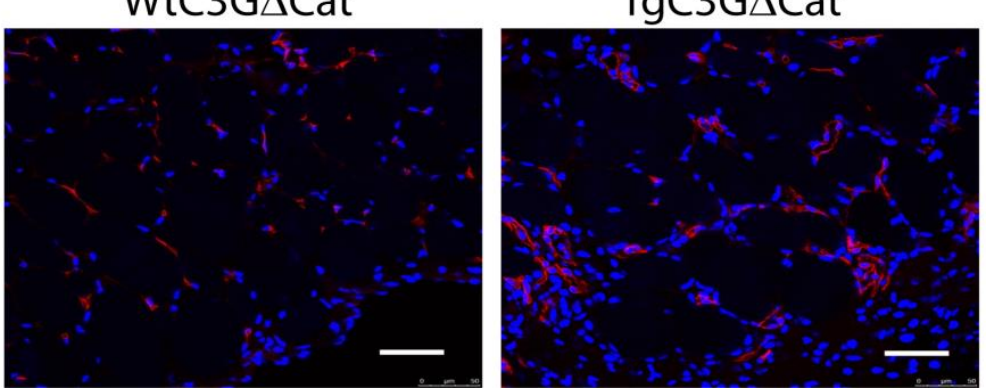
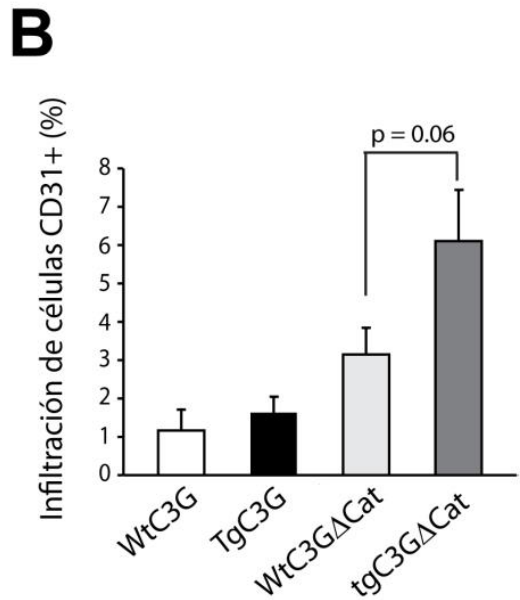

Figura R18. Infiltración de células endoteliales CD31+ en botones de Matrigel enriquecidos con bFGF. (A) Imágenes representativas de microscopía confocal de inmunofluorescencia mostrando la infiltración de células endoteliales CD31+ (rojo) en botones de Matrigel, 7 días después de ser inyectados subcutáneamente en ratones de los diferentes genotipos. Barra: $50 \mu \mathrm{m}$. (B) Cuantificación de la infiltración de células CD31+ expresada como el porcentaje de área ocupada por la señal de CD31 en relación al área ocupada por la señal de DAPI ( $n=4$ ratones por cada genotipo, 3-4 mediciones por ratón).

\section{Mecanismos moleculares involucrados en la regulación mediada por C3G de} la secreción plaquetaria de factores angiogénicos

En la sección final de este trabajo, nos propusimos profundizar en los posibles mecanismos moleculares mediante los cuales C3G lleva a cabo las funciones reguladoras de la secreción de factores angiogénicos por plaquetas activadas. Para ello, evaluamos específicamente la interacción funcional entre C3G y la proteína VAMP7. Se conoce que VAMP7, una proteína de tráfico intracelular asociada a vesículas ( $V$-SNARE), se encuentra asociada a gránulos- $\alpha$ que contienen VEGF (Peters et al., 2012). Además, se ha descrito que esta proteína es necesaria para la exocitosis normal de los gránulos- $\alpha$ plaquetarios (Koseoglu et al., 2015).

\section{C3G interacciona con VAMP7 en plaquetas TgC3G y TgC3GACat}

Debido a que el VEGF es retenido en las plaquetas de ratones TgC3G y TgC3G $\Delta$ Cat, tras la activación con ADP (Figura R6), decidimos profundizar en el estudio de los mecanismos moleculares involucrados y evaluar si C3G podría estar regulando la 
exocitosis de los gránulos que lo contienen, a través de la interacción con VAMP7. En primer lugar, se analizó por microscopía confocal de inmunofluorescencia si C3G colocalizaba con los gránulos que contienen VEGF. Las Figuras R19A y R19B muestran que, en efecto, existe una co-localización significativamente mayor entre C3G y VEGF en las plaquetas $\mathrm{TgC} 3 \mathrm{G}$, con respecto a las plaquetas $\mathrm{WtC} 3 \mathrm{G}$, al ser activadas con ADP. En las plaquetas $\operatorname{TgC} 3 \mathrm{G} \Delta$ Cat también se observó un mayor grado de co-localización entre VEGF y C3G, que en las plaquetas WtC3G $\Delta$ Cat, aunque no fue estadísticamente significativo.

Habiendo confirmado la co-localización entre C3G y VEGF en las plaquetas transgénicas activadas, procedimos a evaluar directamente la interacción entre C3G y VAMP7, a través de co-inmunoprecipitaciones. La Figura R20A muestra que VAMP7 es detectado al inmunoprecipitar $\mathrm{C} 3 \mathrm{G}$ en lisados de plaquetas $\mathrm{TgC3G}$ y $\mathrm{TgC3G} \triangle \mathrm{Cat}$, tanto en reposo como activadas con trombina. Esta interacción también fue detectada en células K562 con sobreexpresión de C3G al inmunoprecipitar cualquiera de las dos proteínas (Figuras R20B y R20C). Además, los niveles de VAMP7 detectados al inmunoprecipitar C3G fueron mayores al activar las células K562 con PMA, el cual es un estimulador de la megacariopoyesis en esta línea celular.

Para profundizar en el estudio de la interacción entre C3G y VAMP7, se realizaron inmunoprecipitaciones de lisados de células HEK293T co-transfectadas con CFP-VAMP7 (CFP-VAMP7-NT: dominio longina, CFP-VAMP7-CT: dominio SNARE, O CFP-VAMP7cyto: región citoplasmática completa), en conjunto con la construcción HA-C3G o pLTR2C3G $\triangle$ Cat (ver Materiales y Métodos). Los resultados mostraron que tanto el dominio longina como el dominio SNARE de VAMP7 contribuyen a la interacción con C3G (Figura R21A) y con C3G $\Delta$ Cat (Figura R21B).

Estos resultados apoyan la hipótesis de que la interacción entre C3G y VAMP7 es uno de los mecanismos responsables de la regulación de la exocitosis de los gránulos-a, y de los factores angiogénicos contenidos en ellos, en las plaquetas transgénicas activadas. Además, el hecho de que VAMP7 interaccione tanto con C3G como con C3G $\triangle$ Cat está en concordancia con la retención de VEGF observada en las plaquetas de ambos genotipos transgénicos. 

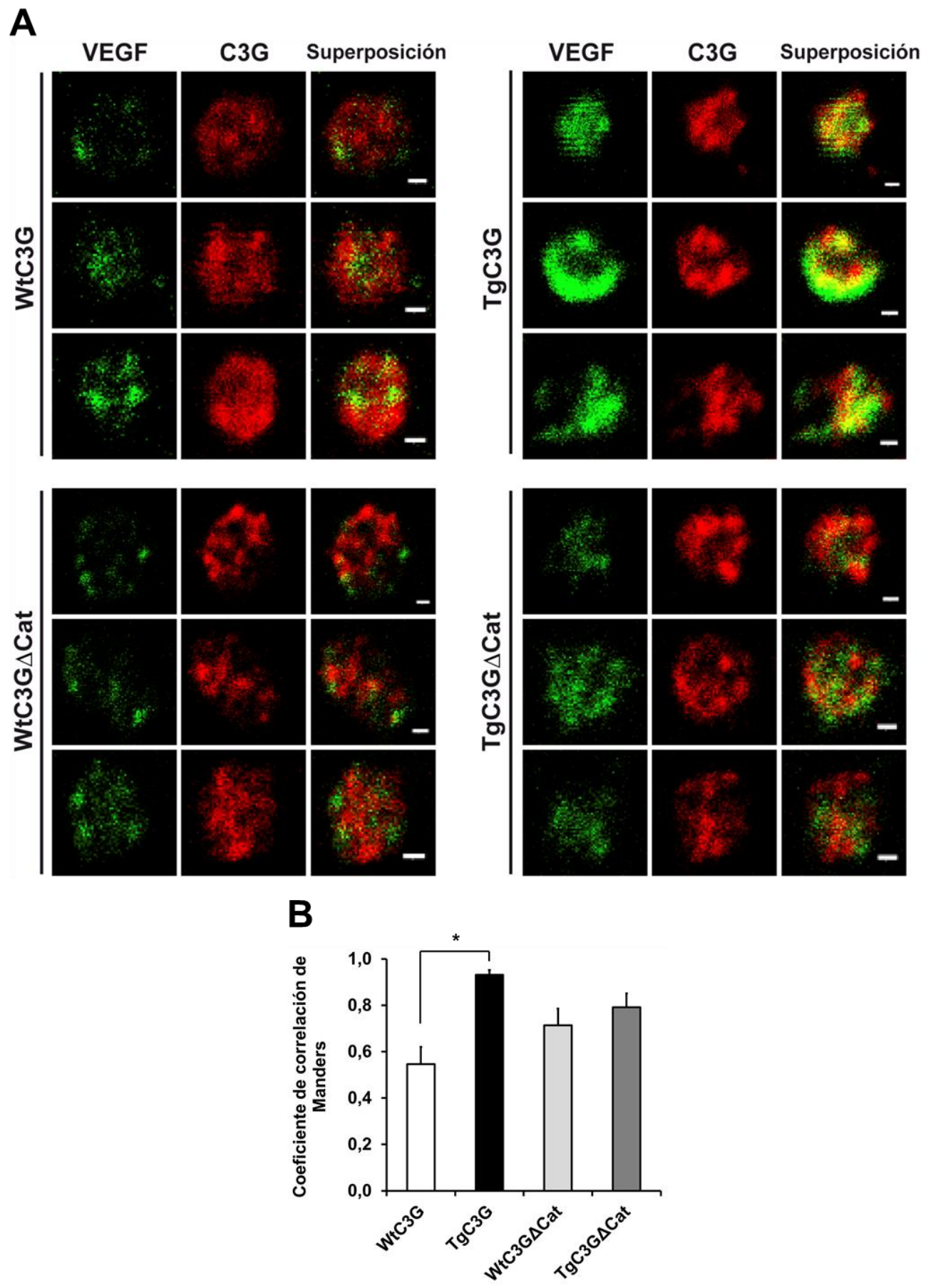

Figura R19. C3G y VEGF co-localizan en plaquetas TgC3G activadas con ADP. (A) Análisis por microscopía confocal de inmunofluorescencia de la distribución subcelular de VEGF (verde), C3G (rojo) y su superposición (amarillo) en plaquetas de ratón activadas con ADP $25 \mu \mathrm{M}$ durante 5 min. Se muestran 3 plaquetas representativas de cada genotipo. Barra: 0,4 $\mu \mathrm{m}$. (B) Análisis cuantitativo del grado de co-localización de ambas señales a través del coeficiente de correlación de Manders en plaquetas de cada genotipo $(n=3)$. * $p<0,05$. 
A

\section{Plaquetas}

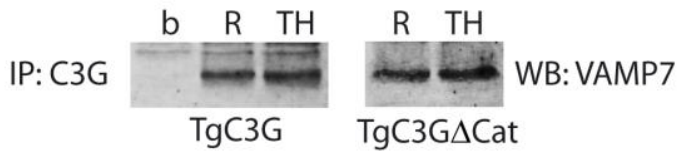
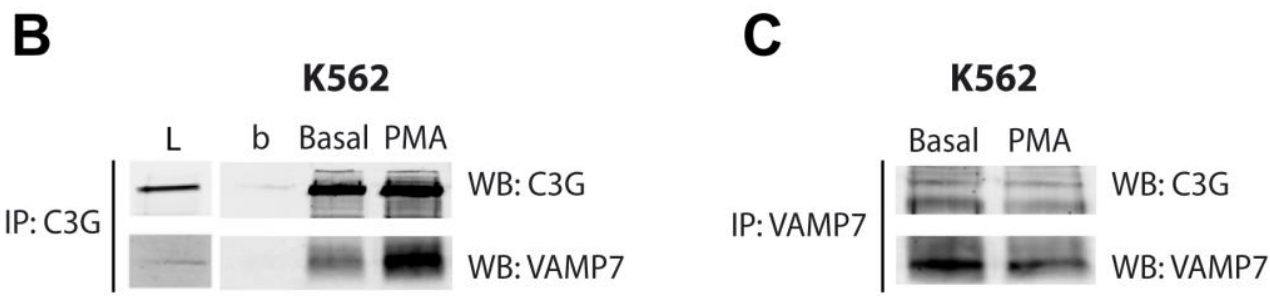

Figura R20. C3G interacciona con VAMP7 en plaquetas TgC3G y TgC3G $\Delta$ Cat, y en células K562 con sobreexpresión de C3G. (A) Inmunoprecipitación de C3G (IP: C3G) en plaquetas transgénicas en reposo (R) o activadas con trombina $0,2 \mathrm{U} / \mathrm{mL}$ durante $5 \mathrm{~min}(\mathrm{TH})$. Se utilizaron lisados celulares de plaquetas de 4 ratones por genotipo. b: lisado incubado sólo con bolas de agarosa. Inmunoprecipitación de C3G (B) o de VAMP7 (C) en células de la línea de eritroleucemia humana K562 con sobreexpresión estable de C3G, en condiciones basales (Basal) o activadas con PMA $20 \mathrm{nM}$ durante $10 \mathrm{~min}$. L: lisado total (50 $\mu \mathrm{g})$. En todos los casos, la detección de VAMP7 y de C3G en los inmunocomplejos se realizó mediante Western blot (WB).
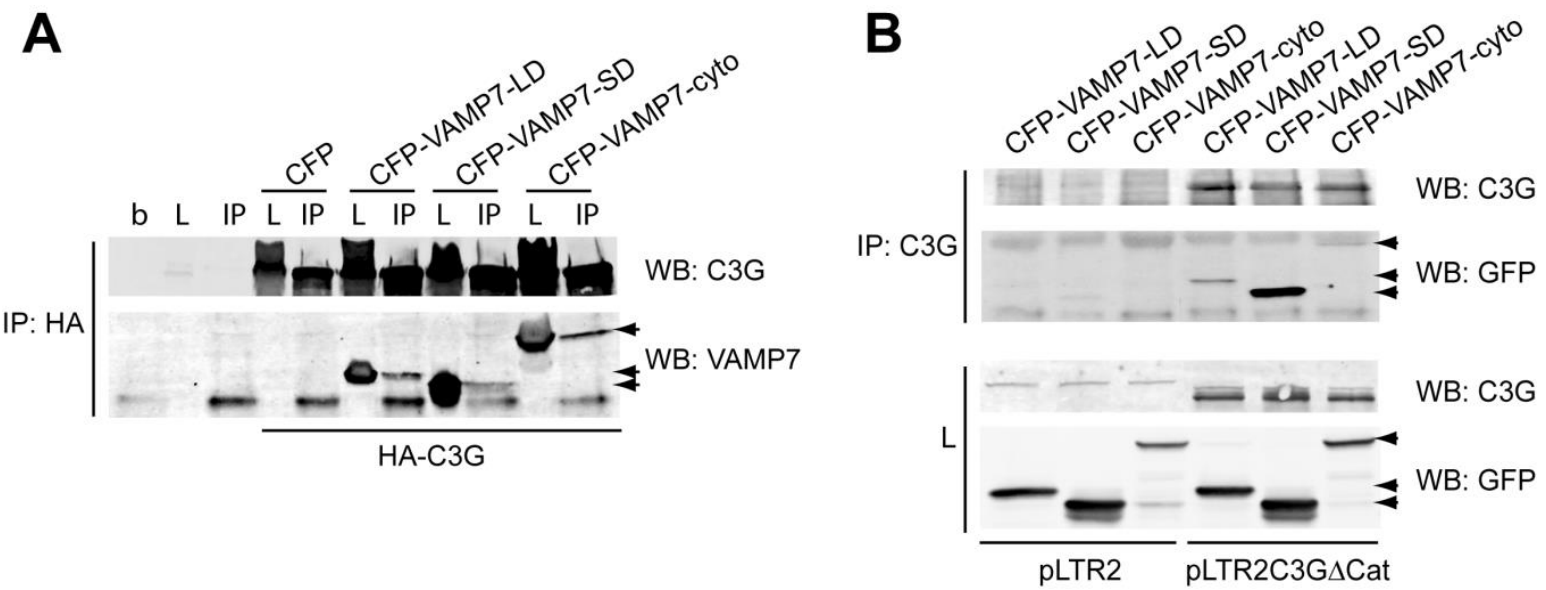

Figura R21. C3G y C3G $\triangle$ Cat interaccionan con VAMP7 en sistemas de co-transfección en células HEK293T. (A) Transfección transiente en células HEK293T de una construcción de C3G etiquetada con HA, en conjunto con las proteínas de fusión CFP-VAMP7 indicadas o el plásmido pCDNA3-CFP-C4 vacío (CFP). El C3G ectópico fue inmunoprecipitado utilizando un anticuerpo contra HA (IP: HA). Las diferentes construcciones de VAMP7 en los inmunocomplejos fueron detectadas mediante Western blot (WB). b: lisado de células no transfectadas incubado sólo con bolas de agarosa. L: lisado total $(50 \mu \mathrm{g})$. (B) Transfección transiente en células HEK293T de la construcción pLTR2C3G $\Delta$ Cat o el vector pLTR2 vacío, en conjunto con las proteínas de fusión CFP-VAMP7 indicadas. C3G fue inmunoprecipitado con un anticuerpo anti-C3G (IP: C3G), y C3G y VAMP7 fueron detectados mediante Western blot utilizando anticuerpos anti-C3G y antiGFP, respectivamente. L: lisados totales. VAMP7-LD: dominio longina de VAMP7 (aminoácidos 1-120); VAMP7-SD: dominio SNARE de VAMP7 (aminoácidos 121-188); VAMP7-cyto: región citosólica de VAMP7 (aminoácidos 1-188). Las flechas indican las diferentes construcciones de VAMP7. 


\section{C3G y C3GACat promueven la extensión plaquetaria sobre sustrato}

Se conoce que VAMP7 está involucrado en la extensión plaquetaria sobre sustrato, a través de su interacción con proteínas como VARP y Arp2/3 (Koseoglu et al., 2015). En este fenómeno, los gránulos- $\alpha$ recubiertos con VAMP7 son reclutados a la periferia de la plaqueta donde se fusionan a la membrana celular y contribuyen al incremento de su superficie durante la extensión plaquetaria (Peters et al., 2012). Con la finalidad de comprobar que la interacción C3G-VAMP7 tiene un efecto a nivel funcional, decidimos evaluar la extensión de las plaquetas sobre poli-L-lisina, tras ser activadas con trombina.

Las Figuras R22A y R22B muestran que la extensión plaquetaria, cuantificada como el área media de las plaquetas extendidas, fue significativamente mayor en plaquetas $\mathrm{TgC} 3 \mathrm{G}$ y $\mathrm{TgC} 3 \mathrm{G} \Delta$ Cat, en comparación con sus respectivos controles silvestres. Para verificar que esta observación a nivel funcional está relacionada con la asociación entre C3G y VAMP7, evaluamos su co-localización en plaquetas extendidas, a través de microscopía confocal de inmunofluorescencia. Las figuras R22C y R22D muestran que el grado de co-localización, según el coeficiente de correlación de Manders, fue significativamente mayor en plaquetas TgC3G en comparación con las plaquetas WtC3G. En el caso de las plaquetas TgC3G $\Delta$ Cat, también se encontró una mayor co-localización entre ambas proteínas, con respecto al control silvestre, pero sin llegar a ser estadísticamente significativa. La localización de VAMP7 en la periferia de las plaquetas extendidas está en concordancia con estudios publicados previamente (Peters et al., 2012). Estos resultados sugieren que C3G regula la extensión plaquetaria sobre sustrato, a través de mecanismos independientes de su actividad GEF, y que involucran su interacción con VAMP7.

Los resultados presentados en este trabajo proporcionan diferentes evidencias que apoyan una novedosa función de C3G en plaquetas. C3G regula la secreción de factores angiogénicos tras la activación, la producción de un secretoma plaquetario con efecto neto pro-angiogénico, tanto in vitro como en diferentes contextos fisiológicos in vivo, y la facilitación de las metástasis tumorales. C3G parece llevar a cabo estas funciones a través de mecanismos dependientes e independientes de su actividad GEF, entre los que se incluye su interacción funcional con la proteína VAMP7, la cual está asociada a una sub-población de gránulos- $\alpha$, y participa tanto en la exocitosis de los gránulos plaquetarios tras la activación, como en la extensión plaquetaria sobre sustrato. 
A

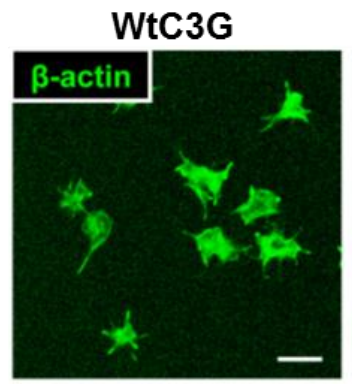

WtC3G $\Delta$ Cat

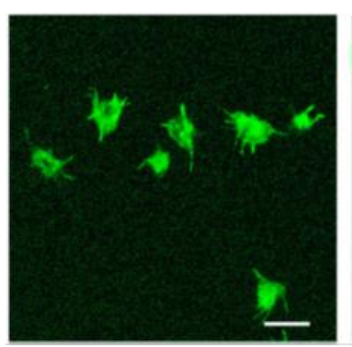

C
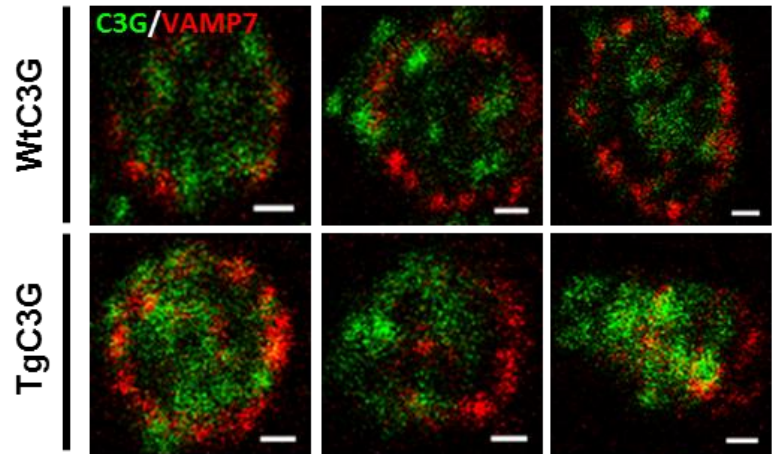

苑
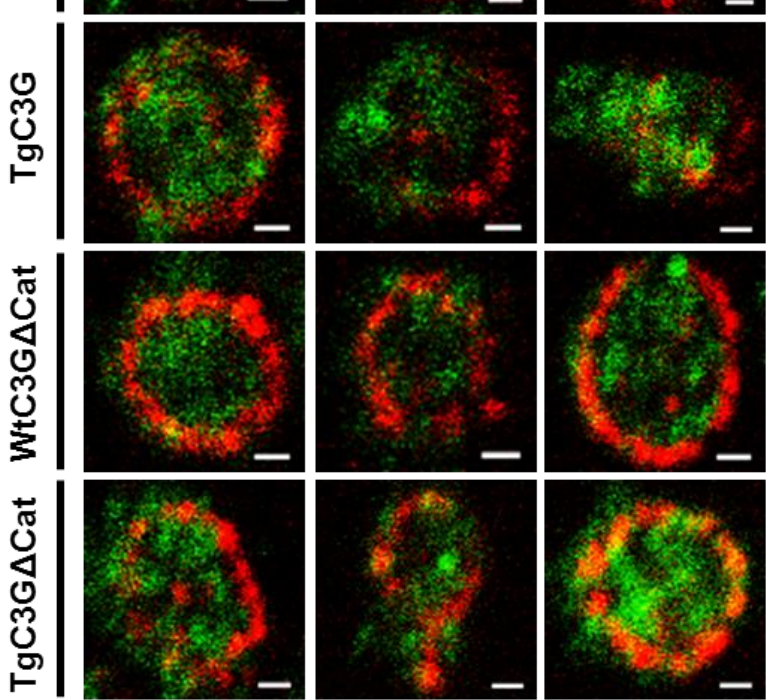

$\operatorname{TgC3G}$

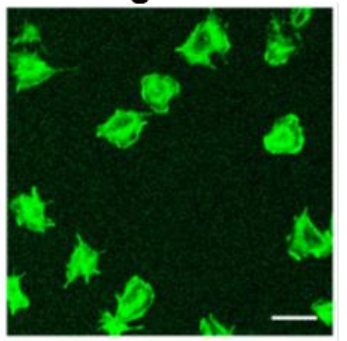

\section{$\operatorname{TgC} 3 \mathrm{G} \Delta$ Cat}

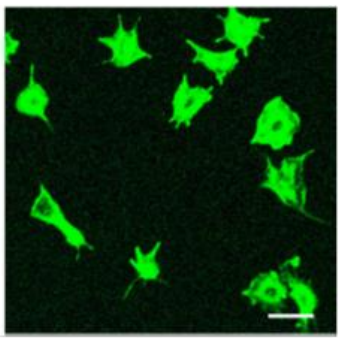

B

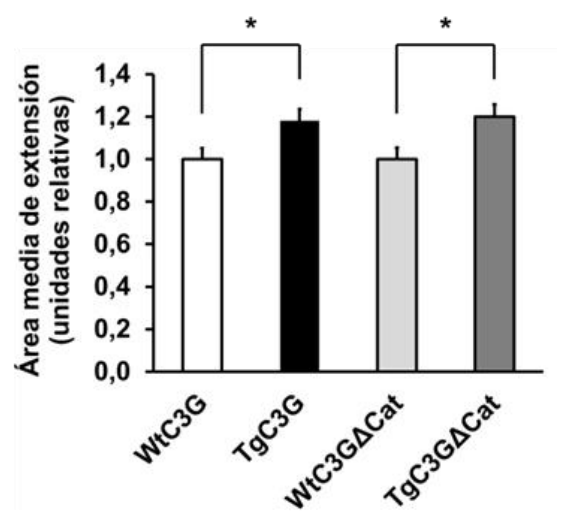

D

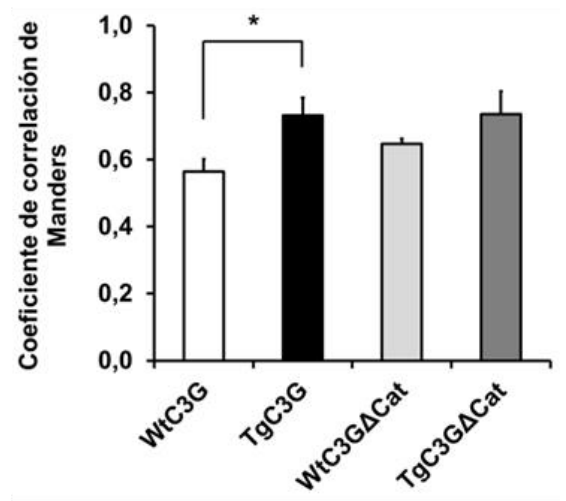

Figura R22. Las plaquetas TgC3G y TgC3G $\triangle$ Cat presentan una mayor área de extensión sobre sustrato, junto con un mayor grado de co-localización entre C3G y VAMP7. (A) Imágenes representativas de microscopía confocal de inmunofluorescencia de plaquetas de ratón extendidas sobre poli-L-lisina tras ser activadas con trombina 0,2 U/mL. Barra: $5 \mu \mathrm{m}$. (B) Cuantificación del área media de extensión plaquetaria en relación al control silvestre correspondiente. Se analizaron un promedio de 48 plaquetas por cada genotipo. (C) Análisis por microscopía confocal de inmunofluorescencia de la distribución subcelular de C3G (verde) y VAMP7 (rojo) en plaquetas de ratón extendidas sobre poli-L-lisina. Se muestran 3 plaquetas representativas de cada genotipo. Barra: $0,5 \mu \mathrm{m}$. (D) Análisis cuantitativo del grado de co-localización de ambas señales a través del coeficiente de correlación de Manders en plaquetas de cada genotipo $(n=3)$. ${ }^{*} p<0,05$. Se utilizó la línea $6 \mathrm{~A} 6$ de ratones WtC3G y $\mathrm{TgC} 3 \mathrm{G}$ para ambos experimentos. 


\section{DISCUSIÓN}



En este trabajo se ha demostrado, por primera vez, que el C3G plaquetario tiene un papel en la regulación de la liberación del contenido de los gránulos- $\alpha$, incluyendo factores proy anti-angiogénicos. Este hecho, modifica positivamente la capacidad angiogénica de la secreción plaquetaria, tanto in vitro como in vivo, afectando procesos como el desarrollo tumoral y las metástasis.

\section{Función reguladora de C3G en la liberación de factores angiogénicos por plaquetas activadas}

Para llevar a cabo este estudio, hemos utilizado ratones transgénicos para el gen C3G humano, y para el mutante C3G $\Delta$ Cat (carente de actividad catalítica GEF), cuya expresión está regulada por el promotor del gen PF4, específico de plaquetas y megacariocitos, y en los cuales ya se ha descrito el papel fundamental que tiene C3G en la agregación plaquetaria, tanto in vitro como in vivo, a través de la activación de Rap1b (Gutiérrez-Herrero et al., 2012).

La cantidad de proteína secretada por las plaquetas de cada genotipo, tras la activación con trombina o ADP, fue similar entre ratones transgénicos y sus respectivos controles. Previamente se ha reportado que las plaquetas TgC3G presentan mayores niveles de activación y de expresión de P-selectina en superficie que las plaquetas WtC3G, mientras que las plaquetas TgC3G $\Delta$ Cat presentan la tendencia contraria con respecto a sus controles silvestres (Gutiérrez-Herrero et al., 2012). Por esta razón, se esperaban diferencias en la secreción de proteína que siguieran la misma tendencia. No obstante, el análisis de la ultraestructura de las plaquetas de cada genotipo reveló que los ratones TgC3G presentaban una menor proporción de plaquetas con más de 3 gránulos- $\alpha$, en comparación con los ratones $\mathrm{WtC} 3 \mathrm{G}$, mientras que los ratones TgC3G $\Delta$ Cat presentaron una mayor abundancia de plaquetas con más de 3 gránulos- $\alpha$, con respecto a sus controles. Tomado en conjunto, la mayor activación de plaquetas TgC3G o WtC3G $\Delta$ Cat, combinado con una menor proporción de plaquetas con gran abundancia de gránulos- $\alpha$, podría explicar la ausencia de diferencias cuantitativas en cuanto a la secreción, con respecto a plaquetas WtC3G o TgC3G $\Delta$ Cat, respectivamente. Las diferencias encontradas en cuanto a la abundancia de gránulos- $\alpha$ en las plaquetas de los diferentes genotipos, sugiere que C3G también podría estar involucrado en la biogénesis de las plaquetas. De hecho, resultados recientes de nuestro grupo han 
demostrado que C3G promueve la maduración megacariocítica y la formación de las proplaquetas (Ortiz, 2017).

Por otra parte, los niveles de secreción de proteína al activar las plaquetas con ADP, fueron aproximadamente la mitad de los encontrados al activar con trombina, en todos los genotipos. En este sentido, se conoce que el ADP es un agonista plaquetario de menor potencia que la trombina y que promueve la liberación de niveles de proteína considerablemente menores, en plaquetas humanas (Coppinger et al., 2004).

El estudio por SDS-PAGE de los secretomas plaquetarios, reveló diferencias cualitativas significativas entre los genotipos transgénicos y sus controles, siendo especialmente evidentes en el caso del genotipo TgC3G. Para poder determinar el perfil proteico de los secretomas plaquetarios, se llevó a cabo un análisis proteómico de muestra completa. Este análisis, permitió también evaluar diferencias en la secreción de las diferentes proteínas entre los genotipos, a través del uso del \#PSM (peptide spectrum matches) como medida cuantitativa de la abundancia de cada proteína en el secretoma, según se ha reportado previamente (Liu et al., 2012). Cabe destacar que nuestro estudio es el primero realizado sobre la identificación del perfil proteico del secretoma de plaquetas de ratones activadas con trombina o ADP. Por ello, hemos comparado los resultados de este trabajo con estudios previos realizados sobre el secretoma de plaquetas humanas activadas con trombina (Coppinger et al., 2004) o TRAP (thrombin receptor activating peptide) (Piersma et al., 2009). En esta comparación se evaluó la presencia de ortólogos, en el secretoma de plaquetas humanas, de las proteínas que fueron identificadas en los secretomas de nuestros modelos animales, encontrándose que la gran mayoría de las proteínas detectadas en el secretoma de las plaquetas de los ratones han sido previamente detectadas en el secretoma de plaquetas humanas. Es interesante destacar el caso específico de la actina, que también ha sido detectada en el secretoma de plaquetas humanas, lo cual nos permite descartar que la integridad de las plaquetas se haya visto comprometida durante el aislamiento de esta fracción. Además, proteínas citosólicas abundantes en plaquetas, tal como Rap1 (Torti \& Lapetina, 1994), no fueron detectadas en los secretomas, lo cual apoya este hecho.

Entre los factores secretados de manera diferencial, se encontraron proteínas involucradas en numerosas funciones como coagulación sanguínea, fibrinolisis, transporte de lípidos en sangre, agregación plaquetaria y angiogénesis. En este último caso, se encontró específicamente que factores anti-angiogénicos como TSP-1, PF4, vWF e inhibidores de metaloproteinasas, fueron secretados en menor cantidad por las plaquetas 
activadas de ambos genotipos transgénicos en comparación con las plaquetas de controles silvestres, lo que sugiere una regulación por parte de C3G que es independiente de su actividad catalítica GEF.

En el análisis proteómico no se detectaron los principales factores proangiogénicos contenidos en las plaquetas como VEGF, bFGF o PDGF, lo cual puede deberse a efectos de la sensibilidad del método. Por esta razón, evaluamos directamente la liberación de dos de ellos (VEGF y bFGF), en conjunto con factores anti-angiogénicos como endostatina y TSP-1, a través de microscopía confocal de inmunofluorescencia. En primer lugar, los resultados mostraron que los factores pro- (VEGF y bFGF) y antiangiogénicos (endostatina y TSP-1) parecen almacenarse de manera diferencial en las plaquetas de todos los genotipos de ratones. En plaquetas humanas, este hecho ha sido previamente reportado y ha constituido la base de estudios subsiguientes que han demostrado una secreción diferencial de factores pro- y anti-angiogénicos en respuesta a agonistas plaquetarios específicos (Italiano et al., 2008). En este sentido, factores proangiogénicos como el VEGF son liberados de manera diferencial al activar el receptor de trombina PAR1 o al estimular con ADP, mientras que factores anti-angiogénicos como la endostatina son liberados tras la activación del receptor de trombina PAR4 o al estimular con agonistas como el tromboxano $\mathrm{A}_{2}$ (Italiano et al., 2008; Battinelli et al., 2011; Chatterjee et al., 2011). Las plaquetas humanas poseen los receptores de trombina PAR1 y PAR4, ambos ligados a rutas de señalización independientes, mientras que las plaquetas de ratón poseen los receptores de trombina PAR3 y PAR4, siendo PAR3 un coactivador de este último (Coughlin, 2000; Nakanishi-Matsui et al., 2000). Por esta razón, en nuestro estudio evaluamos la secreción de los factores por plaquetas de ratón activadas directamente con trombina. Al igual que en plaquetas humanas activadas por agonistas de PAR4, la activación por trombina de las plaquetas de los ratones silvestres mostró la liberación diferencial de factores anti-angiogénicos como endostatina y TSP-1. Del mismo modo, la activación con ADP de las plaquetas de los ratones silvestres produjo la secreción diferencial de factores pro-angiogénicos como VEGF y bFGF. En contraste, la sobreexpresión de ambos transgenes produjo la retención de ambos factores proangiogénicos en plaquetas activadas por ADP, lo que apoya una función de C3G en la regulación de la secreción plaquetaria que es independiente de su actividad catalítica GEF, y en la que probablemente esté involucrada alguno de los dominios estructurales comunes a ambos transgenes. Igualmente, se encontró que ambos transgenes produjeron la retención de TSP-1, tras la activación con trombina, apoyando los 
resultados del análisis proteómico y la hipótesis de una función reguladora para C3G GEF-independiente en la secreción plaquetaria.

Por otra parte, la sobreexpresión de C3G produjo un aumento en la secreción de endostatina en plaquetas activadas con trombina, mientras que la sobreexpresión de C3G $\Delta$ Cat produjo el efecto contrario. Este resultado parecería contradictorio con el mayor potencial pro-angiogénico de las plaquetas TgC3G observado; sin embargo, la endostatina es un factor anti-angiogénico de menor potencia que la TSP-1, que se encontró retenida en gran medida en las plaquetas activadas. Además, la expresión de la endostatina en plaquetas es mucho menor que la de TSP-1, de acuerdo a los datos del análisis proteómico, y a estudios previos en plaquetas humanas y de ratón (Burkhart et al., 2012; Zeiler et al., 2014). De hecho, la endostatina no fue detectada en el análisis proteómico del secretoma, sino únicamente mediante inmunofluorescencia de las plaquetas activadas. Esto apunta a un papel de menor relevancia para la endostatina, con respecto a la TSP-1, en nuestros modelos de angiogénesis. En conjunto, todos estos resultados sugieren que la regulación de la secreción de factores anti-angiogénicos podría ocurrir a través de mecanismos diferentes, que en determinados casos dependería de la actividad catalítica GEF de C3G.

La activación de las plaquetas de los ratones transgénicos, tanto por trombina como ADP, produjo una secreción con capacidad neta pro-angiogénica in vitro, según se determinó por la cuantificación de diferentes parámetros de desarrollo de la red de pseudocapilares formados por las células HUVEC. El mayor efecto pro-angiogénico de los secretomas de plaquetas transgénicas contrastaría con la mayor retención de VEGF observada en ellas. Sin embargo, se ha reportado que el efecto pro-angiogénico de la secreción producida por la activación con trombina de plaquetas humanas es principalmente independiente de VEGF (Etulain et al., 2013), lo que resalta la importancia del balance general del conjunto de factores angiogénicos en la promoción de este efecto. En este sentido, la mayor capacidad pro-angiogénica in vitro de los secretomas de plaquetas transgénicas podría estar también influenciada por los menores niveles de factores anti-angiogénicos, como TSP-1, PF4 y vWF, encontrados en estos secretomas. 


\section{Función del C3G plaquetario en la regulación de la angiogénesis in vivo y la metástasis tumoral}

La mayor capacidad pro-angiogénica de los secretomas de las plaquetas de ratones transgénicos fue confirmada mediante diferentes modelos in vivo. En el modelo de tumor heterotópico de células de carcinoma de pulmón de Lewis (carcinoma de pulmón originado en ratón), ambas líneas de ratones transgénicos presentaron una tendencia a desarrollar tumores de mayor tamaño. Además, el mayor porcentaje de muerte celular encontrado en estos tumores podría estar dado por una tasa de proliferación más elevada, que produciría la formación de necrosis en las regiones internas del tumor si la funcionalidad de la vascularización formada no es óptima, tal como es el caso de la angiogénesis tumoral (Potente et al., 2011; Weis \& Cheresh, 2011). Por otra parte, el análisis histológico del marcador de células endoteliales CD31, reveló un mayor grado de angiogénesis en los tumores de ambas líneas transgénicas de ratón, en comparación con sus respectivos controles. En el caso de los ratones TgC3G, el aumento en el número de vasos podría estar dado por un incremento en el sprouting de las células endoteliales, mientras que el mayor grosor de los vasos encontrados en los tumores de ratones TgC3G $\Delta$ Cat podría deberse a una formación más eficiente del lumen de los vasos formados, así como de su estabilización y maduración (Adams \& Alitalo, 2007; Potente et al., 2011). Paralelamente, se confirmó el incremento en el desarrollo de tumores en ratones $\mathrm{TgC3G}$, al utilizar un modelo de tumor heterotópico de células de melanoma de ratón $\mathrm{B} 16 \mathrm{~F} 10$. En este caso, el desarrollo de los tumores de los ratones transgénicos también se correlaciona con un mayor grado de angiogénesis encontrada en ellos. Este modelo no se pudo evaluar en ratones de las líneas WtC3G $\triangle$ Cat ni TgC3G $\Delta$ Cat, debido a que el fondo genético de estos ratones es Agouti y no Black, tal como es el caso de las líneas WtC3G y TgC3G, y de la propia línea de células B16F10 (Green, 1968).

En los modelos tumorales evaluados, la producción de secretomas proangiogénicos por parte de las plaquetas transgénicas activadas en la zona del tumor podría explicar en gran medida el mayor desarrollo tumoral observado. De hecho, se conoce que ratones deficientes en TSP-1 muestran una revascularización acelerada en un modelo de isquemia de extremidad posterior (Kopp et al., 2006), en concordancia con los menores niveles de este factor que fueron detectados en dichos secretomas, y con su conocido rol negativo en tumorigénesis (Feng et al., 2011; Zaslavsky et al., 2010). No obstante, el desarrollo tumoral es un proceso que involucra numerosas variables y que puede depender de otros elementos que se conoce que lo promueven, tales como el 
incremento en el reclutamiento de plaquetas y su activación en el tumor, el aumento en la secreción de factores de crecimiento con efecto pro-tumorigénico directo, o inclusive la generación de un mayor número de mediadores inflamatorios por parte de las plaquetas activadas (Hanahan and Weinberg, 2011; Weis and Cheresh, 2011; Kuznetsov et al., 2012; Li, 2016). Por otra parte, el mayor grado de angiogénesis encontrado en los ratones transgénicos puede estar también influenciado por la participación de las plaquetas en el incremento de la vasculogénesis dependiente del reclutamiento de progenitores de células endoteliales, ya que se ha reportado que el tratamiento de ratones con aspirina produce una disminución del número de células de la médula ósea que son reclutadas a tumores en desarrollo (Kuznetsov et al., 2012).

Estudios realizados en diferentes modelos in vitro e in vivo, han demostrado la existencia de una correlación entre la capacidad que tienen las células tumorales de inducir la agregación plaquetaria, y su potencial metastásico in vivo (Karpatkin et al., 1988; Nierodzik and Karpatkin, 2006; Gay \& Felding-Habermann, 2011). En este sentido, el incremento en el número de metástasis en pulmón que fueron observadas en los ratones $\mathrm{TgC} 3 \mathrm{G}$, con respecto a ratones control, se correlaciona con estudios previos de nuestro grupo que demuestran un incremento en la activación y agregación plaquetaria, tanto in vitro como in vivo, para este genotipo transgénico (Gutiérrez-Herrero et al., 2012). Asimismo, el mayor número de metástasis encontradas en los pulmones de ratones TgC3G concuerda con el reclutamiento y la activación (expresión de P-selectina) de un mayor número de plaquetas, que fueron observados en los tumores inducidos por células B16F10 en ratones de este genotipo.

En el contexto fisiológico del modelo de angiogénesis por inducción con oxazolona, se encontró que el C3G plaquetario no parece influir en el desarrollo de la inflamación, aunque se encontraron los mismos efectos que en los modelos tumorales, con respecto al incremento de la angiogénesis en ambas líneas de ratones transgénicos. Así, en este modelo, también se encontró un aumento en el número de vasos en las orejas de ratones $\mathrm{TgC} 3 \mathrm{G}$, con respecto a los ratones $\mathrm{WtC} 3 \mathrm{G}$, mientras que las orejas de ratones TgC3G $\Delta$ Cat mostraron vasos de mayor grosor que los encontrados en los respectivos ratones control, lo cual apoya los resultados previos.

En los modelos experimentales previos, las plaquetas TgC3G y TgC3G $\Delta$ Cat mostraron efectos similares en la angiogénesis in vivo. Sin embargo, en el modelo experimental de la inyección subcutánea de botones de Matrigel, sólo en ratones TgC3G $\Delta$ Cat se observó una tendencia pro-angiogénica incrementada con respecto a 
ratones control. Las diferencias detectadas en la secreción de factores específicos como la endostatina, tras la activación con trombina, podrían contribuir a la inducción de una respuesta angiogénica diferencial en contextos fisiológicos determinados, tales como la infiltración de células endoteliales en los botones de Matrigel. En este sentido, niveles elevados de endostatina se han relacionado con diferentes condiciones patológicas, como la enfermedad coronaria, la calcificación de la válvula aortica y la diabetes mellitus (Mitsuma et al., 2007; Sodha et al., 2009; Sponder et al., 2015; 2016). Por otra parte, el modelo experimental se basa en la inyección de botones de Matrigel enriquecidos con bFGF, por lo que la presencia de este factor podría enmascarar o distorsionar los efectos producidos por el conjunto de factores angiogénicos contenidos en la secreción plaquetaria liberada en la zona. Adicionalmente, diferentes estudios han descrito un papel importante del sistema del plasminógeno (plg) en la angiogénesis inducida por Matrigel, encontrándose que explantes de ratones plg -/- que fueron cultivados sobre esta matriz mostraron una ausencia de angiogénesis (Brodsky et al., 2001; Oh et al., 2003). En este sentido, los niveles de plasminógeno encontrados en el secretoma de ratones TgC3G producido por la activación con trombina, fueron mucho menores que los de ratones control, lo cual también podría explicar la débil respuesta angiogénica de ratones de este genotipo a los botones de Matrigel. En contraste, el secretoma de ratones TgC $3 G \Delta C a t$ producido por la activación con trombina, presentó niveles de plasminógeno similares a los encontrados en ratones control. Este hecho, en conjunto con una disminución más pronunciada de factores anti-angiogénicos en el secretoma, podría explicar el incremento en la angiogénesis observada en los botones de Matrigel de ratones TgC $3 G \Delta$ Cat. Por último, se ha descrito que las plaquetas son capaces de la captar y almacenar proteínas circulantes que regulan la angiogénesis (Bambace \& Holmes, 2011; Feng et al., 2011), incluyendo el VEGF contenido en botones de Matrigel (Klement et al., 2009). Por esta razón, otros mecanismos, como la captación diferencial de bFGF de los botones de Matrigel por las plaquetas $\operatorname{TgC3G}$ también podrían contribuir a las diferencias observadas en la angiogénesis.

En conjunto, estos resultados apoyan la función reguladora del C3G plaquetario en la liberación de factores angiogénicos, a través de mecanismos dependientes e independientes de su actividad GEF, en contraste con su función en la activación de la integrina allbß3 y la agregación plaquetaria que dependen de la activación de Rap1b (Gutiérrez-Herrero et al., 2012). En concordancia con esta hipótesis, se ha descrito que la secreción de VEGF y endostatina puede ocurrir independientemente de la respuesta de 
agregación plaquetaria (Etulain et al., 2013). Adicionalmente, se conoce que la secreción de los gránulos- $\alpha$, pero no la secreción de gránulos densos ni la agregación plaquetaria, se encuentra involucrada en la angiogénesis mediada por plaquetas (Feng et al., 2011).

\section{Mecanismos moleculares involucrados en la regulación mediada por C3G de la secreción plaquetaria de factores angiogénicos}

Previamente, estudios realizados en plaquetas humanas han descrito la presencia de una subpoblación de gránulos- $\alpha$ recubiertos por la v-SNARE VAMP7, que contienen factores pro-angiogénicos como VEGF, mientras que los factores anti-angiogénicos son contenidos en una subpoblación de gránulos- $\alpha$ recubiertos por VAMP-8 (Peters et al., 2012). Los datos del presente trabajo muestran la co-localización entre C3G y VEGF en plaquetas activadas, lo que llevó al estudio de una posible interacción entre C3G y VAMP7 como base molecular para explicar este fenómeno, así como la retención del VEGF tras la activación. Además, conociendo que VEGF y bFGF parecen almacenarse en la misma subpoblación de gránulos- $\alpha$ (Italiano et al., 2008), la interacción entre C3G y VAMP7 también podría explicar la inhibición de la liberación de este factor proangiogénico. Tal como se muestra en los resultados, C3G y VAMP7 parecen interaccionar en las plaquetas en reposo y activadas de ambos genotipos transgénicos. Asimismo, esta interacción fue observada en células K562 con sobreexpresión de C3G, en las cuales el incremento en los niveles de esta proteína induce características megacariocíticas (Ortiz, 2017). La interacción entre C3G y VAMP7 también fue detectada en experimentos in vitro, los cuales sugieren que C3G puede interaccionar, tanto con el dominio longina como con el dominio SNARE de VAMP7, de manera similar a lo descrito con la proteína VARP (Burgo et al., 2009).

La proteína VARP es un GEF de la GTPasa Rab21 (Zhang et al., 2006), y se conoce que regula la exocitosis de los gránulos- $\alpha$ plaquetarios mediante su interacción con VAMP7 y ARP2/3 (Koseoglu et al., 2015). Tras la activación plaquetaria, VARP se libera de su unión a VAMP7, lo que permite la interacción de esta v-SNARE con las t-SNAREs de la membrana extracelular plaquetaria (Koseoglu et al., 2015). Datos preliminares de nuestro laboratorio muestran que C3G interacciona con el dominio ID de VARP, sólo en presencia de VAMP7. Este hecho, en conjunto con los resultados de este trabajo, sugiere que la interacción entre C3G y VAMP7 podría impedir la liberación de VARP del complejo, produciendo la subsiguiente inhibición de la fusión de esta 
subpoblación de granulos- $\alpha$ a la membrana extracelular, y la liberación de los factores pro-angiogénicos que contienen. Sin embargo, la movilización de los gránulos- $\alpha$ VAMP7+ hacia la membrana extracelular durante la extensión plaquetaria no parece verse afectada, tal como sugieren nuestros resultados. Por otra parte, la retención de VARP en un complejo con C3G y VAMP7, podría limitar su actividad como GEF de Rab21, afectándose negativamente la exocitosis de otras subpoblaciones de gránulos- $\alpha$ específicas, como la que contendría a los factores anti-angiogénicos. No obstante, la secreción plaquetaria a nivel general no se encuentra afectada, ya que no se observan diferencias en los niveles de proteína liberada tras la activación, y de hecho, las plaquetas transgénicas muestran una mayor área de extensión sobre sustrato.

En estudios previos, se ha demostrado la contribución que tiene la fusión de gránulos- $\alpha$ VAMP7+ a la membrana extracelular, en la extensión plaquetaria sobre sustrato (Koseoglu et al., 2015). Sin embargo, estos estudios también demuestran que la deleción de VAMP7 no inhibe por completo la extensión, por lo que sería sólo uno de varios mecanismos posibles a través de los cuales podría ocurrir el suministro de membrana durante la extensión de la membrana extracelular plaquetaria. En este sentido, la retención de los gránulos- $\alpha$ VAMP7+ no estaría necesariamente en contradicción con los mayores niveles de extensión observados en las plaquetas transgénicas, ya que la fusión de otras subpoblaciones de gránulos-a y los gránulos densos podrían estar actuando como fuentes de suministro de membrana durante este proceso, en conjunto con el despliegue del OCS (Escolar et al., 1989; White \& Escolar, 1991). Por otra parte, estudios previos también sugieren que la extensión plaquetaria depende de la actividad de RhoA y es independiente de la activación de Rap1 (Aslan \& McCarty, 2013). Sin embargo, no es necesariamente independiente de C3G, ya que resultados preliminares de nuestro grupo muestran que tanto $C 3 G$ como $C 3 G \Delta$ Cat son fosforiladas y activadas durante la extensión plaquetaria, lo que concordaría con las mayores áreas de extensión observadas en las plaquetas de ambos genotipos transgénicos. Adicionalmente, se ha descrito extensamente la participación de C3G en los complejos de las adhesiones focales y en el remodelado del citoesqueleto (Martín-Encabo et al., 2007; Dayma \& Radha 2011; Radha et al., 2011; Maia et al., 2013; Kumar et al., 2015), lo cual constituye otra posibilidad mediante la cual C3G podría estar involucrada en la regulación positiva de la extensión plaquetaria, a través de un mecanismo independiente de su efecto sobre la secreción de subpoblaciones de gránulos- $\alpha$ específicas. 
Una de las características particulares de C3G es su capacidad para llevar a cabo numerosas funciones que son independientes de su dominio catalítico, responsable de la actividad GEF (Guerrero et al., 1998; 2004; Martín-Encabo et al., 2007; Radha et al., 2011). Dado que C3G es una proteína con diferentes dominios funcionales, el control de la secreción plaquetaria podría incluir mecanismos como interacciones proteína-proteína a través de su dominio SH3-b. Este dominio, se encuentra contenido tanto en C3G como en C3G $\Delta$ Cat, y se encontraría sobreexpresado en las plaquetas de ambas líneas de ratones transgénicos utilizadas en este estudio. Esta posibilidad es la que se encuentra resaltada en los resultados del presente trabajo en la cual la interacción, tanto de C3G como de C3G $\triangle$ Cat, con VAMP7 parece ser uno de los mecanismos moleculares responsables de la regulación de la liberación los factores pro- y anti-angiogénicos contenidos en los gránulos- $\alpha$. Además, como se ha apuntado anteriormente, estos resultados sugieren que el papel de C3G en la regulación de la secreción plaquetaria y en la angiogénesis mediada por plaquetas es independiente de la activación de Rap1, en contraste con el rol que tiene en la agregación plaquetaria, que es dependiente de Rap1b (Gutiérrez-Herrero et al., 2012).

Los resultados del presente trabajo han sido obtenidos a partir del análisis de la expresión transgénica de C3G y C3G $\Delta$ Cat en plaquetas de ratón. En estudios realizados en plaquetas humanas y de ratón, se ha detectado la expresión endógena de C3G mediante técnicas genómicas y proteómicas (Rowley et al., 2011; Burkhart et al., 2012; Zeiler et al., 2014), lo cual sugiere un papel relevante de C3G en plaquetas. Adicionalmente, resultados de nuestro laboratorio muestran que el silenciamiento de C3G, o su deleción, en las líneas celulares eritroleucémicas K562 y HEL, previene la adquisición de características megacariocíticas (Ortiz, 2017). En cualquier caso, el papel regulador que se describe para el C3G plaquetario, debe ser contrastado con análisis realizados en ratones $\mathrm{KO}$. Dicho estudio no ha sido llevado a cabo hasta la fecha, debido a la dificultad involucrada en la generación del modelo animal. En este sentido, se conoce que la deleción de C3G es letal (Ohba et al., 2001), y se ha tenido que proceder a la construcción de un modelo de ratón KO condicional para el C3G plaquetario. Próximamente, este modelo animal se encontrará disponible en nuestro laboratorio para proceder a los análisis correspondientes y corroborar el papel de C3G en la regulación de las funciones descritas.

En resumen, este trabajo proporciona evidencias, por primera vez, que sugieren que C3G está involucrado en la regulación de la secreción plaquetaria, la angiogénesis 
mediada por plaquetas y el desarrollo tumoral. Además, la función reguladora en la secreción de los gránulos- $\alpha$ parece estar influenciada por la interacción entre C3G y VAMP7 durante la activación plaquetaria. También se muestran evidencias, por primera vez, que indican una función pro-metastásica para el C3G plaquetario. En caso de confirmarse estas funciones en los análisis con ratones KO, C3G se perfilaría como una diana terapéutica potencial en el tratamiento de las metástasis tumorales, y de patologías relacionadas con la angiogénesis mediada por plaquetas, como el desarrollo tumoral. 



\section{CONGLUSIONES}



1. C3G y C3G $\Delta$ Cat modifican cualitativa y cuantitativamente la secreción plaquetaria, produciendo una disminución general de la secreción de factores antiangiogénicos, como TSP-1, PF4 y vWF, y de factores pro-angiogénicos, como VEGF y bFGF.

2. C3G promueve la liberación de endostatina por plaquetas activadas, mientras que C3G $\Delta$ Cat tiene un efecto opuesto.

3. C3G y C3G $\Delta$ Cat promueven la liberación de un secretoma plaquetario con características netas pro-angiogénicas in vitro.

4. C3G y C3G $\triangle$ Cat plaquetarios regulan positivamente el desarrollo de la angiogénesis en tumores y en orejas de ratón inflamadas.

5. C3G plaquetario favorece el reclutamiento de las plaquetas a tumores en desarrollo, y la producción de metástasis tumorales.

6. C3G $\Delta$ Cat promueve la angiogénesis en botones de Matrigel inyectados subcutáneamente en ratones.

7. La interacción de C3G y C3G $\triangle$ Cat con VAMP7 en plaquetas activadas constituye uno de los mecanismos moleculares que participan en la regulación de la secreción de factores angiogénicos por las plaquetas y en la extensión plaquetaria sobre sustrato.

8. El efecto de C3G sobre la regulación de la secreción plaquetaria es mayoritariamente independiente de su actividad GEF. 



\section{BIBLIOGRAFÍA}



Adams, R. H., and Alitalo, K. (2007). Molecular regulation of angiogenesis and lymphangiogenesis. Nat. Rev. Mol. Cell Biol. 8, 464-78.

Alberts, P., Rudge, R., Irinopoulou, T., Danglot, L., Gauthier-Rouvière, C., and Galli, T. (2006). Cdc42 and actin control polarized expression of TI-VAMP vesicles to neuronal growth cones and their fusion with the plasma membrane. Mol. Biol. Cell 17, 1194-203.

Alonso-Escolano, D., Strongin, A. Y., Chung, A. W., Deryugina, E. I., and Radomski, M. W. (2004). Membrane type-1 matrix metalloproteinase stimulates tumour cell-induced platelet aggregation: role of receptor glycoproteins. Br. J. Pharmacol. 141, 241-52.

Alsayed, Y., Uddin, S., Ahmad, S., Majchrzak, B., Druker, B. J., Fish, E. N., and Platanias, L. C. (2000). IFN-gamma activates the C3G/Rap1 signaling pathway. J. Immunol. 164, 1800-6.

Arai, A., Nosaka, Y., Kanda, E., Yamamoto, K., Miyasaka, N., and Miura, O. (2001). Rap1 is activated by erythropoietin or interleukin-3 and is involved in regulation of beta1 integrin-mediated hematopoietic cell adhesion. J. Biol. Chem. 276, 10453-62.

Arai, A., Nosaka, Y., Kohsaka, H., Miyasaka, N., and Miura, O. (1999). CrkL activates integrinmediated hematopoietic cell adhesion through the guanine nucleotide exchange factor C3G. Blood 93, 3713-22.

Aslan, J. E., and McCarty, O. J. (2013). Rho GTPases in platelet function. J. Thromb. Haemost. 11, 35-46.

Bambace, N. M., and Holmes, C. E. (2011). The platelet contribution to cancer progression. Journal of Thrombosis and Haemostasis 9, 237-249.

Bastida, E., Escolar, G., Almirall, L., and Ordinas, A. (1986). Platelet activation induced by a human neuroblastoma tumor cell line is reduced by prior administration of ticlopidine. Thromb. Haemost. 55, 333-7.

Battinelli, E., Markens, B., and Italiano, J. (2011). Release of angiogenesis regulatory proteins from platelet alpha granules: modulation of physiologic and pathologic angiogenesis. Blood 118, 1359-1369.

Becker, R. P., and Bruyn, P. P. De (1976). The transmural passage of blood cells into myeloid sinusoids and the entry of platelets into the sinusoidal circulation; a scanning electron microscopic investigation. Am. J. Anat. 145, 183-205.

Benz, P. M., Laban, H., Zink, J., Günther, L., Walter, U., Gambaryan, S., and Dib, K. (2016). Vasodilator-Stimulated Phosphoprotein (VASP)-dependent and -independent pathways regulate thrombin-induced activation of Rap1b in platelets. Cell Commun. Signal 14, 21.

Berger, G., Massé, J. M., and Cramer, E. M. (1996). Alpha-granule membrane mirrors the platelet plasma membrane and contains the glycoproteins Ib, IX, and V. Blood 87, 1385-95.

Bhuin, T., and Roy, J. K. (2014). Rab proteins: the key regulators of intracellular vesicle transport. Exp. Cell Res. 328, 1-19.

Bikfalvi, A. (2004). Recent developments in the inhibition of angiogenesis: examples from studies on platelet factor-4 and the VEGF/VEGFR system. Biochem. Pharmacol. 68, 1017-21.

Blair, P., and Flaumenhaft, R. (2009). Platelet alpha-granules: basic biology and clinical correlates. Blood Rev. 23, 177-89.

Bokoch, G. M. (1993). Biology of the Rap proteins, members of the ras superfamily of GTP-binding proteins. Biochem. J. 289 ( Pt 1), 17-24.

Bolte, S., and Cordelières, F. P. (2006). A guided tour into subcellular colocalization analysis in light microscopy. J Microsc 224, 213-32.

Boriack-Sjodin, P. A., Margarit, S. M., Bar-Sagi, D., and Kuriyan, J. (1998). The structural basis of the activation of Ras by Sos. Nature 394, 337-43. 
Borsig, L., Wong, R., Hynes, R. O., Varki, N. M., and Varki, A. (2002). Synergistic effects of L- and Pselectin in facilitating tumor metastasis can involve non-mucin ligands and implicate leukocytes as enhancers of metastasis. Proc. Natl. Acad. Sci. U.S.A. 99, 2193-8.

Bos, J. L. (1998). All in the family? New insights and questions regarding interconnectivity of Ras, Rap1 and Ral.

Bos, J., Rehmann, H., and Wittinghofer, A. (2007). GEFs and GAPs: Critical Elements in the Control of Small G Proteins. Cell 129, 865-877.

Boukerche, H., Berthier-Vergnes, O., Penin, F., Tabone, E., Lizard, G., Bailly, M., and McGregor, J. L. (1994). Human melanoma cell lines differ in their capacity to release ADP and aggregate platelets. Br. J. Haematol. 87, 763-72.

Bradford, M. M. (1976). A rapid and sensitive method for the quantitation of microgram quantities of protein utilizing the principle of protein-dye binding. Anal. Biochem. 72, 248-54.

Brass, L.F., Stalker, T.J., Zhu, L., \& Woulfe, S. (2007). Signal Transduction During Platelet Plug Formation. En A.D. Michelson, Platelets (págs 319-346). Elsevier.

Braun, V., Fraisier, V., Raposo, G., Hurbain, I., Sibarita, J.-B. B., Chavrier, P., Galli, T., and Niedergang, F. (2004). TI-VAMP/VAMP7 is required for optimal phagocytosis of opsonised particles in macrophages. EMBO J. 23, 4166-76.

Bretscher, M. S. (1996). Moving membrane up to the front of migrating cells. Cell 85, 465-7.

Brodsky, S., Chen, J., Lee, A., Akassoglou, K., Norman, J., and Goligorsky, M. S. (2001). Plasmindependent and -independent effects of plasminogen activators and inhibitor-1 on ex vivo angiogenesis. Am. J. Physiol. Heart Circ. Physiol. 281, H1784-92.

Broos, K., Feys, H., Meyer, S., Vanhoorelbeke, K., and Deckmyn, H. (2011). Platelets at work in primary hemostasis. Blood Rev 25, 155-167.

Buensuceso, C. S., and O'Toole, T. E. (2000). The association of CRKII with C3G can be regulated by integrins and defines a novel means to regulate the mitogen-activated protein kinases. $J$. Biol. Chem. 275, 13118-25.

Burgo, A., Sotirakis, E., Simmler, M.-C. C., Verraes, A., Chamot, C., Simpson, J. C., Lanzetti, L., Proux-Gillardeaux, V., and Galli, T. (2009). Role of Varp, a Rab21 exchange factor and TIVAMP/VAMP7 partner, in neurite growth. EMBO Rep. 10, 1117-24.

Burkhart, J. M., Vaudel, M., Gambaryan, S., Radau, S., Walter, U., Martens, L., Geiger, J., Sickmann, A., and Zahedi, R. P. P. (2012). The first comprehensive and quantitative analysis of human platelet protein composition allows the comparative analysis of structural and functional pathways. Blood 120, e73-82.

Camerer, E., Qazi, A. A., Duong, D. N., Cornelissen, I., Advincula, R., and Coughlin, S. R. (2004). Platelets, protease-activated receptors, and fibrinogen in hematogenous metastasis. Blood 104, 397-401.

Chatterjee, M., Huang, Z., Zhang, W., Jiang, L., Hultenby, K., Zhu, L., Hu, H., Nilsson, G. P., and Li, N. (2011). Distinct platelet packaging, release, and surface expression of proangiogenic and antiangiogenic factors on different platelet stimuli. Blood 117, 3907-11.

Chevallet, M., Luche, S., and Rabilloud, T. (2006). Silver staining of proteins in polyacrylamide gels. Nat Protoc 1, 1852-8.

Chiang, S. H., Baumann, C. A., Kanzaki, M., Thurmond, D. C., Watson, R. T., Neudauer, C. L., Macara, I. G., Pessin, J. E., and Saltiel, A. R. (2001). Insulin-stimulated GLUT4 translocation requires the CAP-dependent activation of TC10. Nature 410, 944-8.

Chiariello, M., Marinissen, M. J., and Gutkind, J. S. (2000). Multiple mitogen-activated protein kinase signaling pathways connect the cot oncoprotein to the c-jun promoter and to cellular transformation. Mol. Cell. Biol. 20, 1747-58. 
Chrzanowska-Wodnicka, M., Smyth, S., Schoenwaelder, S., Fischer, T., and White, G. (2005). Rap1b is required for normal platelet function and hemostasis in mice. J Clin Invest 115, 680-687.

Cifuni, S., Wagner, D., and Bergmeier, W. (2008). CalDAG-GEFI and protein kinase C represent alternative pathways leading to activation of integrin $\alpha \mathrm{llb} \beta 3$ in platelets. Blood 112, 16961703.

Clapp, C., Thebault, S., Jeziorski, M. C., and Martínez De La Escalera, G. (2009). Peptide hormone regulation of angiogenesis. Physiol. Rev. 89, 1177-215.

Clemetson, K. (2012). Platelets and Primary Haemostasis. Thromb Res 129, 220-224.

Coppinger, J. A., Cagney, G., Toomey, S., Kislinger, T., Belton, O., McRedmond, J. P., Cahill, D. J., Emili, A., Fitzgerald, D. J., and Maguire, P. B. (2004). Characterization of the proteins released from activated platelets leads to localization of novel platelet proteins in human atherosclerotic lesions. Blood 103, 2096-104.

Coppinger, J., O'Connor, R., Wynne, K., Flanagan, M., Sullivan, M., Maguire, P., Fitzgerald, D., and Cagney, G. (2007). Moderation of the platelet releasate response by aspirin. Blood 109, 4786-4792.

Coughlin, S. (2000). Thrombin signalling and protease-activated receptors. Nature 407, 258-264.

Crittenden, J. R., Bergmeier, W., Zhang, Y., Piffath, C. L., Liang, Y., Wagner, D. D., Housman, D. E., and Graybiel, A. M. (2004). CalDAG-GEFI integrates signaling for platelet aggregation and thrombus formation. Nat. Med. 10, 982-6.

Dangelmaier, C. A., and Holmsen, H. (1980). Determination of acid hydrolases in human platelets. Anal. Biochem. 104, 182-91.

Davì, G., and Patrono, C. (2007). Platelet activation and atherothrombosis. N. Engl. J. Med. 357, 2482-94.

Dayma, K., \& Radha, V. (2016). C3G. En S. Choi, Encyclopedia of Signaling Molecules (págs. 1-10). Springer Science+Business Media LLC. DOI 10.1007/978-1-4614-6438-9_101544-1.

DeCicco-Skinner, K. L., Henry, G. H., Cataisson, C., Tabib, T., Gwilliam, J. C., Watson, N. J., Bullwinkle, E. M., Falkenburg, L., O’Neill, R. C., Morin, A., et al. (2014). Endothelial cell tube formation assay for the in vitro study of angiogenesis. J Vis Exp, e51312.

DeNardo, D. G., Andreu, P., and Coussens, L. M. (2010). Interactions between lymphocytes and myeloid cells regulate pro- versus anti-tumor immunity. Cancer Metastasis Rev. 29, 309-16.

Dent, J., Kato, K., Peng, X.-R. R., Martinez, C., Cattaneo, M., Poujol, C., Nurden, P., Nurden, A., Trimble, W. S., and Ware, J. (2002). A prototypic platelet septin and its participation in secretion. Proc. Natl. Acad. Sci. U.S.A. 99, 3064-9.

Deryugina, E. I., and Quigley, J. P. (2006). Matrix metalloproteinases and tumor metastasis. Cancer Metastasis Rev. 25, 9-34.

Dunn, K. W., Kamocka, M. M., and McDonald, J. H. (2011). A practical guide to evaluating colocalization in biological microscopy. Am. J. Physiol., Cell Physiol. 300, C723-42.

Erpenbeck, L., Nieswandt, B., Schön, M., Pozgajova, M., and Schön, M. P. (2010). Inhibition of platelet GPIb alpha and promotion of melanoma metastasis. J. Invest. Dermatol. 130, 57686.

Erpenbeck, L., and Schön, M. P. (2010). Deadly allies: the fatal interplay between platelets and metastasizing cancer cells. Blood 115, 3427-36.

Escolar, G., Leistikow, E., and White, J. G. (1989). The fate of the open canalicular system in surface and suspension-activated platelets. Blood 74, 1983-8.

Estrov, Z., Talpaz, M., Mavligit, G., Pazdur, R., Harris, D., Greenberg, S. M., and Kurzrock, R. (1995). Elevated plasma thrombopoietic activity in patients with metastatic cancer-related thrombocytosis. Am. J. Med. 98, 551-8. 
Eto, K., Murphy, R., Kerrigan, S. W., Bertoni, A., Stuhlmann, H., Nakano, T., Leavitt, A. D., and Shattil, S. J. (2002). Megakaryocytes derived from embryonic stem cells implicate CalDAGGEFI in integrin signaling. Proc. Natl. Acad. Sci. U.S.A. 99, 12819-24.

Etulain, J., Fondevila, C., Negrotto, S., and Schattner, M. (2013). Platelet-mediated angiogenesis is independent of VEGF and fully inhibited by aspirin. Brit J Pharmacol 170, 255-265.

Fader, C. M., Aguilera, M. O., and Colombo, M. I. I. (2012). ATP is released from autophagic vesicles to the extracellular space in a VAMP7-dependent manner. Autophagy 8, 1741-56.

Feng, W., Madajka, M., Kerr, B. A., Mahabeleshwar, G. H., Whiteheart, S. W., and Byzova, T. V. (2011). A novel role for platelet secretion in angiogenesis: mediating bone marrow-derived cell mobilization and homing. Blood 117, 3893-902.

Fitch-Tewfik, J. L., and Flaumenhaft, R. (2013). Platelet granule exocytosis: a comparison with chromaffin cells. Front Endocrinol (Lausanne) 4, 77.

Fitzgerald, M. L., and Reed, G. L. (1999). Rab6 is phosphorylated in thrombin-activated platelets by a protein kinase C-dependent mechanism: effects on GTP/GDP binding and cellular distribution. Biochem. J. 342 ( Pt 2), 353-60.

Flaumenhaft, R. (2003). Molecular basis of platelet granule secretion. Arteriosclerosis Thrombosis Vasc Biology 23, 1152-60.

Flaumenhaft, R., Croce, K., Chen, E., Furie, B., and Furie, B. C. (1999). Proteins of the exocytotic core complex mediate platelet alpha-granule secretion. Roles of vesicle-associated membrane protein, SNAP-23, and syntaxin 4. J. Biol. Chem. 274, 2492-501.

Folkman, J. (2002). Role of angiogenesis in tumor growth and metastasis. Semin. Oncol. 29, 15-8.

Frojmovic, M. M., and Milton, J. G. (1982). Human platelet size, shape, and related functions in health and disease. Physiol. Rev. 62, 185-261.

Fukami, M. H. (1992). Isolation of dense granules from human platelets. Meth. Enzymol. 215, 3642.

Gasic, G. J., Gasic, T. B., and Stewart, C. C. (1968). Antimetastatic effects associated with platelet reduction. Proc. Natl. Acad. Sci. U.S.A. 61, 46-52.

Gay, L. J., and Felding-Habermann, B. (2011). Contribution of platelets to tumour metastasis. Nat. Rev. Cancer 11, 123-34.

Gerrard, J., \& White, J. G. (1980). The cell biology of platelets. En G. Weissman, Handbook of inflammation: The cell biology of inflammation (págs. 83-143). New York: Elsevier/North Holland.

Gómez-Hernández, M. (2014). Caracterización de la organización estructural del factor de intercambio de nucleótido de guanina C3G. Tesis Doctoral. Universidad de Salamanca. Salamanca.

Gotoh, T., Hattori, S., Nakamura, S., Kitayama, H., Noda, M., Takai, Y., Kaibuchi, K., Matsui, H., Hatase, O., and Takahashi, H. (1995). Identification of Rap1 as a target for the Crk SH3 domain-binding guanine nucleotide-releasing factor C3G. Mol. Cell. Biol. 15, 6746-53.

Gotoh, T., Niino, Y., Tokuda, M., Hatase, O., Nakamura, S., Matsuda, M., and Hattori, S. (1997). Activation of R-Ras by Ras-guanine nucleotide-releasing factor. J. Biol. Chem. 272, 18602-7.

Graham, G. J., Ren, Q., Dilks, J. R., Blair, P., Whiteheart, S. W., and Flaumenhaft, R. (2009). Endobrevin/VAMP-8-dependent dense granule release mediates thrombus formation in vivo. Blood 114, 1083-90.

Green, E.L. (1968). Handbook on Genetically Standardized Jax Mice. 2nd ed. Bar Harbor, Maine: The Jackson Laboratory.

Grivennikov, S. I., Greten, F. R., and Karin, M. (2010). Immunity, inflammation, and cancer. Cell 140, 883-99. 
Grunewald, M., Avraham, I., Dor, Y., Bachar-Lustig, E., Itin, A., Jung, S., Yung, S., Chimenti, S., Landsman, L., Abramovitch, R., et al. (2006). VEGF-induced adult neovascularization: recruitment, retention, and role of accessory cells. Cell 124, 175-89.

Guerrero, C., Fernandez-Medarde, A., Rojas, J. M., Font de Mora, J., Esteban, L. M., and Santos, E. (1998). Transformation suppressor activity of C3G is independent of its CDC25-homology domain. Oncogene 16, 613-24.

Guerrero, C., Martín-Encabo, S., Fernández-Medarde, A., and Santos, E. (2004). C3G-mediated suppression of oncogene-induced focus formation in fibroblasts involves inhibition of ERK activation, cyclin $\mathrm{A}$ expression and alterations of anchorage-independent growth. Oncogene 23, 4885-93.

Gutiérrez-Berzal, J., Castellano, E., Martín-Encabo, S., Gutiérrez-Cianca, N., Hernández, J. M. M., Santos, E., and Guerrero, C. (2006). Characterization of p87C3G, a novel, truncated C3G isoform that is overexpressed in chronic myeloid leukemia and interacts with Bcr-Abl. Exp. Cell Res. 312, 938-48.

Gutiérrez-Herrero, S., Maia, V., Gutiérrez-Berzal, J., Calzada, N., Sanz, M., González-Manchón, C., Pericacho, M., Ortiz-Rivero, S., González-Porras, J. R. R., Arechederra, M., et al. (2012). C3G transgenic mouse models with specific expression in platelets reveal a new role for C3G in platelet clotting through its GEF activity. Biochim. Biophys. Acta 1823, 1366-77.

Hanahan, D., and Weinberg, R. A. (2011). Hallmarks of cancer: the next generation. Cell 144, 64674.

Harburger, D. S., Bouaouina, M., and Calderwood, D. A. (2009). Kindlin-1 and -2 directly bind the Cterminal region of beta integrin cytoplasmic tails and exert integrin-specific activation effects. J. Biol. Chem. 284, 11485-97.

Harker, L. A. (1977). The kinetics of platelet production and destruction in man. Clin Haematol 6, 671-93.

Hawas, R. Al, Ren, Q., Ye, S., Karim, Z. A., Filipovich, A. H., and Whiteheart, S. W. (2012). Munc18b/STXBP2 is required for platelet secretion. Blood 120, 2493-500.

Hogan, C., Serpente, N., Cogram, P., Hosking, C. R., Bialucha, C. U., Feller, S. M., Braga, V. M. M., Birchmeier, W., and Fujita, Y. (2004). Rap1 regulates the formation of E-cadherin-based cellcell contacts. Mol. Cell. Biol. 24, 6690-700.

Houng, A., Polgar, J., and Reed, G. L. (2003). Munc18-syntaxin complexes and exocytosis in human platelets. J. Biol. Chem. 278, 19627-33.

Hundelshausen, P. von, and Weber, C. (2007). Platelets as immune cells: bridging inflammation and cardiovascular disease. Circ. Res. 100, 27-40.

Ichiba, T., Hashimoto, Y., Nakaya, M., Kuraishi, Y., Tanaka, S., Kurata, T., Mochizuki, N., and Matsuda, M. (1999). Activation of C3G guanine nucleotide exchange factor for Rap1 by phosphorylation of tyrosine 504. J. Biol. Chem. 274, 14376-81.

Ikeda, M., Furukawa, H., Imamura, H., Shimizu, J., Ishida, H., Masutani, S., Tatsuta, M., and Satomi, T. (2002). Poor prognosis associated with thrombocytosis in patients with gastric cancer. Ann. Surg. Oncol. 9, 287-91.

Italiano, J., Richardson, J., Patel-Hett, S., Battinelli, E., Zaslavsky, A., Short, S., Ryeom, S., Folkman, J., and Klement, G. (2008). Angiogenesis is regulated by a novel mechanism: pro- and antiangiogenic proteins are organized into separate platelet $\alpha$ granules and differentially released. Blood 111, 1227-1233.

Jain, S., Harris, J., and Ware, J. (2010). Platelets: linking hemostasis and cancer. Arteriosclerosis Thrombosis Vasc Biology 30, 2362-7. 
Jiménez, B., Volpert, O. V., Crawford, S. E., Febbraio, M., Silverstein, R. L., and Bouck, N. (2000). Signals leading to apoptosis-dependent inhibition of neovascularization by thrombospondin1. Nat. Med. 6, 41-8.

Jong, J., and Dekker, L. (2010). Platelets and Cardiac Arrhythmia. Front Physiology 1.

Jong, R. de, Wijk, A. van, Heisterkamp, N., and Groffen, J. (1998). C3G is tyrosine-phosphorylated after integrin-mediated cell adhesion in normal but not in $\mathrm{Bcr} / \mathrm{Abl}$ expressing cells. Oncogene 17, 2805-10.

Jonnalagadda, D., Izu, L. T., and Whiteheart, S. W. (2012). Platelet secretion is kinetically heterogeneous in an agonist-responsive manner. Blood 120, 5209-16.

Kakkar, A. K., DeRuvo, N., Chinswangwatanakul, V., Tebbutt, S., and Williamson, R. C. (1995). Extrinsic-pathway activation in cancer with high factor VIla and tissue factor. Lancet 346, 1004-5.

Kamykowski, J., Carlton, P., Sehgal, S., and Storrie, B. (2011). Quantitative immunofluorescence mapping reveals little functional coclustering of proteins within platelet $\alpha$-granules. Blood $118,1370-3$.

Karniguian, A., Zahraoui, A., and Tavitian, A. (1993). Identification of small GTP-binding rab proteins in human platelets: thrombin-induced phosphorylation of rab3B, rab6, and rab8 proteins. Proc. Natl. Acad. Sci. U.S.A. 90, 7647-51.

Karpatkin, S., Pearlstein, E., Ambrogio, C., and Coller, B. S. (1988). Role of adhesive proteins in platelet tumor interaction in vitro and metastasis formation in vivo. J. Clin. Invest. 81, 10129.

Kaser, A., Brandacher, G., Steurer, W., Kaser, S., Offner, F. A., Zoller, H., Theurl, I., Widder, W., Molnar, C., Ludwiczek, O., et al. (2001). Interleukin-6 stimulates thrombopoiesis through thrombopoietin: role in inflammatory thrombocytosis. Blood 98, 2720-5.

Khorana, A. A. (2003). Malignancy, thrombosis and Trousseau: the case for an eponym. J. Thromb. Haemost. 1, 2463-5.

Khorana, A. A., and Connolly, G. C. (2009). Assessing risk of venous thromboembolism in the patient with cancer. J. Clin. Oncol. 27, 4839-47.

Kim, Y. J., Borsig, L., Han, H. L., Varki, N. M., and Varki, A. (1999). Distinct selectin ligands on colon carcinoma mucins can mediate pathological interactions among platelets, leukocytes, and endothelium. Am. J. Pathol. 155, 461-72.

Kim, Y. J., Borsig, L., Varki, N. M., and Varki, A. (1998). P-selectin deficiency attenuates tumor growth and metastasis. Proc. Natl. Acad. Sci. U.S.A. 95, 9325-30.

Kirsch, K. H., Georgescu, M. M., and Hanafusa, H. (1998). Direct binding of p130(Cas) to the guanine nucleotide exchange factor C3G. J. Biol. Chem. 273, 25673-9.

Kisucka, J., Butterfield, C. E., Duda, D. G., Eichenberger, S. C., Saffaripour, S., Ware, J., Ruggeri, Z. M., Jain, R. K., Folkman, J., and Wagner, D. D. (2006). Platelets and platelet adhesion support angiogenesis while preventing excessive hemorrhage. Proc. Natl. Acad. Sci. U.S.A. 103, 85560.

Klement, G. L., Yip, T.-T. T., Cassiola, F., Kikuchi, L., Cervi, D., Podust, V., Italiano, J. E., Wheatley, E., Abou-Slaybi, A., Bender, E., et al. (2009). Platelets actively sequester angiogenesis regulators. Blood 113, 2835-42.

Klinz, F. J., Seifert, R., Schwaner, I., Gausepohl, H., Frank, R., and Schultz, G. (1992). Generation of specific antibodies against the rap1A, rap1B and rap2 small GTP-binding proteins. Analysis of rap and ras proteins in membranes from mammalian cells. Eur. J. Biochem. 207, 207-13.

Knudsen, B. S., Feller, S. M., and Hanafusa, H. (1994). Four proline-rich sequences of the guaninenucleotide exchange factor C3G bind with unique specificity to the first Src homology 3 domain of Crk. J. Biol. Chem. 269, 32781-7. 
Kopp, H.-G. G., Hooper, A. T., Broekman, M. J., Avecilla, S. T., Petit, I., Luo, M., Milde, T., Ramos, C. A., Zhang, F., Kopp, T., et al. (2006). Thrombospondins deployed by thrombopoietic cells determine angiogenic switch and extent of revascularization. J. Clin. Invest. 116, 3277-91.

Kopp, H.-G. G., Placke, T., and Salih, H. R. (2009). Platelet-derived transforming growth factor-beta down-regulates NKG2D thereby inhibiting natural killer cell antitumor reactivity. Cancer Res. 69, 7775-83.

Koseoglu, S., and Flaumenhaft, R. (2013). Advances in platelet granule biology. Curr. Opin. Hematol. 20, 464-71.

Koseoglu, S., Peters, C. G., Fitch-Tewfik, J. L., Aisiku, O., Danglot, L., Galli, T., and Flaumenhaft, R. (2015). VAMP-7 links granule exocytosis to actin reorganization during platelet activation. Blood 126, 651-60.

Kumar, S. K., Ramadhas, A, Nayak, SC, Kaniyappan, S, Dayma, K, and Radha, V (2015). C3G (RapGEF1), a regulator of actin dynamics promotes survival and myogenic differentiation of mouse mesenchymal cells. Biochimica et Biophysica Acta (BBA)-Molecular Cell Research 1853, 2629-2639. Available at: http://www.sciencedirect.com/science/article/pii/S0167488915002050.

Kuznetsov, H., Marsh, T., Markens, B., Castaño, Z., Greene-Colozzi, A., Hay, S., Brown, V., Richardson, A., Signoretti, S., Battinelli, E., et al. (2012a). Identification of luminal breast cancers that establish a tumor-supportive macroenvironment defined by proangiogenic platelets and bone marrow-derived cells. Cancer Discov 2, 1150-65.

Kuznetsov, H. S., Marsh, T., Markens, B. A., Castaño, Z., Greene-Colozzi, A., Hay, S. A., Brown, V. E., Richardson, A. L., Signoretti, S., Battinelli, E. M., et al. (2012b). Identification of luminal breast cancers that establish a tumor-supportive macroenvironment defined by proangiogenic platelets and bone marrow-derived cells. Cancer Discov 2, 1150-65.

Käll, L., Canterbury, J. D., Weston, J., Noble, W. S., and MacCoss, M. J. (2007). Semi-supervised learning for peptide identification from shotgun proteomics datasets. Nat. Methods 4, 9235.

Labelle, M., Begum, S., and Hynes, R. O. (2011). Direct signaling between platelets and cancer cells induces an epithelial-mesenchymal-like transition and promotes metastasis. Cancer Cell 20, 576-90.

Lafuente, E. M., Puijenbroek, A. A. A. van, Krause, M., Carman, C. V., Freeman, G. J., Berezovskaya, A., Constantine, E., Springer, T. A., Gertler, F. B., and Boussiotis, V. A. (2004). RIAM, an Ena/VASP and Profilin ligand, interacts with Rap1-GTP and mediates Rap1-induced adhesion. Dev. Cell 7, 585-95.

Lai, K. C., and Flaumenhaft, R. (2003). SNARE protein degradation upon platelet activation: calpain cleaves SNAP-23. J. Cell. Physiol. 194, 206-14.

Lawler, J. (2002). Thrombospondin-1 as an endogenous inhibitor of angiogenesis and tumor growth. J Cell Mol Med 6, 1-12.

Lemons, P. P., Chen, D., and Whiteheart, S. W. (2000). Molecular mechanisms of platelet exocytosis: requirements for alpha-granule release. Biochem. Biophys. Res. Commun. 267, 875-80.

Leslie, M. (2010). Cell biology. Beyond clotting: the powers of platelets. Science 328, 562-4.

Li, N. (2016). Platelets in cancer metastasis: To help the "villain" to do evil. Int. J. Cancer 138, 2078-87.

Li, Z., Delaney, M. K., O'Brien, K. A., and Du, X. (2010a). Signaling during platelet adhesion and activation. Arteriosclerosis, thrombosis, and vascular biology 30, 2341-9. Available at: http://www.ncbi.nlm.nih.gov/pubmed/21071698. 
Li, Z., Delaney, M. K., O'Brien, K. A., and Du, X. (2010b). Signaling during platelet adhesion and activation. Arterioscler. Thromb. Vasc. Biol. 30, 2341-9.

Ling, L., Zhu, T., and Lobie, P. E. (2003). Src-Crkll-C3G-dependent activation of Rap1 switches growth hormone-stimulated p44/42 MAP kinase and JNK/SAPK activities. J. Biol. Chem. 278, 27301-11.

Liu, Y., Luo, X., Hu, H., Wang, R., Sun, Y., Zeng, R., and Chen, H. (2012). Integrative Proteomics and Tissue Microarray Profiling Indicate the Association between Overexpressed Serum Proteins and Non-Small Cell Lung Cancer. Plos One 7.

Lyden, D., Hattori, K., Dias, S., Costa, C., Blaikie, P., Butros, L., Chadburn, A., Heissig, B., Marks, W., Witte, L., et al. (2001). Impaired recruitment of bone-marrow-derived endothelial and hematopoietic precursor cells blocks tumor angiogenesis and growth. Nat. Med. 7, 1194201.

Läubli, H., and Borsig, L. (2010). Selectins promote tumor metastasis. Semin. Cancer Biol. 20, 16977.

Maia, V., Ortiz-Rivero, S., Sanz, M., Gutierrez-Berzal, J., Alvarez-Fernández, I., Gutierrez-Herrero, S., Pereda, J. M. de, Porras, A., and Guerrero, C. (2013). C3G forms complexes with Bcr-Abl and p38a MAPK at the focal adhesions in chronic myeloid leukemia cells: implication in the regulation of leukemic cell adhesion. Cell Commun. Signal 11, 9.

Malik, A. B. (1983). Pulmonary microembolism. Physiol. Rev. 63, 1114-207.

Martinez-Arca, S., Alberts, P., Zahraoui, A., Louvard, D., and Galli, T. (2000). Role of tetanus neurotoxin insensitive vesicle-associated membrane protein (TI-VAMP) in vesicular transport mediating neurite outgrowth. J. Cell Biol. 149, 889-900.

Martinez-Arca, S., Coco, S., Mainguy, G., Schenk, U., Alberts, P., Bouillé, P., Mezzina, M., Prochiantz, A., Matteoli, M., Louvard, D., et al. (2001). A common exocytotic mechanism mediates axonal and dendritic outgrowth. J. Neurosci. 21, 3830-8.

Martín-Encabo, S., Santos, E., and Guerrero, C. (2007). C3G mediated suppression of malignant transformation involves activation of PP2A phosphatases at the subcortical actin cytoskeleton. Exp. Cell Res. 313, 3881-91.

Massberg, S., Konrad, I., Schürzinger, K., Lorenz, M., Schneider, S., ZohInhoefer, D., Hoppe, K., Schiemann, M., Kennerknecht, E., Sauer, S., et al. (2006). Platelets secrete stromal cellderived factor 1alpha and recruit bone marrow-derived progenitor cells to arterial thrombi in vivo. J. Exp. Med. 203, 1221-33.

Maynard, D. M., Heijnen, H. F., Horne, M. K., White, J. G., and Gahl, W. A. (2007). Proteomic analysis of platelet alpha-granules using mass spectrometry. J. Thromb. Haemost. 5, 194555.

McCarty, O. J., Mousa, S. A., Bray, P. F., and Konstantopoulos, K. (2000). Immobilized platelets support human colon carcinoma cell tethering, rolling, and firm adhesion under dynamic flow conditions. Blood 96, 1789-97.

McNicol, A., and Israels, S. J. (1999). Platelet dense granules: structure, function and implications for haemostasis. Thromb. Res. 95, 1-18.

Mitra, A., and Radha, V. (2010). F-actin-binding domain of c-Abl regulates localized phosphorylation of C3G: role of C3G in C-Abl-mediated cell death. Oncogene 29, 4528-42.

Mitsuma, W., Kodama, M., Hanawa, H., Ito, M., Ramadan, M. M., Hirono, S., Obata, H., Okada, S., Sanada, F., Yanagawa, T., et al. (2007). Serum endostatin in the coronary circulation of patients with coronary heart disease and its relation to coronary collateral formation. Am. J. Cardiol. 99, 494-8. 
Monreal, M., Fernandez-Llamazares, J., Piñol, M., Julian, J. F., Broggi, M., Escola, D., and Abad, A. (1998). Platelet count and survival in patients with colorectal cancer--a preliminary study. Thromb. Haemost. 79, 916-8.

Nakanishi-Matsui, M., Zheng, Y. W., Sulciner, D. J., Weiss, E. J., Ludeman, M. J., and Coughlin, S. R. (2000). PAR3 is a cofactor for PAR4 activation by thrombin. Nature 404, 609-13.

Nayak, M. K., Kulkarni, P. P., and Dash, D. (2013). Regulatory role of proteasome in determination of platelet life span. J. Biol. Chem. 288, 6826-34.

Nierodzik, M. L., and Karpatkin, S. (2006). Thrombin induces tumor growth, metastasis, and angiogenesis: Evidence for a thrombin-regulated dormant tumor phenotype. Cancer Cell 10, 355-62.

Nurden, A. T., Nurden, P., Sanchez, M., Andia, I., and Anitua, E. (2008). Platelets and wound healing. Front. Biosci. 13, 3532-48.

Oh, C.-W. W., Hoover-Plow, J., and Plow, E. F. (2003). The role of plasminogen in angiogenesis in vivo. J. Thromb. Haemost. 1, 1683-7.

Oh, J., Seo, D.-W. W., Diaz, T., Wei, B., Ward, Y., Ray, J. M., Morioka, Y., Shi, S., Kitayama, H., Takahashi, C., et al. (2004). Tissue inhibitors of metalloproteinase 2 inhibits endothelial cell migration through increased expression of RECK. Cancer Res. 64, 9062-9.

Ohba, Y., Ikuta, K., Ogura, A., Matsuda, J., Mochizuki, N., Nagashima, K., Kurokawa, K., Mayer, B. J., Maki, K., Miyazaki, J., et al. (2001). Requirement for C3G-dependent Rap1 activation for cell adhesion and embryogenesis. EMBO J. 20, 3333-41.

Ohba, Y., Mochizuki, N., Yamashita, S., Chan, A. M., Schrader, J. W., Hattori, S., Nagashima, K., and Matsuda, M. (2000). Regulatory proteins of R-Ras, TC21/R-Ras2, and M-Ras/R-Ras3. J. Biol. Chem. 275, 20020-6.

Okada, S., and Pessin, J. E. (1997). Insulin and epidermal growth factor stimulate a conformational change in Rap1 and dissociation of the Crkll-C3G complex. J. Biol. Chem. 272, 28179-82.

Ortiz-Rivero, S. (2017). Role of C3G in the differentiation and maturation of megakaryocytes. Tesis Doctoral. Universidad de Salamanca. Salamanca.

Pacchiarini, L., Zucchella, M., Milanesi, G., Tacconi, F., Bonomi, E., Canevari, A., and Grignani, G. (1991). Thromboxane production by platelets during tumor cell-induced platelet activation. Invasion Metastasis 11, 102-9.

Paganini, S., Guidetti, G. F., Catricalà, S., Trionfini, P., Panelli, S., Balduini, C., and Torti, M. (2006). Identification and biochemical characterization of Rap2C, a new member of the Rap family of small GTP-binding proteins. Biochimie 88, 285-95.

Patzelt, J., and Langer, H. F. (2012). Platelets in angiogenesis. Curr Vasc Pharmacol 10, 570-7.

Peters, C. G., Michelson, A. D., and Flaumenhaft, R. (2012). Granule exocytosis is required for platelet spreading: differential sorting of $\alpha$-granules expressing VAMP-7. Blood 120, 199206.

Piersma, S. R., Broxterman, H. J., Kapci, M., Haas, R. R. de, Hoekman, K., Verheul, H. M., and Jiménez, C. R. (2009). Proteomics of the TRAP-induced platelet releasate. J Proteomics 72, 91-109.

Pocard, T., Bivic, A. Le, Galli, T., and Zurzolo, C. (2007). Distinct v-SNAREs regulate direct and indirect apical delivery in polarized epithelial cells. J. Cell. Sci. 120, 3309-20.

Potente, M., Gerhardt, H., and Carmeliet, P. (2011). Basic and therapeutic aspects of angiogenesis. Cell 146, 873-87.

Quilliam, L. A., Rebhun, J. F., and Castro, A. F. (2002). A growing family of guanine nucleotide exchange factors is responsible for activation of Ras-family GTPases. Prog. Nucleic Acid Res. Mol. Biol. 71, 391-444. 
Raaijmakers, J. H., and Bos, J. L. (2009). Specificity in Ras and Rap signaling. The Journal of biological chemistry 284, 10995-9. Available at: http://www.jbc.org/cgi/pmidlookup?view=long\&pmid=19091745.

Radha, V., Mitra, A., Dayma, K., and Sasikumar, K. (2011a). Signalling to actin: role of C3G, a multitasking guanine-nucleotide-exchange factor. Bioscience reports 31, 231-44. Available at: http://www.ncbi.nlm.nih.gov/pubmed/21366540.

Radha, V., Mitra, A., Dayma, K., and Sasikumar, K. (2011b). Signalling to actin: role of C3G, a multitasking guanine-nucleotide-exchange factor. Biosci. Rep. 31, 231-44.

Radha, V., Rajanna, A., Mitra, A., Rangaraj, N., and Swarup, G. (2007). C3G is required for c-Ablinduced filopodia and its overexpression promotes filopodia formation. Exp. Cell Res. 313, 2476-92.

Radha, V., Rajanna, A., and Swarup, G. (2004). Phosphorylated guanine nucleotide exchange factor C3G, induced by pervanadate and Src family kinases localizes to the Golgi and subcortical actin cytoskeleton. BMC Cell Biol. 5, 31.

Reedquist, K. A., Fukazawa, T., Panchamoorthy, G., Langdon, W. Y., Shoelson, S. E., Druker, B. J., and Band, H. (1996). Stimulation through the T cell receptor induces $\mathrm{Cbl}$ association with $\mathrm{Crk}$ proteins and the guanine nucleotide exchange protein C3G. J. Biol. Chem. 271, 8435-42.

Ren, Q., Barber, H. K., Crawford, G. L., Karim, Z. A., Zhao, C., Choi, W., Wang, C.-C. C., Hong, W., and Whiteheart, S. W. (2007). Endobrevin/VAMP-8 is the primary v-SNARE for the platelet release reaction. Mol. Biol. Cell 18, 24-33.

Rhee, J.-S. S., Black, M., Schubert, U., Fischer, S., Morgenstern, E., Hammes, H.-P. P., and Preissner, K. T. (2004). The functional role of blood platelet components in angiogenesis. Thromb. Haemost. 92, 394-402.

Rolli, M., Fransvea, E., Pilch, J., Saven, A., and Felding-Habermann, B. (2003). Activated integrin alphavbeta3 cooperates with metalloproteinase MMP-9 in regulating migration of metastatic breast cancer cells. Proc. Natl. Acad. Sci. U.S.A. 100, 9482-7.

Rossi, V., Banfield, D. K., Vacca, M., Dietrich, L. E., Ungermann, C., D’Esposito, M., Galli, T., and Filippini, F. (2004). Longins and their longin domains: regulated SNAREs and multifunctional SNARE regulators. Trends Biochem. Sci. 29, 682-8.

Rowley, J., Oler, A., Tolley, N., Hunter, B., Low, E., Nix, D., Yost, C., Zimmerman, G., and Weyrich, A. (2011). Genome-wide RNA-seq analysis of human and mouse platelet transcriptomes. Blood 118, e101-e111.

Sabrkhany, S., Griffioen, A. W., and Oude Egbrink, M. G. (2011). The role of blood platelets in tumor angiogenesis. Biochim. Biophys. Acta 1815, 189-96.

Sakkab, D., Lewitzky, M., Posern, G., Schaeper, U., Sachs, M., Birchmeier, W., and Feller, S. M. (2000). Signaling of hepatocyte growth factor/scatter factor (HGF) to the small GTPase Rap1 via the large docking protein Gab1 and the adapter protein CRKL. J. Biol. Chem. 275, 107728.

Schmitt, A., Guichard, J., Massé, J.-M., Debili, N., and Cramer, E. (2001). Of mice and men Comparison of the ultrastructure of megakaryocytes and platelets. Exp Hematol 29, 12951302.

Schraw, T. D., Rutledge, T. W., Crawford, G. L., Bernstein, A. M., Kalen, A. L., Pessin, J. E., and Whiteheart, S. W. (2003). Granule stores from cellubrevin/VAMP-3 null mouse platelets exhibit normal stimulus-induced release. Blood 102, 1716-22.

Schultess, J., Danielewski, O., and Smolenski, A. P. (2005). Rap1GAP2 is a new GTPase-activating protein of Rap1 expressed in human platelets. Blood 105, 3185-92. 
Schäfer, I. B., Hesketh, G. G., Bright, N. A., Gray, S. R., Pryor, P. R., Evans, P. R., Luzio, J. P., and Owen, D. J. (2012). The binding of Varp to VAMP7 traps VAMP7 in a closed, fusogenically inactive conformation. Nat. Struct. Mol. Biol. 19, 1300-9.

Schönherr, C., Yang, H.-L. L., Vigny, M., Palmer, R. H., and Hallberg, B. (2010). Anaplastic lymphoma kinase activates the small GTPase Rap1 via the Rap1-specific GEF C3G in both neuroblastoma and PC12 cells. Oncogene 29, 2817-30.

Shattil, S., and Newman, P. (2004). Integrins: dynamic scaffolds for adhesion and signaling in platelets. Blood 104, 1606-15.

Shirakawa, R., Higashi, T., Tabuchi, A., Yoshioka, A., Nishioka, H., Fukuda, M., Kita, T., and Horiuchi, H. (2004). Munc13-4 is a GTP-Rab27-binding protein regulating dense core granule secretion in platelets. J. Biol. Chem. 279, 10730-7.

Shirakawa, R., Yoshioka, A., Horiuchi, H., Nishioka, H., Tabuchi, A., and Kita, T. (2000). Small GTPase Rab4 regulates Ca2+-induced alpha-granule secretion in platelets. J. Biol. Chem. 275, 338449.

Shivakrupa, R., Radha, V., Sudhakar, C. h, and Swarup, G. (2003). Physical and functional interaction between Hck tyrosine kinase and guanine nucleotide exchange factor C3G results in apoptosis, which is independent of C3G catalytic domain. J. Biol. Chem. 278, 52188-94.

Sierko, E., and Wojtukiewicz, M. Z. (2007). Inhibition of platelet function: does it offer a chance of better cancer progression control? Semin. Thromb. Hemost. 33, 712-21.

Sierko, E., and Wojtukiewicz, M. Z. (2004). Platelets and angiogenesis in malignancy. Semin. Thromb. Hemost. 30, 95-108.

Sodha, N. R., Clements, R. T., Boodhwani, M., Xu, S.-H. H., Laham, R. J., Bianchi, C., and Sellke, F. W. (2009). Endostatin and angiostatin are increased in diabetic patients with coronary artery disease and associated with impaired coronary collateral formation. Am. J. Physiol. Heart Circ. Physiol. 296, H428-34.

Sponder, M., Fritzer-Szekeres, M., Litschauer, B., Binder, T., and Strametz-Juranek, J. (2015). Endostatin and osteopontin are elevated in patients with both coronary artery disease and aortic valve calcification. IJC Metabolic \& Endocrine 9, 5-9. Available at: http://www.sciencedirect.com/science/article/pii/S2214762415300074.

Sponder, M., Fritzer-Szekeres, M., Marculescu, R., Litschauer, B., and Strametz-Juranek, J. (2016). Physical inactivity increases endostatin and osteopontin in patients with coronary artery disease. Heart Vessels 31, 1603-8.

Stefanini, L., Boulaftali, Y., Ouellette, T., Holinstat, M., Désiré, L., Leblond, B., Andre, P., Conley, P., and Bergmeier, W. (2012). Rap1-Rac1 Circuits Potentiate Platelet Activation. Arteriosclerosis Thrombosis Vasc Biology 32, 434-441.

Stefanini, L., Roden, R. C., and Bergmeier, W. (2009). CalDAG-GEFI is at the nexus of calciumdependent platelet activation. Blood 114, 2506-14.

Suzuki, A., Takahashi, T., Nakamura, K., Tsuyuoka, R., Okuno, Y., Enomoto, T., Fukumoto, M., and Imura, H. (1992). Thrombocytosis in patients with tumors producing colony-stimulating factor. Blood 80, 2052-9.

Symbas, N. P., Townsend, M. F., El-Galley, R., Keane, T. E., Graham, S. D., and Petros, J. A. (2000). Poor prognosis associated with thrombocytosis in patients with renal cell carcinoma. BJU Int. 86, 203-7.

Südhof, T. C., and Rothman, J. E. (2009). Membrane fusion: grappling with SNARE and SM proteins. Science 323, 474-7.

Takai, Y., Sasaki, T., and Matozaki, T. (2001). Small GTP-binding proteins. Physiol. Rev. 81, 153-208. 
Tanaka, S., Morishita, T., Hashimoto, Y., Hattori, S., Nakamura, S., Shibuya, M., Matuoka, K., Takenawa, T., Kurata, T., and Nagashima, K. (1994). C3G, a guanine nucleotide-releasing protein expressed ubiquitously, binds to the Src homology 3 domains of CRK and GRB2/ASH proteins. Proc. Natl. Acad. Sci. U.S.A. 91, 3443-7.

Thon, J., \& Italiano, J. (2012). Platelets: Production, Morphology and Ultrastructure. En P. Gresele, G. V. Born, C. Patrono, \& C. P. Page, Antiplatelet Agents, Handbook of Experimental Pharmacology Volume 210 (págs. 3-22). Berlin Heidelberg: Springer-Verlag.

Torti, M., and Lapetina, E. G. (1994). Structure and function of rap proteins in human platelets. Thromb. Haemost. 71, 533-43.

Trikha, M., Zhou, Z., Timar, J., Raso, E., Kennel, M., Emmell, E., and Nakada, M. T. (2002). Multiple roles for platelet GPIIb/IIla and alphavbeta3 integrins in tumor growth, angiogenesis, and metastasis. Cancer Res. 62, 2824-33.

Tsukamoto, N., Hattori, M., Yang, H., Bos, J. L., and Minato, N. (1999). Rap1 GTPase-activating protein SPA-1 negatively regulates cell adhesion. J. Biol. Chem. 274, 18463-9.

Urbich, C., and Dimmeler, S. (2004). Endothelial progenitor cells: characterization and role in vascular biology. Circ. Res. 95, 343-53.

Utreras, E., Henriquez, D., Contreras-Vallejos, E., Olmos, C., Genova, A. Di, Maass, A., Kulkarni, A. B., and Gonzalez-Billault, C. (2013). Cdk5 regulates Rap1 activity. Neurochem. Int. 62, 84853.

Verheul, H. M., Hoekman, K., Lupu, F., Broxterman, H. J., Valk, P. van der, Kakkar, A. K., and Pinedo, H. M. (2000). Platelet and coagulation activation with vascular endothelial growth factor generation in soft tissue sarcomas. Clin. Cancer Res. 6, 166-71.

Ware, J., Corken, A., and Khetpal, R. (2013). Platelet function beyond hemostasis and thrombosis. Curr Opin Hematol 20, 451.

Watanabe, N., Bodin, L., Pandey, M., Krause, M., Coughlin, S., Boussiotis, V. A., Ginsberg, M. H., and Shattil, S. J. (2008). Mechanisms and consequences of agonist-induced talin recruitment to platelet integrin alphallbbeta3. J. Cell Biol. 181, 1211-22.

Weis, S. M., and Cheresh, D. A. (2011). Tumor angiogenesis: molecular pathways and therapeutic targets. Nat. Med. 17, 1359-70.

White, J. G. (1969). The dense bodies of human platelets: inherent electron opacity of the serotonin storage particles. Blood 33, 598-606.

White, J. G., and Escolar, G. (1991). The blood platelet open canalicular system: a two-way street. Eur. J. Cell Biol. 56, 233-42.

White, J. G. (2007). Platelet Structure. En A. D. Michelson, Platelets (págs. 45-73). Elsevier.

Wojtukiewicz, M. Z., Zacharski, L. R., Memoli, V. A., Kisiel, W., Kudryk, B. J., Rousseau, S. M., and Stump, D. C. (1990a). Fibrinogen-fibrin transformation in situ in renal cell carcinoma. Anticancer Res. 10, 579-82.

Wojtukiewicz, M. Z., Zacharski, L. R., Memoli, V. A., Kisiel, W., Kudryk, B. J., Rousseau, S. M., and Stump, D. C. (1990b). Malignant melanoma. Interaction with coagulation and fibrinolysis pathways in situ. Am. J. Clin. Pathol. 93, 516-21.

Ye, S., Karim, Z. A., Hawas, R. Al, Pessin, J. E., Filipovich, A. H., and Whiteheart, S. W. (2012). Syntaxin-11, but not syntaxin-2 or syntaxin-4, is required for platelet secretion. Blood 120, 2484-92.

Yokote, K., Hellman, U., Ekman, S., Saito, Y., Rönnstrand, L., Saito, Y., Heldin, C. H., and Mori, S. (1998). Identification of Tyr-762 in the platelet-derived growth factor alpha-receptor as the binding site for Crk proteins. Oncogene 16, 1229-39. 
York, R. D., Yao, H., Dillon, T., Ellig, C. L., Eckert, S. P., McCleskey, E. W., and Stork, P. J. (1998). Rap1 mediates sustained MAP kinase activation induced by nerve growth factor. Nature 392, 622-6.

Zacharski, L. R., Memoli, V. A., Ornstein, D. L., Rousseau, S. M., Kisiel, W., and Kudryk, B. J. (1993). Tumor cell procoagulant and urokinase expression in carcinoma of the ovary. J. Natl. Cancer Inst. 85, 1225-30.

Zaslavsky, A., Baek, K.-H. H., Lynch, R. C., Short, S., Grillo, J., Folkman, J., Italiano, J. E., and Ryeom, S. (2010). Platelet-derived thrombospondin-1 is a critical negative regulator and potential biomarker of angiogenesis. Blood 115, 4605-13.

Zeiler, M., Moser, M., and Mann, M. (2014). Copy number analysis of the murine platelet proteome spanning the complete abundance range. Mol. Cell Proteomics 13, 3435-45.

Zerial, M., and McBride, H. (2001). Rab proteins as membrane organizers. Nat. Rev. Mol. Cell Biol. 2, 107-17.

Zhang, X., He, X., Fu, X.-Y. Y., and Chang, Z. (2006). Varp is a Rab21 guanine nucleotide exchange factor and regulates endosome dynamics. J. Cell. Sci. 119, 1053-62.

Zufferey, A., Schvartz, D., Nolli, S., Reny, J.-L. L., Sanchez, J.-C. C., and Fontana, P. (2014). Characterization of the platelet granule proteome: evidence of the presence of MHC1 in alpha-granules. J Proteomics 101, 130-40. 

ANEXOS 

Tabla A1. Proteínas más abundantes (top 100) presentes en el secretoma de plaquetas WtC3G y TgC3G activadas con trombina.

\begin{tabular}{|c|c|c|c|c|c|c|}
\hline \multirow{2}{*}{ № Uniprot } & \multirow{2}{*}{ Proteína } & \multirow{2}{*}{$\underset{[\mathrm{kDa}]}{\mathrm{MM}}$} & \multicolumn{2}{|c|}{ WtC3G } & \multicolumn{2}{|c|}{$\operatorname{TgC3G}$} \\
\hline & & & \# PSMs & Ranking & \# PSMs & Ranking \\
\hline P07724 & Serum albumin & 68.6 & 603 & 1 & 635 & 1 \\
\hline Q80YQ1 & Thrombospondin 1 & 129.6 & 194 & 2 & 151 & 2 \\
\hline Q921I1 & Serotransferrin & 76.6 & 129 & 3 & 111 & 3 \\
\hline Q9Z126 & Platelet factor 4 & 11.2 & 99 & 4 & 85 & 4 \\
\hline Q61838 & Alpha-2-macroglobulin & 165.7 & 68 & 5 & 41 & 5 \\
\hline P60710 & Actin. cytoplasmic 1 & 41.7 & 48 & 6 & 37 & 6 \\
\hline P26039 & Talin-1 & 269.6 & 47 & 7 & 21 & 10 \\
\hline P63260 & Actin. cytoplasmic 2 & 41.7 & 47 & 8 & 36 & 7 \\
\hline Q00623 & Apolipoprotein A-I & 30.5 & 47 & 9 & 34 & 8 \\
\hline P01942 & Hemoglobin subunit alpha & 15.0 & 42 & 10 & 26 & 9 \\
\hline E9PV24 & Protein Fga & 87.3 & 39 & 11 & 18 & 13 \\
\hline A8DUK4 & Beta-globin & 15.7 & 37 & 12 & - & - \\
\hline A0A075B5P6 & Ig mu chain $\mathrm{C}$ region (Fragment) & 50.0 & 30 & 13 & - & - \\
\hline Q91X72 & Hemopexin & 51.2 & 28 & 14 & 17 & 14 \\
\hline Q01339 & Beta-2-glycoprotein 1 & 38.5 & 26 & 15 & - & - \\
\hline E9QPU1 & von Willebrand factor & 308.9 & 25 & 16 & 12 & 21 \\
\hline P01027 & Complement C3 & 186.3 & 25 & 17 & 6 & 38 \\
\hline A0A0R4J0I1 & MCG1051009 & 46.6 & 24 & 18 & 20 & 11 \\
\hline P20918 & Plasminogen & 90.7 & 22 & 19 & 2 & 92 \\
\hline P21614 & Vitamin D-binding protein & 53.5 & 21 & 20 & 14 & 17 \\
\hline Q8BFZ3 & Beta-actin-like protein 2 & 41.9 & 20 & 21 & - & - \\
\hline Q8VDD5 & Myosin-9 & 226.2 & 19 & 22 & 12 & 20 \\
\hline Q9EQ15 & $\begin{array}{l}\text { Chemokine (C-X-C motif) ligand } 7 . \\
\text { isoform CRA_b }\end{array}$ & 12.2 & 19 & 23 & 20 & 12 \\
\hline Q8K0E8 & Fibrinogen beta chain & 54.7 & 19 & 24 & 5 & 44 \\
\hline P23953 & Carboxylesterase $1 \mathrm{C}$ & 61.0 & 16 & 25 & 13 & 19 \\
\hline B7FAV1 & Filamin. alpha (Fragment) & 274.4 & 16 & 26 & 10 & 23 \\
\hline P17182 & Alpha-enolase & 47.1 & 15 & 27 & 9 & 26 \\
\hline P05064 & Fructose-bisphosphate aldolase A & 39.3 & 15 & 28 & 6 & 39 \\
\hline P08905 & Lysozyme C-2 & 16.6 & 14 & 29 & 16 & 15 \\
\hline P28665 & Murinoglobulin-1 & 165.1 & 14 & 30 & 7 & 34 \\
\hline Q00896 & Alpha-1-antitrypsin 1-3 & 45.7 & 13 & 31 & 14 & 18 \\
\hline O08677-2 & Isoform LMW of Kininogen-1 & 47.8 & 13 & 32 & 8 & 30 \\
\hline P17742 & Peptidyl-prolyl cis-trans isomerase A & 17.9 & 12 & 33 & 10 & 22 \\
\hline P68368 & Tubulin alpha-4A chain & 49.8 & 12 & 34 & 9 & 25 \\
\hline P63017 & Heat shock cognate $71 \mathrm{kDa}$ protein & 70.8 & 11 & 35 & 8 & 28 \\
\hline Q64727 & Vinculin & 116.6 & 11 & 36 & 7 & 33 \\
\hline Q8VCM7 & Fibrinogen gamma chain & 49.3 & 11 & 37 & 3 & 71 \\
\hline D3Z5G7 & Protein Ces $1 b$ & 62.1 & 11 & 38 & - & - \\
\hline
\end{tabular}




\begin{tabular}{|c|c|c|c|c|c|c|}
\hline P29699 & Alpha-2-HS-glycoprotein & 37.3 & 10 & 39 & 7 & 31 \\
\hline P62962 & Profilin-1 & 14.9 & 10 & 40 & 5 & 49 \\
\hline D6RGQ0 & Complement factor $\mathrm{H}$ & 124.9 & 10 & 41 & - & - \\
\hline E9Q748 & Antileukoproteinase & 11.9 & 10 & 42 & 3 & 76 \\
\hline O88342 & WD repeat-containing protein 1 & 66.3 & 9 & 43 & 4 & 50 \\
\hline Q60605 & Myosin light polypeptide 6 & 16.9 & 9 & 44 & 3 & 66 \\
\hline G3X9T8 & Ceruloplasmin & 121.0 & 9 & 45 & 6 & 41 \\
\hline A0A075B5V0 & MCG114299 (Fragment) & 12.9 & 8 & 46 & - & - \\
\hline P06330 & Ig heavy chain $V$ region AC38 205.12 & 12.9 & 8 & 47 & - & - \\
\hline O35930 & Platelet glycoprotein Ib alpha chain & 80.0 & 8 & 48 & 5 & 42 \\
\hline Q8CG19-3 & $\begin{array}{l}\text { Isoform } 3 \text { of Latent-transforming } \\
\text { growth factor beta-binding protein } 1\end{array}$ & 147.3 & 8 & 49 & - & - \\
\hline P06728 & Apolipoprotein A-IV & 45.0 & 8 & 50 & 7 & 37 \\
\hline Q00897 & Alpha-1-antitrypsin 1-4 & 45.9 & 8 & 51 & 8 & 29 \\
\hline A2AQ07 & Tubulin beta- 1 chain & 50.4 & 7 & 52 & 8 & 27 \\
\hline P20029 & $78 \mathrm{kDa}$ glucose-regulated protein & 72.3 & 7 & 53 & 6 & 40 \\
\hline Q9JJZ2 & Tubulin alpha-8 chain & 50.0 & 7 & 54 & 7 & 32 \\
\hline Q00898 & Alpha-1-antitrypsin 1-5 & 45.8 & 7 & 55 & - & - \\
\hline P18760 & Cofilin-1 & 18.5 & 7 & 56 & 5 & 46 \\
\hline Q01853 & $\begin{array}{l}\text { Transitional endoplasmic reticulum } \\
\text { ATPase }\end{array}$ & 89.2 & 7 & 57 & 4 & 55 \\
\hline D3YY36 & Protein 1300017J02Rik & 68.5 & 7 & 58 & 4 & 52 \\
\hline P21107-2 & $\begin{array}{l}\text { Isoform } 2 \text { of Tropomyosin alpha-3 } \\
\text { chain }\end{array}$ & 29.0 & 7 & 59 & - & - \\
\hline P22599 & Alpha-1-antitrypsin 1-2 & 45.9 & 7 & 60 & 7 & 36 \\
\hline Q07797 & Galectin-3-binding protein & 64.4 & 6 & 61 & 5 & 43 \\
\hline AOAON4SVL8 & Multimerin-1 & 135.7 & 6 & 62 & - & - \\
\hline P20065-2 & Isoform Short of Thymosin beta-4 & 5.0 & 6 & 63 & - & - \\
\hline P63101 & 14-3-3 protein zeta/delta & 27.7 & 6 & 64 & 7 & 35 \\
\hline P39876 & Metalloproteinase inhibitor 3 & 24.1 & 6 & 65 & 2 & 84 \\
\hline E9Q7Q3 & Tropomyosin alpha-3 chain & 28.7 & 6 & 66 & - & - \\
\hline Q9R0P5 & Destrin & 18.5 & 6 & 67 & - & - \\
\hline P09813 & Apolipoprotein A-II & 11.3 & 6 & 68 & 4 & 61 \\
\hline Q02053 & $\begin{array}{l}\text { Ubiquitin-like modifier-activating } \\
\text { enzyme } 1\end{array}$ & 117.7 & 5 & 69 & 4 & 56 \\
\hline P57780 & Alpha-actinin-4 & 104.9 & 5 & 70 & - & - \\
\hline Q6IRU2 & Tropomyosin alpha-4 chain & 28.4 & 5 & 71 & 5 & 48 \\
\hline Q64442 & Sorbitol dehydrogenase & 38.2 & 5 & 72 & 5 & 47 \\
\hline P06151 & L-lactate dehydrogenase $\mathrm{A}$ chain & 36.4 & 5 & 73 & 4 & 60 \\
\hline Q08761 & Vitamin K-dependent protein S & 74.8 & 5 & 74 & 2 & 78 \\
\hline O88783 & Coagulation factor $\mathrm{V}$ & 247.0 & 5 & 75 & 4 & 59 \\
\hline P17751 & Triosephosphate isomerase & 32.1 & 5 & 76 & - & - \\
\hline P01029 & Complement C4-B & 192.7 & 5 & 77 & 3 & 67 \\
\hline P68510 & 14-3-3 protein eta & 28.1 & 5 & 78 & - & - \\
\hline Q19LI2 & Alpha-1B-glycoprotein & 56.5 & 5 & 79 & - & - \\
\hline
\end{tabular}




\begin{tabular}{|c|c|c|c|c|c|c|}
\hline P52480 & Pyruvate kinase PKM & 57.8 & 4 & 80 & 4 & 51 \\
\hline A0A0R4J1N3 & Apolipoprotein C-III & 10.9 & 4 & 81 & 3 & 62 \\
\hline O89020 & Afamin & 69.3 & 4 & 82 & 4 & 58 \\
\hline F8WI14 & Extracellular matrix protein 1 & 62.6 & 4 & 83 & 2 & 80 \\
\hline Q9D6F9 & Tubulin beta- $4 \mathrm{~A}$ chain & 49.5 & 4 & 84 & 4 & 57 \\
\hline P04202 & Transforming growth factor beta- 1 & 44.2 & 4 & 85 & 2 & 88 \\
\hline O70400 & PDZ and LIM domain protein 1 & 35.7 & 4 & 86 & - & - \\
\hline Q9QWK4 & CD5 antigen-like & 38.8 & 4 & 87 & - & - \\
\hline Q7TQE2 & Zyx protein & 56.9 & 4 & 88 & - & - \\
\hline Q03350 & Thrombospondin-2 & 129.7 & 4 & 89 & 2 & 86 \\
\hline A0A0A6YWH7 & Antithrombin-III (Fragment) & 31.9 & 4 & 90 & 2 & 91 \\
\hline A0A075B5P3 & Protein Ighg2b (Fragment) & 36.6 & 4 & 91 & 3 & 63 \\
\hline S4R2J8 & Bridging integrator 2 & 50.8 & 4 & 92 & - & - \\
\hline Q91VW3 & $\begin{array}{l}\mathrm{SH} 3 \text { domain-binding glutamic acid- } \\
\text { rich-like protein } 3\end{array}$ & 10.4 & 4 & 93 & - & - \\
\hline Q8K558 & Trem-like transcript 1 protein & 33.5 & 4 & 94 & 2 & 100 \\
\hline H3BJP2 & $\begin{array}{l}\text { S-formylglutathione hydrolase } \\
\text { (Fragment) }\end{array}$ & 27.1 & 4 & 95 & 3 & 74 \\
\hline P57774 & Pro-neuropeptide $Y$ & 10.8 & 4 & 96 & 2 & 98 \\
\hline A0A075B5M7 & Protein Igkv5-39 & 10.4 & 4 & 97 & 3 & 68 \\
\hline P27773 & Protein disulfide-isomerase $\mathrm{A} 3$ & 56.6 & 4 & 98 & 3 & 65 \\
\hline Q61646 & Haptoglobin & 38.7 & 4 & 99 & - & - \\
\hline P50228 & C-X-C motif chemokine 5 & 14.2 & 4 & 100 & - & - \\
\hline E9Q223 & $\begin{array}{l}\text { Hemoglobin subunit beta-1 } \\
\text { (Fragment) }\end{array}$ & 11.1 & - & - & 15 & 16 \\
\hline P01872 & Ig mu chain $\mathrm{C}$ region & 49.9 & - & - & 9 & 24 \\
\hline I7HJR3 & Beta-2-glycoprotein 1 (Fragment) & 16.8 & - & - & 5 & 45 \\
\hline Q99JY9 & Actin-related protein 3 & 47.3 & - & - & 4 & 54 \\
\hline Q07456 & Protein AMBP & 39.0 & - & - & 4 & 53 \\
\hline O08538 & Angiopoietin-1 & 57.5 & - & - & 3 & 72 \\
\hline Q9ESB3 & Histidine-rich glycoprotein & 59.1 & - & - & 3 & 75 \\
\hline Q61703 & $\begin{array}{l}\text { Inter-alpha-trypsin inhibitor heavy } \\
\text { chain H2 }\end{array}$ & 105.9 & - & - & 3 & 70 \\
\hline Q7TMM9 & Tubulin beta-2A chain & 49.9 & - & - & 3 & 69 \\
\hline P99024 & Tubulin beta- 5 chain & 49.6 & - & - & 3 & 73 \\
\hline Q6P1B1 & Xaa-Pro aminopeptidase 1 & 69.5 & - & - & 3 & 64 \\
\hline Q9Z1Q5 & $\begin{array}{l}\text { Chloride intracellular channel protein } \\
1\end{array}$ & 27.0 & - & - & 2 & 93 \\
\hline A0A0A6YWP4 & Complement factor $\mathrm{H}$ (Fragment) & 94.2 & - & - & 2 & 89 \\
\hline Q8K1B8 & Fermitin family homolog 3 & 75.6 & - & - & 2 & 90 \\
\hline P07901 & Heat shock protein HSP 90-alpha & 84.7 & - & - & 2 & 85 \\
\hline A0A075B5P4 & $\begin{array}{l}\text { Ig gamma-1 chain } \mathrm{C} \text { region secreted } \\
\text { form (Fragment) }\end{array}$ & 35.7 & - & - & 2 & 82 \\
\hline Q9QUM0 & Integrin alpha-lib & 112.6 & - & - & 2 & 87 \\
\hline O55222 & Integrin-linked protein kinase & 51.3 & - & - & 2 & 95 \\
\hline P03987-2 & $\begin{array}{l}\text { Isoform } 2 \text { of Ig gamma-3 chain } C \\
\text { region }\end{array}$ & 36.2 & - & - & 2 & 96 \\
\hline
\end{tabular}




\begin{tabular}{lllllll} 
Q91XL1 & Leucine-rich HEV glycoprotein & 37.4 & - & - & 2 & 81 \\
\hline Q9D154 & Leukocyte elastase inhibitor A & 42.5 & - & - & 2 & 83 \\
P09411 & Phosphoglycerate kinase 1 & 44.5 & - & - & 2 & 77 \\
Q9DBJ1 & Phosphoglycerate mutase 1 & 28.8 & - & - & 2 & 99 \\
P26262 & Plasma kallikrein & 71.3 & - & - & 2 & 97 \\
Q99PT1 & Rho GDP-dissociation inhibitor 1 & 23.4 & - & - & 2 & 79 \\
D3Z2H9 & Uncharacterized protein & 29.0 & - & - & 2 & 94 \\
\hline
\end{tabular}

EI \#PSM (peptide spectrum matches) fue utilizado como medida cuantitativa de la abundancia relativa de cada proteína en el secretoma (Liu et al., 2012). (-) Indica que la proteína no fue detectada en el secretoma. El análisis fue realizado con $15 \mu \mathrm{L}$ a partir de $200 \mu \mathrm{L}$ de secretoma aislados de plaquetas de 3 ratones de cada genotipo. MM: masa molecular.

Tabla A2. Proteínas más abundantes (top 100) presentes en el secretoma de plaquetas WtC3G $\Delta$ Cat y TgC3G $\Delta$ Cat activadas con trombina.

\begin{tabular}{|c|c|c|c|c|c|c|}
\hline \multirow{2}{*}{ № Uniprot } & \multirow{2}{*}{ Proteína } & \multirow{2}{*}{$\underset{[\mathrm{kDa}]}{\mathrm{MM}}$} & \multicolumn{2}{|c|}{ WtC3G $\Delta$ Cat } & \multicolumn{2}{|c|}{ TgC3G $\Delta$ Cat } \\
\hline & & & \# PSMs & Ranking & \# PSMs & Ranking \\
\hline P07724 & Serum albumin & 68.6 & 650 & 1 & 790 & 1 \\
\hline Q80YQ1 & Thrombospondin 1 & 129.6 & 163 & 2 & 99 & 3 \\
\hline Q921I1 & Serotransferrin & 76.6 & 127 & 3 & 158 & 2 \\
\hline Q91VB8 & Alpha globin 1 & 15.1 & 73 & 4 & - & - \\
\hline Q9Z126 & Platelet factor 4 & 11.2 & 71 & 5 & 65 & 7 \\
\hline Q61838 & Alpha-2-macroglobulin & 165.7 & 67 & 6 & 89 & 4 \\
\hline P60710 & Actin, cytoplasmic 1 & 41.7 & 59 & 7 & 29 & 12 \\
\hline P63260 & Actin, cytoplasmic 2 & 41.7 & 57 & 8 & 29 & 11 \\
\hline P26039 & Talin-1 & 269.6 & 55 & 9 & 31 & 10 \\
\hline A8DUK4 & Beta-globin & 15.7 & 54 & 10 & 66 & 6 \\
\hline A0A0R4J0I1 & MCG1051009 & 46.6 & 54 & 11 & 56 & 9 \\
\hline Q00623 & Apolipoprotein A-I & 30.5 & 42 & 12 & 71 & 5 \\
\hline Q8VDD5 & Myosin-9 & 226.2 & 35 & 13 & 12 & 29 \\
\hline E9PV24 & Protein Fga & 87.3 & 31 & 14 & - & - \\
\hline P20918 & Plasminogen & 90.7 & 30 & 15 & 22 & 17 \\
\hline E9QPU1 & von Willebrand factor & 308.9 & 29 & 16 & 19 & 19 \\
\hline P01027 & Complement C3 & 186.3 & 28 & 17 & 22 & 15 \\
\hline P21614 & Vitamin D-binding protein & 53.5 & 26 & 18 & 26 & 13 \\
\hline P28665 & Murinoglobulin-1 & 165.1 & 26 & 19 & 12 & 30 \\
\hline Q9EQ15 & $\begin{array}{l}\text { Chemokine (C-X-C motif) ligand } 7 \text {, } \\
\text { isoform CRA_b }\end{array}$ & 12.2 & 25 & 20 & 12 & 31 \\
\hline Q91X72 & Hemopexin & 51.2 & 25 & 21 & 23 & 14 \\
\hline B7FAV1 & Filamin, alpha (Fragment) & 274.4 & 22 & 22 & 16 & 22 \\
\hline P23953 & Carboxylesterase $1 \mathrm{C}$ & 61.0 & 21 & 23 & 21 & 18 \\
\hline P01872 & Ig mu chain $\mathrm{C}$ region & 49.9 & 20 & 24 & 15 & 23 \\
\hline P62962 & Profilin-1 & 14.9 & 19 & 25 & 7 & 50 \\
\hline P29699 & Alpha-2-HS-glycoprotein & 37.3 & 16 & 26 & 18 & 20 \\
\hline
\end{tabular}




\begin{tabular}{|c|c|c|c|c|c|c|}
\hline Q8CG19 & $\begin{array}{l}\text { Latent-transforming growth factor } \\
\text { beta-binding protein } 1\end{array}$ & 186.5 & 16 & 27 & 6 & 56 \\
\hline P08905 & Lysozyme C-2 & 16.6 & 15 & 28 & 14 & 25 \\
\hline P17742 & Peptidyl-prolyl cis-trans isomerase A & 17.9 & 15 & 29 & 10 & 34 \\
\hline P17182 & Alpha-enolase & 47.1 & 15 & 30 & - & - \\
\hline P63017 & Heat shock cognate $71 \mathrm{kDa}$ protein & 70.8 & 15 & 31 & 10 & 35 \\
\hline O88342 & WD repeat-containing protein 1 & 66.3 & 14 & 32 & 7 & 46 \\
\hline P68369 & Tubulin alpha- $1 \mathrm{~A}$ chain & 50.1 & 14 & 33 & - & - \\
\hline Q00896 & Alpha-1-antitrypsin 1-3 & 45.7 & 14 & 34 & 22 & 16 \\
\hline D6RGQ0 & Complement factor $\mathrm{H}$ & 124.9 & 14 & 35 & 10 & 38 \\
\hline O08677-2 & Isoform LMW of Kininogen-1 & 47.8 & 14 & 36 & 10 & 36 \\
\hline P68368 & Tubulin alpha- $4 \mathrm{~A}$ chain & 49.8 & 13 & 37 & 9 & 40 \\
\hline Q60605 & Myosin light polypeptide 6 & 16.9 & 13 & 38 & 3 & 99 \\
\hline P09813 & Apolipoprotein A-II & 11.3 & 13 & 39 & 16 & 21 \\
\hline A2AQ07 & Tubulin beta- 1 chain & 50.4 & 12 & 40 & 4 & 76 \\
\hline P52480 & Pyruvate kinase PKM & 57.8 & 12 & 41 & 6 & 53 \\
\hline P63101 & 14-3-3 protein zeta/delta & 27.7 & 12 & 42 & 8 & 44 \\
\hline Q00897 & Alpha-1-antitrypsin 1-4 & 45.9 & 12 & 43 & 14 & 26 \\
\hline G3X9T8 & Ceruloplasmin & 121.0 & 12 & 44 & 10 & 37 \\
\hline P22599 & Alpha-1-antitrypsin 1-2 & 45.9 & 12 & 45 & 15 & 24 \\
\hline P20029 & $78 \mathrm{kDa}$ glucose-regulated protein & 72.3 & 11 & 46 & 9 & 39 \\
\hline P05064 & Fructose-bisphosphate aldolase A & 39.3 & 11 & 47 & 13 & 28 \\
\hline O88783 & Coagulation factor $\mathrm{V}$ & 247.0 & 11 & 48 & 3 & 88 \\
\hline P52480-2 & Isoform M1 of Pyruvate kinase PKM & 57.9 & 11 & 49 & - & - \\
\hline Q01339 & Beta-2-glycoprotein 1 & 38.5 & 11 & 50 & 5 & 63 \\
\hline P27773 & Protein disulfide-isomerase A3 & 56.6 & 11 & 51 & 4 & 74 \\
\hline Q9DBD0 & Inhibitor of carbonic anhydrase & 76.7 & 10 & 52 & 14 & 27 \\
\hline Q8VCM7 & Fibrinogen gamma chain & 49.3 & 10 & 53 & 5 & 67 \\
\hline P68372 & Tubulin beta-4B chain & 49.7 & 10 & 54 & - & - \\
\hline O35930 & Platelet glycoprotein Ib alpha chain & 80.0 & 10 & 55 & 5 & 62 \\
\hline Q8K0E8 & Fibrinogen beta chain & 54.7 & 10 & 56 & - & - \\
\hline Q00898 & Alpha-1-antitrypsin 1-5 & 45.8 & 9 & 57 & 8 & 45 \\
\hline AOAON4SVL8 & Multimerin-1 & 135.7 & 9 & 58 & 4 & 72 \\
\hline Q64442 & Sorbitol dehydrogenase & 38.2 & 9 & 59 & 5 & 61 \\
\hline Q01853 & $\begin{array}{l}\text { Transitional endoplasmic reticulum } \\
\text { ATPase }\end{array}$ & 89.2 & 8 & 60 & 4 & 81 \\
\hline Q64727 & Vinculin & 116.6 & 8 & 61 & 3 & 95 \\
\hline P18760 & Cofilin-1 & 18.5 & 8 & 62 & 4 & 79 \\
\hline Q07235 & Glia-derived nexin & 44.1 & 8 & 63 & - & - \\
\hline P17751 & Triosephosphate isomerase & 32.1 & 8 & 64 & 5 & 65 \\
\hline P06728 & Apolipoprotein A-IV & 45.0 & 8 & 65 & 12 & 32 \\
\hline A0A075B5P3 & Protein Ighg2b (Fragment) & 36.6 & 8 & 66 & 6 & 58 \\
\hline Q9WVF5 & Epidermal growth factor receptor & 72.8 & 8 & 67 & 6 & 60 \\
\hline Q02053 & $\begin{array}{l}\text { Ubiquitin-like modifier-activating } \\
\text { enzyme } 1\end{array}$ & 117.7 & 7 & 68 & - & - \\
\hline
\end{tabular}




\begin{tabular}{|c|c|c|c|c|c|c|}
\hline P06151 & L-lactate dehydrogenase $\mathrm{A}$ chain & 36.4 & 7 & 69 & 4 & 80 \\
\hline Q9WVA4 & Transgelin-2 & 22.3 & 7 & 70 & - & - \\
\hline P04202 & Transforming growth factor beta- 1 & 44.2 & 7 & 71 & - & - \\
\hline P04186 & Complement factor B & 84.9 & 7 & 72 & 7 & 51 \\
\hline P20065-2 & Isoform Short of Thymosin beta-4 & 5.0 & 7 & 73 & 7 & 48 \\
\hline Q7TQE2 & Zyx protein & 56.9 & 7 & 74 & 3 & 93 \\
\hline P68510 & 14-3-3 protein eta & 28.1 & 7 & 75 & 5 & 71 \\
\hline P57780 & Alpha-actinin-4 & 104.9 & 6 & 76 & - & - \\
\hline P97315 & Cysteine and glycine-rich protein 1 & 20.5 & 6 & 77 & - & - \\
\hline O88947 & Coagulation factor $X$ & 53.9 & 6 & 78 & - & - \\
\hline Q9DBB9 & Carboxypeptidase $\mathrm{N}$ subunit 2 & 60.4 & 6 & 79 & 3 & 92 \\
\hline P09411 & Phosphoglycerate kinase 1 & 44.5 & 6 & 80 & - & - \\
\hline Q6IRU2 & Tropomyosin alpha-4 chain & 28.4 & 6 & 81 & 4 & 75 \\
\hline P99024 & Tubulin beta- 5 chain & 49.6 & 6 & 82 & - & - \\
\hline P21107-2 & $\begin{array}{l}\text { Isoform } 2 \text { of Tropomyosin alpha-3 } \\
\text { chain }\end{array}$ & 29.0 & 6 & 83 & - & - \\
\hline Q91VW3 & $\begin{array}{l}\text { SH3 domain-binding glutamic acid- } \\
\text { rich-like protein } 3\end{array}$ & 10.4 & 6 & 84 & 5 & 69 \\
\hline H3BJP2 & $\begin{array}{l}\text { S-formylglutathione hydrolase } \\
\text { (Fragment) }\end{array}$ & 27.1 & 6 & 85 & 6 & 59 \\
\hline Q8K558 & Trem-like transcript 1 protein & 33.5 & 6 & 86 & - & - \\
\hline P08226 & Apolipoprotein E & 35.8 & 6 & 87 & 9 & 41 \\
\hline Q06890 & Clusterin & 51.6 & 6 & 88 & 5 & 66 \\
\hline P29788 & Vitronectin & 54.8 & 6 & 89 & 7 & 52 \\
\hline P08113 & Endoplasmin & 92.4 & 6 & 90 & - & - \\
\hline A0A0R4J1N3 & Apolipoprotein C-III & 10.9 & 5 & 91 & 7 & 47 \\
\hline Q6YJU1 & Fetuin-B & 33.8 & 5 & 92 & - & - \\
\hline S4R1B8 & Bridging integrator 2 & 51.5 & 5 & 93 & - & - \\
\hline Q08761 & Vitamin K-dependent protein S & 74.8 & 5 & 94 & 4 & 77 \\
\hline E9Q7Q3 & Tropomyosin alpha-3 chain & 28.7 & 5 & 95 & 3 & 100 \\
\hline P50396 & Rab GDP dissociation inhibitor alpha & 50.4 & 5 & 96 & - & - \\
\hline P40142 & Transketolase & 67.5 & 5 & 97 & - & - \\
\hline P26262 & Plasma kallikrein & 71.3 & 5 & 98 & 7 & 49 \\
\hline P39876 & Metalloproteinase inhibitor 3 & 24.1 & 5 & 99 & - & - \\
\hline Q9ESB3 & Histidine-rich glycoprotein & 59.1 & 5 & 100 & 3 & 98 \\
\hline P01942 & Hemoglobin subunit alpha & 15.0 & - & - & 60 & 8 \\
\hline G3X8T9 & $\begin{array}{l}\text { Serine (Or cysteine) peptidase } \\
\text { inhibitor, clade A, member } 3 N \text {, } \\
\text { isoform CRA_a }\end{array}$ & 46.7 & - & - & 11 & 33 \\
\hline Q99K47 & Fibrinogen, alpha polypeptide & 61.2 & - & - & 8 & 42 \\
\hline P68373 & Tubulin alpha- $1 \mathrm{C}$ chain & 49.8 & - & - & 8 & 43 \\
\hline A2A997 & $\begin{array}{l}\text { Complement component C8 alpha } \\
\text { chain }\end{array}$ & 65.3 & - & - & 6 & 54 \\
\hline A0A075B5P4 & $\begin{array}{l}\text { Ig gamma- } 1 \text { chain } \mathrm{C} \text { region secreted } \\
\text { form (Fragment) }\end{array}$ & 35.7 & - & - & 6 & 57 \\
\hline Q61703 & $\begin{array}{l}\text { Inter-alpha-trypsin inhibitor heavy } \\
\text { chain H2 }\end{array}$ & 105.8 & - & - & 6 & 55 \\
\hline P01029 & Complement C4-B & 192.7 & - & - & 5 & 64 \\
\hline
\end{tabular}




\begin{tabular}{|c|c|c|c|c|c|c|}
\hline Q61129 & Complement factor I & 67.2 & - & - & 5 & 70 \\
\hline H7BX99 & Prothrombin & 70.1 & - & - & 5 & 68 \\
\hline 089020 & Afamin & 69.3 & - & - & 4 & 73 \\
\hline Q19LI2 & Alpha-1B-glycoprotein & 56.5 & - & - & 4 & 84 \\
\hline B7ZNJ1 & Fibronectin & 239.5 & - & - & 4 & 78 \\
\hline P03987-2 & $\begin{array}{l}\text { Isoform } 2 \text { of Ig gamma-3 chain } \mathrm{C} \\
\text { region }\end{array}$ & 36.2 & - & - & 4 & 83 \\
\hline Q91XL1 & Leucine-rich HEV glycoprotein & 37.4 & - & - & 4 & 82 \\
\hline A0A075B5V1 & Protein Ighv1-31 & 10.9 & - & - & 4 & 85 \\
\hline P13609 & Serglycin & 16.7 & - & - & 4 & 86 \\
\hline A0A0A6YX70 & Antithrombin-III (Fragment) & 11.5 & - & - & 3 & 94 \\
\hline Q07968 & Coagulation factor XIII B chain & 76.1 & - & - & 3 & 89 \\
\hline P28798 & Granulins & 63.4 & - & - & 3 & 97 \\
\hline P01660 & $\begin{array}{l}\text { Ig kappa chain V-III region PC } \\
3741 / \text { TEPC } 111\end{array}$ & 12.0 & - & - & 3 & 90 \\
\hline Q07456 & Protein AMBP & 39.0 & - & - & 3 & 91 \\
\hline A0A0A6YYE7 & Protein Igkv4-57 (Fragment) & 12.6 & - & - & 3 & 87 \\
\hline Q6P1B1 & Xaa-Pro aminopeptidase 1 & 69.5 & - & - & 3 & 96 \\
\hline
\end{tabular}

Tabla A3. Proteínas más abundantes (top 100) presentes en el secretoma de plaquetas WtC3G y TgC3G activadas con ADP.

\begin{tabular}{|c|c|c|c|c|c|c|}
\hline \multirow{2}{*}{ № Uniprot } & \multirow{2}{*}{ Proteína } & \multirow{2}{*}{ MM [kDa] } & \multicolumn{2}{|c|}{ WtC3G } & \multicolumn{2}{|c|}{ TgC3G } \\
\hline & & & \# PSMs & Ranking & \# PSMs & Ranking \\
\hline P07724 & Serum albumin & 68,6 & 501 & 1 & 684 & 1 \\
\hline Q92111 & Serotransferrin & 76,7 & 110 & 2 & 117 & 2 \\
\hline Q61838 & Alpha-2-macroglobulin & 165,7 & 81 & 3 & 51 & 4 \\
\hline Q80YQ1 & Thrombospondin 1 & 129,6 & 72 & 4 & 62 & 3 \\
\hline P26039 & Talin-1 & 269,7 & 50 & 5 & 19 & 12 \\
\hline P60710 & Actin, cytoplasmic 1 & 41,7 & 48 & 6 & 24 & 8 \\
\hline P63260 & Actin, cytoplasmic 2 & 41,8 & 46 & 7 & 22 & 10 \\
\hline A0A075B5P6 & Ig mu chain $\mathrm{C}$ region (Fragment) & 50,0 & 46 & 8 & - & - \\
\hline A0A0R4J0I1 & MCG1051009 & 46,6 & 43 & 9 & 20 & 11 \\
\hline E9PV24 & Protein Fga & 87,4 & 42 & 10 & - & - \\
\hline P01027 & Complement C3 & 186,4 & 42 & 11 & 25 & 7 \\
\hline Q91X72 & Hemopexin & 51,3 & 41 & 12 & 24 & 9 \\
\hline Q8K0E8 & Fibrinogen beta chain & 54,7 & 40 & 13 & 7 & 48 \\
\hline Q8VDD5 & Myosin-9 & 226,2 & 38 & 14 & 17 & 14 \\
\hline P21614 & Vitamin D-binding protein & 53,6 & 33 & 15 & 26 & 6 \\
\hline Q8VCM7 & Fibrinogen gamma chain & 49,4 & 30 & 16 & 7 & 45 \\
\hline P20918 & Plasminogen & 90,7 & 30 & 17 & 10 & 32 \\
\hline
\end{tabular}




\begin{tabular}{|c|c|c|c|c|c|c|}
\hline Q00623 & Apolipoprotein A-I & 30,6 & 29 & 18 & 30 & 5 \\
\hline Q01339 & Beta-2-glycoprotein & 38,6 & 28 & 19 & 12 & 25 \\
\hline A8DUK4 & Beta-globin & 15,7 & 26 & 20 & - & - \\
\hline D6RGQ0 & Complement factor $\mathrm{H}$ & 125,0 & 26 & 21 & 10 & 31 \\
\hline P63017 & Heat shock cognate $71 \mathrm{kDa}$ protein & 70,8 & 25 & 22 & 12 & 23 \\
\hline G3X9T8 & Ceruloplasmin & 121,0 & 24 & 23 & 9 & 37 \\
\hline P28665 & Murinoglobulin-1 & 165,2 & 24 & 24 & 7 & 47 \\
\hline Q61147 & Ceruloplasmin & 121,1 & 23 & 25 & - & - \\
\hline E9QPU1 & von Willebrand factor & 309,0 & 23 & 26 & 9 & 36 \\
\hline B7FAU9 & Filamin, alpha & 280,3 & 21 & 27 & 18 & 13 \\
\hline P05064 & Fructose-bisphosphate aldolase $\mathrm{A}$ & 39,3 & 19 & 28 & 11 & 27 \\
\hline P17742 & Peptidyl-prolyl cis-trans isomerase A & 18,0 & 19 & 29 & 16 & 16 \\
\hline P20029 & $78 \mathrm{kDa}$ glucose-regulated protein & 72,4 & 18 & 30 & 12 & 22 \\
\hline O88342 & WD repeat-containing protein & 66,4 & 17 & 31 & 11 & 26 \\
\hline Q9DBD0 & Inhibitor of carbonic anhydrase & 76,7 & 17 & 32 & 9 & 35 \\
\hline P22599 & Alpha-1-antitrypsin 1-2 & 45,9 & 17 & 33 & 12 & 24 \\
\hline Q00897 & Alpha-1-antitrypsin 1-4 & 46,0 & 16 & 34 & 11 & 29 \\
\hline P23953 & Carboxylesterase $1 \mathrm{C}$ & 61,0 & 15 & 35 & 13 & 19 \\
\hline P01942 & Hemoglobin subunit alpha & 15,1 & 15 & 36 & 13 & 21 \\
\hline P68368 & Tubulin alpha-4A chain & 49,9 & 15 & 37 & 7 & 50 \\
\hline P68369 & Tubulin alpha-1A chain & 50,1 & 14 & 38 & - & - \\
\hline Q00896 & Alpha-1-antitrypsin 1-3 & 45,8 & 14 & 39 & 14 & 18 \\
\hline P63101 & 14-3-3 protein zeta/delta & 27,8 & 14 & 40 & 11 & 28 \\
\hline P06728 & Apolipoprotein A-IV & 45,0 & 14 & 41 & 6 & 61 \\
\hline P29699 & Alpha-2-HS-glycoprotein & 37,3 & 13 & 42 & 6 & 53 \\
\hline Q60605 & Myosin light polypeptide 6 & 16,9 & 13 & 43 & 7 & 49 \\
\hline A2AQ07 & Tubulin beta- 1 chain & 50,4 & 13 & 44 & 5 & 64 \\
\hline Q61129 & Complement factor I & 67,2 & 13 & 45 & 3 & 100 \\
\hline P17182 & Alpha-enolase & 47,1 & 13 & 46 & 6 & 56 \\
\hline P21107-2 & $\begin{array}{l}\text { Isoform } 2 \text { of Tropomyosin alpha-3 } \\
\text { chain }\end{array}$ & 29,0 & 13 & 47 & 8 & 42 \\
\hline Q9QWK4 & CD5 antigen-like & 38,8 & 12 & 48 & 4 & 77 \\
\hline Q9Z126 & Platelet factor 4 & 11,2 & 12 & 49 & 10 & 30 \\
\hline O08677-2 & Isoform LMW of Kininogen-1 & 47,9 & 12 & 50 & 7 & 46 \\
\hline P27773 & Protein disulfide-isomerase A3 & 56,6 & 11 & 51 & 8 & 43 \\
\hline Q61703 & $\begin{array}{l}\text { Inter-alpha-trypsin inhibitor heavy } \\
\text { chain H2 }\end{array}$ & 105,9 & 11 & 52 & - & - \\
\hline A0A075B5P3 & Protein Ighg2b (Fragment) & 36,7 & 11 & 53 & 5 & 68 \\
\hline O89020 & Afamin & 69,3 & 11 & 54 & 8 & 41 \\
\hline P17751 & Triosephosphate isomerase & 32,2 & 11 & 55 & 8 & 40 \\
\hline P56480 & $\begin{array}{l}\text { ATP synthase subunit beta, } \\
\text { mitochondrial }\end{array}$ & 56,3 & 10 & 56 & 4 & 86 \\
\hline G3X8T9 & $\begin{array}{l}\text { Serine (Or cysteine) peptidase } \\
\text { inhibitor, clade A, member } 3 \mathrm{~N} \text {, } \\
\text { isoform CRA_a }\end{array}$ & 46,7 & 10 & 57 & 7 & 51 \\
\hline P52480 & Pyruvate kinase PKM & 57,8 & 10 & 58 & - & - \\
\hline
\end{tabular}




\begin{tabular}{|c|c|c|c|c|c|c|}
\hline P08226 & Apolipoprotein E & 35,8 & 10 & 59 & 5 & 69 \\
\hline Q19LI2 & Alpha-1B-glycoprotein & 56,5 & 10 & 60 & - & - \\
\hline P08905 & Lysozyme C-2 & 16,7 & 9 & 61 & 8 & 38 \\
\hline O35930 & Platelet glycoprotein lb alpha chain & 80,0 & 9 & 62 & 9 & 34 \\
\hline Q02053 & $\begin{array}{l}\text { Ubiquitin-like modifier-activating } \\
\text { enzyme } 1\end{array}$ & 117,7 & 9 & 63 & - & - \\
\hline Q00898 & Alpha-1-antitrypsin 1-5 & 45,9 & 9 & 64 & 5 & 70 \\
\hline P68372 & Tubulin beta-4B chain & 49,8 & 9 & 65 & - & - \\
\hline P40142 & Transketolase & 67,6 & 9 & 66 & 4 & 74 \\
\hline P62962 & Profilin-1 & 14,9 & 9 & 67 & 4 & 78 \\
\hline Q7TQE2 & Zyx protein & 57,0 & 9 & 68 & 4 & 81 \\
\hline Q9EQI5 & $\begin{array}{l}\text { Chemokine (C-X-C motif) ligand } 7 \text {, } \\
\text { isoform CRA_b }\end{array}$ & 12,2 & 9 & 69 & 10 & 33 \\
\hline P04186 & Complement factor B & 85,0 & 9 & 70 & 4 & 88 \\
\hline Q9ESB3 & Histidine-rich glycoprotein & 59,1 & 9 & 71 & - & - \\
\hline P01592 & Immunoglobulin $\mathrm{J}$ chain & 18,0 & 9 & 72 & - & - \\
\hline A0A075B5V0 & MCG114299 (Fragment) & 12,9 & 8 & 73 & - & - \\
\hline Q91XL1 & Leucine-rich HEV glycoprotein & 37,4 & 8 & 74 & 3 & 94 \\
\hline Q9JJZ2 & Tubulin alpha-8 chain & 50,0 & 8 & 75 & - & - \\
\hline P68510 & 14-3-3 protein eta & 28,2 & 8 & 76 & 8 & 44 \\
\hline Q61646 & Haptoglobin & 38,7 & 8 & 77 & - & - \\
\hline E9Q7Q3 & Tropomyosin alpha-3 chain & 28,7 & 8 & 78 & 8 & 39 \\
\hline A0A075B5V1 & Protein Ighv1-31 & 11,0 & 7 & 79 & - & - \\
\hline Q64442 & Sorbitol dehydrogenase & 38,2 & 7 & 80 & 6 & 54 \\
\hline P09411 & Phosphoglycerate kinase 1 & 44,5 & 7 & 81 & - & - \\
\hline Q6IRU2 & Tropomyosin alpha-4 & 28,5 & 7 & 82 & 5 & 65 \\
\hline Q9WVF5 & Epidermal growth factor receptor & 72,9 & 7 & 83 & 3 & 97 \\
\hline Q8CG19 & $\begin{array}{l}\text { Latent-transforming growth factor } \\
\text { beta-binding protein } 1\end{array}$ & 186,6 & 7 & 84 & - & - \\
\hline Q9DBB9 & Carboxypeptidase $\mathrm{N}$ subunit 2 & 60,4 & 7 & 85 & - & - \\
\hline P29788 & Vitronectin & 54,8 & 7 & 86 & - & - \\
\hline P13020-2 & Isoform 2 of Gelsolin & 80,7 & 7 & 87 & 3 & 98 \\
\hline P01029 & Complement C4-B & 192,8 & 7 & 88 & 4 & 87 \\
\hline P18760 & Cofilin-1 & 18,5 & 7 & 89 & 6 & 55 \\
\hline Q9WVA4 & Transgelin-2 & 22,4 & 7 & 90 & 4 & 79 \\
\hline A2A5N1 & 14-3-3 protein beta/alpha (Fragment) & 18,3 & 7 & 91 & - & - \\
\hline P50396 & Rab GDP dissociation inhibitor alpha & 50,5 & 7 & 92 & - & - \\
\hline P32261 & Antithrombin-III & 52,0 & 7 & 93 & - & - \\
\hline A0A075B5P2 & Protein Igkc (Fragment) & 11,9 & 7 & 94 & - & - \\
\hline P01837 & Ig kappa chain $\mathrm{C}$ region & 11,8 & 7 & 95 & - & - \\
\hline A0A0A6YXA5 & MCG114298 (Fragment) & 12,9 & 6 & 96 & - & - \\
\hline S4R1B8 & Bridging integrator 2 & 51,6 & 6 & 97 & - & - \\
\hline A0A0R4J1N3 & Apolipoprotein C-III & 10,9 & 6 & 98 & 4 & 73 \\
\hline Q64727 & Vinculin & 116,6 & 6 & 99 & 5 & 67 \\
\hline Q01853 & Transitional endoplasmic reticulum & 89,3 & 6 & 100 & 4 & 82 \\
\hline
\end{tabular}




\begin{tabular}{|c|c|c|c|c|c|c|}
\hline & ATPase & & & & & \\
\hline P01872 & $\lg$ mu chain $\mathrm{C}$ region & 49,9 & - & - & 16 & 15 \\
\hline E9Q223 & $\begin{array}{l}\text { Hemoglobin subunit beta-1 } \\
\text { (Fragment) }\end{array}$ & 11,1 & - & - & 15 & 17 \\
\hline Q99K47 & Fibrinogen, alpha polypeptide & 61,3 & - & - & 13 & 20 \\
\hline P68373 & Tubulin alpha-1C chain & 49,9 & - & - & 7 & 52 \\
\hline A0A075B5M7 & Protein Igkv5-39 & 10,4 & - & - & 6 & 57 \\
\hline A0A075B5P4 & $\begin{array}{l}\text { Ig gamma-1 chain } \mathrm{C} \text { region secreted } \\
\text { form (Fragment) }\end{array}$ & 35,7 & - & - & 6 & 58 \\
\hline P20065-2 & Isoform Short of Thymosin beta-4 & 5,0 & - & - & 6 & 59 \\
\hline P06151 & L-lactate dehydrogenase $\mathrm{A}$ chain & 36,5 & - & - & 6 & 60 \\
\hline Q91VW3 & $\begin{array}{l}\mathrm{SH} 3 \text { domain-binding glutamic acid- } \\
\text { rich-like protein } 3\end{array}$ & 10,5 & - & - & 6 & 62 \\
\hline P68254-2 & Isoform 2 of $14-3-3$ protein theta & 27,7 & - & - & 6 & 63 \\
\hline A0A0R4J1P2 & Tropomyosin alpha-3 chain & 32,8 & - & - & 5 & 66 \\
\hline Q9CQV8 & 14-3-3 protein beta/alpha & 28,1 & - & - & 5 & 71 \\
\hline P09813 & Apolipoprotein A-II & 11,3 & - & - & 5 & 72 \\
\hline P06330 & $\begin{array}{l}\text { Ig heavy chain V region AC38 } \\
205.12\end{array}$ & 12,9 & - & - & 4 & 75 \\
\hline Q9R0P5 & Destrin & 18,5 & - & - & 4 & 76 \\
\hline H3BJP2 & $\begin{array}{l}\text { S-formylglutathione hydrolase } \\
\text { (Fragment) }\end{array}$ & 27,1 & - & - & 4 & 80 \\
\hline P61982 & 14-3-3 protein gamma & 28,3 & - & - & 4 & 83 \\
\hline P03987-2 & $\begin{array}{l}\text { Isoform } 2 \text { of Ig gamma-3 chain } C \\
\text { region }\end{array}$ & 36,2 & - & - & 4 & 84 \\
\hline A0A0A6YX70 & Antithrombin-III (Fragment) & 11,6 & - & - & 4 & 85 \\
\hline P08249 & $\begin{array}{l}\text { Malate dehydrogenase, } \\
\text { mitochondrial }\end{array}$ & 35,6 & - & - & 4 & 89 \\
\hline P01660 & $\begin{array}{l}\text { Ig kappa chain V-III region PC } \\
3741 / \text { TEPC } 111\end{array}$ & 12,1 & - & - & 3 & 90 \\
\hline Q8CG19-3 & $\begin{array}{l}\text { Isoform } 3 \text { of Latent-transforming } \\
\text { growth factor beta-binding protein } 1\end{array}$ & 147,3 & - & - & 3 & 91 \\
\hline F8WI14 & Extracellular matrix protein 1 & 62,7 & - & - & 3 & 92 \\
\hline Q07456 & Protein AMBP & 39,0 & - & - & 3 & 93 \\
\hline P97315 & Cysteine and glycine-rich protein 1 & 20,6 & - & - & 3 & 95 \\
\hline Q9Z2U1 & Proteasome subunit alpha type- 5 & 26,4 & - & - & 3 & 96 \\
\hline P97447 & $\begin{array}{l}\text { Four and a half LIM domains protein } \\
1\end{array}$ & 31,9 & - & - & 3 & 99 \\
\hline
\end{tabular}

EI \#PSM (peptide spectrum matches) fue utilizado como medida cuantitativa de la abundancia relativa de cada proteína en el secretoma (Liu et al., 2012). (-) Indica que la proteína no fue detectada en el secretoma. El análisis fue realizado con $15 \mu \mathrm{L}$ a partir de $200 \mu \mathrm{L}$ de secretoma aislados de plaquetas de 3 ratones de cada genotipo. MM: masa molecular.

Tabla A4. Proteínas más abundantes (top 100) presentes en el secretoma de plaquetas WtC3GACat y TgC3G $\Delta$ Cat activadas con ADP.

\begin{tabular}{|c|c|c|c|c|c|c|}
\hline \multirow{2}{*}{ № Uniprot } & \multirow{2}{*}{ Proteína } & \multirow{2}{*}{$\begin{array}{c}\text { MM } \\
{[\mathrm{kDa}]}\end{array}$} & \multicolumn{2}{|c|}{ WtC3GACat } & \multicolumn{2}{|c|}{$\operatorname{TgC3G} \Delta$ Cat } \\
\hline & & & \# PSMs & Ranking & \# PSMs & Ranking \\
\hline P07724 & Serum albumin & 68,6 & 616 & 1 & 685 & 1 \\
\hline Q921/1 & Serotransferrin & 76,7 & 115 & 2 & 120 & 2 \\
\hline
\end{tabular}




\begin{tabular}{|c|c|c|c|c|c|c|}
\hline Q80YQ1 & Thrombospondin 1 & 129,6 & 84 & 3 & 44 & 5 \\
\hline Q61838 & Alpha-2-macroglobulin & 165,7 & 73 & 4 & 58 & 4 \\
\hline Q91VB8 & Alpha globin 1 & 15,1 & 61 & 5 & - & - \\
\hline Q00623 & Apolipoprotein A-I & 30,6 & 47 & 6 & 66 & 3 \\
\hline P60710 & Actin, cytoplasmic 1 & 41,7 & 45 & 7 & 29 & 7 \\
\hline P63260 & Actin, cytoplasmic 2 & 41,8 & 43 & 8 & 26 & 8 \\
\hline A0A0R4J0I1 & MCG1051009 & 46,6 & 43 & 9 & 39 & 6 \\
\hline P26039 & Talin-1 & 269,7 & 37 & 10 & 16 & 14 \\
\hline A8DUK4 & Beta-globin & 15,7 & 32 & 11 & - & - \\
\hline Q8VDD5 & Myosin-9 & 226,2 & 25 & 12 & 7 & 38 \\
\hline P01027 & Complement C3 & 186,4 & 23 & 13 & 19 & 11 \\
\hline Q91X72 & Hemopexin & 51,3 & 23 & 14 & 15 & 17 \\
\hline P21614 & Vitamin D-binding protein & 53,6 & 22 & 15 & 19 & 12 \\
\hline P01872 & Ig mu chain $\mathrm{C}$ region & 49,9 & 21 & 16 & 15 & 16 \\
\hline Q9Z126 & Platelet factor 4 & 11,2 & 21 & 17 & 17 & 13 \\
\hline Q99K47 & Fibrinogen, alpha polypeptide & 61,3 & 21 & 18 & 10 & 29 \\
\hline A0A0R4J0X5 & Alpha-1-antitrypsin 1-3 & 45,8 & 19 & 19 & - & - \\
\hline B7FAV1 & Filamin, alpha (Fragment) & 274,5 & 18 & 20 & 13 & 19 \\
\hline P28665 & Murinoglobulin-1 & 165,2 & 17 & 21 & 13 & 20 \\
\hline P17742 & Peptidyl-prolyl cis-trans isomerase A & 18,0 & 17 & 22 & 8 & 35 \\
\hline Q9EQI5 & $\begin{array}{l}\text { Chemokine (C-X-C motif) ligand } 7 \text {, } \\
\text { isoform CRA_b }\end{array}$ & 12,2 & 17 & 23 & 10 & 27 \\
\hline P23953 & Carboxylesterase $1 \mathrm{C}$ & 61,0 & 16 & 24 & 11 & 22 \\
\hline P20918 & Plasminogen & 90,7 & 16 & 25 & 11 & 24 \\
\hline P09813 & Apolipoprotein A-II & 11,3 & 15 & 26 & 10 & 28 \\
\hline Q8K0E8 & Fibrinogen beta chain & 54,7 & 14 & 27 & 7 & 39 \\
\hline P05064 & Fructose-bisphosphate aldolase A & 39,3 & 14 & 28 & 10 & 30 \\
\hline P22599 & Alpha-1-antitrypsin 1-2 & 45,9 & 14 & 29 & 11 & 23 \\
\hline O08677-2 & Isoform LMW of Kininogen-1 & 47,9 & 14 & 30 & 14 & 18 \\
\hline P07758 & Alpha-1-antitrypsin 1-1 & 46,0 & 13 & 31 & - & - \\
\hline P63101 & 14-3-3 protein zeta/delta & 27,8 & 13 & 32 & - & - \\
\hline Q00897 & Alpha-1-antitrypsin 1-4 & 46,0 & 13 & 33 & 10 & 26 \\
\hline P20029 & $78 \mathrm{kDa}$ glucose-regulated protein & 72,4 & 11 & 34 & 3 & 71 \\
\hline O88342 & WD repeat-containing protein 1 & 66,4 & 11 & 35 & 5 & 43 \\
\hline P68373 & Tubulin alpha-1C chain & 49,9 & 11 & 36 & - & - \\
\hline E9QPU1 & von Willebrand factor & 309,0 & 11 & 37 & 4 & 52 \\
\hline P63017 & Heat shock cognate $71 \mathrm{kDa}$ protein & 70,8 & 11 & 38 & 5 & 47 \\
\hline G3X9T8 & Ceruloplasmin & 121,0 & 11 & 39 & 9 & 31 \\
\hline P68368 & Tubulin alpha-4A chain & 49,9 & 10 & 40 & 7 & 37 \\
\hline O35930 & Platelet glycoprotein lb alpha chain & 80,0 & 10 & 41 & 6 & 40 \\
\hline Q9DBD0 & Inhibitor of carbonic anhydrase & 76,7 & 10 & 42 & 9 & 32 \\
\hline P62962 & Profilin-1 & 14,9 & 9 & 43 & - & - \\
\hline P08905 & Lysozyme C-2 & 16,7 & 9 & 44 & 4 & 56 \\
\hline
\end{tabular}




\begin{tabular}{|c|c|c|c|c|c|c|}
\hline P29699 & Alpha-2-HS-glycoprotein & 37,3 & 9 & 45 & 12 & 21 \\
\hline Q6IRU2 & Tropomyosin alpha-4 chain & 28,5 & 9 & 46 & 4 & 54 \\
\hline Q00898 & Alpha-1-antitrypsin 1-5 & 45,9 & 8 & 47 & 5 & 42 \\
\hline D6RGQ0 & Complement factor $\mathrm{H}$ & 125,0 & 8 & 48 & - & - \\
\hline P18760 & Cofilin-1 & 18,5 & 8 & 49 & 3 & 70 \\
\hline Q7TQE2 & Zyx protein & 57,0 & 8 & 50 & 2 & 93 \\
\hline P21107-2 & $\begin{array}{l}\text { Isoform } 2 \text { of Tropomyosin alpha-3 } \\
\text { chain }\end{array}$ & 29,0 & 8 & 51 & - & - \\
\hline P06151 & L-lactate dehydrogenase $\mathrm{A}$ chain & 36,5 & 8 & 52 & 3 & 85 \\
\hline Q01339 & Beta-2-glycoprotein 1 & 38,6 & 8 & 53 & - & - \\
\hline P68510 & 14-3-3 protein eta & 28,2 & 8 & 54 & - & - \\
\hline P17751 & Triosephosphate isomerase & 32,2 & 7 & 55 & 3 & 73 \\
\hline Q8VCM7 & Fibrinogen gamma chain & 49,4 & 7 & 56 & 4 & 55 \\
\hline P27773 & Protein disulfide-isomerase $\mathrm{A} 3$ & 56,6 & 7 & 57 & - & - \\
\hline Q01853 & $\begin{array}{l}\text { Transitional endoplasmic reticulum } \\
\text { ATPase }\end{array}$ & 89,3 & 7 & 58 & - & - \\
\hline P08226 & Apolipoprotein E & 35,8 & 7 & 59 & 4 & 53 \\
\hline A2AQ07 & Tubulin beta- 1 chain & 50,4 & 6 & 60 & 8 & 34 \\
\hline Q64442 & Sorbitol dehydrogenase & 38,2 & 6 & 61 & - & - \\
\hline P04186 & Complement factor B & 85,0 & 6 & 62 & 5 & 45 \\
\hline Q60605 & Myosin light polypeptide 6 & 16,9 & 6 & 63 & - & - \\
\hline Q64727 & Vinculin & 116,6 & 6 & 64 & 2 & 95 \\
\hline A0A075B5P4 & $\begin{array}{l}\text { Ig gamma-1 chain } \mathrm{C} \text { region secreted } \\
\text { form (Fragment) }\end{array}$ & 35,7 & 6 & 65 & 4 & 58 \\
\hline A0A075B5P3 & Protein lghg2b (Fragment) & 36,7 & 6 & 66 & 3 & 74 \\
\hline A0A075B5V1 & Protein Ighv1-31 & 11,0 & 6 & 67 & 4 & 62 \\
\hline A0A0J9YUQ8 & Gelsolin (Fragment) & 62,3 & 6 & 68 & - & - \\
\hline P52480 & Pyruvate kinase PKM & 57,8 & 5 & 69 & 3 & 78 \\
\hline Q02053 & $\begin{array}{l}\text { Ubiquitin-like modifier-activating } \\
\text { enzyme } 1\end{array}$ & 117,7 & 5 & 70 & - & - \\
\hline H3BJP2 & $\begin{array}{l}\text { S-formylglutathione hydrolase } \\
\text { (Fragment) }\end{array}$ & 27,1 & 5 & 71 & 3 & 87 \\
\hline P40142 & Transketolase & 67,6 & 5 & 72 & - & - \\
\hline P09411 & Phosphoglycerate kinase 1 & 44,5 & 5 & 73 & 2 & 94 \\
\hline A0A075B5V0 & MCG114299 (Fragment) & 12,9 & 5 & 74 & - & - \\
\hline Q9WVF5 & Epidermal growth factor receptor & 72,9 & 5 & 75 & - & - \\
\hline Q91VW3 & $\begin{array}{l}\text { SH3 domain-binding glutamic acid- } \\
\text { rich-like protein } 3\end{array}$ & 10,5 & 5 & 76 & 3 & 72 \\
\hline P20065-2 & Isoform Short of Thymosin beta- 4 & 5,0 & 5 & 77 & 6 & 41 \\
\hline P06728 & Apolipoprotein A-IV & 45,0 & 5 & 78 & 9 & 33 \\
\hline P61982 & 14-3-3 protein gamma & 28,3 & 5 & 79 & - & - \\
\hline Q9ESB3 & Histidine-rich glycoprotein & 59,1 & 5 & 80 & 4 & 63 \\
\hline A0A0A6YXN4 & Protein Ighv1-18 (Fragment) & 12,9 & 4 & 81 & - & - \\
\hline A0A0R4J1N3 & Apolipoprotein C-III & 10,9 & 4 & 82 & 4 & 49 \\
\hline Q9DBB9 & Carboxypeptidase $\mathrm{N}$ subunit 2 & 60,4 & 4 & 83 & 4 & 50 \\
\hline Q9QWK4 & CD5 antigen-like & 38,8 & 4 & 84 & 4 & 60 \\
\hline O54890 & Integrin beta-3 & 86,7 & 4 & 85 & 2 & 99 \\
\hline
\end{tabular}




\begin{tabular}{|c|c|c|c|c|c|c|}
\hline P14152 & Malate dehydrogenase, cytoplasmic & 36,5 & 4 & 86 & - & - \\
\hline O89020 & Afamin & 69,3 & 4 & 87 & 4 & 51 \\
\hline Q61129 & Complement factor I & 67,2 & 4 & 88 & - & - \\
\hline S4R2J8 & Bridging integrator 2 & 50,9 & 4 & 89 & - & - \\
\hline P56480 & $\begin{array}{l}\text { ATP synthase subunit beta, } \\
\text { mitochondrial }\end{array}$ & 56,3 & 4 & 90 & - & - \\
\hline Q9D6F9 & Tubulin beta- $4 \mathrm{~A}$ chain & 49,6 & 4 & 91 & 3 & 84 \\
\hline E9Q453 & Tropomyosin alpha-1 chain & 28,5 & 4 & 92 & 2 & 98 \\
\hline A0A075B5P2 & Protein Igkc (Fragment) & 11,9 & 4 & 93 & - & - \\
\hline E9Q748 & Antileukoproteinase & 11,9 & 4 & 94 & - & - \\
\hline Q7TMM9 & Tubulin beta-2A chain & 49,9 & 4 & 95 & - & - \\
\hline Q61703 & $\begin{array}{l}\text { Inter-alpha-trypsin inhibitor heavy } \\
\text { chain H2 }\end{array}$ & 105,9 & 4 & 96 & 4 & 66 \\
\hline P01654 & $\begin{array}{l}\text { Ig kappa chain V-III region PC } \\
\text { 2880/PC } 1229\end{array}$ & 12,0 & 3 & 97 & - & - \\
\hline Q8CG19 & $\begin{array}{l}\text { Latent-transforming growth factor } \\
\text { beta-binding protein } 1\end{array}$ & 186,6 & 3 & 98 & - & - \\
\hline P17182 & Alpha-enolase & 47,1 & 3 & 99 & - & - \\
\hline A0A075B5N9 & Protein Igkv3-7 & 10,9 & 3 & 100 & - & - \\
\hline P01942 & Hemoglobin subunit alpha & 15,1 & - & - & 23 & 9 \\
\hline E9Q223 & $\begin{array}{l}\text { Hemoglobin subunit beta-1 } \\
\text { (Fragment) }\end{array}$ & 11,1 & - & - & 22 & 10 \\
\hline Q00896 & Alpha-1-antitrypsin 1-3 & 45,8 & - & - & 16 & 15 \\
\hline G3X8T9 & $\begin{array}{l}\text { Serine (Or cysteine) peptidase } \\
\text { inhibitor, clade A, member } 3 \mathrm{~N} \text {, isoform } \\
\text { CRA_a }\end{array}$ & 46,7 & - & - & 10 & 25 \\
\hline A0A0A6YWP4 & Complement factor $\mathrm{H}$ (Fragment) & 94,2 & - & - & 8 & 36 \\
\hline D3YXF4 & 14-3-3 protein zeta/delta (Fragment) & 5,1 & - & - & 5 & 44 \\
\hline I7HJR3 & Beta-2-glycoprotein 1 (Fragment) & 16,8 & - & - & 5 & 46 \\
\hline A0A0A6YYE7 & Protein Igkv4-57 (Fragment) & 12,7 & - & - & 4 & 48 \\
\hline A0A0A6YWH7 & Antithrombin-III (Fragment) & 31,9 & - & - & 4 & 57 \\
\hline P29788 & Vitronectin & 54,8 & - & - & 4 & 59 \\
\hline P26262 & Plasma kallikrein & 71,3 & - & - & 4 & 61 \\
\hline P01029 & Complement C4-B & 192,8 & - & - & 4 & 64 \\
\hline Q19LI2 & Alpha-1B-glycoprotein & 56,5 & - & - & 4 & 65 \\
\hline H7BX99 & Prothrombin & 70,2 & - & - & 4 & 67 \\
\hline A0A0B4J1I9 & Protein Igkv4-55 (Fragment) & 12,7 & - & - & 3 & 68 \\
\hline Q07456 & Protein AMBP & 39,0 & - & - & 3 & 69 \\
\hline Q99PT1 & Rho GDP-dissociation inhibitor 1 & 23,4 & - & - & 3 & 75 \\
\hline O55222 & Integrin-linked protein kinase & 51,3 & - & - & 3 & 76 \\
\hline O70400 & PDZ and LIM domain protein 1 & 35,8 & - & - & 3 & 77 \\
\hline Q9QUM0 & Integrin alpha-Ilb & 112,6 & - & - & 3 & 79 \\
\hline Q91XL1 & Leucine-rich HEV glycoprotein & 37,4 & - & - & 3 & 80 \\
\hline A2A997 & $\begin{array}{l}\text { Complement component C8 alpha } \\
\text { chain }\end{array}$ & 65,4 & - & - & 3 & 81 \\
\hline P01660 & $\begin{array}{l}\text { Ig kappa chain V-III region PC } \\
3741 / \text { TEPC } 111\end{array}$ & 12,1 & - & - & 3 & 82 \\
\hline D3Z6I8 & Tropomyosin alpha-3 chain & 28,7 & - & - & 3 & 83 \\
\hline
\end{tabular}


ANEXOS

\begin{tabular}{|c|c|c|c|c|c|c|}
\hline P42703-2 & $\begin{array}{l}\text { Isoform } 2 \text { of Leukemia inhibitory factor } \\
\text { receptor }\end{array}$ & 81,2 & - & - & 3 & 86 \\
\hline P03987-2 & $\begin{array}{l}\text { Isoform } 2 \text { of lg gamma-3 chain } \mathrm{C} \\
\text { region }\end{array}$ & 36,2 & - & - & 3 & 88 \\
\hline P01592 & Immunoglobulin $\mathrm{J}$ chain & 18,0 & - & - & 2 & 89 \\
\hline Q8BH35-2 & $\begin{array}{l}\text { Isoform } 2 \text { of Complement component } \\
\text { C8 beta chain }\end{array}$ & 58,4 & - & - & 2 & 90 \\
\hline A0A0A6YY53 & Protein Ighg2c (Fragment) & 36,5 & - & - & 2 & 91 \\
\hline Q9DAC2 & $\begin{array}{l}\text { Complement component 8, gamma } \\
\text { subunit, isoform CRA_b }\end{array}$ & 18,9 & - & - & 2 & 92 \\
\hline Q8K1B8 & Fermitin family homolog 3 & 75,6 & - & - & 2 & 96 \\
\hline O88947 & Coagulation factor $X$ & 54,0 & - & - & 2 & 97 \\
\hline Q07968 & Coagulation factor XIII B chain & 76,1 & - & - & 2 & 100 \\
\hline
\end{tabular}

El \#PSM (peptide spectrum matches) fue utilizado como medida cuantitativa de la abundancia relativa de cada proteína en el secretoma (Liu et al., 2012). (-) Indica que la proteína no fue detectada en el secretoma. El análisis fue realizado con $15 \mu \mathrm{L}$ a partir de $200 \mu \mathrm{L}$ de secretoma aislados de plaquetas de 3 ratones de cada genotipo. MM: masa molecular. 
"But of the tree of knowledge of good and evil you shall not eat; the moment you eat from it you are surely doomed to die" (Genesis 2:17).

"You certainly will not die", the serpent said to the woman. "For God knows that when you eat from it your eyes will be opened and you will be like God, knowing good and evil" (Genesis 3:4-5). 


